\title{
Co-Constructive Consulting
}

A Pragmatic, Relational Constructionist Approach

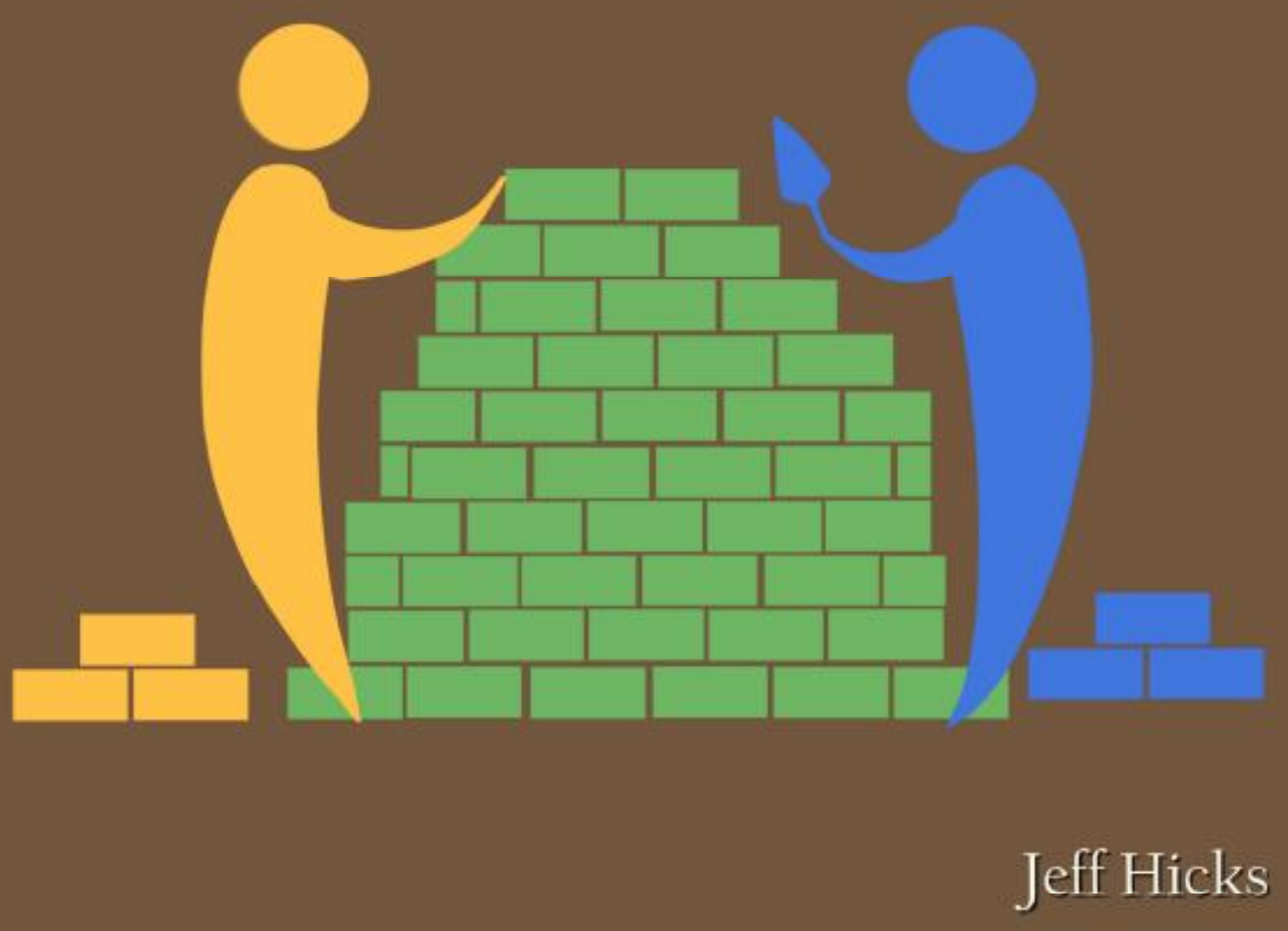


Management consulting is a $\$ 300$ billion industry, about $70 \%$ of which is accounted for by organizational change work. These numbers aren't especially remarkable, unless you consider that a similar percentage of change initiatives-about $70 \%$, according to numerous studies - fail to meet their stated objectives, It's not too difficult, in other words, to make a case for fundamental change in management and business consulting.

In this dissertation, we develop an alternative approach we refer to as "co-constructive consulting: With this alternative, the focus is less on the transfer of existing knowledge, and more on the co-constructing of new knowledge that is fit-for-purpose. Clientconsultant relationships are considered to be the co-constructed result of close collaboration, rather than simply a conduit for exchange between individuals.

Co-constructive consulting draws from the pragmatism of Richard Rorty, the social constructionism of Ken Gergen, and the relational constructionism of Dian Marie Hosking. It makes use of practical tools and methods from sociology, psychology and anthropology, including sensemaking, framing, the notion of affordances, situated knowledge, situated learning, distributed cognition and others.

These tools and methods are useful when we embrace the indeterminacy of practice and the low predictability of change outcomes, rather than seeking only to control for them; when we treat these not as risks to be minimized, but as ongoing opportunities for co-constructing and innovating.

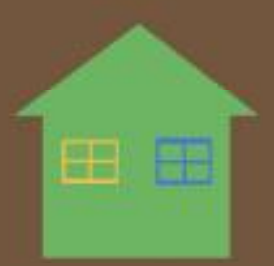




\title{
Co-C onstructive Consulting
}

\section{A Pragmatic, Relational C onstructionist Approach}

\author{
Jeff Hicks
}


Graduation Committee:

Prof. dr. Paul van Loon (Chair)

Prof. dr. Dian Marie Hosking (Promoter)

Prof. dr. Celeste P. M. Wilderom (Promoter)

Prof. dr. Jos van Hillegersberg

Prof. dr. Dennis Muntslag

Prof. dr. René Bouwen

Prof. dr. John Rijsman
University of Twente

Utrecht University

University of Twente

University of Twente

University of Twente

University of Leuven

Tilburg University 


\title{
CO-CONSTRUCTIVE CONSULTING: \\ A PRAGMATIC, RELATIONAL CONSTRUCTIONIST APPROACH
}

\author{
DISSERTATION
}

to obtain the degree of doctor

at the University of Twente, under the authority of the rector magnificus, prof. dr. H. Brinksma, on account of the decision of the graduation committee, to be publicly defended on

Wednesday, the $17^{\text {th }}$ of February, 2010 at $16.45 \mathrm{hrs}$

by

Jeffrey Neal Hicks

born on the $29^{\text {th }}$ of January 1964

in El Paso de Robles, California, United States of America 
This $\mathrm{PhD}$ dissertation has been approved by:

Prof. dr. Dian Marie Hosking (Promoter)

Prof. dr. Celeste P. M. Wilderom (Promoter)

Cover illustration: Misaki Hicks

ISBN: 978-90-365-2992-1

Copyright (C) 2010 by Jeffrey N. Hicks, Enschede, the Netherlands 
For Hiroko, M isaki, N atsuki and Sam 
PDF created with pdfFactory trial version www.pdffactory.com 


\section{Contents}

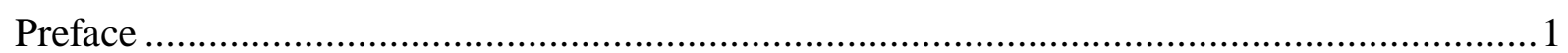

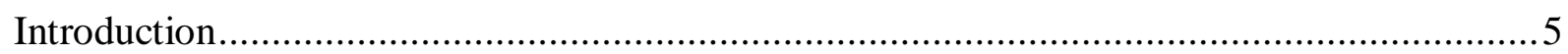

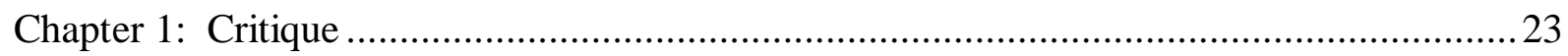

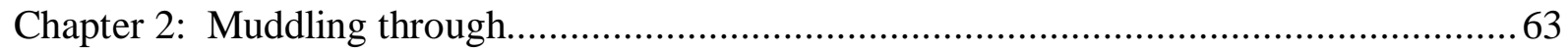

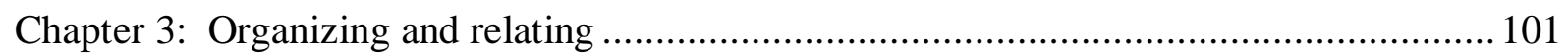

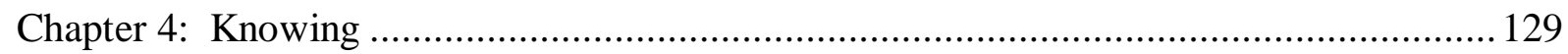

Chapter 5: Brokering open, generative dialogue among clients and consultants ................ 157

Chapter 6: If you can't solve the problem, change the problem you're solving.................. 181

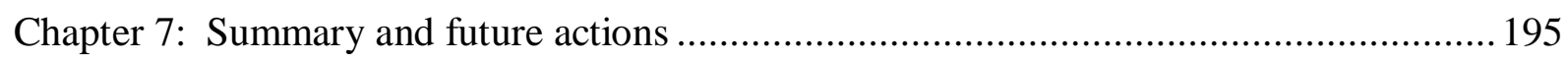

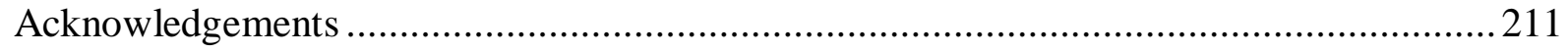

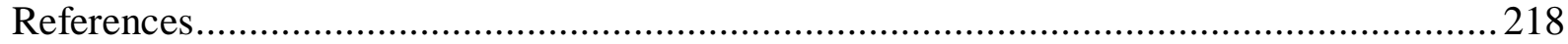

\section{Figures and Tables}

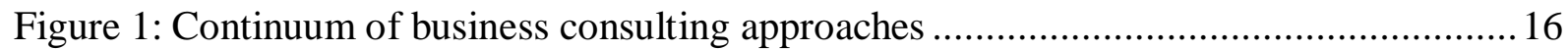

Figure 2: Sampling of organizational change/improvement initiatives ..............................50

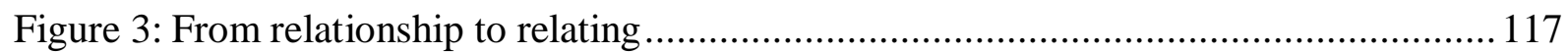

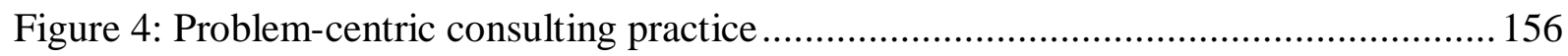

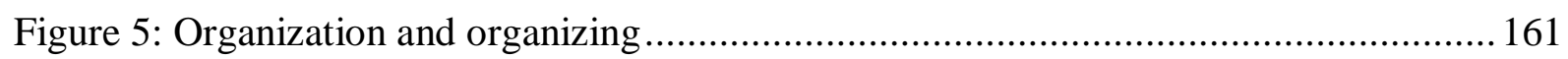

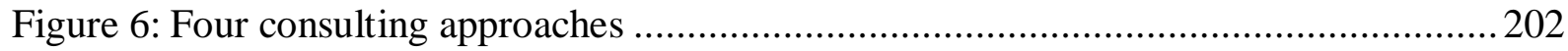

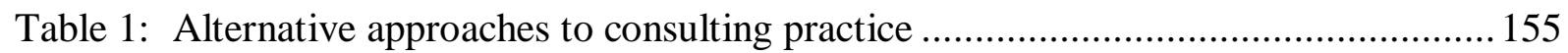

Table 2: Being right vs. being useful: Two approaches to problem solving ...................... 188

Table 3: Summary comparison of three consulting approaches ........................................2 205 
PDF created with pdfFactory trial version www.pdffactory.com 


\section{Preface}

$M$ anagement consulting is a $\$ 300$ billion industry. About $70 \%$ of that expenditure is accounted for by organizational change work, of one form or another. These numbers aren't especially remarkable, unless you consider that a similar percentage of change initiatives-about $70 \%$, according to numerous studies- fail to meet their stated objectives. It's not too difficult, in other words, to make a case for fundamental change in management and business consulting.

Fundamental change, in turn, calls for a reconsideration of some of the fundamental assumptions on which the current and prevailing 'expert approach' to consulting is built. These assumptions include, for example: 1) that organizational change outcomes are predictable and controllable, 2) that knowledge is transferable, and 3) that the client-consultant relationship is essentially a conduit for exchange bet ween individuals.

These assumptions guide our formal, 'official' proposals and project plansdocuments that describe a linear progression, through methodologicallydriven phases, toward pre-determined outcomes, and that bear little resemblance to the messy bricolage and pragmatic improvisation that constitutes day-to-day consulting practice. Overturning these assumptions to arrive at an alternative consulting approach is not trivial, however,

\section{Voorw oord}

W ereldwijd heeft de organisatieadviesbranche een omzet van 300 miljard dollar. Ongeveer $70 \%$ van die uitgaven wordt in een of andere vorm besteed aan organisatieverandering. Deze getallen zijn niet bijzonder opmerkelijk, ware het niet dat een ongeveer gelijk percentage van veranderinitiatieven- ongeveer $70 \%$, volgens verscheidene studies- niet de gestelde doelen bereikt. Anders gesteld, het is niet bijzonder vergezocht om te pleiten voor fundamentele verandering in management- en organisatieadvies.

Fundamentele verandering vraagt echter om een heroverweging van een aantal van de fundamentele veronderstellingen waarop de huidige en dominante 'expert benadering' van organisatieadvies is gestoeld. Deze veronderstellingen zijn bijvoorbeeld: 1) dat uitkomsten van organisatieverandering voorspelbaar en beheersbaar zijn, 2) dat kennis overdraagbaar is, en 3) dat de cliëntadviseur relatie in essentie een medium is voor de uitwisseling tussen afzonderlijke individuen.

Deze veronderstellingen sturen onze formele, 'officiële' voorstellen en project plannen. Documenten die een lineaire voortgang beschrijven, door methodegedreven fasen, in de richting van tevoren bepaalde uitkomsten-en die weinig lijken op het creatieve knutsel werk en de pragmatische improvisatie waaruit de dagelijkse adviespraktijk bestaat. Het omverwerpen van deze veronderstellingen om te komen tot een alternatieve 
because their origins run quite deep-back to the beginnings of organizational studies in the 1950s, to 18th century Enlightenment ideals, and even back to the pre-Socratic origins of W estern thought.

In this dissertation, using this historical perspective, and also accounts of how other professions-including medicine, public planning and others- have evolved over time, we develop an alternative approach that we refer to as 'co-constructive consulting.' W ith this alternative approach, the focus is less on the transfer of existing knowledge, and more on the coconstructing of new knowledge that is fitfor-purpose; client-consultant relationships are considered to be the co-constructed and continuously re-constructed result of close collaboration, rather than simply a conduit for exchange. The focus of practicing is shifted 'upstream' toward the dynamic and unpredictable activities of 'organizing,' and away from the 'downstream' notion of 'organization' as a designed, assumedly controllable entity; toward the upstream activities of 'knowing' rather than the downstream 'knowledge' that results, and toward activities of 'relating' rather than the downstream 'relationships' that result.

Co-constructive consulting draws from the pragmatism of Richard Rorty, the social constructionism of Ken Gergen, and the relational constructionism of Dian Marie Hosking. It also makes use of practical adviesbenadering is echter niet triviaal, omdat deze diep geworteld zijn-in het begin van de organisatiestudies in de jaren 50 van de vorige eeuw, in de 18e-eeuwse verlichtingsidealen, en zelfs in de presocratische origine van het W esterse denken.

Gebruik makend van dit historisch perspectief, en ook beschouwingen over hoe andere professies-zoals de geneeskunde en ruimtelijke ordening - zich ontwikkeld hebben, ontwikkelen wij in deze dissertatie een alternatieve benadering die we 'coconstruerend advies' noemen. Met deze alternatieve benadering ligt de focus minder op de overdracht van bestaande kennis, en meer op het co-construeren van nieuwe kennis die 'fit-for-purpose' is; cliëntadviseurrelaties worden gezien als cogeconstrueerd en continue gereconstrueerde uitkomst van innige samenwerking, in plaats van simpel weg een medium voor uitwisseling. De focus van praktiseren wordt 'stroomopwaarts' gebracht naar de dynamische en onvoorspelbare activiteiten van 'organiseren', en weg van de 'stroomafwaartse' notie van 'organisatie' als een ontworpen, schijnbaar beheersbare entiteit; naar de stroomopwaartse activiteiten van 'kennen' in plaats van de stroomafwaartse 'kennis' als uitkomst, en naar activiteiten van 'relateren' in plaats van de stroomafwaartse 'relatie' als uitkomst.

Co-constructief adviseren maakt gebruik van het pragmatisme van Richard Rorty, het sociaal constructionisme van Ken Gergen, en het relationele constructionisme van Dian Marie Hosking. Het maakt ook 
tools and methods from sociology, psychology and anthropology, including sensemaking, framing, the notion of affordances, situated knowledge, situated learning, distributed cognition and others. These tools and methods are useful when we embrace- rather than seeking only to control for-the indeterminacy of practice and the low predictability of change outcomes, not as risks to be minimized, but as ongoing opportunities for coconstructing and innovating.

This dissertation is a reflective practitioner tale, and tells a story of developing a 'coconstructive' approach to consulting. The dissertation is not intended to be about consulting and how to help clients, consultants and researchers of consulting. $R$ ather, the purpose is to be helping them. Still more specifically, the purpose is to be helping them address organizational problems, issues and opportunities, by articulating and developing, together with them, one additional alternative to the prevailing 'expert' approach to business consulting. gebruik van praktische methoden en technieken uit de sociologie, psychologie, en antropologie, waaronder 'sensemaking', 'framing', en 'affordances', situationele kennis, situationeel leren, en verspreide cognitie. Deze methoden en technieken zijn nuttig wanneer we- in plaats van alleen te zoeken naar beheersing-het ondeterministische van de praktijk en de lage voorspelbaarheid van veranderuitkomsten omarmen, niet als risico's die geminimaliseerd moeten worden, maar als voortdurende mogelijkheden voor co-construeren en innoveren.

Deze dissertatie is een reflectieve praktijkman's relaas en vertelt een verhaal over het ontwikkelen van een 'coconstructieve' benadering voor organisatieadvies. Deze dissertatie is niet bedoeld als een verhandeling over organisatieadvies en hoe cliënten, adviseurs en onderzoekers van organisatieadvies te helpen. Het doel is hen te helpen. Nog specifieker, het doel is hen te helpen organisatieproblemen, kwesties en kansen aan te pakken, door het, samen met hen, articuleren en ontwikkelen van een additioneel alternatief voor de dominante 'expert' benadering in organisatiead vies. 
PDF created with pdfFactory trial version www.pdffactory.com 


\section{Introduction}

In the spring of 2003, I was working in the Tokyo office of a global management consultancy, one of the (then) 'big five' firms. ${ }^{1}$ While I enjoyed working with and helping clients, I had nevertheless become increasingly dissatisfied with having to play the role of 'expert,' even though project environments, always in flux and unpredictable, seemed to call for a much more open-ended and collaborative approach. Consultancy training courses, stacks of management books and my own notes from business school offered only more of the same, namely, detailed methodologies or deterministic plans that sought to control for, but never embrace the dynamic nature of practice. So in 2004, after a year of indecision and more than a decade in consulting practice, I left to begin pursuit of a $\mathrm{PhD}$, initially to demonstrate how an 'expert approach' to consulting was a fundamental mismatch with the indeterminate organizational contexts where consulting was practiced. But what began as a rather cynical critique of one approach, evolved into a more positive co-constructing of an alternative approach, together with clients, consultants and researchers: an approach that gives primacy to purpose and action; an approach that is not 'expert-driven,' or even 'client-centered,' but one that puts organizational issues, problems or goals 'in the center;' an approach that welcomes the talents and efforts of everyone involved-not as clients, consultants or researchers, but as people-in the resolving, dissolving or achieving of these same issues, problems or goals. This dissertation is the story of developing that alternative approach, which I refer to as 'coconstructive consulting.'

\section{Helping}

Management consulting is sometimes referred to as 'the advice industry' (Fombrun and Neevins, 2004) and the activity of consulting is sometimes considered to be one of 'giving advice.' Those who plan to present a critical view on consultants or consulting may use the phrase 'dispensing advice.' My guess is that they prefer the verb 'dispense' because it implies an easy, arms-length transaction, a handing over of something already made, some thing without strings attached or the need for messy involvement or customization. Need some advice? Just pay the fee and we'll dispense some. It's easy.

\footnotetext{
${ }^{1}$ The 'big five' accountancies/consultancies in 2003 were Accenture, Deloitte \& Touche, Ernst \& Young, KPMG, and PricewaterhouseCoopers.
} 
Ed Schein, a well-known author and consultant with more than 40 years of experience, feels differently. To paraphrase Schein: 'Whatever else consulting may be, the giving or the dispensing of advice it is not' (2002: 21). Ed Schein feels, as I do, that consulting is helping, and that if you don't have any feeling of wanting to help, of wanting to serve, you're probably going to have a hard time of it. Unlike dispensing, helping has many strings attached, and is often very involved and very customized. Helping, at least the type of helping $\mathrm{we}^{2}$ are concerned with, is not the passing back and forth of knowledge, information, advice or any thing else. Rather, it is the creating of, the co-constructing of the new. Helping is the holding open of a closing subway door for another passenger, and the 'thank you' spoken in returnacts that jointly create, on that day, on that train at least, an improved morning commute; helping is the offering and the accepting of new ideas by members of a project team, ideas that build on one another and lead to unexpected and promising paths forward. Helping can thus be quite challenging, since regardless of your own best efforts or intentions, the decision as to whether or not what you've been doing is indeed 'helping,' is never yours alone to make; helping, in other words, is relational. Thus, we can say that for us, helping is a constructing, relating activity.

Helping is also the purpose of this thesis. More specifically, my purpose is to be helping clients, consultants and academic researchers of consulting. Still more specifically, my purpose is to be helping them address organizational problems, issues and opportunities, by articulating and developing, together with them, one additional alternative to the prevailing 'expert' approach to business consulting. This discussion of purpose brings us to one of two important influences that motivate and influence this thesis: pragmatism.

\section{Pragmatism and the primacy of purpose and action}

For those who, like me, adopt a pragmatist view, in the tradition of Richard Rorty (19312007), John Dewey (1859-1952), William James (1842-1910), Charles Sanders Pierce (18391914) and others, purpose and action are primary. The words of this introduction-and of the entire thesis for that matter-are not intended to be passive or neutral; nor are they intended to be primarily 'a description,' the quality of which would depend on how accurately they

\footnotetext{
${ }^{2}$ I use the word 'we' here intentionally. My consulting experiences, and the meanings derived from them, were generated by relating and interacting with others. As Mikhail Bakhtin wrote of Dostoevsky's novels, Dostoevsky speaks with many voices, each through a different character. As I write this thesis, it's difficult for me to think of my experiences as wholly 'mine.' The ideas and words of clients and colleagues are mingled in, inseparably. Sometimes 'I' seems to come naturally; other times 'we.' I think (and hope) that the sense of connectedness provided by using the word 'we' will overcome any awkwardness for the reader.
} 
represent something. These words are intended to be doing something, ${ }^{3}$ with their quality being judged (hopefully) not according to the accuracy of representation, but the extent to which they have achieved and are achieving their purpose, according to those who have read and engaged with them. This thesis is not intended to be about consulting and how to help clients, consultants and researchers; it is intended to be helping them.

The adoption of a pragmatist perspective affects the entire dissertation. For a pragmatist, it's difficult to fully make sense of a situation, or take action, until we are at least somewhat clear about what the purpose is. What words should I choose for the introduction to this dissertation? How should I structure the dissertation, and what methods should I use? The answers depend on the purpose. Because my purpose is to be helping clients, consultants, and academics, I will write this dissertation with language and a vocabulary that is (at least intended to be) accessible to them all. And this can be a challenge, because the vocabularies they currently use, and the way they speak and write are, in my experience at least, very different. But without clients, consultants and researchers-both as readers and as participants, as co-constructors-the relational activity of helping as I have defined it quickly fades.

I also want to make it clear early on that I'm less interested in what is 'right,' and more interested in what is 'useful,' and that those looking for a more traditional piece of research, or 'out with the bad, in with the good' arguments, or detailed or prescriptive methods for consulting, may find this work to be less than satisfying. The purpose is not to 'prove' that one approach to business consulting-including the co-constructive consulting approach we will be developing-is necessarily better than any other approach. I seek instead to offer an additional, alternative approach; alternative ways of consulting as supplements to, rather than as replacements for, what we are already more accustomed to.

\footnotetext{
${ }^{3}$ This is closely aligned with John Dewey's (1938) theory of inquiry, the purpose of which was not to obtain the truth, or even a better understanding, but rather for achieving some purpose. For Dewey, logic is a theory of the process of inquiry, where inquiry occurs whenever we encounter an indeterminate situation. Inquiry is not for the sake of inquiry, but for achieving some purpose. For many, inquiry means research-research undertaken to 'know' so that we can then take action, or live. But for Dewey, the process of inquiry is inseparable from living itself. Vernon Cronen (2001) provides two examples: "A flower adjusts its position to the sunlight that shines through the atmosphere ... . This is inquiry it its basic form;" and a young lioness "does not repeatedly catch prey in order to have a well-developed theory of hunting," but rather so that she can eat (p. 20).
} 
Relatedly, and at the risk of dwelling too long on what this effort is not, just as it is not intended as a replacement of the prevailing approach to consulting, neither is it intended to be the consulting approach for all time. For the most part, pragmatists are non-foundationalist, which means we don't consider the principles and purposes that guide our actions to be timeless or ahistorical, but to be changing over time. Richard Rorty (1989, p. 73) uses the phrase "final vocabulary" for the set of words people use to justify their own beliefs and actions, and to formulate their deepest doubts and highest hopes. This vocabulary is "final" in the sense that it is as far as one can go with language, and that beyond that, one can respond only with passivity, or force. A pragmatist, then, is one who allows their "final vocabulary" to change, to become not necessarily better-which would imply movement toward some ultimate, foundational position—but different, and more suitable for the purpose at hand. Importantly, however, this does not mean we are anti-foundationalist, i.e. concerned with 'proving' there are no foundations, which would be non-sensical. Instead, we would simply rather spend our time trying to make progress toward constructed purposes, than trying to establish that the world is one way or another. So ours is an attempt to develop a consulting approach that is relevant and useful not for all time, but this time, for 2010 , for now. Richard Rorty begins his Philosophy and the Mirror of Nature - an important work in the philosophy of pragmatism-as follows:

\footnotetext{
"Almost as soon as I began to study philosophy, I was impressed by the way in which philosophical problems appeared, disappeared or changed shape, as a result of new assumption or vocabularies. From Richard McKeon and Robert Brumbaugh I learned to view the history of philosophy as a series, not of alternative solutions to the same problems, but of quite different sets of problems" (Rorty, 1979, xiii).
}

For Rorty, then, philosophical problems are not timeless. Rather, an immeasurable confluence of historical/economic events, politics, weather patterns, etc., results in the crystallizing of something which we decide at the time is a problem, like the witchcraft that overtook colonial Massachusetts in the 1690s, or the urgent need for American business to respond to the 'Japanese threat' in the 1980s, or the more recent call for management consultants to be more accountable for the consistently poor outcomes of organizational change initiatives (e.g. National Audit Office, 2006; Phillips, 2000). These problems are not 'solved,' and then neatly packed away as we move on to the next, but rather fade away, some more abruptly than others; they cease to be of primary importance, relative to new problems 
that crystallize and overtake them. This discussion, which we will return to later, has particular relevance for management consultants, who are often accused by management scholars of propagating, with client complicity, a seemingly endless string of managerial 'fads and fashions.'

So what can be useful and relevant for mainstream management consulting now? In my view, and based on recent conversations I had with a few dozen clients, consultants and academic researchers of consulting while preparing this thesis (as presented in Chapter 5), 'now' is a time when both clients and consultants see the merits of closer collaboration and a more openended, exploratory and generative style of practice, but are reluctant to step out of their official roles-e.g. 'consultant,' 'expert,' 'client'-in order to pursue these merits. Now is a time when the 'official accounts' of consulting practice-i.e. client-authored RFPs, ${ }^{4}$ and consultant-authored proposals and project plans-bear more resemblance to an outdated 1940 's professionalism than they do to the day-to-day goings on of consulting practice; now is a time when many clients and consultants have clear ideas about what consulting practice is not-namely, consulting is not this: an expert consultant, detached and objective, applying a standardized body of knowledge for the resolution of clients' problems. These same clients and consultants, however, often have much less developed ideas and vocabulary about what consulting is, or, better yet, could be, or better still, could be doing. 'Now' is a time when more traditional, formal techniques and methods of consulting-e.g. project planning, detailed methodologies, OD-based 'intervention' strategies, etc.- are well documented and supported by management education and theory. But now is also a time when the more informal abilities-e.g. dealing with ambiguity, innovating, or simply 'getting along' in pressure-filled environments - are left in the background, un-named and under-developed (Anderson, 1997; Visscher, 2001), even though clients, consultants and researchers alike report these informal abilities as being more critical for project success (Alvesson, 1995; Crucini, 2002; Werr, 2002). Now is a time when, if you're a business consultant wanting to pursue something other than an expert or other deterministic approach, the places you can turn to for assistance, with a few notable exceptions, e.g. appreciative inquiry (Cooperrider, 1987; Cooperrider, Sorensen, Whitney, and Yaeger, 2000), are very limited. ${ }^{5}$

\footnotetext{
${ }^{4}$ Request for proposal

${ }^{5}$ Later, we will discuss a few of the well-known approaches that are sometimes considered to offer a non-expert, including Ed Schein's Process Consultation (1969) and the work of Peter Block (2000) and David Maister (1997). Our view is that they do indeed offer a more collaborative approach, but that, similar to an expert
} 
In summary, now is a time when mainstream management consulting faces the both the need, and the opportunity, for fundamental change. The fact that the success rate of organizational change initiatives, which account for the majority of consulting work, has been so low, for so long, suggests at least a couple of possibilities: 1) that our performance to date is indeed abysmal, or 2) that it's time to question this measurement itself and its implicit, underlying assumptions about 'organizations' that lead to a belief that our success rates should be much higher. In either case the implications are the same: 1) that a re-consideration of the fundamental assumptions underlying the prevailing approach to management consulting seems warranted, and 2) that developing one additional, alternative approach for this $\$ 300$ billion industry, based on different assumptions, seems worthwhile.

If I state all this as a 'research problem,' which I am hesitant to do, it would be something like: 'Clients and consultants suffer from the lack of a well-developed non-expert approach to business consultancy.' I am hesitant to state it as a 'research problem,' because it then becomes my responsibility, in a traditional, positivistic mode of research, to 'prove' this statement is true, and such is not my purpose. This need for an alternative approach is my own construction, just as 'the Japanese threat' was a construction (and one which, by the way, quietly faded away as American economic conditions improved); it is a choice I am making, with all the responsibility that implies, to focus my efforts here and not elsewhere. Of all the other ways I could spend my time-demonstrating against the Burmese junta, giving more support to family and friends, etc.-I am choosing instead to focus here, and I must take responsibility for that choice. Focusing on proving or disproving something about a reality that is 'out there,' in contrast, seems to me a comparatively safe business, an opinion I became more convinced of as the research moved forward, and I moved farther from traditional scientific research methods. After all, problems that are 'out there' and independent of me, are not of my making, and I bear no responsibility for them. While researching in the positivistic tradition, "it is method and method alone that "produces" findings" (Schwandt, 1996, p. 58). But when we adopt a pragmatic, constructionist perspective, the questions we face begin to shift, sometimes uncomfortably, from the innocuous 'is this the real problem?' to questions much closer to home: 'why did you choose this problem, and ignore all the possible others?' or 'why did you construct the problem that way?' With a pragmatic constructionist perspective, 'we have some skin in the game.' The idea that problems are not 'out there' and 
waiting to be 'found,' but are instead constructions over which we have control and choice, leads us to the second of the motivating influences: social and relational constructionism.

\section{Social and relational constructionism}

It appears I may have gotten ahead of myself, because I have already talked about witchcraft in Salem, and the Japanese 'threat' to American business: these are constructions we made in the past, and they are 'social' in the sense that they derive their meaning and their importance socially; that is, many people believe them to exist-i.e. they act as if they exist-and to be important enough to be labeled and responded to. Conversely, 'social' also means that if no one draws a discrete border around 'it,' or draws up a list of criteria to describe 'it,' or points to some thing, some activity or some situation and says 'look, here's one,' then whatever 'it' is will for us cease to exist. As a belief is accepted by more and more people, the more it is accepted as real and true. The more that someone's beliefs are thought to be shared with no one else, the more we say they are 'solipsistic,' or, more often, simply crazy. The next time a passerby says to you "Hello, how are you?" try responding with "Tuesday," or hold up three fingers, glare at them, and walk away. They will be dumbfounded. Behave like this too much, especially toward the people you work with, and you may find yourself called in for counseling, or out of a job altogether. Simple experiments like this one show us just how thin and brittle the veneer of constructed social reality can be (see also Goffman, 1959). They also show us how pervasive our degree of socialization is, such that when we overturn or flout a social convention that is considered basic and shared by all civil people, even a trivial one like how to greet a passerby, the consequences are often not trivial at all. And finally, this is also an example of how meaning is constructed relationally. Without co-operation and coordination, there is no co-construction, and, as in the experiment above, no creation of meaning, or at least, no creation of anything that is meaningful socially. Notice that coconstruction is different than, and more than, just sharing. In the experiment above, each party does share something-one a friendly greeting, the other a nonsensical reply. A more successful, and more normal outcome of such an exchange would be the joint or coconstruction of feelings of satisfaction: for the greeter, satisfaction that they had acknowledged a colleague, and received a friendly, acknowledging response; and for the greeted, satisfaction that they had been acknowledged, and that they had successfully returned 
the favor. This satisfaction cannot be created by either of them alone-it is relationally constructed. ${ }^{6}$ Dian Marie Hosking helps us to summarize:

"The most general point here is our talk about relating. Regardless of what is being related with what; we can use the term inter-action to embrace all of these relational possibilities. Inter-actions can include a handshake or some other non-verbal gestures, can be conversations about markets and strategy, can be the playing of a string quartet. Inter-actions involve texts, actions, objects, and artefacts available to be made part of some ongoing process, to be re-constructed, to be made relevant or irrelevant, meaningful or meaningless, good or bad, by being put into relation" (Hosking, 2006, p. 58, emphasis in original).

I should be careful when choosing examples, to avoid implying that social constructions are only in the past. Looking back in history, and particularly to constructions that have since been discarded or 'debunked,' like the witchcraft of Salem, helps us to see their constructedness, but around us now are numerous constructions as well: 2008 was a presidential election year in the United States and 'the economy' was a key issue ('issues' are also constructions). But just where is 'the economy'? Can we touch it? How much does it weigh? What color is it? And where, for that matter, are 'racial prejudice,' 'consumer confidence' or 'national pride' hiding out? Other than the buildings and furniture and equipment, where is 'the organization' we work for, or 'the culture' that we would say, with confidence even, that our organization most definitely 'has'? 'The economy' is a useful label (i.e. construction) we can apply to a diverse range of concepts, activities, statistics about wages, unemployment and inflation, etc. It is a convenient 'handle' we can use to gather together all these disparate things and thereby succinctly and conveniently talk and debate about them; it is a kind of social/verbal shorthand. But if we demand too much precision from this or any of these terms (i.e. constructions), subject them too much scrutiny, or try to establish precise definitions for them, or predict their behavior, the tangibility we

\footnotetext{
${ }^{6}$ Later, we will make the same points regarding 'knowledge management' or 'knowledge transfer' or 'knowledge sharing'-all important initiatives for business consulting. Such initiatives are often unsuccessful, despite significant investment. We will say that many knowledge management initiatives are based on the idea of 'transference' alone. If transference is the goal, this can be accomplished by handing over books or information or databases of best practices. None of this is useful, however, until it is taken up, read, engaged with and applied by someone else. We see this taking up and using less as 'knowledge transfer' and more as 'knowledge creation.' Just as with 'satisfaction' in the example above, this knowledge creation cannot be achieved by either party alone. Until knowledge creation occurs, the value of transferring or sharing of information or knowledge, is, we believe, limited.
} 
unquestioningly and routinely attribute to them disappears, and our discussion quickly splinters into dozens of different topics. Constructions are the result of what we have chosen to pay attention to, to treat as important, with all that implies, morally and ethically, about what we decide to treat as unimportant, i.e. what we intentionally ignore, or unintentionally fail to see altogether. To summarize, 'the economy' and countless other constructions that make up so much of each day's headlines are all very real, and very relevant for now, but they will not always be so.

But constructions are not at all confined to the past, and neither are they always intangible: When I first lived in Japan, there was a pottery shop nearby where I found a nice set of bowls for my kitchen. A Japanese friend was surprised to see me eating cereal out of them. "Jeff," he said, laughing, "those aren't cereal bowls, those are ramen bowls!" I said they seemed to be doing just fine for eating cereal out of as well. "Every time I visit you, here you are, creating new culture." So were they 'really' ramen bowls, which I just happened to be using 'as if' they were cereal bowls? Or were they, for me at least, 'really' cereal bowls? Both 'ramen bowl' and 'cereal bowl' are social constructions that are also very tangible. I do not deny the non-human, non-socially-constructed reality of the materials from which they were made, but I do maintain that the reality of them being 'ramen bowls' or 'cereal bowls' or whatever to be a socially constructed one. ${ }^{7}$

So what does all this have to do with consulting? There are several reasons why I have adopted the ideas of social and relational construction, and why I believe they are, along with pragmatism, useful for business consulting. The first has to do with the organizational context where consulting occurs. Failure rates of $60-70 \%$ or higher for organizational change initiatives suggests that a reconsideration of our current construction of 'organization' as a predictable, controllable entity might be useful. In my experience, and that of other colleagues and authors (Schön, 1971, 1983; Sturdy, 1997) organizations and their

\footnotetext{
${ }^{7}$ I cannot deny the non-social-constructedness of the materials, but here as well, humanity and culture (i.e. 'sociality') creep in, inescapably, with the use of words and language, no matter how innocuous or neutral I try to keep that language. Words like 'clay' or 'glaze,' or even more generic terms like 'materials'-these words tie me to a specific, English-speaking culture. Our culture is always already (Heidegger, 1962) in the language we use. So 'the materials' may not be socially constructed, but the words 'the materials' and the meaning attached to those words, are socially constructed, inescapably so, I believe. Perhaps there is some reality beyond our socially derived language, but about such a reality, we must, by definition remain silent, or invent words know only to ourselves, and in either case the result is the same-any such reality would not exist socially.
} 
environments are dynamic, uncertain, ${ }^{8}$ and always emerging. Again based on my experience, getting along in such environments requires you to 'think on your feet,' to be resilient after things don't work out as planned (which, if we go with the published percentages, is most of the time). It also requires you, well in advance, to have built up client relationships that are strong enough and trusting enough so that you aren't kicked out when things don't work out as planned (which, again, lest we forget, is most of the time). In such environments, as changing conditions inevitably force deviations from our pre-defined plans, we have a choice to treat these deviations as problems, or as opportunities. Adopting the idea of social constructionism, we can take advantage of the opportunity to not find the root cause of the problem(s) that are assumed to be 'out there' and beyond our control; rather we can proactively construct and design problems that are actionable and inspiring for us in the first place. In the example above, if I had gone to the pottery shop in search of a cereal bowl, I would have come home empty-handed. If however, I went to search for something out of which I could eat cereal, regardless of what it happens to be used for (or named) in Japanese culture, the problem is dissolved. In consulting practice, getting stuck on a seemingly unsolvable problem can be, if we allow it to be, a signal that there's an opportunity to redesign the problem, or re-construct it more usefully. The end of one line of work is the start of another, on a different trajectory. This is a kind of stubborn refusal to be defeated, a refusal to accept any situation as hopeless. In my experience, as we discuss more fully in Chapter 6 , project teams, almost without exception, demonstrate a significant underestimation of the opportunity they have to proactively and creatively design problems that are not only more actionable, but also more interesting (i.e. motivating) for them to work on.

These then, are some of the ways that social constructionism can useful for the practicing of consulting. The 'social' of social constructionism also reminds me that the purpose(s) I pursue are, and should remain, of social origin. They are not 'mine' alone, but result from interactions and relatings with countless others, over many years. For me, this helps take the edge off what might otherwise be the more individualistic instrumentality of pragmatism.

As for relational constructionism, this places greater emphasis on the 'upstream,' generative activities of relating, whereby the 'downstream' relationships and meaning itself, are created. Relational constructionism brings the focus closer to particular people, to how we might 'get

\footnotetext{
${ }^{8}$ See Yehouda Shenhav (2005) for further discussion on the origins of 'uncertainty' in organizational theory.
} 
along' better together, possibly_but not necessarily —as 'clients' and 'consultants,' in relation, to address issues and problems. The focus is not on explicating the attributes of 'the client-consultant relationship,' as something that exists between two separate, discrete and 'self-contained' individuals, but rather on people successfully relating, successfully creating 'relational realities.' Social constructionism considers meaning to be constructed socially. Relational construction, at least as applied to consulting, is in a way more specific, in that it remains focused on meaning constructed not by the amorphous and distant notion of 'society' but by specific people (e.g. clients and consultants) interacting in specific situations. Much more on this later.

\section{Styles, methods and approaches to consulting}

Another important bit of housekeeping before I can begin in earnest is to explain, and put out a few caveats, regarding what I mean by an 'approach' to consulting. In the American Heritage Dictionary, among the several definitions for the word 'approach' (as a noun), we find: "a way or means of accessing something." None of the definitions there seem exactly right, but this one, and especially the use of the word 'way' seems to come closest to what we mean by a consulting approach; an approach is a way of doing consulting. To further clarify, we can compare 'consulting approach' to 'consulting style' or to 'consulting method.' Method seems clearest, so we start there: a consulting method specifies the steps to be taken, the relationship between those steps, and the output. Kurt Lewin (1951), for example, defined a high-level 3-step method for organizational change-the well-known 'unfreeze-changerefreeze.' A 'consulting style,' in contrast, describes for example our demeanor, or the project/team atmosphere we may strive to cultivate-a 'casual, informal style,' for example; a 'no-nonsense, rigorous and fact-based style.' Our idea of a consulting approach falls somewhere in between method and style: more concrete, and more specific than a consulting style, but less so than a consulting method. A person's preferred approach to consulting, for example, may tell us something about how they plan to go about their work, but not the specific steps. It might tell us whether they 1) intend to take the problem as-is, go away and 'figure it out' on their own and report back, or, in contrast, 2) plan to work collaboratively and

\footnotetext{
${ }^{9}$ To clarify, we see 'client' and 'consultant,' and also 'expert' or even 'the guy who really understands the underlying technology' - we see these as constructed identities. They can be useful, when, for example we ask: 'Can you please take this contract over to the client and get it signed.' They can also be detrimental and constrictive, when a consultant withholds or disguises their feelings of indecision because of felt pressure to 'play the role' or 'assume the identity' of the 'expert.' In this thesis, we will be proposing that it's useful to pay closer attention to the identities we are constructing, and that we have some measure of control over the identities we choose to construct, or not.
} 
constructively with clients and colleagues, not only on the 'answers' but on the questions as well. More specifically, and as we will develop later on, a person's approach can inform us about the assumptions they may hold related to: organizations-what they are and how they behave; knowledge - the nature of it and its use in consulting practice; and work relationships_-in general, and the client-consultant relationships in particular.

\section{A commonly-adopted continuum of business consulting approaches}

The various approaches to business consulting are often plotted along a simple, linear continuum with 'expert' approaches (expert-driven, directive, prescriptive) at one end, and socalled 'process-oriented' approaches (facilitative, non-directive) at the other (see Figure 1). ${ }^{10}$ This 'expert' approach and the 'process-oriented' approach can be seen as ideal or illustrative types. Most mainstream management consulting firms-e.g. Accenture, BearingPoint, Capgemini,

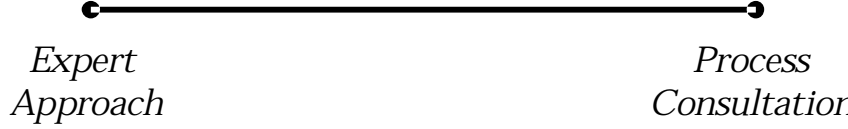

Figure 1: Continuum of business consulting approaches McKinsey-operate well toward the 'expert' end of such a continuum (Cummings, 2005; Werr and Stjernberg, 2003). Ed Schein's 'process consultation' (1969; 1999) is generally considered to be the archetypal process-oriented approach. Other well-known approaches, including those of Peter Block (2000) and David Maister (1989) can be said to fall somewhere in between. In addition to the large, global consultancies that are the focus of this thesis, there are also thousands of individual practitioners and small, specialized consultancies or 'boutique' firms, each with their own approach. Given that consulting firms-at least for marketing purposes-are constantly re-positioning themselves, the classifying and categorizing of consulting approaches is a challenging and perhaps never-finished task.

With an expert approach, the expert claims exclusivity over both the ability to find and diagnose the problem, and also over the possession of the knowledge resources required to address it. Process consultants, in comparison, strive for a more transparent 'process' of finding and diagnosing the problem together with their clients (hence the name 'process consultation'), and then decide on how to acquire the required knowledge resources. For the

\footnotetext{
${ }^{10}$ There are a number of frameworks for classifying various approaches to consulting. See for example Thomas Cummings (2004), David Maister (1999), Ed Schein (1969; 1999), and the (in my view witheringly complex) 'consulcube' by Blake and Mouton (1976).
} 
expert consultants, the possession of specialized knowledge is their primary source of power to influence and bring about closure. For the process consultant, it is possessions of the specialized knowledge of the problem solving process that is the source of power. An important first step in process consultation, is for the consultant to equilibrate the power relationship, and prevent defensive behavior on the part of the client.

Although an expert approach and process consultation lie at opposite ends of this commonly adopted continuum, they nevertheless share a commitment to an external and independently existing reality. In other words, for both the expert and the process consultation approach, the organizational problems we face are said to exist 'out there,' somewhere in the organization or its environments, but independent, nevertheless, from us. In still other words, the 'root cause' of a problem-production inefficiency, for example—simply is what it is: regardless of the perspective from which it is viewed, or by whom, the problem remains one of production inefficiency. Because the problem is said to be 'out there,' good problem definitions are thus characterized by their 'accuracy,' i.e. accurately describing the problem out there. With such an approach, the task at hand, therefore, is to first 'find' and diagnose the problem, and then apply knowledge resources to bring about a resolution. The two approaches are also similar in their treat power as a possession, a possession that is used to influence, bring about closure, or have 'power over' the other. The salient difference between an expert and a process consultation approach, therefore, is primarily one of method: i.e. the tasks of finding the problem out there, and developing solutions to address it, are either done 'to' the client, or together 'with' the client.

Today, 'more innovative' consulting practice is often synonymous with a move away from an expert approach toward process consultation. As we develop an alternative approach, we will endeavor to stretch this continuum of consulting approaches well beyond its current end point at process consultation. We will claim there is much greater potential for innovation and creativity in consulting practice. With a pragmatic, constructionist approach, we want to be co-constructing actionable, interesting problems, and the joint actions we take to resolve or dissolve them, i.e. the doing of consultancy itself. By focusing on the doing of consultancy itself, we want to take a processual view, including in our treatment of power which can be seen not only as a possession that people 'have,' but also that which they create through successfully performing. Because we don't see problems as being 'out there' and independent from us, but rather as our own social and relational constructions, accuracy will be a relatively 
less important characteristic of a good problem, compared to usefulness. From the paragraph above, for example, we're less interested in whether or not the problem is 'really' one of production inefficiency, and more interested in whether or not that particular construction of the problem (as one of production inefficiency) seems most useful. Following Rorty, Dewey and other pragmatists, we want to ask 'What would it be like to think of it that way?' Our preferred questions are less like 'What is the root cause?' and more like 'What if we treated this as a revenue-related issue, instead of a production-related issue? Would that produce any new insights? Which treatment is most useful, and which leads to the most promising path forward?' To summarize these points, we can say that compared to either an expert or a process consultation approach, a pragmatic, relational constructionist approach to consulting involves a shift from 1) a 'found' reality to a socially constructed one, and 2) from the primacy of possession (of knowledge, power and other resources) to the primacy of practice, or practicing, or performing - i.e. the doing of consultancy itself.

\section{Structure of the thesis}

Much has changed for me since I began this work in 2004: beginning the work while living in Japan, continuing the work in California, and completing the work in The Netherlands. These moves, and the diversity of people and writings I engaged with, have brought about significant changes in my outlook on life. As my outlook changed, so too did the purpose of the research, and the methods by which I undertook it. Looking back, I can see three fairly distinct phases-critique, 'muddling through,' and co-construction. It is around these three phases which I have structured the thesis. Together, they constitute something of a journey, from the critique of one consulting approach, through a period of transitioning, to the coconstructing of an alternative. Let me explain these phases, using my changing view on 'reality' as a reference point.

\section{Critique}

When I began this work, I believed that reality was some thing that existed 'out there,' external to and independent of us, something that could, with persistence, be 'found' through scientific analysis and experimentation. ${ }^{11}$ My beliefs at the time were those of a 'realist' or a 'positivist.'

\footnotetext{
${ }^{11}$ There were of course, some earlier, lingering doubts, such as wondering how I could know with certainty that someone else was seeing the same color as I, just because we both called it 'red.' 'We know,' it was explained to me, 'because we have machines that can objectively measure the wavelength of the light being reflected.' This explanation settled the issue for me at the time, because I had not yet read, for example, someone like Bruno Latour or Jacques Derrida, who might have followed up that explanation with a question like: 'But for the measurement to be conclusive, to be certain, wouldn't the people who built the machine first have had to agree
} 
I considered what I was doing at the time to be 'research,' i.e. the finding of answers and evidence, both theoretical and empirical, in support of my arguments, which, initially, were focused on a critique of the prevailing 'expert' approach to consulting. More specifically, I wanted to 'prove' that certain key aspects and assumptions of an expert approach-e.g. the assumed controllability of organizational change outcomes, and the assumed transferability of knowledge-were simply not borne out by the experience of day-to-day consulting practice. Within academia, I expected, lay the robust theories and knowledge I would need to build a replacement. About 18 months after beginning my research, however, I reached an impasse. While I had been able to complete a critique, I was unable to see an alternative way forward that did not depend on the very same assumptions underlying the expert approach. I was left without an alternative.

\section{Muddling through}

With no alternative to offer, I entered a difficult and rather directionless period of what I'll call 'muddling through,' to borrow Charles Lindblom's memorable phrase. Eventually, influenced by new friends and colleagues, the ideas of pragmatism, of social and relational constructionism, the philosophy of science, ${ }^{12}$ and further reflections on my experiences as a consultant, I did find a new direction for the thesis, centering around a 'processual view' as the foundation of an alternative approach. I rejected my earlier positivistic position, ${ }^{13}$ and came to believe that reality is not 'out there,' passively waiting to be 'found' or 'discovered,' but is instead 'socially constructed', which is to say that reality and meaning are the generally agreed upon results of, are 'constructions' of, earlier debates and discussions, that happen socially. Looking around us, it can be difficult to imagine how the reality of things could somehow be 'constructed,' socially or otherwise. Can we doubt, for example, the concrete and timeless reality of, say, a heliocentric universe? Can we doubt the reality of mycobacterium tuberculosis, the bacteria that causes TB? The 'constructedness' of reality is more apparent, however, when we look to the past and consider that for thousands of years, the idea of a geocentric universe held sway, or that, according to $19^{\text {th }}$ century Londoners, it

\footnotetext{
on what was going to be meant by the word 'wavelength' for example, just as we are now agreeing to call the color we see 'red'?' and so on, until we agree we will go no further, and treat some agreed-upon point as foundational (and therefore ahistorical, timeless).

${ }^{12}$ Including, for example, Thomas Kuhn, Ian Hacking, Karl Popper, Harlene Anderson, Ken Gergen, Dian Hosking, Imre Lakatos, and others.

${ }^{13}$ In this second phase, I would argue with those who believed in an independently existing reality, and try to overturn those beliefs. Fortunately this phase was short. Early $\mathrm{PhD}$ students-with just enough information to be dangerous - are best avoided, along with, for example, wolverines, pit bulls and other irascible, quarrelsome species.
} 
was not bacteria, but rather 'bad air' that caused tuberculosis. These are but two of the innumerable examples of past 'realities' that were once constructed, quite reasonably so, but that have since been discarded. ${ }^{14}$ We should also not forget that many of these past constructions served their purposes very effectively. Changes to building and sanitation codes enacted in London - for the purposes of improving the 'bad air' - also resulted, within just a few years, in a $90 \%$ decline in the number of deaths attributed to (what we today call) tuberculosis. ${ }^{15}$ Were the Londoners 'wrong' in their theory about bad air being the cause, I wondered? I felt the answer was 'no.' Or better yet, if you or one of your family members or friends were among those whose life was spared, would you care at all about whether the theory was right or wrong?'

\section{Construction}

Eventually, however, and similar to my current views, I came to view this second phase and the rejection of my original positivistic beliefs as simply the replacement of one absolutist position-reality is out there-with another absolutist position-reality is socially constructed. I maintained a belief in the social and relational construction of reality, but, fortunately for those around me, accepted that others' beliefs may, and do, of course, differ. Perhaps more importantly, the whole question of what is real or not real ceased to be of central importance. I embraced a non-foundational view. I became, and remain today, more concerned with the purposes I am pursuing, and with doing what is useful for those I'm working with, and achieving or moving toward achieving those co-constructed purposes, as opposed to determining what is real or right or true according to some external and singular standard. But I can still speak positivistic language, if that is what's needed in order to be understood by, or helpful to, those I'm working with. This is, of course, the position of a pragmatist, as I discuss more fully later on. Rather than critiquing the prevailing approach, I am concerned with constructing an alternative, or alternative ways of practicing consulting. I no longer consider what I am doing to be 'research,' in the sense of searching for something

\footnotetext{
${ }^{14}$ See also Morris Berman's (1981) The Reenchantment of the World. Berman refers to anthropologist Paul Riesman: "Our social sciences generally treat the culture and knowledge of other peoples as forms and structures necessary for human life that those people have developed and imposed upon a reality which we know—or at least our scientists know-better than they do. We can therefore study those forms in relation to "reality" and measure how well or ill they are adapted to it. In their studies of the cultures of other people, even those anthropologists who sincerely love the people they study almost never think that they are learning something about the way the world really is. Rather, they conceive of themselves as finding out what other people's conceptions of the world are" (Riesman, 1976, p. 53, emphasis in original, referenced in Berman, 1981, p. 84-85).

${ }^{15}$ See Richard Hobday and John Cason (2009) for a history of so-called 'open-air' treatments of tuberculosis and influenza.
} 
out there, or attempting to 'discover' causal relations and explanations of how things work. Instead, I am trying to be doing something. What I am trying to be doing, is helping; more specifically, helping clients, consultants and academic researchers of consulting, by explicating a processual, pragmatic and relational constructionist alternative to the 'expert' approach to consulting.

\section{Regarding you, the readers}

As I hope is apparent from the discussion above, the journey I have taken has been one of significant personal change. While I believe the ideas of pragmatism and social and relational constructionism can be very useful for the practicing of consulting, I also believe these ideas are different from those of many of you — clients and consultants—and different as well from what many of you encountered during your undergraduate business or MBA education. ${ }^{16}$ To go further, some of the ideas I will discuss here are most likely not only different, but sometimes contradictory, unsettling or even threatening to what you may believe. Thus the risk of losing the audience, i.e. the readers, is not small. I risk losing my academic readers as well, because the methods employed do not conform to traditional academic research. Losing the readers is problematic, because the purpose is to be helping, and helping for me is relational. Losing the readers means the opportunities for relational co-construction are reduced - not only with you and I, as author and reader, but between clients and consultants as well. So, the overall structure of the thesis will be that of a journey, one that passes through a number of places, and hopefully providing each of these groups a number of opportunities to relate. With academic readers, I want to create a fuller appreciation for the challenges of practicing. And for clients and consultants, I want to create a fuller appreciation for the wide variety of research results that are already available for use. And yet, I also hope that clients and consultants in particular, as a result of reading this, will trust themselves and their experience more. I want them to see that, when it comes to embracing and successfully dealing with uncertainty-instead of only trying to control it-your experiences, techniques, intuition, and what you may feel to be your unique or quirky methods, are some of the very best ways we have of getting things done in practice. These ways are every bit as robust, as valid and as effective, if not more effective for practice as anything academia has to offer. Clients, consultants, researchers-and more importantly, the three-dimensional people living

\footnotetext{
${ }^{16}$ For discussions of the challenges involved in bringing non-traditional or critical studies into management education, see for example Hagen, Mill and Johnson (2003), Reynolds (1999a; 1999b), Sinclair (2007), and an article by Tony Watson (2001) that adopts a pragmatist perspective and the use of 'negotiated narratives' which are co-constructed by, in his case, students and instructors.
} 
Introduction

behind these one dimensional labels — can be seen as equal and important co-contributors to getting along better in our 'organizational 'lives,' and our lives in general.

This journey then, begins with my own experiences as a consultant; moves on to my time as a 'researcher,' looking to find answers and evidence in support of my critique of an expert approach to business consulting; finding those answers, only to reach an impasse due to lack of an alternative approach; and then to the later and current days as a 'co-constructor'together with clients, consultants and researchers — of a different approach to consulting. It is, in other words, a journey from critique to construction. This thesis is the story of that journey.

\section{Chapter overview}

In Chapter 1, I will recount the early days of my research, and the work done according to my purpose at that time to 'tear down' the expert approach to consulting, and the impasse at which I eventually arrived. Chapter 2 is the beginning of a transitioning away from critique and toward co-construction. I discuss a period of 'muddling through' following the earlier impasse, which resulted in a very different world view for me, and a different direction, therefore, for the thesis. In Chapters 3 and 4, I present three key aspects of an expert approach to consulting, re-constructed according to a processual view. Chapter 3 covers two of these reconstructions: 'organization' to 'organizing;' and 'relationship to relating.' Chapter 4 covers the third of three, 'knowledge' to 'knowing.' In Chapter 5, I present the results of conversations to explain and further develop this alternative approach with clients, consultants and academic researchers of consulting, undertaken in one-on-one and group discussion formats. In Chapter 6, I present a 'practitioner-oriented' paper demonstrating the use of social constructionism and pragmatism during a business strategy project with a large telecommunications company. And finally, in Chapter 7, I summarize the thesis, and propose opportunities for future action. 


\section{Chapter 1: Critique}

I have said that my purpose with this thesis is to be helping clients, consultants and researchers by developing an alternative approach to business consulting, and so it is. But it certainly didn't start out that way. In 2004, my initial objective was a more narrow and a more cynical one. Having left consulting work over dissatisfaction with the expert approach, my initial objective was to problematize that approach, to 'make it look bad,' as Richard Rorty (2001) might say. In this chapter, I will recount these early days of my research, using excerpts taken from my writings at the time, and show how they eventually led to an impasse and a change of direction for the thesis. This will require some shifting back and forth between earlier and more recent material. When the distinction is important, I will make it clear to you, both textually, and by indenting, as with the following excerpt of material I wrote not long after beginning my research:

\section{Frustrations with playing the role of expert}

When playing the role of expert consultant, certain words and phrases are no longer freely available to you. These include, for example, 'I don't know,' 'This isn't working,' phrases that begin like 'This may seem crazy but what if . . ,' or statements like this: 'Yes, we all know that 'the numbers' support option A. But nobody really likes option A, and we don't want to have to work with Jane's group anyway, so let's just go with option B and be done with it,' etc. The expert consultant is not allowed to 'not know,' and they must remain wary of truly open-ended discussions, i.e. discussions without any predetermined conclusions or direction, that might lead away from their expertise or the product or services they have to offer. When playing - and getting paid for playing - the role of the expert, one must be confident and decisive. Not that there's anything wrong with confidence or decisiveness, but simply that the situations of consulting practice rarely if ever serve up the kind of neatly packaged problems that are easy to be confident and decisive about. "In real-world practice," writes Donald Schön, "problems do not present themselves to the practitioner as givens. They must be constructed from the materials of problematic situations which are puzzling, troubling, and uncertain" (Schön, 1983). There's also nothing wrong with having to face up to uncertainty - unless, that is, you have to do so with a considerable portion of your vocabulary, intuition and the possibility for experimentation or exploration made unavailable to you. Thus there are costs associated with not being allowed to 
'not know,' with maintaining an air of unswerving confidence in the face of uncertainty. The costs include stress on those putting on a brave face, and the cost of foregone opportunities for creativity and innovation whenever the consultant is forced to give answers prematurely, whenever discussions are prematurely foreclosed upon, or whenever the freedom to simply 'try it and see' is disallowed.

These, then, were some of the causes of my dissatisfaction with an expert approach. Certainly they were important motivations for leaving consulting, but not necessarily for entering academia. That motivation came from the belief that somewhere, within academia, lie the robust theories and knowledge I would need to put together the 'real' story for why the 'expert' approach to consulting was not the way to go. I was happy to soon find that the material for building such a case was varied and plentiful, addressing many areas that were relevant for consulting, including, especially, professionalism, organizational development/behavior and organizational change, and knowledge management. I also found several other topics, perspectives and theories with long-established research traditions that had not been part of my business school education or work experience — at least not explicitly_but that were, nevertheless, highly relevant for consulting, topics like power, expert power, and closure theory, for example. In the following pages, I will discuss some of the key points of the arguments I was constructing in the early days of my research. ${ }^{17}$

\section{"The prevailing approach to management consulting ${ }^{18}$ is an expert approach"}

With the rich resources of academic research now available to me, a first task in critiquing the expert approach was to prove that it was indeed the prevailing approach to consulting. With research by Susan Walsh (2001), I found the smoking gun evidence I was looking for. Here is an excerpt from an early paper I wrote:

\footnotetext{
${ }^{17}$ It's important to mention here that I did not at the time consider my work to be the 'constructing' of various options, from which I would choose the one(s) to pursue. At the time, I thought there to be one single argument-i.e. 'the truth'—out there. My work was to find, capture and 're-present' that truth as compellingly, but more importantly, as accurately, as I was able. It is precisely this shift from a 'found' to a 'constructed' view of meaning and reality that marks a fundamental change in my beliefs, and the most important difference between the early and later portions of the story told in this dissertation.

${ }^{18}$ In the early chapters, I refer to 'management consulting,' as this was the target of my research at the time. Later, as the focus of my work shifts from critique (of 'management' consulting) toward construction of an alternative approach, I adopt the term 'business consulting,' or, more generally, simply 'consulting.'
} 


\section{Expert consultants}

During in-depth interviews of 50 partners, directors, and managers of three of the [then] 'big five' accounting and consultancy firms, Walsh found that the majority $(68 \%)$ of the consultants reported themselves as being aligned with an expert approach. She quotes one respondent: "All of our clients are looking for experts . . somebody to stand up and tell the audience what the right answer is" (Walsh, 2001, p. 34-35). And 52\% of those interviewed reported that during the course of a consulting engagement they learned nothing new from their clients:

"The implicit tone was that, as experts, consultants should not look at their clients as potential teachers ... . They view the "real" learning as a one-way process, from consultant to client”' (p. 35)."

And from the clients' perspective, Wood (2002) shows, perhaps not surprisingly, that clients' expectations of consultancies are well-aligned with what the consultants are offering. In a survey of the organizational change projects of 124 large UK companies, 'gaining access to the consultants' special knowledge and skill' was the most-often cited reason for the use of external consultants (Wood, 2002). More recently, Tom Cummings, a consultant/academic from the University of Southern California, says that among the various approaches to consulting, the expert approach, or what he refers to as the "expertise-approach," remains "by far the most common" (Cummings, 2004).

Convinced that I had proven that an expert approach truly was the prevailing approach for mainstream management consulting, I shared an early draft of this paper with Greg, a professor and colleague from Dallas. His reaction was somewhat unexpected:

Jeff: "Well, what do you think?"

Greg: "You make some good points, but they're not really that bad are they?"

Jeff: "Who?"

Greg: "The consultants."

Jeff: "How so?"

Greg: "I mean this whole idea of an expert approach . . . . Consultants don't really operate that way anymore, do they? I'm sure some, say the ones who do only 
technology work, they might do consulting that way. But others, like McKinsey, or people like Peter Block for example, surely they're more collaborative?"

Undeterred, I set to work putting together some even stronger evidence. I intentionally picked out a list of authors who were often credited with being more collaborative, and searched for passages and quotes to prove that underneath their more collaborative style, an expert consultant remained fully in charge. The list included: David Maister, Edgar Schein, and, because Greg mentioned them specifically, Peter Block and McKinsey. The results turned out even better than I had expected. Here is an excerpt from the revised paper:

In The Trusted Advisor, for example, Maister (2000) counsels consultants that they should listen carefully to the client's request, and after explaining all the available options to the client, "You [the consultant] can then gently guide the client to the preferred solution" " (p. 34). In Flawless Consulting, Peter Block (2000) equates effective consulting skill with the ability to get the client to commit to the consultant's ideas, as indicated by the sub-title of the book-A Guide to Getting Your Expertise Used-and in the following passage:

"The line manager ultimately will decide whether to take action, and this choice will be based on how internally committed the line manager is to the concepts the consultant is suggesting. So the consultant needs to be very conscious of building internal commitment all during the consulting process. Effective consulting skills are those steps and behaviors that act to create internal commitment in managers" (Block, 2000: 20, emphasis added).

In Ed Schein's (1999) 'process consultation' approach we read that client participation in addressing their own problems is apparently considered to be optional: "The consultant . . . should not attempt actually to solve the [client's] problems himself unless he is certain that he has the requisite information and expertise" (p. 10). In other words, it is considered quite possible, just not advisable, for the consultant to solve the client's problem without the client's involvement. Similarly, in The McKinsey Way, Ethan Rasiel's (1999) book-length description of the consulting approach of 
McKinsey, neither the verb 'collaborate'-nor any of its derivatives, e.g. 'collaboration,' 'collaborative,' etc., appear even a single time.

\section{Reflection}

Before further discussing other parts of the case I was building, I would first like to reflect on how I was working at the time, and to demonstrate some of the changes in my perspective that have occurred since then.

Based on Walsh's study and the quotes from the consultants themselves, as well as information gathered from several other authors, and my own experiences, it didn't seem unreasonable to conclude that the prevailing approach to management consulting was indeed an expert approach. I thought I had 'proved' this to be true. Or had I? But what if the consultants had responded to Walsh as they did, not because they considered themselves experts, but because, and just as I have done many times, they were simply playing the role of the expert consultant? What if, for example, they were concerned over how her results might be used, or that their anonymity might be compromised, and were therefore careful to respond in a manner appropriate to the role they were being expected (and paid) to play? What if Walsh had somehow biased the results, inadvertently or otherwise? We have no reason to suspect that she did, and also assume the editor, after reviewing Walsh's research methods, would have caught the error before publication anyway. We believe Walsh's study to be no better nor worse than other academic research in terms of quality or rigor. Instead, the point we are trying to make, is that when you have set yourself the objective, as I did at the time, of 'proving' reality to be one way or another, there is always another 'what if' to be dealt with. Today, I consider this to be a limitation of a strictly positivistic position, which requires (what is considered to be) direct, observational 'evidence' (which, of course can nevertheless be endlessly contested and re-interpreted) before something can be said to be conclusively proven. ${ }^{19}$ At the time, however, I did not consider it a limitation, nor had I thought about my

\footnotetext{
${ }^{19}$ Here we should mention the contribution of Karl Popper (2002). Before Popper, philosophers had struggled with the problem of induction, i.e. how to go from single observations, e.g. 'that swan is white,' to general statements or laws, e.g. 'all swans are white,' and to do so with certainty. Popper understood there would always be another 'what if' and recognized the impossibility - without gathering all the world's swans together-of conclusively proving (or 'verifying' or 'confirming') they were indeed all white. To overcome the problem of induction, Popper proposed falsification, instead of verification. Thus instead of deferring judgment until all the 'what ifs' are accounted for (i.e. verification) we can instead begin by accepting the statement 'all swans are white' until such time as an observation — of a black swan, for example—shows that to not be the case (i.e. falsification). For Popper, scientific theory must be 'falsifiable' through experimentation, that is, to be considered
} 
own position enough to even consider it to be 'positivistic'-that 'categorization' or 'labeling' of my own views came only later. At the time, based on the evidence I had gathered, I considered the question of whether or not the prevailing approach was an expert approach, to have been conclusively answered. Later, however, as I began to reflect on earlier work, this came to be one of the first doubts that my arguments-and more importantly the way those arguments were constructed, i.e. with their dependence on conclusive proof-were not so strong after all. Of course I had thought about this before, just as most consultants or managers have worried about the sudden appearance of an unanticipated 'what if' that threatens to contradict their conclusions or overturn their plans. But I had not, until later reflection, thought seriously about the assumptions that had for years underlay my view of how it was that matters came to be 'proven,' either in research, or in life more generally. I believed there was a reality out there, and that there were facts about that reality, and that these facts, once found and stripped of any biases and/or subjectivities, would form the basis of an unambiguous, conclusive proof, or disproof, of some statement or position-they would constitute the Truth. Upon reflection, the certainty of these long-held beliefs was shaken. And not only did the strongest of arguments seem to fall well short of being conclusive, but the question of just how conclusive one had to be and still be considered true- - this turned out to be socially determined. For example, we could continue on with additional, increasingly speculative 'what if' questions of Walsh's work, and whether her results had or had not proved conclusively that most consultants consider themselves to be acting as experts. We could ask, for example, 'What if the editor had concerns about the quality of Walsh's work, but wanted to make a splash, by publishing something sensationalist?' or 'What if the there had been errors in the calculations?' If we were to continue on with such questions, sooner or later we would be accused-rightly so—of simply being ridiculous. But the point at which our questions become 'ridiculous,' the line past which our questioning of her research would no longer be taken seriously, is not completely clear, nor precise, and neither is it statistically or somehow mechanistically derived. The point past which our objections are no longer taken seriously,

scientific, theory should be exposed to falsification, so that over time, the theories that survive are progressively better, with greater explanatory power. Popper's position does indeed seem to be useful for helping us to 'go on' despite unavoidable uncertainty. My reservation is that the objective still seems to be greater understanding of some external reality, rather toward more concrete action, i.e. that what it is that we are moving progressively closer to, is left unsaid. And finally, I should also acknowledge the still-emerging debate over Popper's original 'naïve falsification' ideas, e.g. Thomas Kuhn's (1970) notion that scientific progress happens not through incremental progressions, but during non-linear 'paradigm shifts;' Imre Lakatos' introduction of the idea of a broad 'research programme,' whereby theories could accommodate some change around the periphery, without falsifying the 'hard core' — an approach that is sometimes credited with bringing the otherwise conflicting views of Popper and Kuhn closer together. 
i.e. the point at which Walsh's results are considered to be true, is a socially derived one. The determination that Walsh's results are true does not result from comparing her results with some external reality that exists 'out there.' Instead, truth is simply that which Walsh and the editor have agreed to call true. If we say this just points out the difficulty and limitation of qualitative research, and that quantitative studies would indeed provide conclusive proof, we nevertheless face an endless string of questions about how the measurements were taken, how they were compiled, etc. And if we say that the measurements in such a quantitative study were taken completely 'objectively' by machines, with no human researcher even present in the room, this still does not allow an escape from questions of how it was that the designers and builders of the machines came to their conclusions about what to measure, and what not to measure, how the machine would 'translate' physiological phenomena-e.g. heart rate, level of perspiration-into 'results,' and how those results are interpreted, etc. But none of this makes the results of Walsh's study any less true or real. Regardless of how rigorous or sophisticated, such tests cannot provide a judgment of truth that is independent of us, and all the opinions, and biases we bring as researchers, readers, or even as the engineers who designed and built the equipment. Truth remains that which we agree to call true. Machines give us some distance away from the judgment, and thereby provide us with some sense of relief that the judgments are objective. The machines, nevertheless, as well as the constructs they measure, all are inextricably bound up with, and indeed are products of, our specific culture. For Walsh and the editor at least, (and for me as well because I accept them) the results are both true and real. But it is a truth and a reality that they have co-constructed. It is through these kinds of interactions and "relational processes" back and forth between people, e.g. Walsh and the editor, that these "relational realities" are co-constructed (Hosking, 2006) Edwards and Potter (1992) refer to these relational processes as "reality-constituting practice(s)" (referenced in Hosking, 2006, p. 60). We think this same notion of realityconstructing practice lends a good deal of explanatory power as to how the realties we have discussed earlier-e.g. witchcraft in Salem, the 'Japanese threat,' and the mycobacterium tuberculosis-were constructed. ${ }^{20}$

\footnotetext{
${ }^{20}$ Notice that we intentionally referred to the bacteria, and not 'bad air' as the cause of TB. To say with finality that 'now we know' the cause of TB, is to assume that history stops here, and that it will never come to pass, say a few hundred years from now, that some future, advanced civilization will look back on our own to try and understand why it was that we were so certain that what we called 'bacteria' was the cause of what we called 'tuberculosis.'
} 
However, I want to avoid being guilty of the same charges I have been leveling against a positivistic view. And I will be guilty of precisely that if I say that the positivistic view is wrong, while the pragmatic, constructionist view I am advocating is right. As I mentioned earlier, this would be simply the replacement of one absolutist position with another, and such is not the intent. It would also imply that someone with a pragmatic, constructionist view would be able to, or primarily concerned with, answering the questions of whether something is, in general, right or wrong. For a pragmatist, this begs the question: right or wrong, true or false, according to whom, where and when, and for what purpose? Of course there are statements about which it is easy to say 'true' or 'false': 'Florida lies to the south of New York,' for example, is, for Americans at least, a true statement. The problem with most statements about which it's easy to say whether they are true or false, is that they don't get us very far. They are often facile truisms: 'Florida lies to the south of New York . . and?? Your point is??' In fact, I don't know of even a single social issue-e.g. education, immigration policy, public funding of the arts - that is 1) meaningful or consequential, and, at the same time 2) an issue about which we can make statements that can be said to be clearly true or false. Meaningfulness implies 'debatable-ness;' 'meaningfulness' is a result of earlier discourse, of an earlier constructing of meaning. I see a pragmatic, constructionist view as one additional, and potentially useful, view. This does not mean I do not have a clear preference for one way over the other, which of course I do. But neither does it mean that I cannot accept another, different view, or even adopt it as necessary, for achieving a particular purpose. My purpose here is to be helping, which, as a relational activity, involves others. And for others to be willing to be involved, they will need to feel that the alternative approach I am trying to co-construct with them is sufficiently legitimate. Positivistic positions gain their legitimacy by being as true of a representation as possible of 'the way things really are.' A pragmatic, constructionist view, in contrast, has no such 'anchor.' It must stand on its own merits, without appeal to some external standard. A pragmatic constructionist view gains legitimacy not because it reflects 'the way things are,' but because it is persuasive and/or useful.

Thus far in this reflection, I have discussed two important 'events' that had begun to fundamentally alter my beliefs about, and the importance of, reality and truth: one, that attempts to prove reality to be one way or another are never conclusive, and two, that somehow we are nevertheless able to go on with life, despite this uncertainty, by coconstructing our paths forward together with those with whom we are relating. But an even 
more important reason for distancing myself from a positivistic position, and embracing the ideas of pragmatism and relational constructionism, is a focus on usefulness and action.

Positivism has as its objective the attainment and possession of 'authentic' (i.e. objective, unbiased) knowledge. A pragmatic constructionism, in contrast, has as its objective acting, doing. Positivistic proofs are said to produce some thing-usually knowledge, understanding or truth - that one can have or posses. Going back to the first task of my research - to prove that the prevailing approach to consulting is an expert approach-what do I 'have' as a result of proving that? I will 'have' some (constructed) knowledge that coincides with and confirms what I already believed in the first place, a belief which guided me to find and include information in support of that belief, and to ignore or discard information that did not. But what I will not have is much progress toward an alternative. Greg had already told me the very same thing, when I came to discuss the revised version of my paper. He told me clearly, but I wasn't listening. Here is the conclusion of our conversation:

Jeff: "You see? This is what I was talking about. You mentioned Block, Maister, and Schein as being non-expert or more collaborative. My point is that these are consultants who have a reputation for being collaborative. But when we look more closely, we see that they too are really just pursuing an expert approach."

Greg: "Ok. Perhaps these people run their consulting practices that way, but you don't, do you?"

Jeff: "No."

Greg: "And surely you're not alone?"

Jeff: "Well . . no, probably not."

Greg: "Then why are you spending your time criticizing their approach, instead of just developing your own?"

\section{"Contemporary consulting practice is modeled after an outdated and problematic image of professionalism"}

Having 'proven' that the prevailing approach to management consulting was indeed an expert approach, the next task was to show how and why this approach was problematic. Within the academic literature, further research on an expert approach led in turn to studies of the 
professions, where I found a much different and 'darker' account of the professions than I had known before. ${ }^{21}$

Beginning in the early 1960's, the traditional model of professionalism had come under serious attack (Schön, 1983). The prevailing image of altruistic professionals, objectively applying their expertise for the benefit of their clients and of society, had within a few short years given way to accounts of incompetence and accusations of a self-interested protection of power. A number of professions, including medicine, public planning, transportation, mental health and others, were implicated (Freidson, 1970b; Hall, 1989; Larson, 1979; Schön, 1983). In particular, the professionals' 'body of expert knowledge' and the nature of the traditional professional-client relationship were called into question. Not only was professional knowledge seen as ineffectual for meeting the needs of a complex and changing society, critics also questioned the substance of professional knowledge itself. They suggested that professional knowledge was, at its core, more like common sense, that had been intentionally shrouded behind a professional mystique, in order to protect the professionals' basis of power (Derber, Schwartz, and Magrass, 1990b; Jamous and Peloille, 1970). As for relationships, the 'critical distance' that professionals had traditionally maintained from their clients, in the name of neutrality and objectivity, came to be seen as a way of keeping the professional in a position of power, by precluding the clients from active participation, even during the resolution of their own (the clients') problems.

In The World's Newest Profession, perhaps the only published comprehensive history of management consulting, Chris McKenna (2006) maintains that since the industry's beginnings, consultancies have attempted to closely align themselves with the professions, in

\footnotetext{
${ }^{21}$ The following review of the history of the professions and of management consulting is primarily a review of events in the United States, mostly because management consulting began there, and also developed there, at least until the 1950s, when several firms began expansion into Europe (McKenna, 2006). The work of others whose work we will draw from, in particular Magali Larson (1979) and Eliot Freidson (1970a; 1970b) is also focused primarily on the US. As Andrew Abbott (1988) discusses, the Anglo-American professions, particularly medicine, law, accountancy — and the study of them as well—have always been more occupationally related than the professions of continental Europe, which would also include government-related professions, e.g. civil service and the military, and also the clergy. However, as studies of the professions progressed, the important influence of the government came to be recognized by Larson and other researchers, including Terrence Johnson (1972), and thereby brought the Anglo-American studies of the professions more in line with those of the Continent (Abbott, 1988, p. 19). As we will discuss, governmental influence, in the form of changing regulations, was particularly important for the beginnings of the management consulting industry (McKenna, 2006). Thus, based on 1) the convergence of research of the professions, 2) the global structure of the large consultancies which are the focus of our study, and 3) my own consulting work experience, which includes work in the Americas, Asia and Western Europe, I believe the following review to be most relevant for the US consulting industry, but that useful parallels can be drawn for management consulting in Western Europe as well.
} 
particular the traditional professions of medicine and law. Consultancies have, for example, adopted the language of the professions, e.g. by referring to their business as a 'professional practice.' Like other professions, consultancies base their claims to authority on the possession of a body of expert knowledge, and continue to adopt 'professionalism' as the overarching value to which they aspire in their relationships with clients. Any hint of the historical and more critical view of professionals and professionalism, however, seemed to me wholly and conspicuously absent from the accounts of pro-consultancy authors, and from the consultancies themselves, who continued to align themselves with an image of professionalism I now considered to be outdated, naïve, and problematic. Thus, in my ongoing critique, I wanted to show that a number of assumptions and practices that had been shown to be problematic long ago, were still very much a part of contemporary consulting practice. More specifically, I wanted to show, similar to the criticism that had been leveled against other professions, that a standardized body of expert or professional knowledge was ill-suited for consulting in the dynamic organizational environments where consulting practice was situated. I wanted to show that the transferability of knowledge from one context to another was low, and that decisions made during practice were seldom based on technical or expert knowledge, but rather on the decidedly non-technical judgments and intuition of the consultants and others involved. Regarding client-consultant relationships, I wanted to show that the traditional image of the professional in a position of power, detached and maintaining a 'critical distance,' was out of step with more recent calls for innovation and close collaboration between clients and their consultants. In an attempt to make these arguments more persuasive, I structured them as a historical account, grounded in the events of the 1930s to the 1960s, which many agree was a period of transformational change for the modern professions, and with the implication, of course, that a similar transformation in management consulting was long overdue. I began with a brief review of the work of Talcott Parsons (1902-1979), an American sociologist, whose writings and research on the professions and professionalism have been highly influential.

\section{Parsonian professionalism}

Notwithstanding earlier work by Max Weber (1864-1920), Émile Durkheim (1858-1917) or Auguste Comte (1798-1857), modern studies of the professions are often considered to begin with the work of Talcott Parsons, in particular his writings produced from the 1930 's to the 1960s (Brante, 1988). For Parsons, society follows a progression, from 
simpler to more complex forms, and it is the social class of professionals, with their rational attitudes and behaviors, and their technical, theoretical knowledge, that propels society forward (Boreham, 1983). The importance that Parsons ascribes to the professions is clear in this passage from 1939:

"It seems evident that many of the most important features of our society are to a considerable extent dependent on the smooth function of the professions.... Their results have become so closely interwoven in the fabric of modern society that it is difficult to imagine how it could get along without basic structural changes if they [the professions] were seriously impaired" (Parsons, 1939, p. 457).

In practice, Parsonian professionals are considered uniquely qualified, by virtue of the specialized and superior knowledge they posses, for the diagnosis and resolution of client problems. They are independent, maintaining a 'critical distance' from their clients, in the name of neutrality and objectivity, and applying a formalized body of expert knowledge, regardless of the specifics of context. ${ }^{22}$ Because professional knowledge is specialized, ${ }^{23}$ there is an irreducible 'asymmetry of expertise' between professionals and their clients, and professionals are in a position of power (Abbott, 1988). In order for client interests to be protected, professionals must maintain respect for their clients, and clients in turn must trust the professionals. Since this specialized knowledge could not be easily understood by non-experts outside the profession, client interests were to be further protected by 'self-policing' of the professional group, in the form of codes of ethics, licensing, professional associations, etc. Millerson (1964) offers a perhaps now-familiar list of defining characteristics of the professional:

1. the use of skills based on theoretical knowledge;

2. education and training in these skills;

3. the competence of professionals is ensured by examinations;

4. a code of conduct to ensure professional integrity;

5. performance of a service that is for the common good; and

\footnotetext{
${ }^{22}$ These are taken from Parsons' 'pattern variables,' conceptual dichotomies demonstrating the choices that professionals make in practice (Brante, 1988).

${ }^{23}$ The notion of knowledge being 'specialized' implies a single, hierarchical body of knowledge.
} 
6. a professional activity which organizes its members

By the early 1960s, the place of the professions in society, modeled closely after a Parsonian ideal, was well established (Abbott, 1988, p. 5). Donald Schön writes that in 1963:

"Daedalus, the highly regarded journal of the American Academy of Arts and Sciences, published a volume on the professions that began, "Everywhere in American life, the professions are triumphant." The editors of Daedalus found evidence of triumph in the new visibility of the professions, the growing demand for their services, and their expansion in nearly all fields of practice" (Schön, 1983, p. 5).

\section{The world's newest profession?}

At around the same time when Parsons was publishing his first works on the professions, changing federal regulation in the US banking sector opened up an opportunity for a new industry, management consulting, to take hold. In 1933, the US Senate passed the Glass-Steagall banking act, which separated commercial and investment banking, and, more importantly for our purposes, prohibited lawyers and accountants from providing consulting services (services referred to at the time as "management audits") and thereby promoting the growth of independent management consulting firms (McKenna, 2006, p. 17). Similar to the 'financial audits' produced by the accountants, the consultants' 'management audits' served as an "independent, external confirmation of management's judgment" (Markham, 2003, referenced in McKenna, 2005, p. 10).

In The World's Newest Profession, Christopher McKenna (2006) puts forward a detailed history of management consulting, and describes the efforts that have been made by the industry, since its beginnings, to position itself as a profession. Martin Bower, longtime head of McKinsey \& Co., for example, was known for his strong advocacy of the professional model for consultancy, declaring, "we do not have a business; we have a professional practice," and telling new consultants: 
"If a man today were to take one day away from his current engagement and spend that one day learning the professional approach he would be doing himself and the firm a much greater service than it would be to produce $\$ 75$, $\$ 100$, or $\$ 150$ a day of income for McKinsey \& Co." (McKenna, 2006, p. 203).

Lacking the formal body of knowledge and licensure of the traditional professions, consultancies adopted the language and structure of the professions as a way to bolster their image as a profession (Alvesson and Johansson, 2002; McKenna, 2006), beginning with medical analogies in the 1930s and 1940s:

"Management consultants, according to Fortune magazine's 1944 article on the "doctors of management," "constantly described their activities in medical analogies" (McKenna, 2006, p. 201)

The medical analogies proved problematic, however, because of the implication that the client companies were 'sick' and not well managed:

"The description "business doctor," which was popular in the 1930s, "instantly raised," according to Marvin Bower, "the image of 'sick' companies-an anathema to the managers of successful companies." Management consultants sought not just to promote professional metaphors, but to shift those metaphors away from medicine toward more "bureaucratic" professions. ... Management consultants ultimately decided that the most powerful professional comparison was to corporate law" (McKenna, 2006, p. 201-202).

But even though the consultancies continued to cultivate the image of a profession, the major firms, including McKinsey, Booz, BCG, Anderson, were unwilling to take the required steps that would lead toward more formal professionalization. They did not, for example, require individual consultants to obtain the "Certified Management Consultant" designation, as offered by the Institute for Management Consulting in the late 1960s (McKenna, 2006, p. 203). Since then, and despite the efforts of various regulatory bodies and industry associations, in the US and Europe as well, attempts at more formal professionalization have not been successful (Glückler and Armbruster, 2003; Nikolova, 2006). As of today, none of the major consulting firms are 
represented on the board of directors of the Institute of Management Consultants, the certifying body for management consultants in the US. In an interview with Management Consulting News, Chris KcKenna comments:

" . . the large firms, have been unwilling to take the appropriate steps that would transform consulting into a full-fledged profession. On numerous occasions, people have proposed government regulation, examinations, minimum requirements, standards of malpractice, and so forth. And in each case, consultants have fought against this, arguing both that they want to keep the government out and that they think they can self-police" (2006; News, 2006).

While rejecting more formal professionalization, however, consultancies did adopt the Parsonian notion of an ongoing progression toward a professional ideal. Drawing once again on McKenna's review of the McKinsey archives:

"Consultants dismissed concerns about whether management consulting would ever achieve full professional status, stressing instead their own professional bearing and ethical standards. For, as the partners in McKinsey \& Co. explained to the newly hired staff members, behaving like a professional would serve just as well as becoming one" (McKenna, 2006).

While consultancy's self-portrayal as a profession may not be as pronounced today as it once was, the association remains nevertheless. The McKinsey website, for example, declares: "We believe in professionalism" (McKinsey \& Company, 2006); and on Accenture's website we find: "We value professionalism . . . ." For Deloitte, "conducting business honorably, ethically and with the utmost professionalism is top of mind." According to pro-consultancy authors (e.g. Greiner and Poulfelt, 2005; Greiner and Metzger, 1983; Kubr, 2002) "management consulting has long been recognized as a useful professional service" (Kubr, 2002, p. xvii). David Maister, a well-known consultant to consultants, exhorts consultants to strive for "true professionalism" (Maister, 2000). Mats Alvesson summarizes: "'professionalism' is best seen as a resource on which management consultants can draw selectively in their claims for authority, status and credibility" (Alvesson et al., 2002, p. 228). 


\section{A different view of professionalism}

But what about the nature of this 'professionalism' to which the consultancies have so closely aligned themselves? Since at least the early 1960's, there has been another portrayal of professionalism that differs radically from a 'naïve' Parsonian view, a portrayal highlighting exclusion, the indeterminacy of professional knowledge, and above all, power. Except for treatment by critical academic scholars, however, this alternative view has been and remains conspicuously absent from more mainstream accounts of consulting (Schön, 1983, p. 10). Below, we want to revive some of what was being written and discussed about the professions and professionalism in the 1960s and 70s, and ask a few of the same difficult questions of consulting practice today.

\section{A crisis of confidence}

Even as the societal position of the professions was reaching its peak, the political climate of the 1960s was rapidly changing, and within just a few years there were increasing signs of a "crisis of confidence" in the professions (Schön, 1983, p. 4). In fields as diverse as public planning and housing, mental health, transportation and medicine:

"the most promising solutions, painstakingly worked out and advocated by the experts, came to be seen as problematic. They were ineffective, they created new problems, they were derived from theories which had been shown to be fragile and incomplete" (Schön, 1983, p. 10).

Some of the most visible failures of professional practice were in public planning, where entire neighborhoods, often poor but vibrant, were razed in the name of 'urban renewal,' with one of the most well-known example being Boston's West End (Hall, 1989). In St. Louis, the now-infamous Pruitt-Igoe project, and still the largest public housing project in US history, was immediately beset by crime and violence, and went from groundbreaking, to construction, to decline and demolition within the span of just 16 years (Rainwater, 1970, 1973). In medicine, Henry Beecher (1966), a Harvard anesthesiologist, published an article in The New England Journal of Medicine, giving numerous examples of experimental research that had been carried out on patients, often with fatal consequences, at leading universities and hospitals, and reported in 
leading medical journals. ${ }^{24}$ These and other high-profile problems and scandals led to an unraveling of public confidence in the professions, a questioning of the assumptions on which the professions had been based, and new streams of critical research (Freidson, 1988; Larson, 1979). We present a few of the important arguments below.

\section{Expert power}

Prior to the 1960's, professional standards, e.g. codes of ethics, formal education requirements, licensure, etc., were seen as the means whereby a profession could ensure a high level of quality. But as the high-profile failures mounted, professional standards came to be seen not as a guarantee of quality, but as a set of barriers, often hastily erected, in order to keep others out and to protect the monopoly and power of the already-established professions (Johnson, 1972). The profession of psychiatry, for example, began when certain reform-minded physicians took advantage of the hazy border between physical and mental ailments, wresting control of the latter from other professions, including medicine, psychology and the clergy (Abbott, 1988). While the medical profession had evolved over hundreds of years (albeit with border skirmishes all along the way, resulting in the inclusion or exclusion of homeopathic practitioners, surgeons, osteopaths, etc.), psychiatry "rushed through the formalities of professionalization-association, journal, code [of ethics] -in a decade" (Abbott, 1988, p. 23). In a seminal work, Andrew Abbott (1988) studied more than 130 professions from America, Britain, France and Germany, and showed their history to be largely that of repeated 'border skirmishes' between the professions themselves, with each trying to strengthen its borders against encroachment. Reviving earlier work from Weber (1968), 'closure theorists' (e.g. Johnson, 1972; Parkin, 1979) showed how professionals and experts used their power and claims of expertise to foreclose on further debate that might threaten their position or power. Baritz (1960) showed how professionals also used their power 'behind the scenes' to prevent certain issues from

\footnotetext{
24 Documented cases included the withholding of treatment (by administering placebo medication) in order to study the effects of rheumatic fever, typhoid and other conditions, if left untreated; transplantation of a malignant tumor from a terminally ill child to an otherwise healthy parent, both of whom subsequently died of cancer (Rothman and Rothman, 1984); intentional exposure of patients to hepatitis (West and Div, 1998); and the study of radiation effects on mentally retarded children who were intentionally fed radioactive isotopes (Balint, 1957).
} 
ever making it onto the agenda for discussion in the first place—-the so-called 'second face of power.'

\section{Professional-client relationships}

As for their relationships with clients, the traditional image of the professional-client relationship, characterized by a detached professional maintaining a critical distance and occupying a higher status or position than their clients, also came under criticism. Freidson (1970a) claimed that codes of ethics and licensure were insufficient to ensure that patient concerns were well represented. Although the dates vary by profession, a questioning and general distrust of the professional-centeredness of the professions soon led to significant changes.

In medicine, from example, from the 1920s until the 1960s, doctors had "enjoyed unparalleled dominance; medical authority was seldom questioned, and patience acquiescence was assumed" (Steele, Blackwell, Gutmann, and Jackson, 1987, p. 5). The problems and scandals described above, however, brought about changes to "every aspect of the relationship between doctor and patient" (Rothman, 1991). As Rothman (1991) explains, while the advent of the community general hospital had initially helped to formalize and establish the medical profession, the hospitals' focus on scientific research also contributed to the physician-patient relationship becoming more of a scientist-subject relationship. This furthered the social distance separating physicians and their patients, and was a major contributing factor to what we now, in retrospect, consider to be the egregious violations of patient and human rights that occurred in the form of medical experimentation (Rothman, 1991). The Patient Bill of Rights, issued by the American Hospital Association in 1972; the ideas of 'informed consent' and the 'living will;' the Declaration of Helsinki, a statement of ethical principals for medical research, first issued by the World Medical Association in 1964-all of these initiatives were the result of the dramatic changes that occurred in the medical profession and the physician-patient relationship from the mid 1960s to the early 1970s. George Engel (1977) advocated a new 'biopsychosocial' model that would include social and psychological aspects of health, and re-introduce patients back into their own treatment, from which they had been excluded by the prevailing 
biomedical model. Even the terminology changed, with physicians coming to be called the 'providers,' and patients the 'consumers' of health care services. ${ }^{25}$

In psychology, Carl Rogers' (1951) client-centered therapy stressed empathy with the client, and marked a departure from the (then) predominant psychoanalytic approach, which was characterized by the detached stance of the therapist. In public planning, the highly technical and quantitative nature of planning documents and processes had effectively precluded the public from meaningful collaboration and participation (Hall, 1989). These plans were created and carried out by planning professionals far removed from those for whom the plans were ostensibly created, yet whose 'best interest' the professionals unwaveringly claimed to exclusively know (Allmendinger, 2000; Sandercock, 1998). Changing public opinion, however, brought about "an almost complete inversion of almost every basic value in American planning practice and planning education ... Instead of a belief in top-down planning by benign valuefree experts, there was now a deep distrust of professional expertise and a demand for advocacy planning based on grassroots involvement" (Hall, 1989, p. 280).

\section{Expert knowledge}

In the late 1960's, the 'special knowledge and skill' that had once been considered a defining characteristic of the professions and of professionals, was now called into question (Boreham, 1983, p. 695). Professional knowledge was considered to be "mismatched to the changing character of the situations of practice- the complexity, uncertainty, instability, uniqueness, and value conflicts which are increasingly perceived as central to the world of professional practice" (Schön, 1983: 15). Studies into the work of professionals and experts revealed an indeterminacy and ambiguity surrounding expert knowledge, and showed that in practice, decisions were made by the experts' personal judgments, and not by reference to a body of expert or technical knowledge (Freidson, 1970a). ${ }^{26}$

"Since each problem or case is different, the work of the professional is inevitably unstandardized. It involves applying his judgment to the solution of

\footnotetext{
${ }^{25}$ For additional discussion of the physician-patient relationship see Balint, (2000), Roter (1997), Sledge and Feinstein (1994), and Tresolini and the Pew-Fetzer Task Force (1957).

${ }^{26}$ See also Fox (1945).
} 
a problem and, therefore, a certain amount of originality and imagination" (Gross, 1969, p. 42).

In order to substantiate their claims for legitimacy and autonomy, however, professionals needed to demonstrate to the satisfaction of society (and their paying clientele) that professional practice could help to reduce uncertainty (Katz, 1984; Shenhav, 1994, 2000) and was based on knowledge that was scientifically derived (Derber, Magrass, and Schwartz, 1990a; Hirschkorn, 2006; Reed, 1996). This was problematic for the professionals, however, since if the knowledge base was in fact scientifically derived, it should also then be amenable to formalization and explication, which in turn would make it transferable to non-experts, and thereby undermine the professional's basis of power:

" . . . the expert's success is constantly self-defeating. The rationalization process [i.e. the formalization of expert knowledge] give him power, but the end results of rationalization curtail his power. As soon as a field is wellcovered, as soon as the first institutions and innovations can be translated into rules and programs, the expert's power disappears" (Crozier, 1964, p. 165).

"The trick," argues Michael Reed (1996), "seems to be to strike the right-i.e. inevitably shifting-political balance between indeterminacy and formalization of knowledge and skill as a prerequisite to constructing expert power bases" (p. 578).

One strategy for deflecting unwanted scrutiny was to claim that, because of the complexity of professional knowledge, only the professionals themselves had the ability to understand it (and thus the claim that professions should be 'self-policing'). Jamous and Peloille's (1970) captured well this interplay between the certainty and clarity of scientific knowledge with the uncertainty of professional mystique, using their notion of a ratio of indetermination to technicality, or I/T ratio. Technicality (T), refers to knowledge that can be codified, while Indetermination (I), refers to the knowledge which cannot captured by rules, but is intuitive or gained through experience. Medicine, although grounded in technicality $(\mathrm{T})$ has a high I/T ratio, since the closer we look into the activities of practice, the more the uncertainty of each unique situation asserts itself, as manifested by the high degree of variation in the 
decisions made by the practitioner (Johnson, 1972). Used in combination, technicality and indetermination constitute a mechanism that allows professional groups to move back and forth as necessary, establishing legitimacy based on technicality (T), while protecting from possible incursions through indeterminacy (I). It also enables professional groups to regulate the degree and speed with which portions of their knowledge base are formalized, and thereby commoditized, as when, for example, professional architects come to delegate certain tasks to draftsmen, or when physicians delegate certain tasks to nurses.

\section{Comparison with contemporary consulting practice}

As this brief review demonstrates, the 1960s and early 1970s was a difficult, transformational period for the professions. Yet when we turn to management consulting, we find that, outside of the critical academic literature (e.g. Abrahamson and Eisenman, 2001; Alvesson, 2001; Clark, 1995; Clark and Fincham, 2002; Clark and Salaman, 1998b; Gill and Whittle, 1993), this 'darker' side of a traditional, Parsonian professionalism is overlooked in most published accounts of management consulting. More importantly, we find that many of the assumptions and practices of traditional professionalism that were found to be problematic long ago, are still very much a part of contemporary consulting practice today. Consider, for example, the case of consulting knowledge.

\section{Consulting knowledge}

Judging from many of the contemporary published accounts, it's difficult to overestimate the importance of knowledge for management consultancies. Knowledge is what is disembedded from one context and applied in another for the resolution of client problems. Knowledge is what is transferred during 'knowledge transfer,' a common goal of consulting projects (Werr, 1997). Consultancies are often considered to demonstrate 'best practice' in the management of knowledge resources (Empson, 2001), and many have invested heavily in knowledge management systems and 'knowledge repositories' (Hansen, Nohria, and Tierney, 1999; McDermott, 1999). Gaining access to the knowledge possessed by the consultant is a primary reason for clients' use of external consultants (Wood, 2002: 58). "For the consulting industry," writes Miklos Sarvary (1999), "the firm's core product is knowledge itself. Producing and selling knowledge constitutes their core resource or asset" (p. 97). Thomas 
Davenport and Larry Prusak (2005) consider knowledge to nothing less than "the fuel of consultancy," and argue that its creation and dissemination remains "a key objective for many consulting firms" (Davenport et al., 2005: 306).

Despite the apparent importance of knowledge, however, the experiences of consultancies in using and managing knowledge, based on interviews with the consultants themselves, presents a very different picture. Similar to the findings of earlier studies of other professions, consultants report that technical knowledge often plays only a limited role in resolving even the most difficult problems of practice (Crucini, 2002; Werr, 2002), and is less important for project success than the ability to adapt to novel and changing circumstances (Alvesson, 1995, 2001). Despite their heavy investment in knowledge management systems and repositories, the experience of a number of firms is that after implementation, many of these knowledge repositories remain either empty or idle (Hansen et al., 1999; McDermott, 1999; Newell, Bresnen, Edelman, Scarbrough, and Swan, 2006). Perhaps it is less surprising, then, that when interviewed about their contributions to their own internal knowledge management systems and databases, some consultants respond as follows:

" . . a McKinsey partner explained that he rarely put sufficient information into the organizational database because others would not give him credit for these contributions - crediting themselves, instead, for finding the information. Therefore, he put only enough into the database to tease others into calling him directly, and into acknowledging the current value of his past experiences .... An Accenture partner explained, "Everybody here has their own [network] in terms of just using voice mail and having your own set of personal contacts-I don't think anybody here actually peruses the Knowledge Exchange to get that type of information" (Hargadon and Bechky, 2006: 493-496).

If and when attempts are made to take advantage of information stored in the knowledge repositories, numerous studies suggest that, far from being readily transferable from consultant to client, from one project to another, or even from one department to another, knowledge remains 'tacit' (Nonaka and Takeuchi, 1995; Polanyi, 1967), 'sticky' (Szulanski, 1996; von Hippel, 1994), and otherwise firmly 
embedded in the local contexts where it was first created (Bechky, 2003; Blackler, 1995; Carlile, 2004; Fish, 1980; Granovetter, 1985).

\section{Relationship with clients}

As described above, the professional-client relationship underwent significant changes in the 1960s. In general, there was a move away from an expert-driven approach, and toward a more collaborative approach, an approach both respectful and inclusive of clients' opinions, information, and self-knowledge. When we look at contemporary consulting practice, however, the image of a detached expert, acting independently remains prominent.

For Jagdish Sheth, Professor at Emory University and the author of a number of books of professional advisory relationships, the number one complaint of clients about their advisors involves the latter (the advisors) pursuing their own agenda and acting independent of the client's issues and needs (Sheth and Sobel, 2000, p. 47). Deloitte proclaims that "one of the most visible demonstrations of our integrity is our ability to be independent and objective in providing services and advice to our clients" (Deloitte, 2006, emphasis added), and McKinsey promises to "stay independent" (McKinsey \& Company, 2006). No doubt, some of the need to be seen as being independent—in the sense of being free from conflict of interest—can be attributed to recent events, such as the collapse of Enron, and the liability, direct or implied, that such events have for accountancies, consultancies and other service providers. Nevertheless, the equating of professionalism with maintaining a distance and independence from one's client, in line with a Parsonian image of the detached expert, remains common, as exemplified by this quote from a manager of a large consultancy: "You don't want to have too close a relationship with your clients . . . you need to remain as professional as possible" (1988; Walsh, 2001, p. 36).

For Peter Block, a well-known business consultant and author, consulting seems to be less about collaboration than it is a somewhat unpleasant exercise of knowledge transfer, begrudgingly with client participation:

"The core transaction of any consulting contract is the transfer of expertise from the consultant to the client. . . . Doing the job by yourself is always 
simpler and faster. Having people from the client organization takes more time and agony, yet directly encourages commitment and promotes eventual implementation of the study" (Block, 2000, p. 27-31).

In Schein's (1988) Process Consultation approach, we are presented with an image of a rather feeble client with neither the ability, nor the responsibility for helping him or herself, let alone the capacity for robust collaboration:

"In reality, however, the manager often does not know what he is looking for and indeed should not really be expected to know. All he knows is that something is not working right and he needs some kind of help. . . Managers often sense that all is not well or that things could be better, but they do not have the tools with which to translate their vague feelings into concrete action steps" (Schein, 1988, p.4).

About this passage from Schein, Robin Fincham writes:

"In Schein's (1988) process consultation model, for example, clinical and group theories are pressed into service and, rather like the psychiatric patient, managers are expected to submit to diagnosis. The manager only has a sense that something is wrong but can neither diagnose the problem nor communicate it to the consultant: "They do not have the tools with which to translate their vague feelings into concrete action steps' (p. 4). Those tools, of course, belong to the consultant, and though the process of arriving at a solution is supposedly a partnership, or 'joint diagnosis', the consultant is the senior partner" (Fincham, 1999, p. 337).

Other consulting firms, however, appear to have made a greater effort to move toward a more collaborative approach, most notably Capgemini (2008), who refer to their way of working with clients as the (now trademarked) 'Collaborative Business Experience.' They proclaim that "collaboration is central to the Capgemini philosophy and a pillar of our service delivery," yet when we look to their description of their approach, we find: "Capgemini consultants listen carefully to understand your situation before suggesting a solution;" "our professional expertise and extensive market knowledge 
provide a strong foundation to guide you through transformation;" [we] "will transfer knowledge and capabilities to clients during the course of our relationship."

Our point is not to criticize Cepgemini, but to argue that even though, for this firm at least, there is a recent focus on collaboration, the conception of collaboration itself remains firmly rooted in a traditional, expert approach, in that it involves the 'transfer of existing knowledge between client and consultant,' rather than the 'joint creation of new knowledge by client and consultant.' We see this conception of collaboration not as a mistake, but mostly a missed opportunity for creativity and innovation. Our point is not that we should pursue innovation for innovation's sake, but rather to suggest that 1) given the difficulties the professions_-including consulting — have experienced with the concept of 'expert knowledge' as a clearly defined and transferable asset; and 2) given that, as Freidson (1970b) predicted, ${ }^{27}$ the 'asymmetry of expertise' between professionals and clients has repeatedly resulted in clients' interests not being wellrepresented or protected; and 3) given that the approach taken by clients and consultants thus far has not been successful, as measured by the consistently high rates of failure of their organizational initiatives_-given all these factors, then some kind of innovation in the way clients and consultants work together would certainly seem to be in order.

\section{Reflection}

In the extended excerpt presented above, I was trying to show that contemporary consulting practice continued to be influenced by a traditional, outdated and problematic image of professionalism. Upon reflection, I still believe this to be the case. What is different now is that it is no longer my purpose, as it was at the time, to prove this to be so. At the time I was finishing up the above excerpt, the purpose of 'proving' the prevailing approach to consulting to be one way or another, had been replaced with a question, a doubt, not dissimilar, perhaps to that expressed by Talcott Parsons in 1939, and which I quote again here:

"Their [the professions'] results have become so closely interwoven in the fabric of modern society that it is difficult to imagine how it could get along without basic structural changes if they were seriously impaired" (Parsons, 1939, p. 457).

\footnotetext{
${ }^{27}$ As did Bacon and Nietzsche and Weber and Foucault and Giddens!
} 
Based on what I had read, I now believed that the approach of the traditional professions, and the consulting approach which closely followed it-was indeed seriously impaired. Perhaps moving some 'critical distance' away from traditional professionalism was not so bad! Yet I was not at all sure of what the alternative could be. I no longer believed, and still do not, for that matter, that knowledge is transferable from one client context or project to another; I no longer believed-even for the most technical of decisions of practice-that consultants (or physicians) ultimately turned to anything but their intuition and experience; I no longer believed it was possible for a consultant (or anyone else) to solve someone else's business problem, primarily for two reasons: 1) 'Solutions' to business or organizational problems occur over much longer time frames than do the consulting projects that address them; and 2) if and when we consider a 'solution' to have been reached, it will be the client's solution, just as, although a physician my prescribe antibiotics for a patient's infection, it is the patient that is cured-the physician cannot hand over or somehow experience a cure on behalf of the patient.

To close this reflection, I borrow from Freidson (1970a), whose work was a turning point not only for medicine, but for the study of the professions in general.

"In our day we seem to be turning away from an uncritical optimism about the role of specialized knowledge in ordering human affairs. We have not yet arrived at a satisfactory new position, however, and in the meantime we are treated to despairing violence and self-defeating anti-intellectualism on the part of laymen and their champions, self-interested elitism on the part of the intellectual classes, and downright authoritarianism on the part of even those political leaders with humanitarian intentions" (Freidson, 1970a, p. xi).

Freidson questioned the unquestionable, and was instrumental in helping to ensure the rightful participation of patients in their own treatment. He was also unconvinced, however, that we had arrived at a 'satisfactory new position,' and I felt the same way for management consulting. I did not believe the prevailing approach of consulting, influenced as it has been by a traditional professionalism, to be effective, at least not for me. Yet I also did not believe that letting go of this approach was at all trivial. My research had clarified some of the 
limitations of the prevailing approach, but brought me no closer to a satisfactory alternative. Like Parsons, an alternative was even 'difficult to imagine.'

\section{"'Organizations' are not, and never will be, the predictable, controllable entities they are assumed to be, according to the prevailing 'planned change' approach"}

If you happened to be building a case that the prevailing approach of management consulting is problematic, as I was at the time, then pointing out the consistently and abysmally low success rates of organizational change initiatives (i.e. $30 \%$ to $40 \%$ ), would be one obvious way to strengthen your arguments. And if, in combination with these figures, you were to make use of Greiner and Poulfelt's (2005) estimate that organizational change initiatives account for more than $75 \%$ of consulting revenue, then you could also, without too much of a stretch, make some fairly broad, generalizing statements about the ineffectiveness of management consulting in general. If, however, you were an early $\mathrm{PhD}$ student intent on making your arguments even stronger, as I was at the time, then you could also pull in some additional information from academic research to make the case that not only were the outcomes of organizational change initiatives poor, they were likely to remain so. That is, as long as we continued to treat 'the organization' as being a predictable, controllable entity, the product of intentional design-something an organization never has, nor ever will be, even though it is assumed to be so, according to the prevailing 'planned change' approach to organizational change. It was this assumption or expectation of predictability and controllability of outcomes that I wanted to problematize, and to show that this expectation was in turn enabled by the conception of 'the organization' as being the product of our own intentional design (as opposed to being simply the pattern that our activities of working had, over time, settled into). I wanted to show that, along with some alternative conception of consulting 'professionalism' being long overdue, some alternative conception of 'organization' was long overdue as well. I once again turned to a historical review, this time of organizational studies.

\section{Why is organizational change so difficult?}

Today, it is difficult not to take the presence of organizations for granted. In government or private enterprise, from local to global in scope, organizations are ubiquitous. For Michael Reed (1996) organizations have become "the strategic social 
units for ... the planned reproduction of social systems" (p. 574, emphasis in original). And with more than $75 \%$ of consulting revenue (Greiner and Poulfelt, 2004) accruing from projects to change and/or improve them, organizations are obviously vital for management consulting as well. Yet even though organizational change work accounts for the majority of consulting revenue, the success of those initiatives-with or without the involvement of external consultants-has remained consistently low. In 2000, for example, two Harvard Business School professors, Michael Beer and Nitin Nohria, wrote:

" . . change remains difficult to pull off, and few companies manage the process as well as they would like. Most of their initiatives-installing new technology, downsizing, restructuring, or trying to change corporate culturehave had low success rates. The brutal fact is that about $70 \%$ of all change initiatives fail" (Beer and Nohria, 2000: 133).

More recently, Chris Clegg and Susan Walsh (2004a), completed a survey of the most rigorous studies of organizational change initiatives, with the combined results showing the following:

- $53 \%$ of change initiatives resulted in no change

- $9 \%$ resulted in negative change

- $38 \%$ demonstrated positive change

But why is organizational change so difficult? The large number of change initiatives that have come and (mostly) gone (see Figure 2) suggests that the

- Benchmarking

- BPR: Business process reengineering

- Core competency

- Corporate agility

- CRM : Customer relationship mgt.

- Culture change

- Employee empow erment

- Horizontal corporations

- Knowledge management

- Lean sigma

- M BO: M anagement by objective

- PERT: Prog. evaluation rev. technique

- Quality circles

- Quality of worklife

- Rightsizing

- Sensitivity training/T-groups

- Six sigma

- The learning organization

- TQM

- Valuecreation

$-\ldots$.

Figure 2: Sampling of Organizational Change/Improvement Initiatives

problem is more than just poor execution. We want to present an alternative answer to this question. Given the consistent inability to realize our targeted change outcomes, we can look at organizational change as being an exceptionally difficult task. Or, alternatively, perhaps we have significantly over-estimated in the first place 
the level of control we have over those outcomes. Why, for example, do we assume that a $60-70 \%$ failure rate for organizational change initiatives is bad? Sports analogies come to mind: No one complains that Ty Cobb's lifetime batting average was 'only' .367 (a 36.7\% success rate). Instead, we honor his achievement as the highest lifetime batting average in the history of baseball (National Baseball Hall of Fame, 2006). Implicit in our honoring of his achievement is the belief that he's near some kind of limit, and that achieving a dramatically higher batting average is simply not possible. We would propose that, similarly, a $60-70 \%$ failure rate for organizational change initiatives is considered bad only if we also assume that a much higher rate of success is possible. Our experience, however, from the present day all the way back to the early days of organizational studies, however, shows this assumption of firm controllability over outcomes to be not at all well-founded. In what follows, we will argue that organizations never have, nor ever will be, the predictable, controllable entities they are assumed to be, according to the prevailing 'planned change' approach to organizational change. We want to show that the early days of organizational studies were not about 'organizations' at all, but about 'organizing,' the dynamic and unpredictable activities of working itself. Early writers in the 1930s, for example, were quite aware of the tensions between the desires of individual workers vs. the requirements of the formal organization. A central question then was not only how, but whether or not formal organizations could withstand these tensions that continuously threatened to tear them apart. Over time, and owing to numerous events, we will argue, there was a shift in focus away from the unpredictable activities of work and 'organizing' and toward 'the organization' as a planned and controllable product of intentional design. Along with this conception of 'the organization' as being something we ourselves designed, came an expectation of controllability of organizational change outcomes-precisely the kind of expectation that makes a $60 \%$ to $70 \%$ failure rate look bad and unacceptable. Finally, we will propose that this shift occurred in two partially overlapping phases: first, the reification (i.e. making tangible, or making concrete) of 'the organization' as a designed, tangible entity, which in turn led to the expectation that we could predict and control the 'behavior' of this newly created entity. 


\section{From 'organizing' to 'organization'}

As ancient cave paintings of hunting scenes will attest, for tens of thousands of years people have been organizing themselves to carry out complex tasks. Thus, organizations - the result of people organizing themselves - have also been around for at least as long. The recognition of, and a specific focus on 'the organization' itself, however, is fairly recent. Frederick Taylor (1911) and Henri Fayol ( 1919/1949), for example, sought to redesign work systems-'Taylor from the bottom up; Fayol from the top down,' as the phrase goes—and Weber (1924/1968) studied the workings of administrative systems and bureaucracy. But as Scott (2004) points out, the focus of study began to shift in the 1930s, away from the study of working and toward the study of 'organizations' themselves:

"absent from ... these early approaches was attention to organizations as [being] of interest in their own right. . . Organizations were viewed, at best, as settings within which work was carried out, not as themselves distinctive social systems, let alone collective actors. Barnard (1938) and Selznick (1948) were among the first scholars to focus primary attention on the organization as the unit of interest" (Scott, 2004, p. 2).

The writings of these earlier organizational scholars gives us a window onto the past, to a time when the idea of 'the organization,' unlike today, was not taken for granted, and the definitions still tentative. Chester Barnard, for example, begins his influential book The Functions of the Executive as follows:

"With all the thought that has been turned upon the unrest of the present day in the literature of social reform one finds practically no reference to formal organization as the concrete social process by which social action is largely accomplished" (Barnard, 1938, p. 3, emphasis added).

Here, Barnard expresses surprise that despite all the attention being given to social reform, the formal organizations by which such reforms are carried out are often not explicitly recognized. Yet, notice also that Barnard refers to the organization as a process, and not an entity. Later, Barnard acknowledges that we do personify 
intangible processes, like organizations, but that we do so for practical reasons, to make them more concrete:

"When we are obliged in a practical sense to deal with intangible things chiefly characterized by relationships rather than by substance we have to symbolize them by concrete things, or personify them. In the case of organizations the only practicable device for everyday purposes under most circumstances is to symbolize a system called "an organization" by the persons who are connected with it. Hence, although I do find an organization as a system of cooperative activities of two or more persons -- something intangible and impersonal, largely a matter of relationships -- nevertheless sometimes for convenience of phraseology . . I shall follow the customary practice of referring to organizations as groups of persons and shall speak of such persons as "members" (Barnard, 1938, p. 75).

Thus, while Barnard adopts the use of 'the organization,' he does so somewhat cautiously, for practical reasons, "for convenience of phraseology," and, importantly, does not lose sight of the people of which the (personified) organization consists. But the situation changes rapidly. Consider the following passage by Philip Selznick, written just ten years after Barnard's work:

"The fact that the involvement of individuals as whole personalities tends to limit the adequacy of formal systems of coordination does not mean that organizational characteristics are those of the individual. The organic, emergent character of the formal organization as a cooperative system must be recognized. This means that the organization reaches decisions, takes action, and makes adjustments" (Selznick, 1948, p. 27-28, emphasis in original).

Drawing attention to a couple ideas from this passage, Selznick writes that individuals "limit the adequacy of formal systems of coordination," i.e. organizations. In this and many other passages from Selznick, we see explicit recognition of both the ongoing tension between the desires of individuals and the requirements of the organization; we understand it is not a foregone conclusion that the organization can or will function as planned. Rather, for Selznick, it is the "fundamental paradox" of organization that 
"unpredictable" individual actions "remain at once indispensable to the continued existence of the system of coordination and at the same time the source of friction, dilemma, doubt, and ruin" (Selznick, 1948, p. 25). Secondly, 'the organization' now appears as being clearly separate from the individuals of which it was, according to Barnard, comprised. Not only is it (the organization) separate, but it has begun to take on a life of its own-taking action, making adjustments, etc. Similarly, Parsons (Parsons, 1937), with a focus on social roles, as opposed to the people who occupied those roles, wrote that the organization must be structured "in such a way that individuals will be interchangeable and the organization will thus be free of dependence on personal qualities". ${ }^{28}$

Moving forward another ten years, we see the clear progression from Barnard's 1938 tentative adoption of the term 'organization' to the definition of William Wolf, appearing in the first issue of the Journal of the Academy of Management:

"We can describe an organization as a living thing; it has a concrete social environment, a formal structure, recognized goals and a variety of needs. It is continually adjusting and changing to perpetuate itself and to achieve its overall goals" (Wolf, 1958, p. 14).

By the 1950s, as this series of excerpts demonstrates, a number of ideas had begun to fade to the background, ${ }^{29}$ including: the focus on work and working, the tensions between individual and organizational interests, Barnard's conception of organization as process, and the notion that 'the organization' was less an intentionally designed entity, than it was the result of earlier 'organizing' (Cooper and Burrell, 1988). Coming into the foreground, meanwhile, was a concern with organizational structure and design (Scott, 2004; Walsh, Meyer, and Schoonhoven, 2006)., and the idea of 'the organization' as a (more or less static) object of scientific study (Augier, 2005). With the adoption of systems theory (von Bertalanffy, 1956), i.e. the study of whole systems, the notion of 'the organization' as an entity-designed, tangible, with clear

\footnotetext{
${ }^{28}$ According to Parsons and Selznick, then, organizations would be much more 'adequate' without the people around. This reminds me of the irritable salesman who complains 'Business is great except for these pesky customers that keep calling me all the time!'

${ }^{29}$ In the views of many, of course, e.g. Braverman (1974), it is not a matter of simply 'fading' but of active and intentional 'suppression.'
} 
boundaries and separate from its environment-was strengthened even further (see, for example, Katz and Kahn, 1966; Lawrence and Lorsch, 1967). Other scholars (e.g. 1993; Parsons, 1956; Pugh et al., 1963; Sells, 1964) also took 'the organization' as their starting point, and set about identifying variables to describe and predict the behavior of this newly reified entity called 'organization.' This conception of 'the organization' enabled the assumption that organizations can be controlled, changed and improved. It influenced our thinking about the role and function of management-more specifically, it (the organization) provided a central object toward which the efforts of management could be directed; 'the organization' provides management with 'the thing to managed.'

\section{Organizational development and 'planned change'}

Today's 'organizational change' efforts also adopt the idea of the organization as a tangible entity, and can be traced back to the early 'organization development' efforts of the late 1940's and early 1950s, and in particular to the work of Kurt Lewin (1951). Lewin's 3-step approach to planned change-unfreeze, change, refreeze-would become the most well-known and enduring approach to organizational change. According to this approach, organizations exist in a state of equilibrium. When sufficient pressure for change develops, as a result of, for example, market or customer changes, or the intentional efforts of an external change agent, the organization is said to 'unfreeze' and move, guided by the change agent, and then re-freeze in a new and preferred state of equilibrium. Marshak (1993) summarizes five assumptions in Lewin's approach to planned change: 1) linearity: organizational change proceeds linearly from one state to another; 2) progression: from a less-preferred to a better or more-preferred state; 3) fixed goals: the targeted end state is known or specified in advance; 4) disequilibrium: change requires a move away from a state of stability or equilibrium; and 5) external role of the change agent: change is planned and managed from someone outside and apart from the system.

The influence on contemporary consulting practice of this early approach to change remains clear, with change initiatives often being framed as a move from the 'current state' to a 'future state;' consultancies routinely perform 'gap analyses,' comparing current and future 'states' of the organization; they carry out 'organizational diagnostics' to identify factors that are preventing the organizational from 1) achieving 
pre-determined goals, or 2) distancing itself from its current problematic state. As recently as 1999, the International Management Consulting Association, maintained that the practice of consulting involves "objective consultants, proceeding through clear methodologically determined steps, to the resolution of client problems." As Chris Henry (1996) and others (e.g. Sturdy and Grey, 2003; Weick and Quinn, 1999) have noted, it is difficult to over-estimate the impact of Lewin's approach on our current approach to organizational change:

"Scratch any account of creating and managing change and the idea that change is a three-stage process . . . will not be far below the surface. Indeed it has been said that the whole theory of change is reducible to this one idea of Kurt Lewin's" (Henry, 1996, referenced in Weick et al., 1999).

But despite its longevity, the results of the 'planned change' approach to organizational change remain consistently poor. If we look back to the earlier writings of Barnard and Selznick, for example, and their explicit concern over the tensions threatening to tear the organization apart and limiting its adequacy, the low rate of success of change initiatives-continuously bemoaned in Harvard Business Review, USA Today and similar publications-begins to seem much less surprising. The planned change approach, for example, assumes that organizations exist in a state of more or less static equilibrium. Early writers, however, such as Barnard (1938), Selznick (1958), or Wolf (1958), saw the organization not as existing in any kind of static 'state' of equilibrium but as "continually adjusting and changing" (Wolf, 1958, p. 14). More recently, Brunsson and Olsen (1993) argue that 1) organizations are changing continuously - with or without our efforts to guide the outcomes of that change-and 2) far more change is happening, than can be accounted for by our formal plans. John Law (1994) describes an organization as an ongoing process of ordering. In other words, and in contrast the 'planned change' approach, change (or better yet, changing) is the rule, and stability the exception (Feldman, 2000; Feldman and Pentland, 2003; Tsoukas and Chia, 2002). Far from the idea that organizational change proceeds in linear fashion through 'clear methodologically determined steps,' Selznick wrote more than 60 years ago about the "unpredictable" actions of people, and argued therefore that "the organic, emergent character of the formal organization as a cooperative system must be recognized". More than 25 years ago, Donald Schön famously 
observed that "the situations of practice are . . characterized by uncertainty, disorder, and indeterminacy" (Schön, 1983). ${ }^{30}$ More recently, in research conducted by Klaasjan Visscher (2001), involving surveys and interviews with 292 management consultants, more than $86 \%$ reported that in practice they did not follow any formal methodology, but simply responded to the needs of the situation as they arose.

To summarize, decades of academic research and experience from consulting practice simply do not support the conception of 'the organization' as a designed, tangible entity, whose behavior can be predicted or controlled. Instead, research and practice experience both suggest that a new and alternative conception of 'organization,' and therefore a new and alternative conception of the process of consulting as well, are long overdue.

\section{Reflection}

In the excerpt presented above, I was trying to show that not only were the efforts of client and consultants often ineffective, but also that the prognosis for improvement was poor, because of the problematic underlying assumption of 'the organization' as a predictable, controllable entity. Similar to my earlier reflection, I still believe this to be the case, but no longer have the purpose of proving it to be so. But rather than going into greater detail here on this section alone, however, I would like to take a step back, pull in the earlier discussion of professionalism, and reflect on the current chapter as a whole.

\section{Impasse}

For the first 18 months of my research, I had been developing arguments for why an expert approach to business consulting was problematic. Initially, I was satisfied with the results, because I had been able to put together what I thought at the time to be a number of compelling arguments for why this was indeed the case. What I was not at all prepared for, however, were the questions this work had begun to raise, not only for my research, but for my outlook on the world more generally.

\section{How can we 'get along'?}

If, for example, professionalism has an altogether darker side, characterized by a selfinterested pursuit of power, then how could we, as Parsons and many others have asked, 'get

\footnotetext{
${ }^{30}$ See also Argyris (1989), and Vaill (1996).
} 
along' or move forward, not only with consulting, but with societal relations in general? What if the hard 'core' of professional or expert knowledge turned out to be, as so many critics over the years had persuasively argued, not so 'hard' after all, but rather more like the 'smoke and mirrors' or 'impression management' (e.g. Clark, 1995; Clark and Fincham, 2002) that consultants are often said to employ in order to preserve their own authority? What if, upon closer examination, the expert knowledge that consultants (and other professionals as well, for that matter) claimed to possess, simply dissolved into whatever claims to knowledge their clients (or society) were willing to sanction? And what about the positive aspects of-call it what you will-'professionalism' that I had experienced when joining my first consultancy, where there was, much of the time, a very real, and very high level of genuine dedication to helping the client? Should we forego this as well? If knowledge is not transferable, then how can we apply what we have learned, and of what value is experience? If the outcomes of organizational change initiatives were not controllable, as I had come to believe, then what would/could the role or function of a consultant be in such an environment? And, if we revisit the unquestioned assumptions that 'the organization' is bounded by discrete borders clearly demarcating an inside and outside, what was that 'environment' in the first place?

\section{What's the replacement? And for what and whose benefit is this research being undertaken?}

In my research to date, I had made use of examples from other professions of people who had turned away from an expert-driven approach. In medicine, George Engel (1977) had criticized the prevailing biomedical model and its exclusion of the patient's view; Carl Rogers (1951) rejected the lack of patient empathy in the prevailing psychoanalytic and behavioralist approaches to therapy; in public planning, Charles Lindblom (1959) showed how the prevailing rational-comprehensive approach depended on unrealistic assumptions of having complete information, and was quite unlike the pragmatic approach taken up in practice by public administrators. Like these people, I too had criticized the prevailing model; but unlike them, I had offered no replacement or alternative. Certainly, articulating the limitations of what I viewed to be a problematic approach to consulting had provided a kind of cathartic benefit for me, but was that the only benefit there was to be had? If not, then for what benefit, and for whom, I asked, was this research being undertaken?

\section{What about methods?}

Initially, I had set out to prove that the expert approach was problematic by summarizing and re-presenting the historical arguments that supported my case. But what about the authors or 
information or theories that were not supportive, and that threatened to contradict the story I wanted to tell? The answer-as it usually is when your objective is to prove 'the way it is'-is that I simply left them aside, or at least pursued them much less vigorously. By availing myself of some newly gained theoretical tools and sophisticated vocabulary, I sought to become an expert of a different kind-an academic expert, an expert more qualified than your average, run-of-the-mill management consultant, and therefore qualified to say with authority what organizations are, are not, and how they 'really' operate; an expert capable of bringing about closure on one particular story (mine) of the history of the professions, professionals' functionalist treatment of knowledge and their pursuit of power. Upon reflection, then, how was my own research, conducted in this manner, any different from that which it criticized? Wasn't this simply an attempt to replace one set of expert claims, i.e. those of the expert consultant, with another, i.e. mine? Wasn't this simply a refutation of the expert consultant's claims about 'how things are,' by my claims that they weren't so? Numerous other authors ${ }^{31}$ have of course struggled with these same problems, of publicly facing up to their own manipulation of events and information, of the intentional foregrounding of certain points, and the backgrounding of others, in order to support one's case. Paul Jeffcutt describes a similar experience when he was writing up the results of his own field research:

"The voices of other indigenous participants in the setting, that I so carefully recorded
and transcribed, were indeed extensively presented 'verbatim' in the text. However,
the presence of these indigenous voices, though apparently dialogic was in actuality
dramatic, in which their contributions had been selected and staged as typifications of
a culture to be represented (Clifford, 1988). Hence the participation of other voices in
the text had here been managed by the author as supportive and confirmatory to the
project of achieving a persuasive account" (Jeffcutt, 1994: 251, emphasis added).

Obviously my text had also been 'managed by the author' (me). In this very chapter, for example, I criticized Peter Block (2000) because he 'equated effective consulting skills with the ability to get the client to commit to the consultant's ideas.' Couldn't it be said of my early research (and even now) that I was (am) attempting to get the reader to commit to the ideas I was (am) putting forward? Like Jeffcut, I copied Block's words verbatim, but I also chose passages that would support my own arguments. I also, by the way, failed to mention that I

\footnotetext{
${ }^{31}$ See, for example, Robert Chia (1987), Bruno Latour (1994), John Law (1988), John Van Maanen (1988) and Steve Woolgar (2007).
} 
agree with much of what he writes! But how, then, could one build an argument, or make a point, without resorting to intentional and manipulative backgrounding and foregrounding? The question, then, was not only for whose benefit was this research being undertaken, but also how, i.e. by what methods could it be undertaken without, as they say, 'the pot calling the kettle black'?

\section{Learned helplessness or 'What chance do I really have of making a contribution?'}

When I left day-to-day consulting and began my research, I already had a belief there was something amiss in the treatment of 'knowledge' as a thing or an asset that was transferable from one context to another. I said this was my 'belief' that the treatment of knowledge as an asset was problematic, but at the time it was more of a 'suspicion' or a 'hunch,' since I had already, even within the first year of my work as a researcher, 'learned' (or was made to feel?) that my beliefs or ideas were merely suspicions or hunches, unless they were the product of proper scientific research methods (or until they had been vetted by the reviewers of various academic conferences or journals). ${ }^{32}$ In those days, I felt very much as if I was still sneaking around the halls of academia, with all the worrying over unpreparedness or unlearnedness that a first year student might experience when entering the impressive Cambridge University reading room for the first time. This feeling of unlearnedness was reinforced whenever I would struggle, sometimes for weeks or even months, to gain clarity on my own thoughts or writings, only then to discover, during later reading or conversation, that some other researcher or scholar or philosopher had already thought that thought, and written eloquently about it. Earlier explorers had already landed there, decades, or even centuries before me, claimed the territory, tidied up the boundaries, and finished it all off by planting a flag, inscribed with a label (or name of a theory) for that entire area of now-colonized thought. Journal reviewers guarded the boundaries and used the labels to 'educate' (i.e. bludgeon) naïve students/writers who inadvertently trespassed there.

These labels were not, however, without their benefits, since once you had learned them, or 'earned' them, like a merit badge, you too could brandish them, adopt them into your own writing as a kind of shorthand, make glib reference to them at conferences, etc., and, indeed (and unquestioningly) 'stand on the shoulders of giants.' In my case, 'modernist' was one such

\footnotetext{
${ }^{32}$ Even though, almost without exception, these reviewers reached very different, sometimes wildly divergent conclusions about a single paper. For an illuminating view of the backroom deals of academic publishing, see 'Ring a Ring o' Roses: Quality and Gamesmanship in Management Studies' by Stuart Macdonald and Jacqueline Kam, Journal of Management Studies, 44 (4): 640-655.
} 
label that I had earned the right to use. Within the first year of my research, for example, I had become convinced that the following five ideas were quite problematic: 1) the idea of reality, truth or knowledge existing 'out there' and independent of us; 2) the idea that such reality, truth or knowledge, although independent of us, was nevertheless accessible or 'discoverable' via scientific research and appropriate (i.e. scientific) methods; 3) the treatment of knowledge as a thing or an asset that can be 'disembedded' from one context and transferred to another; 4) the notion that people exist as discrete, non-overlapping individuals-a notion manifested as the 'critical distance' that characterized most professional-client relationships; and 5) the idea that dynamic processes, like those of 'organizing' can be 'thingified' or reified into a static, tangible thing - i.e. 'an organization'- that could in turn be freed from the context and history from which it had emerged, and made available, unproblematically, as an object of scientific study. Most importantly, I also discovered that all of these treatments, ideas and notions that figured prominently in my arguments against the prevailing expert approach to management consulting, I discovered that all of these could be considered examples of a single mode of thought, and therefore could be referred to by a single, convenient label: 'modernist. ${ }^{33}$

When I came to understand more fully what was meant by 'modernism,' or 'modernist thought,' and understood how it could be a 'container' or label for so many of the suspicions I held about consulting, I felt relief ${ }^{34}$ at having gained some new vocabulary, some new shorthand that I could use to bolster my own writing, which I considered to still be very amateurish and decidedly non-academic. With this new shorthand vocabulary, I needn't go into long explanations or give numerous examples of the problematic characteristics of the prevailing approach to management consulting. I could instead knowingly and succinctly refer to these characteristics—and also succinctly dismiss them—as being 'modernist.' This new shorthand freed me from having to cover the basics; I was (almost) in the club. it gave me a new starting point that was further along, further 'downstream' as Robert Chia says; it was a signal to the reviewers that I knew the territory, that I knew how things 'really' were, that I had made it to base camp, and that eventually, I thought, after expanding my vocabulary much more, it would be a signal for the journal reviewers and the $\mathrm{PhD}$ committee that I was

\footnotetext{
${ }^{33}$ These assumptions, which I believe to be shared by many clients and consultants, constitute something of an enabling platform for an expert approach to consulting.

${ }^{34}$ I also felt some embarrassment, due to a dim recollection of having sat through some lecture somewhere, during university or perhaps even high school days (!), where I had first been exposed to the ideas of the Enlightenment and 'modernist thought.'
} 
ready to go exploring on my own. Indeed, all this coincided precisely with what I thought getting a $\mathrm{PhD}$ was all about: one read and internalized the extant material and knowledge in a given area; one read and selected one or more theories, developed hypotheses, tested them, and, assuming the results were confirmatory, one built upon that extant knowledge; one refined what was 'known,' so that it reflected True reality just a little bit more accurately; one added another brick to the wall that others could in turn build further upon in the future. But because of the great height of the shoulders (or the great height of the wall, or the weight of the material-choose your preferred metaphor) upon which one was already standing, any advance, even a modest one, was exceedingly difficult. How, I wondered, could I ever hope to make such an advance with my own research?

In combination, these and other questions about what an alternative approach to consulting might be; how I might go about developing it, without recourse to the very same research methods I had come to doubt; what the role of a consultant could be if 'organizations' turned out to be only a loosely-coupled collection of unpredictable processes; how to go on if knowledge turned out to be non-transferable; how to persevere when the odds of success at making a meaningful contribution seemed so small—these and other questions and doubts effectively brought my research to a halt. 


\section{Chapter 2: Muddling through}

\section{Introduction}

Chapter 2 of the thesis has turned out to be one of the most difficult. It begins with an impasse: a questioning of long-held beliefs, and a lack of understanding about how to proceed. It ends with a very different world view for me, and a tentative outline of one alternative approach to consulting. This chapter is an account of a challenging but rewarding time of 'muddling through.' What I thought would eventually be a fairly straightforward transition from one approach to consulting, to another, a 'clean break,' has turned out to be the starting point of an ongoing period of transitioning — both for me and for the thesis. For me, it's a transitioning away from a foundational world view, with a single reality 'out there,' to a non-foundational view, i.e. our world is as we socially construct it (and re-construct it) to be. For the this thesis, it's a transitioning away from a single foundational approach to consulting — namely, an expert approach — to a non-foundational, processual approach that is pragmatic, relational, and that embraces and adopts multiple perspectives, including, if useful, the perspective of an expert approach. It's also a transitioning away from doing research about consulting, toward action and the doing of consulting.

Several times during the writing of this thesis, I thought I had arrived at some kind of foundational point, past which the going would thereafter be smoother and more straightforward, and would involve mostly 'filling in the details.' And each time, it turned out not to be a foundational point. I completed my initial goal of building a critique of the expert approach, for example, only to be faced with an impasse and a lack of any alternative. I eventually overcame that impasse, as I will discuss here in Chapter 2, settling this time on a “processual view," that I thought explained 'what was really going on in practice,' only to later see that as but one among many possible narratives of consulting practice that could be constructed.

With each of these 'rounds' I moved a little farther away from a modernistic, positivistic world view, toward what might be called a 'postmodern' view. And yet each time, and usually without realizing it, I would fall back to the same old modernist language and methods, in order to tell the story, here in the thesis. Each time, I would struggle, sometimes for weeks, to organize the new thoughts and ideas of the latest round, the latest breakthrough, 
into a few discrete strands that could be woven together into a coherent and (hopefully) interesting story for the thesis.

It was only recently that I asked myself: 'why do I feel so strongly the need to clean-up and reshape these experiences into clear, coherent stories?' I had been trying to write stories, I realized, that were clear and coherent, about experiences that had been neither of those. By a 'clear and coherent' story, I mean one that conforms to what many readers expect: a beginning or introduction, followed by some tension-producing problem or complication, and then a conclusion that releases that tension. Or in the case of this thesis: a critique of the prevailing expert approach, followed by a replacement. In attempting to write a clear and coherent story, I was also engaging in precisely the same behind-the-scenes authorial manipulations discussed earlier, the intentional backgrounding and foregrounding, the nip here and the tuck there, to transform a messy, indeterminate yet fascinating lived experience into a clean, clear story, with a logical progression from beginning to end. I had seen this kind of heavy-handed editing in others' writings, but failed, at least initially, to recognize it here in my own. As I learned from David Boje (1995), Ken Gergen (1994), Paul Jeffcutt (1998) and others, such are the potential pitfalls of storytelling, a powerful way of communicating, co-constructing and also of concealing other possible stories that could have been told.

John Law (1994), among others, describes particular types of stories, referred to as 'metanarratives' (or alternatively 'master-narratives' or 'grand-narratives'). Such narratives purport to offer comprehensive and singular (i.e. totalizing) and often historically-based accounts of 'the way things are.' With meta-narratives, there are no loose ends, everything is neatly accounted for; causal relations are clear, and point unambiguously to (or are reflective of) a single underlying reality or truth. Meta-narratives are also considered to be a central characteristic (and device) of modernist thought. Thus, the difficulty I experienced while writing what I thought would be a straightforward chapter of transition, from one consulting approach to another, was due to much more than the mechanics of writing: I was in the process of distancing myself from one world view, and embracing another. With my writing, I had been trying to fit postmodern stories-e.g. stories of 'knowing,' of 'relational constructionism,' etc.-into neat and tidy, deterministic modernist frameworks-e.g. situation, complication, resolution—and it wasn't working out. Old habits do indeed die hard. Or, as John Macmurray writes: 
"It is one thing to discover the presuppositions underlying a historic tradition, and to recognize they are no longer tenable. It is quite another, if that tradition is one's own, to track down all the effects of those presuppositions upon the body of belief and opinion which one has inherited. The influence of the old assumptions is pervasive and unformulated. It is not possible, even if it were desirable, to empty one's mind completely and start afresh in a condition of intellectual innocence" (Macmurray, 1956).

And so it was in my case. I had built a critique of a modernist-influenced expert approach to consulting, only to fall back on the same modernist-influenced assumptions to 'prove' that a 'processual view' explained what was really going on in practice, and could serve as the basis of an alternative, processual approach.

Finally, after several of these cyclical rounds of impasse, then resolution, then assumed foundation, than impasse again, etc., I began to take more seriously the ideas of the authors I was reading at the time, especially Richard Rorty, who wrote about moving not from any one foundational position to another, but moving away from foundational positions altogether. Or better yet, he wrote about moving away from 'positions' altogetherfoundational or otherwise - and toward action and a so-called 'relativistic' view, a pragmatic view, one that also was accepting of a
On 'views,' 'perspectives,' 'interpretations,' 'positions,' etc....

I make frequent use of the words 'view,' 'perspective,' and also 'alternative view' and 'alternative perspective.' There are a couple of problems with these and similar words and phrases. Western thought itself, along with the English language, force of habit and the limitations of my own writing ability, however, conspire to make it hard to avoid them, and the problems they bring. The first problem, is that 'an alternative view,' for example, may be taken to mean simply a different view on some single reality 'out there,' just like you and I might view a coffee cup, sitting on a table, from two slightly different angles. Mainstream (i.e. positivistic) academic research does just this with the notion of 'triangulation.' Here, the idea is that by using different and multiple research methods, we can triangulate and more accurately identify, locate and describe that singular reality or Truth 'out there.' My meaning is different. For me, an 'alternative perspective' means an 'alternative (social) construction.' So when I suggest it's useful to 'see the problem from a different perspective,' I am not suggesting there is a problem out there, and that we should simply view it from a different angle, or 'interpret it differently.' I am suggesting, rather, that it's useful if we construct a new and different problem. 
modernistic or positivistic view, if that was most useful for the purpose at hand (see inset). ${ }^{66}$ For this dissertation, this meant developing not a new foundational or replacement approach, but simply an alternative approach, one where practicing was guided by the needs of the situation, as constructed by those involved, rather than being guided solely by predetermined methods or project plans. But embracing such a non-foundational view has been difficult, and that's why this chapter is entitled 'muddling through.'

Thomas Schwandt (1996), referencing Richard Bernstein (1991), writes about "Cartesian anxiety," or a kind of fear of uncertainty that we experience when leaving behind the certainty of a traditional, positivistic view-assumed or constructed though that certainty may be. ${ }^{67}$ This is not unlike what I felt at the
On 'views,' 'perspectives,' 'interpretations,' 'positions,' etc.... (continued)

Similarly, I may say 'the fact that . . . ' Isn't this too assuming there is a final, uncontestable 'fact' out there? Not if I take 'facts' to mean socially constructed facts like, for example, 'Chicago is east of Los Angeles.' This fact is socially constructed because the city namesand the notion, in the first place, of 'city,' the notion of 'east' etc.- -are all, inescapably and 'all the way down' to as much detail as you'd care to go, socially constructed, which is to say that such facts would mean nothing to a visitor from outer space. But they do mean something to us Americans, at least, for whom the phrase 'Chicago is east of Los Angeles' is perfectly clear and factual.

The next problem with these words is that they are static, and take us too far away from action and acting. In this regard, the word 'position' is the worst offender, because it is most overtly static and non-changing, although I am usually able to avoid using it. Rather than talking about what my 'position' is, I'd rather talk about 'what I'd prefer to be doing.' The words 'view' and 'perspective' also imply being static, but not so directly as 'position,' and are thus a second-best alternative to acting and doing, but all of them-position, view, perspective imply we are looking out on, and separate from the world, rather than an acting co-constructor of the world.

\footnotetext{
${ }^{66}$ In Philosophy and the Mirror of Nature, Rorty (1979) writes about similar transitions made by Wittgenstein, Heidegger and Dewey: "Each tried, in his early years, to find a way of making philosophy foundational . . . . Each of the three, in his later work, broke free of the Kantian conception of philosophy as foundational, and spent his time warning us against those very temptations to which he himself had once succumbed" (Rorty, 1979, p. 5).

${ }^{67}$ By the 'assumed' or 'constructed' certainty of a positivistic position, I mean an 'unquestioned' certainty. Although a positivistic position purports to offer final, incontrovertible truth, proof, or reality, we can always ask more 'what if' questions; we can attempt to sidestep the problem, and salvage the positivistic view, by adopting Popper's falsificationism, and building an ever bigger list of what isn't, but never, definitively, what is, because definitions simply aren't definitive, but depend on still other definitions, such that 'proving,' at least when it's forced out of the laboratory and into more social situations, turns out to be less like a precise analytical exercise, and more like an exercise for finding the point past which further niggling about the details will be unacceptable to one's peers, a point otherwise known as agreement or consensus, or, from a Foucauldian perspective, 'that which we agree to call the truth.' I'm not a linguist, but I suspect that the phrasing 'that which,' a phrasing Heidegger also used-e.g. 'Dasein is 'that which' takes a stand on its own being' - is striking and insightful because the phrasing 'that which' is one of the most successful attempts at being definitive, at breaking an otherwise endless chain of definition and re-definition. The phrasing seems to me to be effective, to some extent, in breaking this chain, to arrive at meaning by reflecting back onto itself.
} 
time, because my long-held beliefs about truth, reality, objectivity, 'facts' and other (what I had considered) certainties, had been shaken, and I saw no other direction forward. Expressions like 'moving around in the dark,' and 'heading down a slippery slope' come to mind. How else indeed, as both Parsons and Freidson after him had asked, could we 'get along'?

There's also been a good bit of wavering back and forth, and of falling unwittingly back into old habits. More concretely: falling back into old habits means focusing on accounts of 'what consulting practice really is or should be' and proofs thereof, rather than constructing other possible accounts or narratives of what consulting could be; it means centering 'things' and writing 'about' those things, rather than centering 'acting' and 'doing.' And finally-and this has been the most difficult for me to overcome-falling back into old habits also means renouncing a modernist view, only to dogmatically replace it with a postmodern view, i.e. to simply replace one foundational view with another. If one remains true to the spirit of a nonfoundational view, as oxymoronic as that sounds and may very well be, I don't think it gets any easier over time, because it entails deferring closure and staying open for new ideas and experiences; it requires energy and maintaining a 'beginner's mind. ${ }^{68}$

As an author, I can include the story of this wavering here in the text, or present you instead with a 'cleaned-up' version. I'll opt for the former, because I'm certain that I'm not the only one to have struggled with trying to expand one's world view by embracing a new one, by embracing new way of acting in the world, an especially difficult task when the new ways clash with older and more established and familiar ones.

The purpose of Chapter 2, then, is to tell the story of a period of transitioning away from a foundational to a non-foundational view; from an expert approach to consulting, toward an alternative 'processual' approach, motivated and enabled by the ideas of pragmatism and relational constructionism. We will also seek to address the problems constructed in Chapter

\footnotetext{
${ }^{68}$ Some, like Derrida or Heidegger, would probably argue — and as Zizek (1999) has explicitly argued-that the 'modern' and 'postmodern' are, at some more fundamental level, one and the same, or that trying to move 'upstream,' or uncover or discover the reality of 'organizing' behind the reified façade of 'organization' is modernism par excellence, that someone who is strictly adhering to a 'non-foundational' view, is, by definition, doing so 'foundationally,' etc. Perhaps they are, but this is where I lose interest in the fight, where I am likely to reply - as Rorty sometimes did, to those whose would argue on and on about the inconsistencies of his version of pragmatism - 'Oh, all right then,' because I think there are more important things to be doing than defending one's view, like trying to help clients and consultants and academic researchers of consulting.
} 
1, with an approach that makes use of alternative constructions of 'organization,' 'knowledge,' 'professionalism,' and 'client-consultant relationships,' and without relying on the assumptions of an expert approach, or a traditional (i.e. modernist) professionalism. The tentative outline of this alternative approach arrived at here will be further developed-and further constructed with conversations and case studies from practice-in subsequent chapters.

\section{Muddling through}

My initial (and in retrospect, rather short-sighted and cynical) purpose of tearing down the expert approach had led to an impasse, mostly because if I took seriously the arguments I myself had constructed - that knowledge was not transferable, that organizational change outcomes couldn't be predicted or controlled, that 'professional relationships' were characterized by an irreducible separation and an asymmetry of knowledge and power between client and consultant-if I took these arguments seriously, then it wasn't at all clear what the role of a consultant could possibly be, or how I might go about developing an alternative consulting approach, without resorting to the very same methods and assumptions which I had come to question. A breakthrough came, ironically enough, when I began to question the very same body of critical research, on which I had so heavily depended.

\section{Critique of the critique of consulting}

Thanks to a very large body of critical research on consulting, (e.g. Alvesson, 2001; Clark et al., 2002; Fincham, 1999; Gill and Whittle, 1993; Sturdy, Clark, Fincham, and Handley, 2004), the early days of my research, when I too was preoccupied with critique, went along without too much difficulty. As I wrote in another paper (appearing as Chapter 5):

The breadth and creativity of the perspectives brought to bear on consultants and consulting - 'fantasy theme analysis' (Jackson, 2002), 'dramaturgical analysis' (Clark and Salaman, 1998a), even 'magic' (Fincham, 2000)—seem to have been eclipsed only by the sheer volume of material produced, prompting Collins (2004) to observe that the debunking of consulting knowledge "has become something of a mass participation sport for academics" (p. 557).

But then came an impasse, and the need for ideas and proposals for how we might go about consulting practice differently. And here, these same authors, and the body of research on 
which I had relied, fell silent. And the alternatives that were offered by the critical research (and by much of the 'pro-consultancy' research (e.g. Greiner et al., 2004; Kubr, 2002) and the OD-influenced research as well (e.g. Argyris, 1970; Schein, 1969, 1988)) seemed to depend on the very same modernistic assumptions, away from which I was hoping to move. For example, here again is a paragraph from Fincham (1999), and his critique of Schein:

"In Schein's (1988) process consultation model, for example, clinical and group theories are pressed into service and, rather like the psychiatric patient, managers are expected to submit to diagnosis. The manager only has a sense that something is wrong but can neither diagnose the problem nor communicate it to the consultant: 'They do not have the tools with which to translate their vague feelings into concrete action steps' (p. 4). Those tools, of course, belong to the consultant, and though the process of arriving at a solution is supposedly a partnership, or 'joint diagnosis', the consultant is the senior partner" (Fincham, 1999, p. 337).

But elsewhere in the same paper, we read:

"The management consulting industry is attracting more and more attention. The critical literature in particular has questioned how a non-codified body of knowledge like 'consultancy' could become so apparently influential . . . . Moreover, consultants see their own work as knowledge creation, and again whatever we may think about the worth of this 'knowledge' they are consciously and explicitly in the business of producing it" (Fincham, 1999, p. 335-336).

In the first passage, Fincham is criticizing Schein's implied claim that it is only the consultants, and not the clients, who have the necessary tools-just as we used this passage earlier in our own critique of consultants. But how is this any different from Fincham's implied claim in the second passage that it is only the academics, and not the consultants, who are the 'senior partner,' and who have privileged access to an authentic, codified 'body' of knowledge? What is called for seems to be simply the replacement of one body of expert knowledge - that of the consultants-with another-that of the critical scholars. Not much progress here. In addition, as we wrote in Chapter 1, the 'standardized, codified bodies of knowledge' that medicine, consulting and other professions had claimed to posses, often turned out to be rather vague and indeterminate, and to not play a significant role, even in 
successful practice. What we do not find here is any reconceptualization of knowledge that might be more useful for practice.

In "Management by Panacea," something of a consultant-bashing classic by John Gill and Sue Whittle (1993), the authors write that with more theory and more rigorous diagnostic analysis, ${ }^{69}$ clients and managers can be helped to "understand what is really going on" and thereby be provided with a "countervailing influence to the drift from reality induced by many consulting packages" (p. 292). It's more or less clear that Gill and Whittle consider themselves to be in possession of this 'reality,' but, "predictably"-a much-favored word during rants like theirs and this one-predictably we are not made privy as to what this reality is, nor how we might, as they say in the Southern US, 'get a hold of' some of it. Their article, and others like it, including my own critique in Chapter 1, are critical of clients' and consultants' attempts to achieve some 'ideal organizational state,' by pursuing one initiative after another. And yet at the same time, these authors continue to hold out the hope that the organizations is, after all controllable:

"there is predictably little published, critical examination of their [the consultants'] efforts which would have enabled improved understanding of what works, what does not and why (Brandon, 1988)" (Gill and Whittle, 1993: p. 288, emphasis added).

Apparently, then, there is, after all, some hidden formula for organizational success? The implications seems to be that all the failed change efforts could have been avoided, if only we had subjected all our past projects to some kind of academic post mortem analysis. Who knew?! Here, as with so much of the critical research on consulting, authors attempt to cut the supports out from under the consultant's position, while standing on the very same modernist platform. And again what we miss are possible reconceptualizations of 'organization.' What we miss are proposals for alternative practice that do not rely on the assumptions of organizations as controllable entities, or the effectiveness of codified bodies of expert knowledge. The difficulties we constructed in Chapter 1 -i.e. the low rate of success for organizational change initiatives, the apparent non-transferability of knowledge, and the 'critical distance' characterizing traditional professional-client relationships-these difficulties remained unaddressed.

\footnotetext{
${ }^{69}$ We will return again later to discuss 'organizational diagnostics.'
} 
And finally with the extant critical research on consulting, there was simply the question of relevance. While these authors - and I-were busy with our respective critiques, it seems we overlooked (or perhaps, failed to look out from the tiny windows high atop the ivory tower to see 'out there'?) that, regardless of how solid our arguments, and how vocal and incisive our criticism, the management consulting industry continued to grow, and to grow rapidly, surpassing in 2006 the $\$ 300$ billion mark in annual revenue, an all-time high for the industry (Kennedy Information, 2007). No, of course market success didn't mean everything was okay with the prevailing approach to consulting (see Chapter 1), but it did raise some rather unavoidable doubts as to the relevance of all the critical research. ${ }^{70}$ Predictably, a number of authors, e.g. Graeme Salaman (2002a), Frank Heller (2002) and Stewart Clegg, Martin Kornberger and Carl Rhodes (2004b; 2004c) have written of the critical literature on consulting that, essentially, 'enough is enough' and have argued in favor of moving beyond narrow critique, and toward alternative proposals.

\section{The beginning of a breakthrough}

It was this question of relevance that led to the beginning of a breakthrough, which was simply this: the recognition-or I should say, the construction — that despite all the erudite criticism, and despite my own doubts as to how we could possibly get along in consulting without transferable knowledge, and without controllable change outcomes, etc.; the simple recognition was that despite all this, consulting was, nevertheless, somehow, getting along. Management consulting — and an expert approach to consulting, no less—had not ground to a halt, any more than had medicine or public planning or any of the professions, for that matter, whose knowledge and efficacy had also been seriously and publicly questioned. So while it was not without difficulty, and not without criticism from clients, critical scholars and $\mathrm{PhD}$ students alike, the business of consulting, if measured by revenue or industry growth, was getting along just fine, thank you very much, just as it had been since its inception, and with consistent increases in revenue, every year, except for 2002, since the 1960s (Kennedy Information, 2004)!

The breakthrough was simply the recognition that neither the critical researchers, nor I-nor anyone, nor any group, for that matter-had privileged access to 'how consulting really is.'

\footnotetext{
${ }^{70}$ For a review of this literature, told with wit and humor to boot, see David Collins (2000; 2001; 2003; 2004a; 2004b).
} 
Instead, these were different narratives, constructed by different communities, for different purposes. The recognition was that there had to be, therefore, other ways as well. When I began my research, I believed there was a single truth out there. I assumed that my own consulting experiences - i.e. the cutting and pasting of templates, the using of under-theorized models, muddling through the haphazard and messy activities of practicing-were not the 'real story,' and that once inside academia I would find that single truth in the form of fundamental theories on organizations and knowledge, and robust methods that could form a foundational consulting approach. It was only after I had reached an impasse, and became less enamored of the well-written critiques of consulting, that I noticed the wide disparity between the dour prognoses of so many of the critical scholars, and the unabated market success of consultancy. So if the scholars-critical or otherwise-did not have privileged access to or authorship of the narrative on consulting, I thought, then perhaps there was no single narrative of consulting. Perhaps there were multiple narratives, by different communities, for different purposes. This was for me, a loosening of the modernist idea that out there somewhere was the story of how things really are, and also a reminder that determining 'how things really are' need not be the purpose anyway. We could instead construct narratives of how consulting could be.

Looking back on this time, with vocabulary I can now use, but could not at the time, I can also say that the difference between the critical scholars' and my own efforts become more clear if we, as Rorty and others suggest, step away from treating them as different 'views' and treat them instead as different 'performances.' The critical scholars were engaging in the performance of writing critical accounts of consulting and consulting knowledge, for publication in academic journals. They were co-constructing with peers (i.e. co-authors, reviewers, editors, colleagues) a social reality wherein consulting knowledge was faulty. ${ }^{71}$ The performance I was at least attempting to engage in, however, was a different one. I was trying to construct, using experience gained as a consultant (and academic theories and knowledge as well), a different way of doing consulting that clients and consultants and researchers would find useful.

\footnotetext{
${ }^{71}$ And I should mention here again that I am not referring to individual or subjective realities. Even if I withdraw into my own little world (and from my experience, the $\mathrm{PhD}$ process can be a very effective and efficient means for doing just that!), the meanings I take with me into my world are socially derived; they are social 'all the way down,' and when they cease to be-if in fact they could be, which is a far from answered question - there, and not before, is the point where we cross over into individual subjective realties, and, also, by the way, the point where we cross over into what we refer to as 'psychosis.'
} 


\section{Some changes in direction}

This notion that there could be multiple and simultaneously existing world views and different consulting narratives helped me move past the impasse described at the end of the previous chapter. I was more confident that some new alternative was possible-not to be found, but co-constructed. And although I had no clear ideas yet as to how this alternative might eventually turn out, some ideas about what I hoped to construct, and a number of ways of working (i.e. consulting) that I hoped this alternative approach would enable, were beginning to emerge.

I wanted the approach to be useful and relevant for clients, consultants and researchers, and to, even if only a little, reduce the distance between these communities. In turn came the ideas to structure the thesis as a journey, to show that I too have 'walked a mile in their moccasins' and to speak and relate more directly with (and occasionally poke a little at) each of these groups. I also decided to make use of less formal (i.e. academic or theoretical) language and methods. I can also say, looking back, that here was probably the beginning of a decline in my interest in 'pure' i.e. non-applied and/or critical academic research. As obvious as it may be in retrospect, it was also here that I began to see a clear difference between the practicing of consulting, and research 'about' consulting practice. This 'aboutness' research is yet another characteristic of a modernist view (see Hosking, 2005), namely that the goal of research is to learn and produce knowledge 'about' the world out there, in this case, knowledge about consulting practice. ${ }^{72}$ This, in turn, led to a transitioning of the thesis away from 'research about consulting' to a focus on 'action' and 'helping' and the 'doing' of consulting. I wanted the approach to allow clients, consultants and researchers to act non-foundationally, that is, pragmatically, with action guided more by usefulness, and less by pre-determined methods. I wanted the approach to be a proposal, and invitation to co-

\footnotetext{
${ }^{72}$ This was also one of the experiences whereby some of the critique of modernism began to make sense for me. At the risk of sounding like oh-so-many academic paper beginnings, I think there is something of a gap in this area between, for lack of better words, modern and post-modern writings. Modernist writing doesn't at all question research 'about' some thing, while post-modern writing often launches into detailed critique of 'aboutness' that demands too much of readers newly exposed to post-modern ideas. It leaves them asking 'so what?' I suppose much of the difficulty is due to the fact that academic and non-academic publishing seldom overlap. I don't know of too may papers or books (I think Ken Gergen's (1999) An Invitation to Social Construction is one) that spends some time discussing how research 'about' some thing can be limiting; how, for example, it reinforces the view that we are separate from the world around us, that doing research about some thing will always fall short of more direct action to change and improve some thing. So for me, the limitations of 'aboutness' I had often read about, began to make much more sense only when I came to what were for me concrete meaningful examples of them, when I saw that 'doing research about consulting' would never be 'doing consulting,' and that these were two very different performances, with very different purposes.
} 
construct, and an alternative or supplement to—not a replacement for-whatever was already available. The motivation was no longer to prove one way to be better than another. I remembered all the way back to the discussion I had with Greg, my colleague in Dallas, and his question 'Why are you spending your time criticizing the expert approach, instead of just developing your own?' That was good advice, and it took me a year and a half or so to understand why.

Albeit slowly, I had begun to address some of the questions posed at the impasse, namely 'For whose benefit is this research undertaken?' One answer: consultants, clients and academics. And 'How might I go about developing an alternative without resorting to the same positivistic methods?' One answer: by offering 'proposals for how we could go on differently,' instead of 'proof for why we should go on differently.'

\section{New and useful ideas}

Having finally picked up on the rather obvious clue that business consulting (expert approach or otherwise) was indeed, somehow, getting along (and leaving off of the rather arrogant method of seeking to make a positive change by proving to clients and consultants how misguided they all were), anxiety gave way to curiosity, and to the questions of what an alternative approach to consulting could be, and what other narratives of consulting I could construct.

There is an old expression that goes something like: 'You can't tear down the master's house, using the master's tools.' What I had been trying to do was different, yet equally ineffective, namely, using the master's (modernist) tools to try and build a very different (postmodern) house. And so I began to look elsewhere for other tools, outside the mainstream research (critical or otherwise) on consulting, organizations, and management, and instead to sociology, psychology, anthropology, and philosophy. Specifically, I looked for work that provided different notions of 'organizations,' 'knowledge' and 'relationships,' so as to (potentially) be useful for alternative forms of consulting practice. That search soon began to pay off.

The first of these new and useful ideas had to do with knowledge, or rather a shift in focus 'upstream' to the activities that produce or result in knowledge. The work of Jean Lave and Etienne Wenger (1991), Scott Cook and John Brown (1999), and David Nicolini, Silvia 
Gherardi and Dvora Yanow (2003) focused not on knowledge as an asset or thing or resource, but instead on the process of knowing. According to this view, 'knowing' is acting to achieve some purpose. When we are knowing, we are thus both producing new knowledge, and using past knowledge or experience — and also tools (i.e. computers), intuition, and of course even our 'best guesses' and hunches-in order to resolve issues and move closer to achieving our purpose(s). Knowledge and experience, then, result from the activity of knowing; they are products or byproducts of the activities of knowing, i.e. talking, discussing, trying, organizing, experimenting, etc. The focus shifts 'upstream,' away from knowledge, away from a reliance on 'knowledge transfer,' and toward the successful performing of meaningful activities, i.e. toward practicing itself. The example that is often used here is that of riding a bicycle. We don't expect, for example, that a child learns to ride a bicycle, based only on the 'transfer' of knowledge or advice from parents. Instead, we expect that, ultimately, the child must get on and ride the bicycle for themselves. As much as nervous parents might like to, they simply cannot ride the bicycle for or on behalf of their children. With this new perspective of knowing, successfully riding the bicycle depends on, and results from, the creation of knowledge, by the rider, during riding, rather than the transfer of knowledge from parents. This is not to deny that the information from parents may be useful. It is to say, however, that knowledge is useful to the rider, only to the extent that it is actually used by the rider, ${ }^{73}$ and at which point it is considered to be self-created by the rider, more than being transferred from the parents. It is to say that an instruction manual for some gadget you've purchased is valuable not when it has been 'transferred' to you by the shop clerk, but only after you open it, read it, make sense of it while using the gadget, and thereby create knowledge, or make the information contained in the manual, your own. It is also to say the primary concern is achieving or moving closer to achieving the purpose, say of successfully riding the bicycle, and that attempts to enumerate and provide beforehand all the information, skill and other 'inputs' we think may be required, are of secondary concern. This focus on the 'upstream' activity of knowing, instead of on the 'downstream' result of knowing, i.e. knowledge, was a new and interesting perspective for me, and seemed to offer important insights for a nonexpert approach to consulting, an approach where the primary focus could be on practicing

\footnotetext{
${ }^{73}$ A stronger statement would be to say that knowledge simply does not exist until some action takes place, action which makes use of information, memories, thereby creating knowledge, calling knowledge into existence, by using it. From this perspective, books sitting closed on a shelf might be said not to contain knowledge, until they're read. A library, in other words, is not 'full of knowledge' for someone who cannot read.
} 
itself, on helping and collaborating with clients and consultants, and with built-for-purpose knowledge as a fortuitous byproduct.

Knowing also offered a compelling rationale for why the knowledge management efforts of clients and consultants were often seen as ineffective-namely that 'knowledge transfer' relies on the assumption that knowledge is a thing or asset that has been packaged up and is simply awaiting transfer. But if we assume for the moment that knowledge is the result of knowing, then any effort that tries to capture and transfer only the result, i.e. knowledge, without the upstream activities that produce that knowledge in the first place, i.e. the activities of knowing, then it makes sense that such an effort is going to be difficult, to say the least. Rather than amassing knowledge 'assets' that may or may not be used or prove useful for practicing; rather than relying on the problematic notion of 'knowledge transfer,' as do most knowledge management efforts (McDermott, 1999; Newell et al., 2006), knowing maintains a primary focus on doing and successfully performing.

This, for me, was another breakthrough, and helped to answer more of the questions I'd posed at the impasse: 'How could we go on with consulting, if knowledge turned out to be 'nontransferable'?' One answer: by shifting the focus upstream, toward 'knowing' and practicing itself, and away from a downstream focus on 'knowledge' and a commensurate reliance, therefore, on the problematic notion of the transference. The prospects for developing an alternative way of consulting that did not depend on the transferability of knowledge, therefore, now seemed a lot brighter. Another question had been: 'What can my contribution be?' One answer: the pulling in to consulting practice relevant and useful ideas and new vocabulary from sociology, anthropology and other disciplines-ideas that addressed the problems constructed in Chapter 1 and without relying on the assumptions of an expert approach or, for that matter, the similar assumptions made by process consultation and other OD-influenced approaches.

\section{An emerging 'processual view'}

So 'knowing' was a new and useful way of thinking about knowledge in a consulting context, but equally importantly, it was also, along with the notion of 'organizing,' another example or instance of what I will call a 'processual view' that had begun to emerge for me, influenced by the writing of Hosking and Morley (1985; 1991), Tsoukas and Chia (2002), Polanyi (1967), Bergson (1946), Whitehead and others. A processual view, with its focus on the 
ongoing activities of practicing itself, seemed promising as the basis of an alternative 'processual' approach to consulting practice. It also seemed to explain what was 'really going on,' compared to the official accounts.

The official accounts of consulting practice, i.e. client RFPs, consultant proposals, project plans and final reports, describe 'objective consultants, proceeding through clear methodologically determined steps, to the resolution of client problems.' In my experience, however, the day-to-day activities of practicing consulting-i.e. discussing, knowing, muddling though, organizing, relating, etc.-were messy, unpredictable and always-emerging. These activities were contradictory to the official accounts of consulting practice, but made a lot more sense according to a processual view. It was a processual view, in other words, that for me explained what was really going on in practice. ${ }^{74}$ And it was a processual view that helped, even, to legitimize the messy activities of practicing, and allowed them to, so to speak, 'come out of hiding.' When, for example, the official proposals and project plans promise clear, methodologically driven work, muddling through with your team to find something that works - these are not the ways of working one can speak openly about; they are best downplayed, or even denied altogether. In other words, much of the knowing and organizing of a processual view —although without the vocabulary of 'knowing' and 'organizing' —was already in place, and already being practiced. The 'processual view,' then, appeared to be well-suited as the basis of an alternative 'processual approach' to business consulting. In the following two chapters, I will discuss a processual approach to consulting in greater depth, but I first want to provide here a brief overview of the ideas as they were forming at the time, and why they seemed so attractive.

\section{Overview of a processual approach to consulting}

Both 'knowing' and 'organizing' are 'processual' in the sense that they are not static, they are moving. They are 'upstream' processes or activities, rather than 'downstream' results (Chia, 1996). The relevance for consulting, is that a focus on

\footnotetext{
${ }^{74}$ At this point, I need to provide some clarification for the reader. It gets tricky at certain points, and this is one of them, to write about past events, as you thought about them at the time, especially when your views have since changed. At the time, the processual view seemed to explain 'what was really going on' in practice. Today, I would say that there are different narratives we can construct of consulting practice-one narrative of consulting as a controlled, methodologically-driven process, i.e. what I've been referring to as the 'official accounts' of consulting practice, and another narrative of consulting practicing as something of a mess, emerging, unpredictable, etc. At the time, I was moving toward what Boje (1995, 2001) would call a 'metanarrative,' a totalizing account of 'how things are.'
} 
knowing or organizing is a focus on practicing itself, a focus on performing. An expert approach, in contrast, focuses firstly on entities, i.e. 'knowledge' or 'organizations,' or 'relationships,' and practice then involves the attempted manipulation and attempted control of these downstream results. An expert approach thus adopts not a processual but an 'entitive' view (Hosking et al., 1991). This is consequential for consulting practice, because from the perspective of a processual view, knowledge results from activities of knowing. Therefore, as discussed above, attempts to 'transfer' knowledge, without the activities (knowing) to create that knowledge having occurred in the first place, is not considered feasible. Likewise for 'organization': upstream, are the dynamic, ongoing, emerging and unpredictable activities of 'organizing,' and downstream is the result of these activities: 'organization.' When we take a 'snapshot' of these ongoing activities, like we do when we create organization charts or create diagrams of business processes, we create static representations of always ongoing activities. From a processual view, the expert approach reifies or attributes a tangible reality to 'knowledge' and to 'organization' and also to org charts and process maps, and then attempts to control these reified entities. From a processual view, in the case of 'organization,' an expert approach tries to predict the behavior and outcome of organizational change initiatives, as if 1) 'the organization' were not a reification, not a construction, but an entity with a life of its own, and as if 2) the dynamic and unpredictable activities of working (and the everchanging demands of customers and markets, to which those activities seek to respond) were indeed predictable. From a processual view, to disregard the upstream history, and to start with the downstream reified result, and then to make predictions on how that constructed result will or will not behave, is a difficult task indeed, with not much chance of success. Of course we can, from this perspective, speak of things, like organizations, but it is, and precisely as Barnard (1938) suggested so many years ago, for purposes of convenience, and always with the awareness (if we're mindful enough) that the for-convenience-purposes-frozen-in-time (i.e. reified) 'organization' continues to evolve and change, even as we speak of 'it.' From a processual view, an expert approach focuses first on making changes to static representations-org charts, process maps, policies-in attempts to, ultimately, effectuate change in the ongoing activities of working and the ways people work. Not surprisingly, 'managing worker resistance to change' becomes important, as if the workers and their working were not always and already changing all the time. 
Here, then, with the ideas of 'knowing' and 'organizing' being grouped into what I now called a 'processual view,' there seemed to be some useful responses to the problems constructed in Chapter 1. Based on the history of organizational studies we constructed there-with its early focus on 'organizing,' not 'organizations' - and also our discussion of the past questioning of professional knowledge, a promising way forward for an alternative consulting practice seemed to lie at least partially, and ironically enough, in a resurrection of ideas from the past.

Before going ahead, it's important here to make a distinction between a 'processual view' as we are developing it, and the more traditional 'process analysis,' e.g. Van de Ven and Poole (1995). The processual view we will focus on is concerned primarily with 'moving' while process analysis is concerned with 'things in motion;' a processual view focuses on 'organizing' while process analysis focuses on 'organizations in motion' or 'organizations over time.' Process analyses study the changes occurring to organizations over time in a stopmotion fashion, much as calculus studies 'objects in flight' which we also discuss in Chapter 3. We should also make a distinction between consulting practice according to a processual perspective, and the 'process consultation' of Schein (1969). With process consultation, it is the specific, and to a degree pre-determined process of consulting that is considered important-thus the name 'process' consultation. It is through this process that the consultant leads the client, to discover root causes and make diagnoses. 'Process consultants' for example, will often distinguish between 'content' and 'process,' as if the two were independent. For the processual view we are developing, 'process,' although the word itself is not of primary importance, is the process of emergence, of becoming. ${ }^{75}$

\section{Explaining the mystery of consulting's continued success}

A processual view also offered another important additional benefit: it helped to answer the long-unanswered question as to the 'mystery' (Fincham, 1999) of consulting's continued success. Although many clients and consultants have probably (and fortunately for them) remained unaware of it, there has been, for well over a decade, nothing less than a 'preoccupation' (Salaman, 2002a) ${ }^{76}$ among critical researchers over the question of why management consulting has continued to be so successful, and so highly in demand, despite

\footnotetext{
${ }^{75}$ For a comparison between Schein's process consultation and the relational approach we seek to develop, see a paper by Frank Lambrechts, et al. (Lambrechts, Grieten, Bouwen, and Corthouts, 2009)

${ }^{76}$ More recently, see Clark (2004) for a review of related writings and methods employed; also Ernst and Kieser (2002).
} 
the "disastrous failures associated with some consulting assignments" (Fincham, 1999, p. 336), despite the 'flawed' knowledge, despite the claims of insidious power hidden in "the shadowy world of management consultancy" (Ashford, 2000)—enough material, certainly, for an entire series of paperback mystery/conspiracy novels.

Over the years, a multitude of explanations for the continued success of consultancy, seemingly in spite of the highly-publicized failures, have been put forward by researchers, explanations that were immediately attacked and 'debunked' by still other researchers. But none of them, I felt, had the explanatory power of the processual view. This story of the 'mystery' of consulting's continued success is a bit complicated, and a thorough treatment of it would also take us too far afield (and to another promising dissertation topic!). But because of its importance, both to the thesis and to the debate around consulting in general, I cannot ignore it here altogether. So next, I will provide a summary of this 'mystery,' in order to show how and why a processual view seemed to offer such an attractive resolution. I also want to point out to the reader how, with my intent at the time to explain "what was really going on in practice,' my plans to embrace a non-foundational view, were fading fast.

The abbreviated ${ }^{77}$ 'mystery story' goes something like this: Critical researchers had become preoccupied with the question of why consulting continued to be so successful, despite (from their perspective) its obvious drawbacks-i.e. non-scientifically derived knowledge, the faddish nature of consultant-led initiatives, etc. Some researchers argued that clients had fallen victim to persuasive consultant rhetoric, while others argued that clients were not nearly so passive, and that both clients and consultants were looking to relieve the inherent uncertainty of managing itself. But as Salaman (2002a) pointed out, the question of "why so successful, despite flawed knowledge?' was based on an assumption by researchers, as in the passage from Fincham above, that their knowledge was somehow superior. The "why so successful?' question also led to some rather uncomfortable conclusions, namely that either clients had indeed been 'duped' by consultants, or, that clients-i.e. university graduates, some of them former students of the critical researchers, no less!-were simply not the sharpest tools in the shed, i.e. they were 'dopes.' Obviously, no one was very happy with the choice of 'duped' or 'dopes' to explain consulting's continuing popularity. In addition, when

\footnotetext{
${ }^{77}$ For brevity's sake, I will only a few representative works. Also see the introduction to Critical Consulting (Clark et al., 2002), and, in the same book, the chapter by Graeme Salaman (2002a) entitled 'Understanding Advice: Toward a Sociology of Management Consultancy.'
} 
you added in, as Collins (2004) did, the 'minor' detail that from a market perspective, consulting was a runaway success, the 'why' question and the research it inspired seemed indeed a very dead end. Perhaps because of this, interest in the topic seemed to have cooled off a bit by the time I was writing my thesis. ${ }^{78}$

Yet the question remained: Even if, for example, we dropped the ridiculous 'duped or dopes' idea, and the (equally indefensible?) notion that academic knowledge is somehow 'superior' to consulting knowledge; even if we accepted as valid whatever knowledge, information or experience it was, upon which clients and consultants had agreed to go forward, then, still, why do they—clients and consultants—continue to pursue one initiative after another, when those very same initiatives, over a period of decades, produce only mediocre rates of success, and not according to external, academic standards of success or failure, but according to the standards and measurements that clients and consultants themselves have set? Why indeed do they continue to do that? The notion of 'organizing' had provided one reasonable explanation as to why organizational change was so difficult, but said nothing about why it was undertaken again and again, despite unsatisfactory results. If 'knowledge management' and 'knowledge transfer' efforts are so often unsuccessful, then why, I wondered, do clients and consultants continue to attempt to 'transfer' knowledge from one team to another, or from consultant to client? If collaboration and innovation are increasingly important, why do clients and consultants continue to model their relationships after outdated notions of professionalism with its insistence on the maintenance of a 'critical distance' between them?

The sublimely simple answer, I came to believe, with the insights of a processual view, was this: they don't. The answer as to why clients continue to ask for, and why consultants continue to promise, controllable change outcomes and transferable knowledge, despite consistent failure, is simply that they write one story—in RFPs and proposals-and act out a very different story - in practice. The 'mystery' of consulting success, then, turned out to be no more mysterious than the difference between what clients and consultants said they would do — in the official accounts of consulting practice — and what they are actually doing — during the practicing of consulting. And what is was that they were actually doing, looked a whole lot like the activities of a processual approach.

\footnotetext{
${ }^{78}$ This cooling trend is certainly fortunate, since regardless of your personal stance as to whether or not what we do down here is materially contributory to climate change, most would agree that the last thing Earth's atmosphere needs right now is to have a lot more haught air pumped into it.
} 
Here then, for me at the time, was an answer to the long-unanswered question as to why the consulting industry continued to be so successful, despite unsatisfactory outcomes. The official accounts - e.g. the RFPs, the proposals and plans, written in modernist discourse, promising guaranteed change outcomes, delivered by objective professionals according to robust and proven methodologies - these accounts satisfied the requirements of the modernistinfluenced game that both clients and consultants were playing, while practice, warts and all, bumped along in the background.

I began to experiment with a processual view. For example, if I pulled the day-to-day roughand-tumble activities of practicing into the foreground, and pushed the normally-foregrounded official accounts of practice, and also the modernist discourse into the background, I arrived at some very different stories of the practicing of consulting, stories that helped to explain the 'mystery' of consulting success, and also suggested an alternative way of doing consulting. These are stories, by the way, were also quite similar to my own consulting experiences, and also those of the clients and consultants I have more recently met with.

\section{Creating burning platforms}

Consulting's continued success would indeed have been something of a 'mystery,' if clients and consultants had agreed on a plan and set of activities, executed those activities, failed, and then repeated the very same exercise, over and over-and this is precisely how consulting is portrayed by many authors. Taking a page from the muckraker's handbook, they write sensationalist articles about the continued and dismally low rate of success of organizational change initiatives, articles that make sense only when pitched against the background assumption that better results were to be expected, and as if 'better' were definable, agreed and objectively known. The reports of low success rates are not necessarily inaccurate, but it's a question of how serious those reports are taken in practice. In my experience at least: not very. Low rates of success are effective for creating a 'burning platform' and for the opening paragraphs of papers intended to promote a certain 'solution,' but are taken much less seriously by clients and consultants who continue to be under pressure to deliver the undeliverable, and who, therefore, kick off one initiative after another. 
The 'mystery' of consulting's continued success begins to unravel fairly quickly, however, if we assume that 1) the official accounts are written to conform to the acceptable and prevailing (i.e. modernist) standards of what client RFPs and consultant proposals are supposed to look like, and that, at the same time 2) no one in practice, client or consultant, expects nor enforces anything near to a close correlation between those accounts and day-to-day practice.

An alternative account of the continuing demand for, and criticism of, consulting services The notion that 'the organization' is a thing to be managed began in the 1930s and gained momentum in the 1950s. A product of our own design and construction, the organization was not only a thing to be managed, it was manageable, and controllable. In practice, however, organizations turned out to be not so manageable and not so controllable after all. Managers, i.e. those charged with managing, i.e. consulting clients, never seemed to be able to get it quite right. Outcomes always seemed either to not meet, or diverge significantly from the plans that had been made, resulting in a lot of tailoring of those plans, later on, to justify and legitimize what the outcome had finally been, or, in some cases, to keep the official account in place and unchanged, in the hope that no one would look out onto the shop floor, and notice the difference. There were some successes, of course, not because organizations became controllable, but rather because they were simply controlled by management, with policies, incentives, disciplinary actions, etc, or at least, so it was recorded in the official accounts. But for the most part, managing an organization, according to the official plans and to meet the official objectives, remained a constant struggle. There was never a shortage of methods, published in popular business journals, or promoted by consultants. Most, however, amounted to old wine in new bottles, and continued to promote the objectivity of the external expert, to hold out the hope that organizations could be managed and controlled, and that knowledge could indeed be successfully transferred from one team or factory to another, if they (the managers) could just get it right. So managers continued to muddle through.

This difficult situation was made more sustainable, however, by at least a couple of important factors. One was that the day-to-day practice of managing and organizing was allowed to drift free from the formal plans, methods and theories of management, with a pragmatic focus on getting the work done, even if by different means that were 
often informal and a bit messy. The managers also made use of external consultants. At a minimum, consultants were very good at crafting stories, i.e. proposals and plans, that took the formal methods and theories, and packaged and positioned them, crisply and succinctly, as solutions for the organization's ills. Consultants helped managers legitimize their efforts. And, more often than not, the consultants had some interesting ideas, gained from working with many other companies. When projects were going well, and client-consultant relationships positive, consultants were not 'distant' or even 'objective.' Rather, they were biased in the client's favor. Clients and consultants worked together closely and pragmatically, improvising, trying this, trying that, and generally taking the actions necessary to get the work done. Nevertheless, many of the projects—most in fact—did not achieve their official stated objectives, and consultants were accustomed to shouldering some of the blame for that. The projects did, however, keep things moving in the right and official direction, moving toward realizing the manageable, controllable 'organization' that the formal methods and theories continued to say was realizable, and that managers were continually exhorted to achieve.

The explanations offered here of the mystery of consulting's continued success, were that the modernist theories of organization and of management necessitate management consulting, by holding out hope that an organization is an entity that is controllable if we can just get it right, even as actual activities of practicing unfold very differently. The prevailing and modernist-influenced conceptions of organization, knowledge, and management in general, I wanted to say, ensured both the continued public criticism and the continued business success of consulting.

The so-called 'fads and fashion' literature is an important sub-genre of (primarily critical) consulting literature. As with the former stories, I'm afraid this next one too may come off as a very 'know-it-all' story. The intent, however, at the time, was to sharpen the argument as much as I could, in order to establish a more compelling case for change in our conceptualization of 'organization' and the processes of consulting. The intent was also to write some words that both clients and consultants may have been thinking-and indeed told to me in private conversation-but were unable to say or write more openly. It appears below, unedited from when it was written in the spring of 2008. 


\section{On the fads and fashions of organizational change}

v According to a modernist management paradigm, 'the organization' is considered to be an entity of intentional design, whose behavior is therefore predictable, and whose outcomes (in response to organizational change initiatives) are ther efore controllable

$\checkmark$ The expectation of predictability and controllability produces a continuous demand for initiatives, often consultant-led, that promise to realize 'the organization'

v However, the dynamic, emergent and often unpredictable nature of the activities of 'organizing' itself prevents full realization of 'the organization,' and the percentage of initiatives that fail to reach their own stated objectives is high

v Still, new initiatives continue to beundertaken, despitehigh rates of failure

$\ddot{y}$ Because pursuit of 'the organization' is aligned with the prevailing view

$\ddot{y} \quad$ Because the prevailing view is, for the undertaking manager, thelow-risk view

$\ddot{y} \quad$ Because the RFP's and the proposals and project plans given in response adhere to the accepted language of the prevailing view, i.e. rational, modernist discourse

v Since this conception of 'the organization' is closely aligned with the prevailing view, consequences of failure for the undertaking manager are low, as each failed initiative blends quietly into the next

$v$ If the failure of a particular initiative does become highly publicized, client dissatisfaction often targets 'poor implementation,' but the possibility of realizing 'the organization' remains unchallenged

v In other words, client dissatisfaction with the failed change initiative is usually judged to be the result of "doing things wrong," but seldom if ever "doing the wrong things"

v If the failure of a particular initiative does become highly publicized, clients al ways have the consultants to blame, blame which the consultants usually accept, considering the role of scapegoat to 'come with the territory'

v Because consultants continue to propose, and clients continue to accept, one change initiative after another, management scholars accuse both clients and consultants of propagating managerial 'fads and fashions'

v The successive change initiatives of clients and consultants- termed 'fads and fashions' by management scholars- are more attempts by the former to realize an unrealizable vision of 'the organization' as a predictable, controllable entity

$v$ Research on 'fads and fashions' are a red herring for critical academic research, hastening its own irrelevancy

v The conception of 'the organization' as a predictable, controllable entity is not simply an aberration, but results from the influence of earlier academic-authored organizational studies

v Reconceptualizations of 'organization,' 'organizational change,' and the consulting process itself, arelong overdue 
Apparently, I also had enough free time on my hands to write a short play.

\section{The Ivory Tower}

In the 1930's, as the industrial revolution continued to bring about unprecedented levels of change, a wise group of scholars got together to discuss how people and society might get along during the new and seemingly ever-changing circumstances. The scholars recorded their ideas into a book which they entitled 'Organizing.' The book was very well received, and was adopted by a new group of 'management scholars' as well. Soon, however, the management scholars became dissatisfied with the level of scientific rigor of the original book, and so began a revision. They borrowed metaphors and methods from the natural sciences, trimmed away the fuzzy temporal bits, and described what an 'organization' was, and how to manage one. They renamed the book 'Organization,' and used it as the basis for their teaching of future managers. W ith the management of the organization now on a firm scientific foundation, they retired to theivory tow er.

W hile in the tower, the management scholars developed a number of important new ideas, and made several revisions and improvements to the book, and especially to the chapters describing 'an organization' as a static, predictable and controllable entity. In the new edition, they stressed emergence, the non-predictability of change, and the need for managers to be flexible and creative, thus, ironically enough, restoring many of the chapters that had been deleted from the original book on organizing.

One day, some fifty years later, came a knock at the tow er door. It was a representative from the $U$ niversity Chancellor's office, bearing an important and urgent message about the " $\mathrm{N} \mathrm{ew}$ $3 \mathrm{R}$ 's" of education-Rankings, R elevance and R evenue - and requesting them to take action. The management scholars picked up a few copies of their revised book, and immediately set off to meet with the managers and offer some advice - for a small fee, of course - on how the management of organizations might be improved.

W hen they arrived, they found the managers in heated discussion with a group of welldressed men who called themselves 'management consultants.' The discussion appeared to be over the quality of the services being provided by the consultants. The management scholars asked the managers "W hy are you so unhappy with the services these management consultants provide?"

"Because they make exaggerated promises and never deliver" answ ered the managers.

"Our work is fine," countered the management consultants. "The problem is with your implementation. And besides, any exaggerated promises we make are only in response to the outrageous requests contained in your RFP."

"Just what kind of promises are we talking about?" asked themanagement scholars. 


\section{The Ivory Tow er (continued)}

"Promises to guarantee the outcomes of organizational change initiatives," responded the managers.

"That's ridiculous!" said themanagement scholars.

"It is?" asked themanagement consultants in surprise.

"Of course!" answered the management scholars. "An 'organization' is not some static 'thing' whose behavior can simply be predicted and controlled."

"It isn't?" asked themanagers in surprise.

"Of course not!" said the management scholars. "W hat other promises have they been making?"

"That they would transfer their knowledge to us," answ ered the managers.

"Rubbish," scoffed the management scholars. "Knowledge can't just be packaged up and 'transferred' to someone, like handing over a loaf of bread."

"It can't?" asked themanagers and the management consultants.

"Of course not!" said the management scholars. "From where did you get all these strange ideas in the first place?"

The managers and management consultants looked first to one another, and then-each holding up a well-worn copy of the original book Organization- said to the management scholars: "From you!" 


\section{Tilting at [expert consulting] windmills?}

The simple notion of treating separately the official accounts of consulting practice and the activities of practicing consulting explained a lot for me. It also, however, raised the alarming implication that my earlier critique of expert consulting was a rather quixotic campaign-that is to say, my critique was directed at the accounts of an expert approach to consulting, rather than at the activities of consulting practice. Misery loves company, however, and I was relieved to see that much of the critical research as well, had similarly directed its critique at official accounts, rather than at consulting activities themselves. Here, for example, again is the quote I used earlier from Chris Henry:

"Scratch any account of creating and managing change and the idea that change is a three-stage process . . . will not be far below the surface" (Henry, 1996, referenced in Weick et al., 1999, emphasis added).

Notice that Henry refers to the accounts of managing change, and not to the activities or to practicing itself. ${ }^{79},{ }^{80}$ In their introduction to a special issue of the journal Organization, focused on organizational change and change management, Andrew Sturdy and Christopher Grey (2003) write of the "pious nostrums and simplistic recipes that are the stock in trade of organizational change management" and they are critical of "the most enduring of $\mathrm{OCM}^{81}$ metaphors, that of unfreeze-change-refreeze (Lewin, 1951; see Kanter et al., 1992)" appearing so often in OCM "writings" and "articles" (Sturdy et al., 2003, p. 653-660). ${ }^{82}$ We agree that simplistic recipes for organizational change management are prevalent in 'writings' and 'articles' (and also in consulting proposals and plans and final reports), but, at least in my experience, much less prevalent in consulting practice. We agree that Lewin's model of

\footnotetext{
${ }^{79}$ The distinction I am trying to make here between 'accounts' and 'activities' is a tricky one, because as soon as I put pen to paper, to describe activities, I too, am then creating an 'account.' It's no longer 'consulting activities,' but a different performance- one of 'writing about consulting activities.' So I should say that by 'accounts' I am referring to, for example, written proposals and project plans. And by 'activities,' I am referring to the doing of practicing, which is not normally 'written up' during practicing, but which in order to include it here in this written dissertation, does indeed, also become an 'account.'

${ }^{80}$ It's also interesting to not how these same quotes return again in my own thesis, but serve very different purposes. Earlier, I used the quote from Henry to 'prove' that Lewin's 3-step change method was predominant. Here, however, I use the very same quote to 'show' a failure by researchers to make a distinction between accounts of practice, and practice. Writing to 'prove' one point or another is a dirty business.

${ }^{81}$ 'Organizational Change Management'

82 'Pious nostrums' indeed-precisely what one needs when preaching to the [critical academic] choir, as do these and similar articles that neither clients, consultants, nor anyone outside of academia, for that matter, ever read.
} 
planned change remains prevalent, even predominant in the official accounts of change management practice, but certainly did not experience this to be the case in practice.

Even though I now saw my earlier critique as somewhat misdirected, I nevertheless, optimistically, thought the two formed a very nice package: 1) a critique of outdated modernistic accounts of expert consulting, paired with 2) a processual view to explain what was really going on in practice. And I was more convinced than ever by this point that a processual view not only helped to explain what was going on in practice, but more importantly, that it was indeed the promising foundation of an alternative, 'processual approach' to consulting. Developing that alternative, so I thought, would simply be a matter of searching for and perhaps developing from scratch, tools that aligned with this processual view. Looking back on this time, I can also see that my intent to adopt a non-foundational view, i.e. not be concerned with proving 'what is really going on in practice,' had slipped far into the background. There was, however, one more nagging question that had to be answered before I could get on with the business of rounding out my new processual approach.

\section{'Duped or dopes' vs. 'sham proposals'—are we making any progress here?}

Earlier, I wrote that critical consulting research had steered itself into a dead-end by posing questions which led to untenable conclusions. In order to accept that consulting knowledge was flawed, as the story went, we also needed to believe that clients were either dopes for continuing to pay for it, or that they had been duped. And since we weren't willing to believe either of these, then the original premise-consulting knowledge is flawed-was (more or less) toppled as well. So the nagging question that had to be dealt with here was: was I steering the thesis into a similar dead end by saying that the processual view explained what was really going on in practice, despite the very different official accounts? In other words, were we willing to believe that clients and consultants were indeed willing to work in one fashion, i.e. messy, emergent, processual, even as the official accounts, which they had authored and signed their names to, painted a very different picture of how consulting was practiced, i.e. methodologically and linear? Were they willing, in other words, to work under false pretenses and sham proposals and plans? And was this explanation that consulting could continue on, simply because people looked the other way when it came to the wide disparity between official and unofficial accounts-was this explanation any more plausible than the implication raised earlier by the critical research, namely that clients willingly continued to 
purchase 'flawed knowledge'? Was I making any progress, or was I steering the thesis into a dead end? To clarify, the nagging question on the table was this: Was it plausible that clients and consultants would continue to describe one formal, structured set of activities in the official accounts, while acting out a very different set of activities, in practice?

Keith Grint (1994), Nils Brunsson (1985; 1989; Brunsson et al., 1993), and Steve Barley and Gideon Kunda (1992) said 'yes.' And based on my own experiences, I agreed. Brunsson compares the 'formal' and 'informal' organizations, and writes that day-to-day work gets accomplished by conflicting and overlapping activities that, if compared to the 'formal' accounts, would be considered irrational. While so much of the critical research was preoccupied with the 'mystery' of consulting's continued success, Grint, in what I for one consider to be a very insightful paper, wrote that widespread business initiatives, such as consultant-led re-engineering efforts, swept across the US and UK in the 1980s less because the projects were so successful (which many or even most were not) and more because their business rhetoric was aligned with the zeitgeist of the day. He refers to the persuasiveness and power of this alignment as 'social resonance.' Re-engineering, writes Grint, with its calls for 'blowing up this' and 'transforming that'-i.e. the call to fundamentally rethink one's business - came in response to Japanese companies, whose success in North American and European markets led to a questioning of the fundamentals of the Anglo-Saxon approach to business. Steve Barley and Gideon Kunda (1992), argues similarly that 'human resources,' something we take for granted as a 'normal' or 'naturally occurring' component of business life, started out as a set of temporary worker welfare programs following the Great Depression. Whether re-engineering in the 1980s, or worker welfare programs during the Great Depression-these and other initiatives became widespread not because the activities they engaged in were especially successful, but because the official accounts of those activities resonated strongly with the then-current social conditions. ${ }^{83}$

Their conclusion, like mine reached above-that modernist management necessitates consulting — was that the zeitgeist of management was (is) essentially modernist, and that clients, consultants, many critical scholars and me as well, were indeed playing roles in that modernist game. Similarly, going against or outside of it, is to go against the fundamentals,

\footnotetext{
${ }^{83}$ Mimesis, or the copying of practices, is another explanation offered to explain the spread of consultancy-led initiatives. See also DiMaggio and Powell (1983), Powell and DiMaggio (1998), Ernst and Kieser (2002), and Sturdy (2004).
} 
and put oneself at risk. Earlier, borrowing from Garfinkel (1959) and Gergen (1999), we said that the social veneer was thin, and easily stripped away by something as trivial as a nonsensical reply to a passerby in the hallway. Similarly, going against the unquestioned fundamentals of modernist management-i.e. that organizations are manageable, knowledge transferable, causality definitively researchable-is heretical, or crazy, or both. Going with the fundamentals, however, is safe. As the well-known phrase goes: 'No one gets fired for hiring McKinsey. ${ }^{, 84}$

Thus, the conclusion we reached at that time was: yes, clients and consultants were willing to continue to produce and sign their name to 'official accounts' that bore little resemblance to practice, because 1) consulting proposals responded to and resonated with the modernistinfluenced requests of management; 2) the activities of practicing could nevertheless go on, pragmatically and without the need for detailed documentation; 3) for many, just as I once thought, and as Brunsson and Olsen wrote, the difference between official and unofficial accounts is 'just the way it is with organizations;' 4) for those who did see (or construct, as I now have) this difference, the benefits of pointing it out were outweighed by the risks of doing so (e.g. being ostracized), especially if one did not have a rich enough vocabulary (or confidence) for making the case for an alternative.

\section{Reflection}

I owe you a word of thanks for following me through my account of this period of "muddling through' which is almost—but not quite!-complete. To summarize the journey thus far: I began at an impasse, without a clear direction forward. The breakthrough came with the simple recognition that other narratives were possible, and that neither scholars, nor anyone for that matter, had exclusive access to, nor control over the story of 'how consulting really is' (or, for that matter, how organizations, or knowledge or relationships 'really are'). I thus embraced a non-foundational view, and gained momentum with developing one such alternative consulting narrative when I (truth be told) more or less stumbled onto the idea of knowing, which in turn led to the notion of a 'processual view.' A processual view, i.e. the notions of organizing, of knowing, of relating, were attractive reconceptualizations or reconstructions of their 'non-processual' (i.e. entitive) counterparts—organization, knowledge,

\footnotetext{
${ }^{84}$ This phrase is doubly true-both in the commonly used sense-that McKinsey is the firm that can be hired, and if the project fails, the manager can't be faulted because they have hired 'the best' — and also in another sense: that it is safest to go with the firm whose recommendation will conform closest to the traditional fundamentals of modernist management.
} 
relationships-counterparts which together had formed something of the essential core or foundation - and problematically so-of an expert approach. The momentum gained, and the attraction of a processual view, however, proved strong enough that my intent to embrace a non-foundational view quickly faded, and I once again reverted back to old familiar habits and storying the processual view as explaining 'what is really going on in practice,' and as being the foundation of an alternative, processual approach to consulting, one capable of addressing the limitations of an expert approach, as outlined early on in the thesis.

'With a firm foundation now in place,' I thought at the time, 'I can finally get this research onto a solid footing. I can develop proper problem statements, research questions, and maybe, perchance, even proper methods? Now I can stop avoiding Daniel,' I thought, thinking of my colleague down the hall who was always asking detailed and nosey questions about my 'research methods.' I formulated a problem statement, one that tried to highlight the need for a separate treatment of official accounts of consulting practice, from the messy activities of practicing consulting. It was something like this:

'The practice of consulting, once heavily influenced by the modernist notion of a uniquely-qualified expert, applying a standardized body of knowledge for the resolution of client problems, has moved on, while the official accounts of consulting practice, have not. These official accounts, therefore, have little resemblance to, or usefulness for, the contemporary day-to-day activities of the practicing of consulting."

The remedy for this problem, of course, was that we needed an alternative approach to consulting, one that conformed much more closely to what was really going on in practice, and the processual view provided precisely that. With a foundation of an alternative approach in place, I could begin 'rounding it out,' 'adding some meat to the bones.' For the first time, I had a line of sight to the completion of the dissertation, and hope that it might be a doable exercise after all. That was when I found out that Greg had apparently traded notes with one of my PhD supervisors, Dian Marie, or at least they both had a knack for posing questions that were simple to ask, yet difficult to answer.

\section{Difficult questions}

I shared the newly formulated problem statement with Dian Marie, and calmly waited for her confirmation that this indeed was a good set-up for the thesis. But what came back was not a 
confirmation, but a question— two questions, in fact. The first was: 'You say the activities of practicing consulting have moved on and no longer conform to modernist ideals-did they ever?' And the second question was: 'Since when have you reverted back to the business of proving consulting practice to be one way or another? You're taking prisoners here, and I don't think you need to.'

As to the first question, I really had no idea. On reflection, did I think that people had once acted in a more modernistic way than they did today? Thinking back to my own review of the history of the professions (and of consulting), I would say 'no,' that in these cases, or at least in the accounts of these professions that I had relied on (e.g. Abbott, 1988; Allmendinger, 2000; Alvesson, 1995; Freidson, 1970a; Hall, 1989; Schön, 1983), and with my own experiences as well, practicing had consistently been storied not as formal action but more as 'muddling through.' And 'rationalization' was also consistently, and in Weberian fashion, an activity done post hoc. As for the second question, I was caught red-handed. I had indeed 'reverted back' to an earlier worldview, to positivistic methods, and to building an argument in support of a foundational view of how consulting practice really was, or was not. There was not, and still is not, I believe, anything 'wrong' with basing an alternative approach on a processual view. The problem, as I see it now, had to do with putting this processual view forward as the totalizing account of what was really happening in practice, with the implication that there were no other consulting narratives-precisely the position that expert consultants and many of the critical scholars as well had tried to establish for themselves!

\section{Yet another impasse?}

Now I was indeed in a difficult situation, one that had all the makings of yet another impasse. Should I take a more conservative and traditional approach for the thesis, eliminate the 'reflections,' offer a straight-up critique of an expert approach, and a processual view as a new and modern replacement for outdated ideals_a clean 'out with bad, in with the good' strategy? Or, should I return to the drawing board? Did I really have the energy and time for that?

Or perhaps there was another way? Isn't there always? Hadn't I learned this lesson by now? Of course there was/is. And it is simply this: I will offer a processual approach to consulting, enabled by pragmatism and relational constructionism, as one alternative proposal for how we might do consulting differently. In the thesis, I will state it loud and clear, that it is indeed a 
construction, a proposal, with no promise nor claim to accuracy or generalizability. Metanarratives can indeed be a totalizing device for bringing about closure, but they don't necessarily have to be so, or at least, the narratives and the purposes that motivate them can be made more transparent to the reader. Otherwise, this entire story would become one of 'setting aside the official accounts to uncover what's really going on. ${ }^{, 85}$

Once again, then, the way forward had turned out to be embracing a pragmatic nonfoundational path. I didn't have to 'prove' it was the path. I could simply explore what a pragmatic, processual view could usefully offer for the practicing of consulting. This sounded good. John Shotter (1995) writes similarly that "we must give up our search for any overall, grand theory, and think instead of a conceptual repertoire or toolbag of analytic resources" (p. 125). Giving up grand theory and filling up a tool bag sounded good, too.

Settling on this path, then, for the remainder of the thesis-exploring and developing a processual approach to business consulting, motivated by the ideas of pragmatism and relational constructionism-only became clear to me during the writing of this transitioning chapter, which was truly was a period of muddling through. Comparatively, the critique of an expert approach in Chapter 1 was easy. The doubts which all that criticism eventually raised, however, came home to roost here in Chapter 2. Something else that has become clear is that I will probably always act according to at least two discernable world views, one which more or less conforms to what is called 'modernist,' and another that conforms to what is called 'postmodernist.' There is no clean break from one to another. I hope I have achieved not a just a different world view, but one that is expanded, making use of older and newer (for me) ideas, and staying open for still newer ones as they are co-created by action and experience with others. This, then, is what acting on a non-foundational view means for me-acting as one best sees fit, in particular situations, for achieving explicit but ever-changing purposes, and regardless of whether those actions-if we cared about the matter enough to stop and 'classify' them, which we don't-conform to what we call modernism, post-modernism, pragmatism, constructionism, or whateverism.

\footnotetext{
${ }^{85}$ This was Rorty's point about how the empiricists tried to go a level deeper than the Continental rationalists, and 'ground' their claims with evidence, and how the phenomenologists and experientialists then tried to go a level deeper than the empiricists, and ground their claims on experience and even physiological sensation. This was also how Wittgenstein, Heidegger and Dewey tried in their early years to make philosophy foundational, only to renounce that later. By treating a 'processual view' as the foundation for an alternative approach to consulting, I would be doing precisely as they had done initially, and warned against in their later work.
} 
In the next two chapters, I will go into greater depth and detail on the processual approach, and in particular on the activities of organizing, relating and knowing. But 'a processual approach, motivated and enabled the ideas of pragmatism and relational constructionist ideas' is quite a mouthful, so I should clarify the three terms, each of which adds something important to the mix. By 'processual' I want to acknowledge moving, and the adopting of the assumption that all is always and already changing. I want to say that 'moving' is somehow the 'context' for practicing, but I'm sure that will once again get me into some deeper philosophical waters I cannot navigate, so I'd best leave that alone. By 'pragmatic' I want to acknowledge intentional acting, according to the meanings and purposes, and that those meanings and purposes are always being 'relationally constructed.' A 'processual approach' to consulting, then, means: firstly to be doing, and to be doing purposefully and pragmatically, according to the meanings and purposes we are relationally co-constructing. Later, and ultimately, for purposes of clarity, I will refer to this processual approach as "co-constructive consulting,' because I think the words 'co-constructive,' at least for purposes of the title, are more accessible and more meaningful to more people than the word 'processual.'

Lastly, before moving on to the development of a processual approach to consulting, it seems as if I've found the time to write an Act II of The Ivory Tower. With sincere apologies to playwrights everywhere: 


\section{The Ivory Tower, Act 11}

The scene: $M$ anagers and management consultants have just told the management scholars that it was from their book Organization that they, the managers and the management consultants, first got the idea of 'organization' as a predictable/controllable entity. After an awkward silence, the management scholars respond:

"W ell, that book is terribly outdated. Actually, that was precisely the reason for our visitw e've cometo discuss 're education.' N ow if you'll kindly tak e a seat we can get started."

'"Reeducation'"? asked the managers and the management consultants, in unison, and somewhat incredulously.

"Yes, reeducation," said the management scholars, "because that book is terribly outdated, and only serves to strengthen the reification of organization. N ow if you'll kindly take a seat we can get started."

"W ait, it strengthens the what of organization?" asked the managers and the management consultants, still standing. "In English, please."

"The 'ree uh-fuh-kay-shun' of organization" said the management scholars, slowly. "It means that over time, you begin to assign a tangible, concrete reality to concepts, like 'organization,' which aren't really tangible at all. For example, other than, say, the building and some documents, you can't reach out and touch 'the organization.' So, we would say the work of 'organizing' has been reified as 'organization.' N ow if you'll kindly take a seat we can get started."

"That makes sense," said the managers and the management consultants. "But if organizations are not what wethink they are, then what are they?"

"Good question!" said the management scholars. "They are quasi-stable, locally situated, emerging and collective meaning constructions."

"There he goes again," said the management consultants, rolling their eyes. "In English, please."

"Okay," began the management scholars, "let's see .... Alright, imagine you and a few friends go camping. You find a nice, flat, grass-covered space, one that's sunny, and near to both the forest and also to the river-"

"You mean a meadow ?" ask ed the managers.

"Okay, yes, a meadow" said the management scholars. "So you find a nice meadow, and you make camp. Some go the river to fetch fresh water; others go into the forest to gather firew ood. At first there's a bit of searching around and some confusion, as people familiarize themselves with their new campsite. But after a day or so, everyone settles into their various routines, and some visible lines begin to appear in the grass, showing the various pathways whereby people go ab out their w ork."

"Okay. So what?" ask ed themanagement consultants, exchanging glances with one another 


\section{The Ivory Tow er, Act 11}

and checking their expensive watches for thetime.

"No need to be testy," responded the management scholars. "So let's say that after having spent a few enjoyable days, the campers are now ready to break camp and return home. One of the campers, the one who organized the trip, makes a few detailed sketches of all the now well-worn pathways of their campsite, which turned out to be so well organized, that he hoped to use it as a kind of template for the next timethey went camping."

"Later that summer," they continued, "on the next camping trip, he brought along the sketches, but soon found out they weren't so useful for the new campsite. W hat looked like just a small difference in the way the river curved turned out to make a big difference in the way things needed to be laid out; firew ood wasn't as plentiful, so they needed trails heading off to three different locations, instead of just one. Eventually, he had to abandon the sketches altogether, and- "

"Sorry to interrupt," interrupted the management consultants, "but I really can't see where this is all going," they said, checking their various e-mail/phone/message gadgets.

"W here it's going, is that you can't just take the design from one campsite, and hope to 'transfer' it successfully to another," responded the management scholars confidently. "Good campsites aren't designed; instead they do what we call 'ee-merge,"' they said slowly, drawing out each syllable. "They develop over time. A 'camp-site' is the 'ree-sult' of 'camp-ing,' you see?" ask ed the management scholars.

"OK, that makes sense, but I have to say," countered the management consultants, "who would expect that you'd ever be able to do that successfully - I mean, successfully transfer a design from one campsite to an other?"

"W ell that," responded the management scholars, smiling, "is precisely what you do each time you do one of these so-called 'org design' jobs we've read about, when you 'design' an organization, and then make the work conform to the design, instead of the other way around.

"No wonder these projects never work out!" whispered one management consultant to the other management consultant.

"And that's why those jobs are so difficult to pull off," said the management scholars, then adding quietly, to the management consultants, "Say, um ... just out of curiosity, how much do you make on average for one of those jobs, anyway?"

"It's small potatoes," whispered the management consultants. "W hat it leads to- that's where the money is." Then openly, to everyone, they added: "Anyway, that 'emergence' idea of yours is a good one. Does anyone else know about this?" asked the management consultants, now turning off their e-mail/phone/message gadgets.

"Some, but not a lot, and not even a lot of us management scholars," said the management scholars. 


\section{The Ivory Tower, Act 11}

"So you guys are from some elite group of management scholars, then?" asked the management consultants, showing more interest.

"Yes," replied the management scholars. "W e're postmodernists."

"Postmortemists?" ask ed the managers and management consultants.

“N 0, no, 'post ... modern ... ists,"' said the management scholars slowly.

"Interesting," said the managers. "So, what's next?"

"W hen?" ask ed the management scholars.

"W ell," began the management consultants, "you showed us this error we'd been making about organizations, and treating them as predictable and controllable entities, and that they aren't really organizations, but-what did you call them again?"

"Quasi-stable, locally situated, emerging and collective meaning constructions," repeated the management scholars.

"Right," said the management consultants. "So if that's what organizations are, then what should we be doing differently? What should we be doing, as management consultants, to help our clients?"

"Sorry, that's not our line of work," said the management scholars.

"W hat do you mean?" asked themanagers and themanagement consultants.

"W e aren't interested in improving your work, just critiquing it," said the management scholars.

"Gee, that's not very helpful" said themanagers and the management consultants.

"But we gave you some good ideas, right?" the management scholars reminded them.

"Yeah, I guess so, still .... I I know, what if we all worked on it together?" asked the management consultants.

"W orked on what together?" asked themanagement scholars.

"You know," said the management consultants, "research to come up with tools and ways of working if organizations are the quasi-stable, locally situated emerging and collective meaning constructions you say they are."

"W ow," said the management scholars, "you catch on fast."

"Yeah, we're pretty good talkers," agreed the management consultants. 


\section{The Ivory Tower, Act 11}

"And we're pretty good writers," added the management scholars. "This could be a great team!" said themanagement scholars, shaking hands with themanagement consultants.

"W ait a minute," asked the managers, "where's the money to pay for all this research going to comefrom?"

The management scholars and the management consultants looked first to one another, and then - each holding up a fresh copy of the book Organizing - said to themanagers: "From you!" 
PDF created with pdfFactory trial version www.pdffactory.com 


\section{Chapter 3: Organizing and relating}

\section{Introduction}

In Chapter 1, we focused on a critique of an expert approach to business consulting. More specifically, we argued there that certain key assumptions of this approach, related to organizations, knowledge and professional relationships, were influenced by outdated modernist ideals, and had proven to be problematic for consulting practice, just as they had for other professions and professionals. The problematic assumptions included the treatment of an organization as a predictable, controllable entity; the treatment of knowledge as a transferable asset, and the treatment of the client-consultant relationship as a conduit for exchange, characterized by the intentional maintaining of a 'critical distance' between discrete, separate and self-contained individuals. We concluded that a reconceptualization of these assumptions was long overdue, but reached an impasse due to a lack of clear ideas as to what alternatives might be, or how to go about developing them. In Chapter 2, we introduced a possible reconceptualization or re-construction of these assumptions, according to a 'processual view,' proposing that these re-constructions, along with the motivating influences of pragmatism and relational constructionism, could constitute a potentially useful and alternative 'processual approach' to consulting. In the next two chapters, we want to explore and further develop this processual approach, and in particular the processual constructions of 'organizing' and 'relating,' (in this chapter) and 'knowing' (in Chapter 4). To begin, we present a sketch of a processual approach to consulting compared to, for purposes of clarification, a more traditional expert approach.

\section{What do we mean by a 'processual approach' to business consulting?}

Perhaps the single most important differentiating idea, between a more traditional expert approach to consulting and the processual approach we seek to further develop here, has to do with motion, or better yet, 'moving.' With an expert approach, the default world view is one of 'things at rest.' With a processual approach, the default world view is more simply 'moving.' We do not mean 'things moving,' because this implies there are permanent, discretely bounded, inert (i.e. non-constructed, i.e. Kantian) 'things' which may be set into motion, things that are themselves otherwise immune from changing. With a processual approach, we may speak of things-an 'organization,' for example-for purposes of convenience (as did Barnard, 1938), but the underlying assumption is that this (or any) 'thing' 
of which we can speak, is impermanent, and is a construction, and that the borders (themselves constructions) we use to demarcate what is, or what is not 'the organization' (or what is inside or outside of the organization) are also impermanent and changing.

To bring this closer to the practicing of consulting, an expert approach focuses on things, like knowledge, and the possession of them. Things are considered to have attributes, characteristics. Some knowledge, for example, is considered to have the attribute of being 'sticky,' that is, not easily transferred. Things are said to exist in static states, as in the frequently used phrasing of the 'current state' or 'future state' of organizations, for example. Stability is considered the norm, and often the goal, while movement is considered the exception, and often risky and to be avoided. Practice involves manipulating things from one state to another, toward predicted and controlled outcomes, or alternative states. Causality is assumed to be known, or at least knowable, and actions are taken 'because of' their correspondence to, or their alignment with, reality.

A processual approach, in contrast, focuses less on possessions, and more on performing (although, a focus on possessions or things-that are considered to be impermanent constructions-could also be adopted). Changing is considered the norm, and stability an impermanent construction. To go further, we need to bring in the motivating ideas of pragmatism, and relational constructionism. Practicing, according to a processual approach means, firstly, acting. More specifically, it means acting pragmatically, in order to achieve, or move closer to achieving purposes, that are as explicit as we can make them, and relationally constructed. Although less important, causality is assumed to be (and if need be) 'constructible,' and actions are taken less 'because of,' and more 'in order to' achieve or move closer to achieving constructed purpose(s). ${ }^{55}$ At least some of the energy spent on predicting outcomes is re-directed to producing (constructed) outcomes. A processual approach can make use of the tools and analytical techniques of an expert approach, not as a way of determining a final truth or establishing causality, but as tools or techniques used in the service of achieving constructed purpose(s)— purposes which are also subject to change, or ongoing re-construction.

\footnotetext{
5555 These 'in order to' future- and purpose-oriented motives for action are of central importance for pragmatism, and also the philosophy of Alfred Schutz (1970, p. 129), Martin Heidegger and others.
} 


\section{Processual constructions: 'organizing,' 'knowing,' and 'relating'}

To further develop the processual approach, we now turn to what we can call 'processual constructions' (or 're-constructions') of certain assumptions of an expert approach, related to organizations, knowledge and relationships. With these processual constructionsspecifically, organizing, knowing and relating-we hope to set aside assumptions of predictability and control and also a focus on possession, and move instead 'upstream' to focus on the activities of practicing and performing; we want to move from a static 'entitive' world view (Hosking et al., 1991), towards a processual world view, and the processual approach to consulting that such a view enables. The history of these two world views'entitive' and 'processual,' or also, 'being' and 'becoming'-is a long one, traceable all the way back to the pre-Socratic origins of Western thought. And yet, the debate seems as relevant as it ever has been, particularly for our purposes of developing an alternative consulting approach. Our plan, beginning here and continuing through this chapter and the next, will be to first construct a brief historical narrative of these two world views- 'being,' and 'becoming.' We then want to explore to what extent the 'being' view can help us make sense of our current conceptions of organization, knowledge and relationships, and how a 'becoming' view can enable different conceptions that in turn, are useful for an alternative, processual approach to consulting.

\section{Being and Becoming}

The first of these two world view, the 'becoming' view, is attributed to Heraclitus (540-480 BC), a Greek philosopher of Ephesus, for whom 'everything changes.' Nothing is static or permanent, but all is continually 'becoming;' all is cyclical, with youth giving way to old age, to death, and again to birth and youth, and so on. A contrary world view, known as the 'being' view, is that 'everything stays the same,' that existence is timeless and that change is but an illusion. This view is attributed to Parmenides (520-450 BC), a Greek philosopher from Elea, from whom (through Plato) we get the idea, so prominent in Western thought, of appearance vs. reality.

Judging from the pervasive focus on 'change'-in the articles of Harvard Business Review, during the rhetoric of the recent US presidential election and in the titles of so many business books - it would be reasonable to conclude that the first of these views-'everything changes'-is predominant. And perhaps it is. But the story of these two views of the world is an old one, dating back more than two millennia. So while one view might currently be in the 
ascendancy, it would probably be a bit hasty to write off the other one just yet. Especially when we consider that 1) for much of the last two millennia, and certainly for the past 400 years or so, it has been the other view-i.e. the 'everything thing stays the same' view-that has held sway; and 2) when we take a closer look, we find that the 'everything changes' view still depends quite a bit on things that don't change. For example, if everything changes, then what is a 'thing' anyway? It seems we need to write a caveat or two, somewhere down in the fine print, that a 'thing' shall be defined as that which holds together long enough to be considered a 'thing,' but not so long that it's to be considered permanent, and therefore nonchanging. With this caveat we can say 'over time, everything changes.' This seems to resolve the contradiction, but it doesn't sound nearly as good. Worse yet, it's beginning to sound a lot more like the 'everything stays the same view' or 'being' view, a view which isn't without difficulties of its own. For example, if everything stays the same, and unless you're willing to agree with Parmenides that all change is illusory, then how can we account for motion of objects, say, an arrow flying through the air? Or, how can the runner ever catch up to the tortoise, since by the time the runner reaches the tortoise's position, the tortoise will have already, if ever so slightly, already moved on to a new position?

These and other paradoxical questions, posed by Zeno (490-430 BC), also of Elea, remained more or less unanswered until the mid-1600s, when Isaac Newton and Gottfried Leibniz proposed that the motion of arrows and other objects in flight could be handled by slicing up time into infinitesimally small increments, each of which corresponded to a particular position that a flying arrow could be said to occupy—i.e. to be at rest-at a particular instant in time. Thus the 'becoming' view - the view that everything is changing or moving or becomingbecame explainable in terms of the 'being' view, thereby further strengthening the 'being' view, and also forming the basis of our modern calculus. Yet, despite this breakthrough and all that's resulted from it, motion itself-i.e. moving, becoming, changing-remains (and remains today) mostly unaccounted for. Tsoukas and Chia (2002) refer to the work of Henri Bergson and William James, two so-called "process philosophers" who wrote of the limitations of the 'being' view, and its stop-motion way of handling movement:

Motion is normally defined as "the occupancy of serially successive points of space at serially successive instants of time" (James, 1909/1996, p. 234). Notice how such a definition fails to capture what is distinctive of motion-getting from A to B. Oddly, on this definition, motion is made up of immobilities: An object occupies this position 
now, that position later, and so on indefinitely (Bergson, 1946, p. 145). It could be argued that the more "positions" we identify in an object's movement, the better we describe its motion. But no matter how many such positions are created to represent the trajectory of an object, the fact remains that they contain no element of movement (James, 1909/1996, p. 234). As James aptly remarks, "the stages into which you analyze a change are states; the change itself goes on between them" (p. 236)" (Tsoukas et al., 2002, p. 571, emphasis in original).

But despite the convincing arguments of Bergson and James, and of Heraclitus long before them, the 'everything changes' view has been in the minority. It is the 'being' view-with its notion of the world as a collection of 'things' and 'objects,' and its focus, therefore, on describing the 'states' and 'attributes' which these things and objects have or possess-that has exerted the dominating influence over mathematics, philosophy, science, and Western society in general: from Parmenides, who wrote that all things already exist, and that our perception of them changing and 'becoming' something else is but an illusion; to Aristotle (384-322 BC) with his view of the world as a collection of things (the 'furniture of the universe') and the idea that all things are made up of still smaller (and still smaller) things, and thereby providing the basis for reductionism; to René Descartes (1596-1650), who in order to achieve a sense of certainty (i.e. stability) in an uncertain (i.e. changing) world, carved out an inner mental space where he could be certain and free from doubt, and who also, in a stroke, gave us the ability to talk about 'our minds' and about thoughts and things that 'exist in our minds,' and, more importantly, gave us a place from where we could objectively view the world 'out there,' as if we were separate from it; to Newton and Leibniz, who managed to strengthen the static 'being' view by explaining mobility as a series of closely ordered immobilities; to Immanuel Kant (1724-1824), who, echoing the appearance/reality distinction of Parmenides and the duality of Descartes, gave us the consummate 'thing-in-itself;' the idea that things exist, independent of our senses, without history, i.e. they do not 'become,' but simply and purely are.

Through the remainder of this chapter and the next, we want to apply this discussion of these two contrasting world views to organizations, relationships and to knowledge. More specifically, we want to look at how a 'being' view can help us make sense of our current construction of these as entities and also some of the difficulties we've experienced as a 
result, and finally, how a 'becoming' view allows for their reconstruction not as things or entities, but more as processes, thereby enabling a new processual approach to consulting.

\section{The being and becoming of organizations}

A preference for static 'things' and 'objects' is also evident in the prevailing conception of 'the organization.' Even though recent business and academic publications often focus on 'the increasing pace of organizational change,' their underlying conceptualization of 'the organization' as a thing, an object for study, and their approach to change-by moving the organization from a 'current state' to a 'future state,' these indicate a closer alignment with the 'being' view than with the 'becoming' view (see also Tsoukas et al., 2002).

But it wasn't always so. If, for example, and as we've discussed, we look back to the writings of Chester Barnard in the 1930's, and also the earlier writings of Max Weber, we see the focus was not on what we now call 'the organization' as a thing, but on the processes and activities of 'organizing.' Barnard adopted the term "formal organization" without forgetting it was but a useful label (i.e. construction) for the "consciously coordinated activities or forces of two or more persons" (Barnard, 1938, p. 73). Just 50 years or so after the so-called 'second industrial revolution' of the late 1800s, the idea that men and machines could be gathered together in unprecedented scale for the successful completion of coordinated work was far from a given, as it seems to be today. Rather, the cohesion provided by rules and policies of working were at best tenuous and coercive, and were recognized as such:

"But in fact, successful cooperation in or by formal organizations is the abnormal, not
the normal condition. What are observed from day to day are the successful survivors
among innumerable failures. The organizations commanding sustained attention,
almost all of which are short-lived at best, are the exceptions, not the rule" (Barnard,
1938, p. 5)

People of the late nineteenth and early twentieth centuries watched as new practices and processes emerged and grew in unplanned, unanticipated and often unacceptable ways, e.g. with the exploitation of child labor, and the polluting of the air and waterways, just as we now watch and muddle through as the connectivity of the internet affects our lives, institutions and legal frameworks in unanticipated and unprecedented ways. 
By the late 1940's and early 1950's however, as the story ${ }^{56}$ goes, the concrete walls of the organization had mostly set, and the paint upon them had dried. The coordination of man and materials was a far less novel sight than it had once been. Just as Barnard suggested earlier, it began to make sense to talk about these 'things' that seemed to be sprouting up everywhere as 'organizations.' In the post-war period, academic research of working took a decidedly theoretical turn, adopting the research methods of the hard sciences in an effort to become more rigorous. The number of scholars multiplied, ${ }^{57}$ and the business people and retired executives who had been teaching business classes were replaced by much younger career scholars ${ }^{58}$ who could do academic research and publish (Walsh et al., 2006), and the discipline 'organizational behavior' (OB) was born. Movement toward the conception of 'the organization' as a 'formal structure' (Selznick, 1948), a "living thing” (Wolf, 1958), and finally, an "entity" (Robbins, 1990) moved rapidly apace.

Once the organization is considered to be an object out there, it's perfectly reasonable for academic researchers to set about identifying, describing and categorizing the 'attributes' of successful organizations (attributes which now number in the thousands) and the 'skills' that successful workers are said to posses. When 'the organization' is conceived of as a "formal structure" or "rationally ordered instrument" (Selznick, 1948) then "it is necessary for the relations [of and between people] within the structure to be determined in such a way that individuals will be interchangeable and the organization will thus be free of dependence on personal qualities” (p. 25). 'Organizational design' also becomes a perfectly reasonable activity, and we use 'organization charts' to explain the company to outsiders, even though, at the same time, we may also believe that such charts bear little resemblance to "how the work (and the politics) really get done.'

\footnotetext{
${ }^{56}$ Lest I get ahead of myself, let me remind you, dear reader, and especially myself, that this is a story, a construction, with no claim to be an account of 'how it really is.' It is a story, told more rigorously and more eloquently elsewhere (e.g. Popper, Petersen, and Mejer, 1998; Rorty, 1979) of two different world views-one favoring change, the other stability - and of how the latter has been dominant in the West. To my retelling of that familiar story I have simply tacked on another chapter saying this: 1) the dominance of the 'being' view over the 'becoming' view is also evident in the way that we construct 'organization;' 2) given our continuing dissatisfaction with the low level of control we seem to have over 'the organization' as we have conceived of and constructed it, it seems worthwhile to begin asking questions that are different than those we've been asking for some time, questions that have pre-supposed 'the organization' to be a 'thing,' and have taken this pre-supposed organization to be the starting point for improvement efforts, to be all we have to work with; for some time we've been asking questions like: 'What are the key variables? What are the key skills and resources for organizational success and sustainability?' We propose that new and different questions may be useful, such as "How do we get along if 'the organization' turns out to be more like a set of loosely coupled processes?

${ }^{57}$ A 100-fold increase, according to James March (2007).

${ }^{58}$ Two thirds of the contributors to the first Handbook of Organizations, published in 1965, and a book that would turn out to be a landmark in organizational studies, were less than 40 years old (Walsh et al., 2006).
} 
The conception of organization-as-entity also influences (or could be argued to be largely responsible for) the notion of 'organizational change.' Because the organization is considered to be a product of intentional design, cause and effect relationships are clear, and changing the organization and controlling the outcomes of change-i.e. moving it successfully from one state to another-is a viable proposition. There is, in other words, an expectation that organizational change is 'doable' to some satisfactory degree of success.

But there's a problem: the disappointing results of our change efforts, over a period of decades, suggests that organizational change as we currently approach it is not so easily 'doable' after all. All the characteristics and all the attributes produced by research and experience never led to sustainable success, accurate predictions or control over outcomes, and we began, as we still do today, openly puzzling over the question of why organizational change is so difficult - a question that would have appeared non-sensical less than 75 years ago.

But here, let's invoke the low success rate of organizational change in a different way than we may be accustomed to reading about in the Harvard Business Review or The Journal of the Academy of Management. Let's not consider the low rate of success to be an indicator 1) that the task is especially difficult, or 2) that we lack the required skills and/or resources, or 3) that we need yet another n-step method for change, or 4) that a breakthrough in finding, at last, the key variables behind organizational success and sustainability, is just around the corner, or 5) as we mumble to ourselves while reading accounts of others' failed projects, that 'those guys are just idiots!' Perhaps there is some 'truth' to these explanations, but they're not especially useful. They've been with us for as many decades as the poor results themselves, but, like Zeno's runner, they haven't gotten us very far. They leave a lot unexplained.

Instead, let's take the poor results of organizational change as a suggestion that it might be useful to reconstruct how we think about 'organizations' in the first place. If, for example, we set the idea of 'organization' aside for the moment, adopted the 'becoming' perspective, and focused on the ever-emerging, loosely-coupled processes and activities of organizing, would such a conception help us make sense of the difficulties we've experienced with organizational change? And more importantly, will this re-storying of organization provide 
useful and alternative ways for the practicing consulting? I think the answer to both of these questions, is 'yes.'

If, for example, we are focused on the dynamic and unpredictable activities of organizing, then the low success rate of organizational change initiatives, seems less surprising. It also makes sense to me, therefore, why reification of 'organization' happens, or I should say, I can construct a story that for me at least, makes a good deal of sense, and helps us understand how we might go about avoiding a damaging (i.e. not convenient or useful) reification. People who start up companies, for example, begin with an entrepreneurial spirit, a clear purpose and a focus on the improvisational activities of 'organizing' to achieve that purpose. Over time, however, business grows, people settle into patterns, and then, begin to see that pattern itself - and not the activities from which the pattern resulted-as the 'real' and tangible 'organization,' not because they're stupid or lazy, but simply because those are the activities that have worked out, and because to continually reflect on not only 'what' we're doing but 'why' is difficult—as Barnard writes, it 'commands sustained attention;' it also requires a lot of energy, and perhaps a supple 'beginner's mind.' It makes sense that when we reify or bring about closure, it can bring a sense of stability to our organizational lives, but that too much stability, i.e. a denial of ongoing changing, can be detrimental as well, when we bring about closure prematurely or only implicitly. As Brunsson and Olsen write, what is referred to as 'organizational instability' can be the result not of 'an increasing pace of change' as is reported by the business and academic press, but rather from a suppression of change, or failure to embrace continuous change, such that pressure for change builds up over time, and is released episodically, sporadically, to a degree that ossified policies and procedures cannot accommodate. To summarize, it makes sense to me that when we take the result of the activities of 'organizing,' and reify them into 'the organization;' when we cut the organization off from the dynamic, messy history that produced 'it,' and treat 'it' like a Kantian thing-initself; when we endow it with behavior and adorn it with attributes; when we take the organization not as the result of earlier changing, but the starting point for future changes, then it makes sense to me that we don't have much hope at all of predicting with any degree of success how and in what direction this reified, vivified object is going to change. It's like trying to guide the end of a rope by pushing it, instead of pulling it. 


\section{Implications for practicing}

How would consulting practice be different, then, after the explicit adoption of the processual alternative of organizing? Or better yet, how could consulting be different? How can we story consulting differently?

\section{Acting in the 'here-and-now'}

Firstly, it seems that we could simply take 'things' less for granted, with one of the most important of those things being, of course, 'the organization.' We could shift our focus upstream, to fuller engagement with the 'here-and-now' (McNamee and Gergen, 1998) activities of organizing. We could set aside, even if temporarily, the notion that we are pursuing pre-determined means to pre-determined 'organizational outcomes,' and instead act "in the moment, as each moment unfolds" (Anderson, 2007).

\section{Constructions as 'quasi-stable' platforms for action}

The notion of 'slippage' also seems relevant (Tsoukas and Chia use this term, and also "drift" or "creep" or "spread"). By this we mean that we can usefully make constructions, like "the organization,' and allow them to 'slip' or emerge. This is how a clutch mechanism works in an automobile. It allows for control over how tightly the engine and the transmission of the car are connected. Making the connection too directly strains the metal parts (and your neck, as the car lurches forward or backward); make the connection too weak and the car will not move. The clutch allows for some engagement, yet also some amount of driver-controlled slippage, so that the car moves into motion smoothly. Similarly, in consulting practice, we can decide when to fully engage with a given construction, e.g. 'plan xyz will be effective for the organization,' and move forward, temporarily deferring further questioning of the plan. And we can also decide when to allow for some slippage, and move forward more tentatively, to see whether the current construction or direction will or will not prove useful, according to those involved. For consulting practice, this means we can continue to make formal plans, continue to specify goals and outcomes, to respond to the request of others, including coworkers, and also shareholders. It also means, however, that we can be acting in pragmatic fashion, making changes to those formal plans and goals, as necessary. If the rebuttal to this is that large global organizations (i.e. the ones that commission most of the management consulting work) are not so simple, and that their scale and complexity demands thorough and concrete planning before any action is taken, then the rebuttal to that claim is this: the scale and complexity that drive the assumed need for more planning and more analysis, are the very 
same scale and complexity that makes the assumed controllability over outcomes an even more far-fetched idea. This is not to say, however, that we need to necessarily forget about 'organization' altogether, but rather that it can be useful to treat it more explicitly as a reification, and not (therefore) as fixed or controllable, but "quasi-stable" (Tsoukas et al., 2002) at best.

\section{Avoiding reification of useful construction, i.e. 'holding our metaphors lightly'}

Perhaps ironically, especially useful problem constructions-i.e. constructions that provide energy, motivation, clarity and/or forward momentum for a team-have a downside as well: in my experience, the more useful they are, the harder it can be to let them go, and the more likely it is that the team will forget they're constructions, and treat them as the real-and therefore unchangeable, non-negotiable-problems out there, i.e. reify them. Or, if the team was previously stuck, and a new construction had provided momentum, they may be loathe to re-open what has already been closed for further debate. The analogy that comes to mind is that of being out to sea in a small boat, bound for a very small and therefore difficult-to-find island. Hitting upon a particularly exciting problem construction with an engaged project team is like finding a strong ocean current moving generally in the direction of the island. This current, like a useful problem construction, can be a lifesaver, but once you've given in to it, it can also be difficult to move away from. And if the vector of the current isn't right, it can take you past the island and right back out to sea again. In my experience, effective business consultants can make use of tools and particular problem constructions and particular patterns of working for as long as they're useful, but no longer. They can put aside constructions without becoming too attached to them. They can "hold their metaphors lightly" as Hosking and Bass (2002) write.

\section{Paying attention to what we need to construct (or need not construct)}

And then there's another question, one so obvious that often overlook it: do we, for consulting practice, need the notion of 'organization'? How does that enter into day-to-day practice? I am reminded here of the discussion in Chapter 2. She said: 'Since when have you reverted back to the business of proving consulting practice to be one way or another? You're taking prisoners here, and I don't think you need to.' This is about paying attention to our constructions-both what we construct, because it is helpful and relevant-and being careful to not construct, or get caught chasing after or worrying about, what we don't need to construct. Consider a project targeting, for example, profit improvement for a division of the 
organization. In such a case, what does 'of the organization' add? Do we practice any differently with or without the reification, i.e. the construction, the creation, of 'organization'? I think not. 'The organization' may figure prominently in the official accounts of practice, but not in practice, or at least, not in my experience. Why not, then, simply 'profit improvement for a division'?

At first, the question "what would/could consulting practice be if organizations were not predictable?' indeed sounds like a daunting one. But what if we simply refused to construct 'organization' in the first place? Then we would have just 'profit improvement for a division.' This seems more clear, more tangible, more pragmatic, and ultimately more measureable as well. Practice, or better yet, practicing, becomes doing, acting, until it's agreed (jointly constructed) that profit has improved, can't be improved, or until some other (constructed) problem is foregrounded, relative to concerns over profitability.

We're not out of the woods yet, obviously, because then will come a tendency to fall back once again to attempting to predict what actions will lead to improved profitability, and so on, regressively. Nevertheless, it does seem that by dropping 'of the organization' we're somehow once step closer to something more tangible, one level of abstraction down, toward the concrete. By moving from 'profitability of the organization' to simply 'profitability' we are taking one step back from focusing on what is, effectively, an attribute of a reification. Reifications, it seems, and especially what I will call 'far-off' reifications, like 'the organization,' are not the most secure pegs from which to hang attributes, nor structure our improvement efforts around. By letting go of the reification-in this example: 'organization'-then we can focus on the relatively more concrete, and the relatively more actionable notion of 'profitability,' constructed, and contested though it may be.

Continuing with this same example, if we 1) let go of 'organization,' or just don't bother constructing it in the first place, focusing instead on 'profitability;' and if we also 2) look at 'profitability' as also being a construction-with each of these moves, we're are getting farther and farther away from having our present action being guided by far-off predicted results, and closer and closer to acting 'in the moment' instead. And here, then, we should ask the question again, with renewed focus: How could consulting be different when we focus on 'organizing'? One answer, perhaps, is that we're focused on the achieving of closerin, more concrete constructed purposes, making use of closer-in "discursive objects" (Oswick, 
Keenoy, and Grant, 2000), or "temporary stabilizations of an ongoing process of organizing," as one of the interviewees for Chapter 5 phrased it. These stabilizations and constructions themselves are not the goal—they are tools or stable-enough platforms for use in achieving goals.

\section{A metaphor of organizing}

The image that I have of practicing in this way is that these temporary stabilizations or closerin constructions act like the bow of a ship, parting the waters of an onrushing stream of experience, with knowledge and experience giving strength to the bow, and with purpose giving direction to where the bow is pointed. We make initial judgments as to what is coming our way, and what may constitute an issue or problem worthy of attention, and what is inconsequential. We filter the ongoing, continuous stream of (constructed) project experiences in which we are immersed, and allow for coalescence around issues or problems we see developing and that are preventing us, or that soon may prevent us, from moving in the direction we want to be going. And we raise these issues or problems to clients and colleagues: 'Don't you think this is becoming a problem?' And clients and colleagues say 'No, I think it's okay,' or they say 'Yes, that is becoming a problem,' in which case this closer-in construction is further solidified, and we may initiate some kind of informal or more formal polling or research, depending on the importance of the problem, which in turn serves as the basis of action taken. And the closer in, and the more concrete these constructions, the more we are acting in the moment. This in turn, can lead to the question of what tools or ways or methods are available for 'acting in the moment' or 'consulting in the moment.' The good news here, I believe, is that there are many.

\section{Other tools and metaphors for organizing}

As we will discuss more fully in Chapter 4, while practicing, we could be making use of Gibson's (1977) notion of 'affordances,' to ask not only 'what's next?' but also 'what's possible from where we are now? And how shall we construct 'now' in the first place?' As we demonstrate in Chapter 5, we could take advantage of the opportunity to construct the situation in a way that is advantageous to our team, or as Weick et al. say, in a way that "serves as a springboard into action" (Weick, Sutcliffe, and Obstfeld, 2005, p. 409). For Frank Barrett (1998) and other authors we can make use of the metaphor of jazz improvisation, where the musical key and chord changes are "minimal structures that allow maximum flexibility"- they allow for improvisation, and a shared sense of location, as 
musicians mover through a tune. The organizational equivalent, writes Barrett, could be rapid prototyping:

\footnotetext{
"Rapid prototypes function like the loose framework of the song: they leave a great deal of room to depart and deviate; and yet there is enough structure there to give players enough collective confidence to play together."
}

In my experience, many if not most projects unfold and emerge as do prototypes and jazz improvisation, although, as discussed in the previous chapter, the official accounts often tell a very different story, a story of methodologically-driven activities delivering pre-determined organizational outcomes.

\section{'Organizing' as 'legitimate’ practicing}

One other important way consulting could be different is that the often messy activities of sensemaking, improvising, bricolage, a certain amount of 'trial and error,' of 'non-knowing' (Anderson and Goolishian, 1992), become acceptable and more legitimate. As discussed in Chapter 2, when I began my academic research, I believed that the messy pragmatism I had often resorted to in practice were not the kinds of activities one could speak so openly about, especially in front of clients. I assumed that once I began my research, I would find robust methods and theories to 'clean up the mess' so to speak. When I came across stories of Heraclitus and the 'becoming' view, and also academic accounts-both theoretical and empirical —of the dynamism of practicing and the improvising required to embrace it, I came to believe that my practicing methods weren't as illegitimate as I once thought they were. There was Donald Schön's (1983) classic The Reflective Practitioner: How Professionals Think in Action. There was Charles Lindblom's (1959) 'muddling through,' from where I got the title for Chapter 2. There was Julian Orr's (1996) ethnography of copier repair technicians, and the tremendous creativity and ingenuity they needed to succeed in what turns out to be (surprisingly enough for some) the very complex and unpredictable work of copier repair-work that is far more complex than any formal procedural manual can accommodate. We can look at all these as accounts of practitioners-be they clients or consultants or copier technicians - that are immersed in the ongoing activities of practicing, of organizing. Finally, with a reduced emphasis placed on proposals, plans and fixed outcomes, projects adopting the processual alternative of organizing could more closely resemble the situation already preferred by many consultants and clients alike: namely, assignments that can proceed on the 
basis of verbal agreements and handshakes-i.e. on the basis of trust-and without RFPs and proposals that are often lengthy and expensive for the consultants to produce, and for the clients to vet/review/select.

\section{A rich tradition and vocabulary to draw from}

One last word on the notion of legitimacy, or more positively, on the notion of opportunity: while a becoming view may have been toward the background (at least since the Enlightenment), the embracing of, and the "everyday practical coping" (Chia and Holt, 2006) with the here-and-now-what we are in this context speaking of as 'organizing'—has maintained an unbroken line of thought and influence from Heraclitus forward, to Michel de Montaigne, Friedrich Nietzsche, Martin Heidegger, Georg Wilhelm Friedrich Hegel, William James, John Dewey, Alfred North Whitehead, Henri Bergson, Richard Rorty, Karl Weick, Robert Cooper, Jean Lave and Etienne Wenger, Haridimos Tsoukas and Robert Chia, Ken Gergen, Dian Marie Hosking, and Nils Brunsson and Johan Olsen. For further developing the notion of organizing and a processual approach to business consulting, there is, I believe, a very rich tradition from which we can continue to draw. Although this is much more conjectural, adopting the processual alternative of organizing might even lessen the demand for ever-more new and different initiatives (initiatives often labeled as 'fads' by critical scholars), because the hope of achieving a once-and-for-all ideal 'organization' or 'organizational state' would be lessened as well. So would the number of initiatives go up or down? Perhaps one fortunate outcome would be that the question itself might cease to matter.

\section{From relationships to relating}

The second processual construction is 'relating,' the upstream, generative activities which result in the downstream notion of 'relationship.' As with 'organizing,' we want to look at how a 'being' view can help us make sense of what is perhaps the prevailing notion of 'relationship,' and how we might re-construct or re-story the client-consultant relationship as processual 'relating.'

In many ways, we have already been referring to relating throughout the thesis thus far. We began with 'helping,' which for us is a constructing (i.e. generative) relating activity. A helping hand is extended, accepted, and some degree of trust is created; a relationship is strengthened. We gave an example of an author and an editor, discussing back and forth (i.e. relating) a paper for publication. Through this back and forth relating and inter-acting (for 
this example, and for discourse in general), we said that 'relational realties' (Hosking, 2006) are constructed. In this case, it was the reality that the paper was of acceptable, publishable quality and rigor. When we relate, we create meaning. The creation and re-creation or reinstantiation of meaning happens continuously, and is usually not especially noteworthy. I use the word 'blue' in a sentence and you readily understand. One explanation is that 'blue' is readily understandable because the sky I'm pointing to 'really is, obviously blue.' Another explanation, and one which seems to make more sense if we pursue it far enough, and try to get to the bottom of it, i.e. try to isolate 'blueness,' is that the word is readily understandable because socially, culturally, we long ago agreed on what we would call 'blue' and also the notion of what 'color' is to mean, etc. Within a specific enough culture or situation, 'blue' is no longer contested. Above, we discussed a preferred situation for consultants and many clients: projects that proceed without the formalities of RFPs and proposals. In such cases, clients and consultants have been relating successfully, to the extent that they now share a cocreated or jointly-developed understanding of what the situation is, and what tasks need to be undertaken to address it, even as the need for formal documentation of those tasks, is lessened.

But, just as with 'organization' and 'knowledge,' there is significant tradition and momentum behind the more mainstream (and downstream) notion of 'relationship.' In fact, the Western tendency to reify and thingify, according to a static 'being' view of the world, may be even more pronounced here, with 'relationships,' than it is with 'organization' or 'knowledge.' Compared to 'organizing' and 'knowing,' exactly what a processual alternative to 'relationship' might be, and why one might be useful for practicing consulting, is, I believe, less immediately apparent. As I will discuss later in Chapter 6, this was also the case when discussing processual alternatives with clients and consultants-there was more 'resonance' with, and easier understanding of the ideas of 'organizing' and 'knowing' than with 'relating.' This may be because, as Ken Gergen (1999) writes, the notion of individualism, upon which the notion of 'relationship' rests, is so taken for granted and so foundational (and prized) in Western, particularly American society, that it's seldom if ever explicitly recognized, let alone questioned.

In my case, my questioning of the notion of 'the individual' began with dissatisfaction over the client-consultant relationship, which after much reading and discussing, I came to re-story as: 'the traditional, modernist-influenced professional-client relationship, characterized by 1) 
the maintenance of a critical distance, in the name of objectivity, and 2) the asymmetry of knowledge and power.' Efforts to develop an alternative led me in turn to the work of Edward Sampson (1977; 1988), who writes that people are not immune from our recent (postEnlightenment) societal tendency to 'thingify.' The result is the notion of 'the individual,' a discreet, clearly bounded 'thing'—what Sampson refers to as the 'self-contained individual.' Borrowing from Paul Heelas and Andrew Lock (1981), Sampson describes a line demarcating that which is considered 'self' and that which is considered 'other,' i.e. a 'self-other boundary.' In the West, such boundaries are clearly drawn, and are more exclusionary of others (indeed the notion of 'other' itself results from this separateness). In Asian cultures, in contrast, the self-other boundaries are less clear (i.e. more permeable), and more inclusionary of others-that is, they overlap with others, such that the notion of 'other' becomes less meaningful. A related notion is the 'locus of power and control.' In the West, power and control lies with the individual, whereas in Asian cultures, power and control are more diffuse; there are 'fields' of control. Thus, another product of the Enlightenment thinking that gave us the idea of our own, private and objective view on the world 'out there,' the individual, or so the story goes, is separate not only from the world, but from other individuals as well (and also, because of the creation of a separate 'mental'

space, separate even from our own bodies). Thus, any kind of interaction necessitates a relationship to facilitate exchange

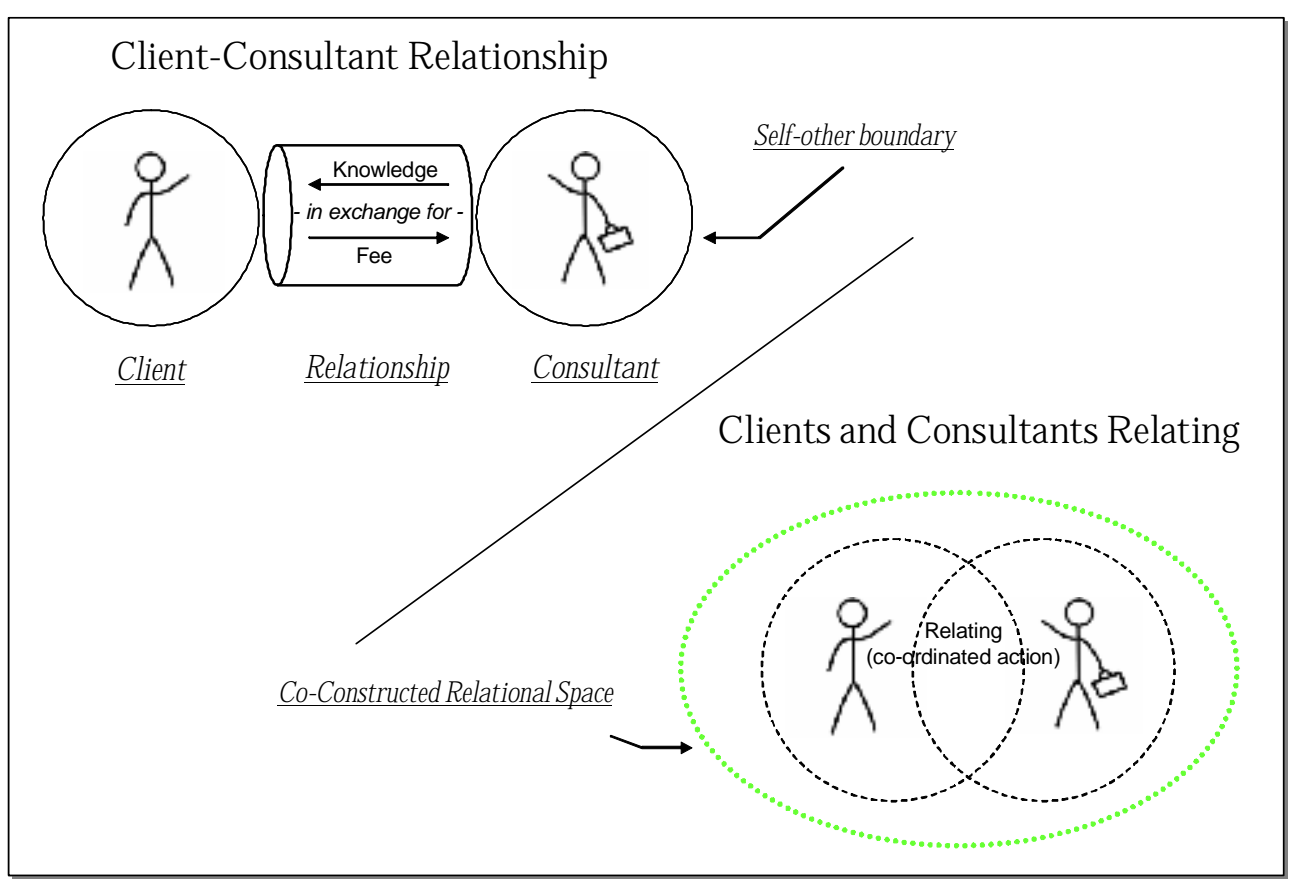

Figure 3: From relationships to relating

between separate, discrete individuals. Relationships are thus transactional and exchange oriented; a conduit for the transfer of things, including knowledge and information (see the upper half of Figure 3). The traditional Parsonian view of professionalism insisted this 'critical distance' between client and professional be maintained, explicitly for purposes of 
objectivity, and implicitly for the protection and preservation of expert power. Thus, not only does 'relating' (i.e. collaborating, innovating) remain in the background, behind 'relationship;' not only does the notion of self-contained individualism separate us from one another, but moreover, in the cases of science and the professions, we also have the culturally entrenched notions of objectivity and 'critical distance' to ensure clients and consultants remain even farther apart. As a result, relationships are not viewed as generative or collaborative, but as instrumental and exchange oriented. Coming from such a heritage, it seems something of a miracle that engaged, open-ended collaborating among clients and consultants could happen at all! A miracle, that is, if we judge according to the 'official' accounts of consulting practice, which do not include the processual vocabulary of 'relating,' 'knowing,' or 'organizing.' If, however, we look at successful, long-standing relationships, the notion of strong relationships being the result of earlier relating doesn't seem so strange, and these long-standing relationships certainly seem too strong to be based only the idea of 'exchange.' 'Exchange' seems too flimsy to serve as the basis of a relationship whereby people might collaborate-let alone co-create. A relationship relying on 'exchange' or 'transfer' seems to me self-serving, transactional, and quite unlike the relationships I enjoy with family, friends, clients and close colleagues.

The notion of self-contained individualism gave me a way of making sense of the exchangeoriented nature of the client-consultant relationship. But I still needed to develop some alternative, which in turn led to the notion of the self not as static and self-contained, but as emerging, relational, and dialogical. Borrowing from Wallace Matson and the ideas in his paper entitled 'Why Isn't the Mind-Body Problem Ancient?' (1966), we can construct a story of the origin of self-contained individualism. This is a story that demonstrates just how deeply ingrained in Western culture is the conception of 'the individual' as a discrete, separate entity, but also, how 'the individual' or 'self' might be storied differently.

\section{One account of the origin of 'the individual' and 'the self'}

This story begins with the distinction between the 'mental' and the 'physical,' and by noting that we aren't the first ones to puzzle over how to draw the line between the two- the Greeks pondered this as well, from Homer to Aristotle. Is depression, for example, simply a mental state? Or is it a physical condition? Cognitive scientists, and more recently those engaged in 'brain research' will say they now have 'conclusive evidence' showing one-to-one unambiguous correlations between certain emotions and brain activity, as measured by 
electrical impulses emitted by the brain, or by chemicals present (or absent) from the bloodstream, thus 'proving' that depression is a physical condition. Others will argue these are simply the physical results or traces of a mental condition. ${ }^{59}$ Just as we go back and forth, so too did the Greeks. But for them, the lines weren't drawn between 'mental' and 'physical' as they commonly are today, but between 'body' and 'soul.' The processes of thinking and of 'mind'—both of which the Greeks acknowledged and wrote about—were on the 'body' side (i.e. the human side), and not the 'soul' side (i.e. the god side). For man, the "soul was not truly theirs, but a gift out of the bag of eternity placed in their incompetent keeping. What was theirs was the body which weighed upon the soul with its animal flesh" (Lyons, 1978, p. 4). With the Enlightenment, however, and for Descartes and others following him, especially David Hume (1711-1776):

"The soul was seen as an unscientific instrument of Church and State to demean men. It might be identified with the mind or heart or pituitary to sway the credulous, but its function was to keep men content with the treadmill of their lives, to force them to accept the caste or Castle into which they were born, the prince who protected their worldly goods, and the priest who mediated with God for their salvation" (Lyons, 1978, p. 4).

With the Enlightenment came the ideas of self-determination and of knowledge-not received from, or mediated by the Church, but discovered on one's own, through scientific methods, and so began the replacement of the soul with the self. But the lines between the spirit and the flesh, between tangible and intangible, were drawn differently this time. With Descartes'

\footnotetext{
${ }^{59}$ And people like me, because we are easily distracted from our self-proclaimed philosophy of not arguing about what is or isn't the case, and are often unable to resist doing precisely that, drop whatever it is that we're doing and argue that 1) their 'conclusive evidence' are not independent 'findings,' but simply a matter of lights on expensive machines lighting up, just as they were designed by the researchers to do-i.e. that the machines indeed found exactly what it was they were designed to find, and failed to see all the other possible explanations that remain forever invisible to these machines, because they were, like all machines, built-for-purpose, and 2) that all the scientists' evidence, conclusive or otherwise, does nothing to alleviate the condition in the first place, which would require going out of the controlled laboratory and into the wild world where people with depression actually live, and where the grandest schemes and treatment regimens are immediately humbled by the radical indeterminacy and complexity of even the most 'straightforward' of cases. To which they would reply that their findings help decide how to go about treating people with depression; to which I would reply they are relying on the assumption of the possibility of generalizability, and that each case does not need to be handled individually, and so on, demonstrating, I believe, yet another problem - that of the misdirection of time, energy and money toward proof of what is or isn't and away from helping more directly. In what I'll call my more mature moments, I'll replace the desire to compete with the scientists for a superior explanation, with admiration and respect for their efforts and engagement in helping people who are suffering, in whatever way they best see fit to do so, and with action on my own part, in the way I best see fit.
} 
creation of a private, inner mental space, the line was no longer drawn between 'body' and 'soul,' but between 'physical' and 'mental'-with Man possessing both halves. No longer the aging vessel for an eternal soul not his own, Man was now an integrated whole, possessing both the mental and the physical, a complete, self-determining package, i.e. an individual. The upside of this new idea of self-contained individualism was self-determination, and control over one's own life; the downside was isolation-from the world 'out there,' from other people, and even isolation of our minds from our bodies, e.g. precisely the lines of debate in the 'mental vs. physical' discussion of depression discussed above. From this perspective, the conception of 'relationship' as a conduit for exchange, or some kind of bridge between now-separated individuals, seems unavoidable.

John Lyons (1978) places culmination of Enlightenment self-determination and "the invention of the self" sometime around the late 1700s, and notes the clear differences between literature before and after that time. In earlier literature, for example, we read extensive and very detailed accounts of the travels Marco Polo, but are told virtually nothing of the author himself. Only 12 years separate the publication of Samuel Johnson's Lives of the Poets (1779), and James Boswell's The Life of Samuel Johnson (1791), but the differences between them are striking. While Johnson's book is a review of work of poets between the Restoration and the 1770s, Boswell's work was a biography—itself a new literary format—of Johnson himself, complete with vulgar quotes and gossip about the personal lives of Johnson and many of his friends. It was, in short, a work that would have been (literally) unthinkable just a few years earlier. Yi-fu Tuan (1982, referenced in Sampson, 1988), notes similar developments in architecture and living space, such as the emergence of communal space being subdivided into separate rooms for individuals, and the appearance of individual knives and forks, to replace communal trenchers. ${ }^{60}$

The point of all this is to suggest the notions of 'individual' and 'self' that we take for granted today were not always so, that they can be said to have been constructed by us, and also, therefore, that such notions might be re-constructed differently by us, today. It is to suggest that, in the longer course of the history of the West, and as compared to other, e.g. Asian cultures, the recent (i.e. from the late $18^{\text {th }}$ century onward) importance placed on individualism may indeed be "peculiar," as cultural anthropologist Clifford Geertz (1973) saw

\footnotetext{
${ }^{60}$ A 'trencher' is 'a rectangular or circular flat piece of wood on which meat, or other food, is served or carved' (Random House Dictionary, 2009).
} 
it, or 'eccentric,' as historian Colin Morris (1972) saw it. It is also to suggest that the idea of 'relationship' as being an exchange-oriented conduit between these separate selves, was not always so, and to propose that with a reconstruction of self can come a reconstruction of relating and relationship as well.

\section{An alternative account of 'the self' and, therefore, of 'relationships'}

One such reconstruction is that of a relational self, or a dialogical self, one that is not selfcontained, but one whose self-other boundaries overlap with others, where the distinction between self and other becomes less distinguishable and less important in the first place, and one for whom meaning of 'self' itself, is relationally constructed (Gergen, 1994; Hermans, Kempen, and Van Loon, 1992; Hosking, 2007; Hosking et al., 1991). To clarify: a relational or dialogical self — and also our earlier use of the activity of 'relating' — does not refer simply to collaboration and creation of knowledge between two otherwise discrete (i.e. selfcontained) individuals. For example, above we wrote that the word 'blue' obtains its meaning from earlier discussions and agreement as to what would be called blue. Thus my referring to the color of the sky as "green" or "Thursday" will carry no social meaning. But the social construction of meaning is not limited to colors, or things, or organizational problems, nor is it somehow 'stopped at the border' of the individual-i.e. a self-other boundary-inside of which, or beyond which we are suddenly in a world all our own. 'Self' in other words is relationally constructed. Relatedly, Gergen et al. (2004) write of the process of thought itself as "public discourse carried out on a private site" (p. 42). Descartes' move, in contrast, and one that in retrospect seems perfectly understandable-given the motivations of Enlightenment thought to move away from meaning prescribed from 'the outside,' 'by king or by cross'-was precisely the opposite, to go inward for the construction of self. The relational self, in contrast, obtains meaning externally, i.e. socially. Or better yet, we can say that the internal/external binary is abandoned. If, for example, we write down on a piece of paper qualities that define who we are or who we aspire to be, we might write 'caring,' or 'ambitious,' etc. But caring or ambitious as compared to whom? Without prior social construction, these words carry no meaning. And, I need to take another step here, because with this example, I too have 'thingified' the self, made it an object which can be described by attributes, e.g. 'caring,' or 'ambitious.' So let me vivify and put the example into motion, into a processual perspective and rephrase as 'what are the activities I'm doing that demonstrate who I am and at the same time make me who I am?' We can also re-phrase a familiar question 'Who are you?' as 'When are you?' Here, the responses might be 'I am, when I am 
caring for others,' and 'I am when I am acting ambitiously.' Thus, from a processual perspective, 'I' am the continually emerging result of the activities I perform, with the meaning of those activities being relationally, socially defined. This is another reason I sometimes use 'we' instead of 'I.' Mostly, this is not intentional, but seems to come naturally, and my drafts are full of red marks to change 'we' to 'I' or vice versa. The 'we' is relational; it is the voice of others I've worked with coming through. ${ }^{61}$

As my supervisor reminds me, talk of 'the origins of Western thought,' etc. are deep waters, both philosophically, and psychologically, and by this point I have no doubt completely exasperated-if indeed any of them have plowed this far-philosophers, psychologists, management scholars, consultants, historians alike, but I will hazard one reflection, one metaphor, before leaving the topic of Western thought, a metaphor which no doubt has been used before elsewhere: that of a 'pendulum.' When discussing the rise of individualism during the Enlightenment, Lyons (1978) uses the metaphor of the hinge, specifically: the notion of the self is "the pin on which the hinge of consciousness turned" (p. 1). He writes, it was "the concept of self, invented in the mid-18th century which led man to view himself as an integrated self rather than a vessel of an immortal soul, thereby precipitating the revolution, romanticism, and alienation characterizing the "modern" age." (Lyons, 1978, p. 1). Motivated as it was by self-determination, and enabled by Science, Enlightenment thought, or so our stories go, pivoted decidedly away from received knowledge, and toward self-determination, and individualism. Along with that move, I want to suggest, came the loss of a collectivity, a relation to other people that had been provided by: the soul. Although the soul was not considered to be Man's own, it did nevertheless provide him some point of commonality with others. Thus, with the rise of modernism and individualism, we went from the collectively accepted notion of the soul, or God, to no collectivity, only individualistic Man. But Descartes' assumption, or so we story it in a post-Wittgenstein world, was that when we withdraw into our private mental spaces, the relationality of words and their meanings are (and can be) somehow left outside. This, for me, is the genius of Wittgenstein, to say that the words and language are not descriptive of an external reality, but inextricable from and constitutive of social reality. Thus language, at least within a culture, is a collectivity. With

\footnotetext{
${ }^{61}$ Mikhail Bakhtin, a Russian literary critic and philosopher writes of this 'polyvocality,' as exemplified in the novels of Fyodor Dostoyevsky, which are written as if by several authors, each appearing as characters in the story. We should also mention William James, who made a distinction between "I" as that which gives us our sense of continuity of self over time, and "me," which extends the narrow Cartesian notion of self to include one's body, one's family, and also the things each of call 'mine.'
} 
the Enlightenment, we could have moved from the collectivity of a soul, to a collectivity of Man, or Men, or People. But we didn't. Instead, we moved from collectivity, to noncollectivity, i.e. to individualism. And now, with relational constructionism especially, we are, I think, in the fashion of a pendulum, swinging back, toward a collectivity, but a different one than before, one provided not by the soul, but by the collective social constructions of people-including of course, for some, God.

As Rorty, Lyons and others discuss, it took some time after Descartes before the fully secularized notion of self could be openly acknowledged and written about, both for reasons of uncertainty, and also for keeping one's head firmly attached to one's shoulders, and as far away as possible from burning stakes. And so it is with me, coming from a traditional Christian upbringing, that writing the above paragraph, about a shift toward a humanconstructed, human-centered collective brings a kind of Faustian nervousness. I occasionally remind myself, for example, that whatever these giant things outside my window 'really' are, these things we have constructed as 'mountains,' they are indifferent to our human constructions of them, constructions which they have 'shrugged off.' They were there before Wittgenstein and I, and will remain long after we're both gone. Dare I admit that I'm something of a Kantian after all? These are deep waters indeed, and I'd better swim back to shore now, even if it's made of shifting sand.

\section{Implications for practicing}

Starting from this conception of a relational self, then, it doesn't make sense to now go on to talk about how relational selves relate to one another with a relationship, because relationship is already embedded in this alternative notion of self (and the notion of 'other' is diminished in the first place). It does seem to me that we can, however, continue to speak meaningfully of the closeness or richness or strength of our relatings with people, our relatings with clients or consultants. As with 'organization,' it doesn't appear that we especially need the downstream notion of 'relationship.' Similarly, as we relate, do we need to construct the roles or the identities of 'client' and 'consultant' in the first place? These identities can, and in my experience often do, result in us acting 'as a consultant' or 'as a client' instead of acting in the moment, as we see fit. As Alvesson (2001; Alvesson and Robertson, 2006) writes, the intentional construction of identity-and specifically an identity of 'elite' — is important for 
sustaining an expert approach for consultancies and individual consultants as well. ${ }^{62}$ Such identities can prevent us from acting in the here-and-now. How then, could consulting practice be different? How could our relatings be different?

While relating, clients and consultants are co-constructing meaning, problems and actions. In subsequent chapters, we will discuss additional ways whereby client and consultants can coconstruct meaning during practice, including the notion of "heedful interrelating" of Karl Weick and Karleen Roberts (1993) in Chapter 4, and Edward Hutchins' (1993) examples of how the efforts of a ship's crew members build off one another, to achieve performances that are not traceable back to the contribution of any one person. Based on their discussions and interviews with management consultants, engineering design consultants and so-called 'internal' (management) consultants, Hargadon and Bechky (2006) offer several examples of how "the locus of creative problem solving shifts, at times, from the individual to the interactions of a collective" (p. 484) in moments of "supraindividual" or "collective creativity."

\section{Constructing relational space}

As shown in the bottom half of Figure 3, the relating of clients and consultants, or coordinated action in pursuit of some purpose, can result in what we'll call an emerging and coconstructed relational space, or project space, with relationships and knowledge as byproducts. We create, act in, and thereby re-create, this relational space (Bohm, Factor, and Garrett, 1991; Senge, Kleiner, Roberts, Ross, and Smith, 1994). ${ }^{63}$ The self-other boundaries overlap and are more permeable than before.

\section{Constructing 'client,' 'consultant' and other identities (or not)}

While we need not necessarily construct the roles or identities of 'client' and 'consultant' (although that's possible and maybe even sometimes useful), we can, however, construct other identities. In my experience, constructive and healthy relating with clients results in identities that are more idiosyncratic, unique, colorful, interesting and much closer to 'who we are' and 'what we can do' as compared to simply 'client' or 'consultant.' As I discuss in Chapter 4 , an identity that emerged for me, was that of someone who could frame and re-

\footnotetext{
62 See also Gerardo Patriotta and Simona Spedale (2009) for a discussion of the construction of identity as a 'vehicle' for sensemaking.

${ }^{63}$ In Chapter 4, we will discuss a similar 'emancipatory space,' as part of a wider discussion of power.
} 
frame problems, in ways that proved useful for helping project teams gain or re-gain their momentum. When I consider the clients I worked with successfully, I don't think of them as 'clients' at all. Rather, I think of, for example, Ed, the CEO of the Japan operations of a USbased medical device manufacturer, as something of an 'integrator extraordinaire' - an integrator of Japanese and American work practices, of languages, of head office and local office policies. Yet these identities can and do change from one situation to another, and from one project to another. What kinds of identities and roles are you co-creating together with friends, clients, consultants and colleagues?

One important clarification here is that if and when we do construct the identity of 'client' (and we are speaking here of the thesis and of practicing), our meaning is not necessarily that of a single person. Recent academic research has called for the need to broaden our focus, to include not only consultants, but clients as well, and to do so with more depth and nuance. ${ }^{64}$ Schein (1997) addressed this some time ago, noting six different types of clients, e.g. 'primary clients'-i.e. those who 'own the issue' or 'pay the bill'; 'intermediate clients'-i.e. those who, while not primary, may be involved in the project, etc. Schien's contribution is useful, but our focus is different. As we have written above, we're proposing that effective relatings result in the falling away of pre-determined identities of 'consultant' and 'client.' Our focus is not a more nuanced construction of 'client,' or even different types of clients, which can preserve the notion of self-contained individuals away from which we want to move. Our focus is on practicing and relating, which if successful, results in a relational space, inhabited by relational selves, not 'clients' or 'consultants'-whether singular or plural. We will discuss this space more in Chapter 4, but we can say here that not only is this relational space inhabited by relational selves, but it is centerless, or at least people move back and forth, toward and away from the center of the 'action' of practicing. When going to sign a contract, we may construct for someone an identity as 'the client,' but during a project, that construction may or may not be useful at all. When teams are closely engaged, there may for some time be no client, and no consultant. This is another area where it seems beneficial to pay attention to the constructions we are (or are not) making. Of course, and again as discussed more fully below and also in Chapter 4, this 'centerless' and (relatively) identityfree mode is made possible when power relations are distributed among participants. For our purposes, we take it as a given that there are many people involved from 'the client's'

\footnotetext{
${ }^{64}$ See, for example, the September, 2009 special issue of the Scandanavian Journal of Management entitled "Management Consulting: Introducing the Client."
} 
organization. And one way forward (for research) may be to construct more nuanced representations of different types of clients, as individuals, but such is not our focus here. Research by Alvesson at el. (2009), with their focus on the various constructions of 'clients,' and how those constructions are produced, is aligned with our view.

\section{Constructing local language}

In my experience, and also as discussed in Chapter 6, close relating and close collaboration result in new vocabulary being generated, vocabulary that is highly specific to each particular project. Local ontologies and language communities are constructed. In my experience, there is a positive correlation between the success of project activities, and the degree to which not only the vocabulary, but also the 'solutions' arrived at, are firmly embedded in (i.e. meaningful for) the context of each specific project, and are not easily 'transferred' or even transferable to other projects, even when the projects seem to involve similar issues, and even for the same or similar clients (i.e. direct competitors).

\section{Relating as energizing}

Another benefit of relating, as Lambrechts et al. (2009) point out, is that it can be energizing and motivating. In my experience, and as already mentioned in the above discussion on 'organizing,' engaged relating and constructing can be hard work: hard work holding off preconceived, already-compartmentalized chunks of meaning, rather than making them from scratch, in the moment, for that particular situation, and for that particular project. Project direction-if allowed-often follows the energy, like giving in to the ocean currents, as discussed above. Relating can engage our whole relational selves. The binary client/consultant roles collapse, as does the binary process/content distinction, as people contribute to both.

\section{Power as processual, and the construction of distributed power relations}

Relating (and also organizing and knowing, for that matter) would seem to be dependent on power relations being evenly distributed among participants, and not 'held' exclusively in the hands of a power-ful expert. Just as an entitive view is prevalent in a traditional approach to consulting, as manifested by the reification of organization, knowledge, etc., so too is power often reified to a thing, a possession that one has (or not) (Hosking et al., 1991). But a processual reconstruction of power is also possible, namely, that people create power during successful performings. Power can thus be seen not only as the exclusive possession of a power-ful expert, but also as the result of upstream successful performings-by everyone 
involved. Because the performings are viewed (constructed) as successful and valuable, power, and also a relational or emancipatory space, are thus created for the performers, within which they may, in turn, have greater freedom to act. Compared to claims of power based on 'possessed knowledge,' which are difficult to substantiate, successful performings are highly visible and verifiable, and the power that results may be considered more legitimate. This processual view of power represents a shift from 'power over' other, toward 'power to' or 'power with,' i.e. power to co-construct' with. In Chapter 4, we will propose that even amidst established relations of power and politics, the indeterminate nature of practice does afford some space for the creation-through relating, organizing, knowing, performing - of more distributed power relations.

\section{Relational responsibility}

When co-constructing, those involved also share responsibility for the constructed problems, for actions taken, and also for outcomes-i.e. the constructed assessment of outcomes, successful or otherwise. ${ }^{65}$ Practicing becomes more than only planning the work, but also doing the work, together (Lambrechts et al., 2009), and thus another common binary of consulting work-planning and implementation-is collapsed as well. Along with the freedom, enablement and empowerment of constructionism, however, comes responsibility, and specifically "relational responsibility" (Hosking, in press; McNamee et al., 1998). When we embrace the constructing of the world around us, we become inseparable from it; we become co-authors of it (Shotter, 1993). We bear relational responsibility for the problems we co-construct and pursue, and also for those we ignore. Our purposes, which guide our constructions, are pushed to the forefront. If we say that we are the co-constructors, that we are the co-authors of problems; if we co-construct stories about the culture of a certain company as being one way or another, we can't then step back later and say that poor outcomes of our problem constructions or our organizational change efforts were beyond our

\footnotetext{
${ }^{65}$ Here, there are significant implications here for the 'business model' of consulting. For most mainstream consultancies, the business model is that of a pyramid, with a low partner-to-consultant ration, e.g. one partner for each 12-20 consultants. Partner fees are kept high, both to support the cost of the lower part of the pyramid, and also so that it makes sense for the client that the partner will only dedicate, say, $20 \%$ to any one client or project. This pyramid model supports short- to medium-term projects (e.g. 2-4 months) focused primarily on planning activities. When, however, role distinctions between client and consultant are lowered, and responsibility is not only for the co-creation of plans, but also the longer-term implementation of those plans, consulting fees-with the current pyramid structure-will quickly outpace the available budget. Thus, the relating, co-constructing approach we are developing here would most likely require smaller consultant teams, and a flatter hierarchy in the consultancy business model-i.e. with less of a differential between fees for partners and junior consultants. Thus instead of one partner at 20\%, and 6-9 full-time consultants, we might expect to see, for example, 3-4 full-time consultants, of comparatively similar levels of experience.
} 
control, because the stories we tell of those outcomes, successful or otherwise-these are our constructions as well. If you want to take advantage of the enabling and empowering affects on the front end, then you also, or so I believe, need to take responsibility for where your own constructions may lead you. Social constructionism, in other words, is something of a double edged sword.

\section{Summing up}

In this chapter, we have put forward processual re-constructions of 'organization' and 'relationship': namely, 'organizing' and 'relating,' respectively. The proposal we are making is that 'organizations' need not necessarily be constructed as an entity, and that indeed they were not always so, and the re-constructing them as a bundle of dynamic, only partially predictable processes need not necessarily be the end of consulting, but the beginning of a different way of consulting. Similarly, when viewed over a longer period of history, our current individualism can be seen as recent (even, by some, 'aberrant'). Re-construction of the notion of the self as relational can lead to different paths and fuller and less exchangeoriented relationships. The opportunities afforded by a relational self in my view add considerable weight and richness to the recently popular ideas of 'collaboration' and of 'partnership.' In the next chapter, we take up the third of three processual re-constructions, this time, from 'knowledge' to 'knowing.' 


\section{Chapter 4: Knowing}

\section{Introduction}

In Chapter 4, we will discuss 'knowing,' the third of three processual reconstruction that together-with 'organizing' and 'relating'—can constitute a processual approach to business consulting. This chapter was originally sent to the journal Management Learning in the spring of 2008, and finally published there in the summer of 2009. Because of its submission to an academic journal, the style is somewhat different, and more formal than what has come before, here in the thesis. It is, nevertheless, aligned with the question of what consulting could be, and the proposing of a processual approach as one possible answer to that question. Extending Chapter 3, I will propose several theories and additional 'alternative ways of practicing consulting' that may be useful when the focus of practice shifts upstream, to the processual activity of knowing, and away from the treatment of knowledge as a readily transferable asset. 
PDF created with pdfFactory trial version www.pdffactory.com 


\title{
What if we shifted the basis of consulting \\ from knowledge to knowing $?^{66}$
}

\author{
Jeff Hicks \\ University of Twente, The Netherlands \\ Padmakumar Nair \\ University of Texas, Dallas \\ Celeste P. M. Wilderom \\ University of Twente, The Netherlands
}

\begin{abstract}
In this paper, we argue that a focus on the debunking of consulting knowledge has led to a disconnect between the research and the practice of management consulting. A renewed focus on consulting practice, i.e. the doing of consultancy itself, affords an opportunity for bringing clients, practitioners and researchers of consulting closer together. We sketch an outline of an alternative approach to consulting practice, based not on knowledge, but on knowing, the socially situated activity whereby knowledge is applied and created. Borrowing from the practice-based theories of organizational knowledge and knowing, we explore how key aspects of consulting practice-problem solving, participation and knowledge transfermight be handled differently when we give primacy to practice. We discuss the viability of this alternative approach, and argue that despite established relations of power and politics, the dynamic and indeterminate nature of practice does afford some space for this and other alternative forms of consulting practice to take hold.
\end{abstract}

\section{Introduction}

Academic research of management consulting, according to Fincham and Clark (2002: 387), can be divided into two phases. An Organization Development (OD) phase, authored

\footnotetext{
${ }^{66}$ This paper was published in the Management Learning, Vol. 40 No. 3, 2009, pp. 289-310. Earlier versions were presented at the 2005 meeting of the European Group for Organizational Studies (EGOS) in Berlin, Germany, and the 2005 and 2006 meetings of the Academy of Management, in Honolulu, Hawaii, and Atlanta, Georgia, respectively.
} 
primarily by practicing consultants and dominant through the mid-1980s, was concerned with 'maximizing the effectiveness of consultants' organizational interventions' (Fincham et al., 2002: 5). A second 'critical phase' then emerged, authored primarily by critical management scholars, who problematized consulting's status as a profession, and the truth status of the knowledge consultancies claimed to possess (Fincham et al., 2002: 6-7). The breadth and creativity of the perspectives that have been brought to bear on consultants and consulting during this critical phase-'fantasy theme analysis' (Jackson, 2002), 'dramaturgical analysis' (Clark et al., 1998a), even 'magic' (Fincham, 2000)_-seem to have been eclipsed only by the sheer volume of material produced, prompting Collins (2004) to observe that the debunking of consulting knowledge "has become something of a mass participation sport for academics" (p. 557).

There is, however, a sobering counterpoint to this discussion, which is that in spite of all the criticism, management consulting revenues, except for a brief slow-down following the collapse of the 'tech bubble' in 2002, have increased every year for nearly 40 years (Kennedy Information, 2004). In 2007, the total global expenditure on management consulting services is estimated to have surpassed the $\$ 300 \mathrm{~B}$ mark, a new record high for the industry (Kennedy Information, 2007). Clearly, there is a disconnect between the research and the practice of management consulting. Granted, much of the currently dominant critical research stream has not had the objective of a close alignment with practice (Fincham et al., 2002: 7). But given the increasing impact of management consulting, we advocate here a broadened research agenda, and more active engagement with issues relevant to practice.

For Salaman (2002; see also Collins, 2001) the disconnect results from an overly narrow range of research problematics, in particular a "pre-occupation with the truth status of consultants' knowledge" (Salaman, 2002b: 250). Because consulting knowledge is considered to be flawed, the strong demand that clients continue to have for the services based on that knowledge becomes problematic, and therefore in need of explanation. Not surprisingly, numerous studies have addressed the question: 'Why do clients continue to purchase consulting advice based on knowledge which objective analysis shows to be flawed?' (for a review, see Clark and Salaman (1998b) and Salaman (2002b)). While instructive, these studies are not highly relevant for practice, since clients are concerned less about the truth of consulting knowledge, than they are about its effectiveness, and how that effectiveness can be measured (Phillips, 2000; Schaffer, 2002). Moreover, these studies seem 
to have diverted research attention away from the development of alternatives for what consulting practice could be in the future (Clegg et al., 2004b; Collins, 2001, 2004; Salaman, 2002b; Sturdy et al., 2004). Without the provision of alternatives, argue Alvesson and Deetz (2000), research runs the risk of becoming 'hypercritical' and 'sterile'. This coincides with the assessment of Sturdy et al. (2004) of what the research literature on management consulting has already become: "largely sterile, atheoretical and overly prescriptive" (Sturdy et al., 2004: 337). Thus, developing possible alternatives for consulting practice is important not only for revitalizing the academic research agenda, but also for responding to the needs of consulting clients, who, despite their continued expenditures, are only slightly less vocal than the academic researchers in their criticism of what consulting delivers, although for very different reasons (Ashford, 1998; National Audit Office, 2006).

The purpose of this paper, therefore, is to explore one such alternative for what consulting practice could be. Borrowing from the practice-based theories of organizational knowledge and knowing, we sketch an outline of an alternative approach to consulting practice based not on knowledge, but on knowing, the socially situated activity whereby knowledge is both applied and created. These practice-based theories (e.g. situated learning theory (Lave et al., 1991), distributed cognition (Hutchins, 1993), the theory of affordances (Gibson, 1977) and others) have made significant contributions to other fields of research, but have not been applied in any significant degree to management consulting (Czarniawska, 2001; and Newell et al., 2006, are notable exceptions). Our goal is not the development of a prescriptive method, but rather to explore how consulting practice could be different, by embracing, rather then attempting only to control for, the indeterminacy of practice environments. As a basis for this exploration, the practice-based approaches are well-fit for purpose. Because consulting practice is relevant for clients, practitioners and researchers of consulting alike, it affords an opportunity to bring the research and the practice of a multi-billion dollar industry closer together. Thus, the central we address is 'What if we shifted the basis of consulting from knowledge to knowing?'

The paper is written in four sections. In the first section, we argue that an overriding focus on consulting knowledge has overshadowed further exploration of consulting practice. In the second section we introduce the practice-based approaches to organizational knowledge and knowing and further develop the notion of 'knowing' which unites consulting knowledge with consulting practice in a mutually constituting relationship. In section three, we sketch an 
outline of an alternative approach to consulting practice. More specifically, we use practicebased theories to explore how three key aspects of consulting practice-problem solving, participation and knowledge transfer-might be handled differently when we cede primacy to practice. In the fourth and final section, we discuss the viability of this outlined approach. We will argue that despite established relations of power and politics, the dynamic and indeterminate nature of practice does afford some space for this and other alternative forms of consulting practice to take hold.

\section{The central importance of knowledge for management consulting}

While differing in their respective service offerings, consultancies, and in particular large, mainstream management consultancies (e.g. Accenture, BearingPoint, Capgemini, McKinsey and others) have traditionally adopted a functionalist treatment of knowledge, relying on the knowledge 'resources' and intellectual capital possessed by the firms and their consultants (Davenport et al., 2005; Rasiel, 1999; Walsh, 2001; Werr, 2002). Consultants apply their knowledge to solve client problems, and transfer their knowledge to clients during 'skill transfer', an objective of many consulting projects (Ko, Kirsch, and King, 2005; Poulfelt, Greiner, and Bhambri, 2005). Management consultancies actively promote themselves as demonstrating 'best practice' in the management of knowledge resources (Davenport et al., 2005; Empson, 2001). Critical management scholars, of course, see a very different picture. For these researchers, consulting knowledge is a rhetorical construction, made possible by the exercise of consultant power (Fincham et al., 2002). From the critical perspective, consultancies and other 'knowledge intensive firms' (KIFs) are characterized less by their knowledge, than by their claims to knowledge-intensiveness (Alvesson, 2001). Clients, meanwhile, despite their criticism of the outcomes of projects involving and/or led by management consultants, continue to cite 'gaining access to consultant knowledge' as a primary reason for their use of external consultants (Davenport et al., 2005: 305; Walsh, 2001; Werr, 2002: 92; Wood, 2002: 57-58).

\section{But what about consulting practice?}

But what about the practice of consulting itself? Empirical research (e.g. Alvesson, 1995; Crucini, 2002; Werr, 2002; Werr et al., 2003) suggests the skilful application of knowledge, i.e. practice, is as important for the success of consulting assignments, as is the possession of knowledge resources - this according to both researchers and the consultants themselves. Nevertheless, it appears that the overriding focus on consulting knowledge-whether that 
knowledge is being criticized, promoted or purchased, by researchers, consultants, or clients, respectively-seems to have overshadowed further exploration of the how-to of consulting practice, i.e. the doing of consultancy itself.

A comparatively limited understanding of practice is not confined to consulting, of course, but is characteristic of the study of the professions in general (Abbott, 1988; Brante, 1988; Derber et al., 1990a; Hirschkorn, 2006; Reed, 1996). Reasons given for why professional practice-compared to professional knowledge-remains relatively unexplored include, for example, the indeterminate nature of the environments where professional practice is situated, and which defies formalization (Alvesson, 1993, 2001; Glückler et al., 2003; Schön, 1983; Sturdy, 1997). For closure theorists (e.g. Abbott, 1988; Freidson, 1988; Johnson, 1972; Larson, 1990) and researchers focused on organizational politics (Eisenhardt and Bourgeois, 1988; Ferdinand, 2004), the 'mystification' of practice by practitioners is intentional, so as to protect their autonomy and basis of power. And finally, the language and vocabulary of practice-for not only describing practice, but for creating new forms of it-is underdeveloped (Nicolini et al., 2003). Compared to the numerous and sophisticated taxonomies for categorizing different types of static knowledge (e.g. Grant, 1996; Nonaka et al., 1995; Spender, 1996), the language describing how knowledge is used, i.e. the language of practice, is often left to a list of not-so-illuminating verbs: 'apply', 'leverage', use', etc. Regardless of which of these or other rationales one accepts, it nevertheless remains that one of the least understood aspects of professional practice, is practice itself (Hirschkorn, 2006). And there are yet further reasons for why this may be particularly the case for consulting practice. Because the boundaries delimiting the body of knowledge on which consulting depends are ill-defined, it becomes even less clear where possession (of consulting knowledge) ends, and the practice (of consulting) begins. This lack of clarity between consulting practice and consulting knowledge, combined with the high priority that consultants place on their knowledge, results in what we see as a pervasive tendency, in both research and practice, to conflate (static) knowledge with (dynamic) practice. Later, we offer two examples of this, related to knowledge management and knowledge transfer. This conflation, we argue, hinders efforts to gain a discrete focus on consulting practice itself. The so-called practice turn' in social and organizational studies (Schatzki, Knorr-Cetina, and Savigny, 2001) is also motivated by the desire to gain a better understanding of practice, and we turn next to a discussion of these practice-based approaches. As we will demonstrate, not only do they help with an understanding and exploration of practice, they also provide a way, through the 
notion of 'knowing', for keeping consulting knowledge and consulting practice clear and distinct, yet connected.

\section{Practice-based approaches to knowledge and knowing in organizations}

The practice-based approaches can be demarcated as studies which develop accounts of practices, or those studies that treat the field of practice as the primary site for study (Schatzki et al., 2001). They include situated learning theory (Lave et al., 1991), situated action (Suchman, 1987), distributed cognition (Hutchins, 1993), activity theory (Vygotsky, 1978), the theory of affordances (Gibson, 1977) and others. As their name implies, the practicebased approaches take the dynamic 'doing of' practice and the 'using of' knowledge as their primary focus. Where a functionalist perspective is focused on knowledge, a practice-based approach is focused on knowing. Knowledge is what one has; knowing is what one is doing. 'Knowing' is defined here as the socially situated activity whereby knowledge is both applied and, thereby, created during practice (Blackler, 1995; Brown and Duguid, 1991; Cook et al., 1999; Lave et al., 1991; Orlikowski, 2002; Schön, 1983). Borrowing from two well-known examples, knowledge is the understanding one has of the game of chess, while knowing is the playing of the game (Ryle, 1949); knowledge is the advice a child has from parents about how to ride a bicycle, while knowing is actually riding it (Polanyi, 1967). Cook and Brown (1999) make a distinction between 'knowing' and 'practice', with the latter being not just any doing or acting, but doing or acting that is "informed by meaning drawn from a particular group context" (p. 387). But in this paper, and following Maturana and Varela (1998) we will treat 'knowing' as synonymous with 'doing' and also with 'practice', and we will use all three terms.

To begin to demonstrate how the notion of 'knowing' can be help to gain a better understanding of consulting practice, we offer two examples of how knowledge and knowing, or, alternatively, knowledge and practice, are routinely conflated in both practice and research, and we show how 'knowing' can help to disentangle them. The first example is related to knowledge management, and the second to knowledge transfer.

\section{Diagnosing the difficulties with knowledge management and knowledge transfer}

Knowledge management is big business. In order to promote re-usage of knowledge, transfer best practices, or improve collaboration, organizations, and especially consultancies, have invested heavily in knowledge management systems and 'knowledge repositories'. Yet after 
implementation, many of these knowledge repositories remain either empty or idle (Hansen et al., 1999; McDermott, 1999; Newell et al., 2006). As McDermott (1999) points out, "if a group of people don't already share knowledge, don't already have plenty of contact, don't already understand what insights and information will be useful to each other"-in other words, if they don't already collaborate, then collaboration is unlikely to begin, simply through the introduction of a knowledge repository (McDermott, 1999: 104).

In this example, problems of practice are addressed as if they were solely problems of possession, or rather insufficient possession, of knowledge resources. Cook and Brown (1999), referencing Dewey, write: "to talk about activity in terms of knowledge is to mistake an abstract, static concept [knowledge] for a concrete, dynamic activity [practice]. It is to make a kind of category" (Cook et al., 1999: 387). But when the primary focus is on knowledge resources, problems are often framed as not having enough knowledge, and 'solutions', therefore, call for having more. And without sufficient language to enable a more discrete focus on practice itself, the problem of insufficient collaborating goes either 1) unrecognized as a problem with practice, or 2) misdiagnosed as solely a problem of possession. Diagnosing this same example using the idea of 'knowing', however, we get some sense of explanatory power regarding the limited success of the initiative. It enables us to say, for example, 'they took care of knowledge, but overlooked knowing', and thus also begins to improve our vocabulary and our ability to discretely focus on practice and practicing.

Similar difficulties exist with studies of knowledge transfer. A number of well-known studies, for example, have focused on the difficulties involved with knowledge transfer or the transfer of best practices (e.g. Kogut and Zander, 1992; Szulanski, 1996; von Hippel, 1994). In these studies, the difficulty is attributed to knowledge itself, which is considered to be "sticky", for example (von Hippel, 1994). The perhaps equally-well known critiques of such studies often invoke Reddy's (1979) argument against a conduit metaphor of communication. According to the critique, the reason why 'knowledge transfer' is problematic, is not because knowledge is sticky, but because the meaning of the knowledge being transferred is different for the sender than it is for the receiver, and this is indeed problematic. But there are other difficulties - in both the original studies and the critique-which the idea of 'knowing' helps to makes clear. 
In neither the original studies nor the critiques, for example, is there any explicit provision for the dynamic using of 'knowledge', i.e. for knowledge creation, or knowing. Regardless of whether it's 'knowledge' or 'meaning' that is being transferred-both rely solely on the metaphor of 'transfer'. But the 'transferring' of knowledge or meaning will always be one step short of the 'using' of it, i.e. one step short of knowing. The word 'meaning' is indeed some improvement over the word 'knowledge', because it at least implies that some knowing is happening, but it is left unclear, especially when it continues to depend on the same 'transfer' metaphor for its conveyance. And as for the metaphor of conveyance, 'sharing' is sometime used to replace the word 'transfer' (e.g. Bechky, 2003), to render: 'the sharing of meaning', instead of 'the transfer of knowledge.' As before, 'sharing' seems to be an improvement over the word 'transfer', because it implies some interaction, but again it is only implied. It also assumes that meaning is something that can be shared with some person, as opposed to that which must be created by that person. To summarize, the phrase 'the sharing of meaning' is seen as only a slight improvement over the phrase 'the transfer of knowledge'. It continues to rely on a functionalist treatment of knowledge, but more problematically, it makes no explicit provision for knowledge creation, and thus leaves knowing or practice non-discrete and unclear.

A metaphor from the telecom industry can hopefully clarify. In that industry, people speak of 'the last mile', which refers to the point at which larger, long-distance cables, arriving near to the final destination, must be separated into smaller, shorter cables to connect with individual customers. Compared to the work involved in moving large amounts of data across long distances, the 'last mile' is short, but expensive, involving tricky issues of property access, etc., and is generally considered difficult to administer. Nevertheless, until the last mile is covered, service cannot begin. Similarly, 'the transfer of knowledge' or 'the sharing of meaning' make no provision for the critical 'last mile'. For knowledge to have an impact on practice - positive or otherwise — knowing is an obligatory passage point (Callon, 1986). The point is not that these studies are wrong, but that, because they do not make explicit provision for knowing, of for practice, their usefulness for gaining a discrete focus on practice, for the purposes of understanding and improving it, is limited. Ultimately, as Brown and Duguid (2001) argue, it's a choice as to where one assigns the attributes for study, a decision which in turn is driven by different perspectives and purposes of inquiry. From an asset-based view, it may make sense to assign attributes to knowledge itself, like 'sticky', and then investigate how the transfer of these sticky assets might be improved. From a practice-based 
perspective, as we are concerned with here, it makes sense to assign the problematic elsewhere, to practice itself. That is what we will do later in the paper, when we explore three specific attributes or aspects of consulting practice.

As the above examples hopefully demonstrate, there is routine conflation of issues of knowledge, with issues of knowing or practice, in both the research and the practice of consulting, a conflation which knowing can help to clarify. However, a renewed focus on knowing does not mean that knowledge resources then become any less important-on the contrary, both are required for effective practice. Thus, having spent some time attempting to disentangle knowledge and knowing (or practice) into somewhat discrete and separate strands, in the next section we attempt to weave them back together again, but in such a way that they remain discrete and clear, yet connected.

\section{Knowledge and knowing as mutually constitutive}

In the previous section, we discussed how successful performance in practice depends on both knowledge and knowing. Nevertheless, much of the literature on knowledge in organizations (Marshall and Rollinson, 2004; Spender, 1996), and in consultancies in particular (e.g. Hansen et al., 1999; Marshall et al., 2004; Sarvary, 1999) presents an 'either/or' treatment of knowledge and knowing, i.e. "knowledge as an asset" or "knowing as a process" (Empson, 2001: 812). The 'codification vs. personalization' strategies for managing knowledge, for example, are a well-known example of this either/or treatment (Hansen et al., 1999). But if we strictly adopt a 'knowledge as an asset' approach, then no provision is made for the using of that asset, and practice thus remains under-served, which is precisely the issue we are seeking to address. On the other hand, strictly adopting 'knowledge as a process' risks overlooking knowledge resources and experience. Perhaps not surprisingly, more recent empirical research shows that in practice, consultants routinely use both knowledge and knowing, or some processual equivalent, and regardless of whether the consultancies are strategy- or technology-oriented, or local or global in scale (Crucini, 2002; Hargadon et al., 2006; Werr, 2002; Werr et al., 2003).

Yet while this research recognizes the importance of both knowledge and knowing, the relationship between the two remains undeveloped. For example, knowledge and knowing are said to be 'complementary' to one another (Crucini, 2002: 128). Or, for Nonaka and Takeuchi (1995) there is a processual component only at the time when knowledge is said to 
be "converted" from tacit to explicit. However, once this conversion is complete, and the explicit knowledge has been created, it can then be "readily transmitted between individuals" (Nonaka and Konno, 1998: 42), and assumedly without further assistance from the 'conversion' process that created it.

Compared to research that adopts an either/or treatment of knowledge and knowing, or that does not clearly define the relationship between the two, Orlikowski (2002) offers a promising alternative:

"It leads us to understand knowledge and practice as reciprocally constitutive, so that it does not make sense to talk about either knowledge or practice without the other. It suggests there may be value in a perspective that does not treat these as separate or separable, a perspective that focuses on the knowledgeability of action, that is on knowing (a verb connoting action, doing, practice) rather than knowledge (a noun connoting things, elements, facts, processes, dispositions)" (Orlikowski, 2002: 250251, emphasis in original).

Orlikowski's usage of 'practice' in the passage above is similar to what we have been referring to, interchangeably, as 'practice' or 'knowing'. Following Orlikowski (2002) above, and incorporating similar insights from Tsoukas (1996) and Cook and Brown (1999), we will adopt the view that the relationship uniting knowledge and knowing is mutually constitutive. Thus, knowing creates knowledge, which in turn guides and influences future knowing, in a fashion similar to the agents and structures of structuration theory (Giddens, 1986). Knowledge is "a tool at the service of knowing" (Cook et al., 1999: 388). Also, knowing is performing, and is dependent upon relevant knowledge for the performance to be an effective one (Cook et al., 1999; Lave et al., 1991). Knowing without relevant knowledge to draw from is still a performance, but is likely to be amateurish or inappropriate for the purpose at hand. From this perspective, existing knowledge is not simply 'transferred' as-is into a new context (Freidson, 1988). Rather, with re-contextualization, knowledge is changed, and thereby created anew, but only for an instant, as it begins slipping immediately into a decontextualized past.

'Knowing as performance' and the 'decontextualizing' of knowledge raise especially important implications for consulting practice. Because of decontextualizing, or simply forgetting, the 
knowledge which enabled past successful performances, may not be available for future performances; because practice is indeterminate, past knowledge, even if available, may not be appropriate. In other words, 'expertise' is no longer seen as a possessed capability, but an emergent accomplishment (Lave et al., 1991; Orlikowski, 2002; Tsoukas et al., 2002).

We now have a better understanding of both knowledge and knowing, and also how they can be combined, not haphazardly, but in a mutually constitutive relationship, and so as to form the basis of an alternative approach to consulting practice.

\section{What if we shifted the basis of consulting from knowledge to knowing?}

We now return to our central question, and sketch an outline of an alternative approach to consulting practice. We do this by considering the implications that result from shifting the basis of consulting practice from where it is today-knowledge, to where it could beknowing. This is not a trivial shift, because it means to embrace, rather than attempt to control for, the indeterminacy of practice environments. Practice environments are indeterminate precisely because they call for knowledge and experience that are not 'ready to hand' (Heidegger, 1962). This does not mean abandoning existing knowledge or methods, because we do not adopt an either/or treatment of knowledge or knowing. And because knowing is neither a body of knowledge nor a method, it is suitable for providing an alternative approach, or a perspective on consulting - an approach that gives primacy to practice.

We will look at how three aspects consulting practice-problem solving, participation and knowledge - might be handled differently, using practice-based theories to add vocabulary, some level of processual guidance, and to make the description of the alternative approach to consulting practice more full and concrete.

\section{Problem solving}

Problem solving is a central activity of consulting practice. Traditionally, it is a matter of 'applying' knowledge resources to the problem at hand. But without a default reliance on a body of knowledge, how might the problem solving activity be different? The theory of affordances, based on the work of Gibson (1977) provides one possibility. 


\section{Ecological psychology and the theory of affordances}

How do we perceive a given situation? For Gibson (1977), perception is guided by the opportunities for action that the situation affords. For example, a tree in a park affords us the opportunity to take shelter from the sun on a hot day. An 'affordance' is thus an opportunity for action, that exists for a given agent, in a given situation (Gaver, 1996; Greeno, 1994). A measure of a person's height has no inherent meaning, but when combined with a specific situation, determines whether, for example, one is afforded the opportunity to operate the controls on a kitchen stove, or, for small children, hopefully not. An architect may be commissioned to re-design an office to afford more opportunities for collaboration. As we discuss below, the theory of affordances can also be a useful guide for problem solving, particularly amidst the shifting environments of practice.

Gibson's (1977) theory of affordances, a part of his theory of ecological psychology, differs from cognitive, social or behavioral psychology in a number of ways. First, ecological psychology considers the environment not as background or the inert context for perception, but as constitutive of perception (Greeno, 1998). Thus, as the environment changes, so too does our perception of the opportunities for action that are afforded to us. For example, on a rainy day, the same tree in the park now affords us the opportunity to stay dry. A second important difference of an ecological psychology is that it is interactionist; that is, it seeks to understand perception from the perspective of an observer that is not only moving, but moving in relation to, and in interaction with, the environment (Greeno, 1994). The actor is not simply in an environment, they are an inseparable part of the environment, in a way that cuts across traditional subject-object dualities (Gaver, 1996).

By introducing some of the vocabulary of ecological psychology, we can describe how it helps to guide problem solving. 'Affordances', as explained, are opportunities for action. An 'ability'_or, alternatively, an 'aptitude' or an 'effectivity'—is, as it sounds, the ability to do something. Importantly, however, abilities are related to the affordances of a given situation. "Neither an affordance nor an ability is specifiable in the absence of specifying the other" (Greeno, 1994: 338). An ability is thus oriented to the doing of some specific task that presents itself, in some specific situation. Finally, 'attunements' are the adjustments made by the problem solver, in response to 'constraints' that are encountered within a problem space. Pulling all this together, problem solving then becomes: taking advantage of the positive 
affordances, by enacting abilities, and making attunements to constraints, while interacting with and progressing through a problem space. Greeno (1998; referencing Reitman, 1965) gives the example of a composer of a fugue, who composes, in consideration of the affordances and constraints of both the musical form (the fugue) and the instrument (say, a piano). In organizational contexts, problem solving from this perspective involves the "continual negotiation of people with each other and with the resources of their environments" (Greeno, 1998: 9). As the process unfolds "every step is controlled not by reinstantiated grammars and previously constructed plans, but adaptively recoordinated from previous ways of seeing, talking and moving" (Clancey, 1995: 49). The typical project plan, in contrast, sets out prescribed actions that have no connection with the current situation. As a result, we often ask 'How can the plan be tailored for the current situation?' The theory of affordances goes one important, and possibly creative step further, to ask 'What actions are possible, given our perception of the current situation?'

As we will discuss in more detail later, any negotiation of meaning will take place amidst relations of power and politics (Blackler and McDonald, 2000; Marshall et al., 2004; Weick, 1995). In such an environment, the use of affordances can also help to mediate the influence of politics on decision making. As shown by Eisenhardt and Bourgeois (1988), politics in decision making are related to covert actions and "behind-the-scenes coalition formation" (1988: 738). By forcing the question of not just 'What's next?' but rather 'What's possible?', affordance theory helps bring any pre-conceived and covert rationale to the surface. It helps to prevent attempts at premature closure by either clients or consultants. In addition, the open-ended nature of 'What's possible?' is essentially an invitation to participate, which brings us to another aspect of consulting practice that stands to be affected by a shift of primacy to practice.

\section{Participation}

Who participates in the consulting process? In the traditional expert-driven approach, which in turn relies heavily on a functionalist treatment of knowledge, participation is primarily limited to those who are in possession of the knowledge that is considered necessary for the task at hand. When we give primacy to practice, however, and embrace the indeterminacy of practice environments, more inclusive participation, bringing more experience and different perspectives, is beneficial. But it brings additional challenges as well. For example, how can the "dispersed bits of incomplete and contradictory knowledge" (Hayek, 1945) of multiple 
individual team members be coordinated and synthesized to successfully accomplish complex tasks? This is the kind of question for which distributed cognition is useful.

\section{Distributed cognition}

Distributed cognition "is not some "new" kind of cognition, [but] rather a recognition of the perspective that all of cognition can be fruitfully viewed as occurring in a distributed manner" (Halverson, 2002: 248). Similar to the theory of affordances, distributed cognition looks beyond individuals to focus on 'systems', that include a "distributed collection of interacting people and artifacts" (Nardi, 1995) such as, for example, an 'airplane cockpit system', or, we propose, a consulting engagement. These systems have goals, e.g. the successful completion of a flight. Because of these systems' distributed nature, we cannot understand how their goals are achieved by understanding individual agents alone. Distributed cognition helps understand how tasks that are well beyond the capability of any one individual, can nevertheless be accomplished. Distributed cognition thus extends knowing from the individual to the collective level. Hutchins (1993), for example, shows how the determination of a ship's bearing is accomplished only through the collective action of several crew members. Cohen et al. (2006) used distributed cognition to identify systemic factors contributing to errors in a psychiatric emergency department, errors that are simply not visible when based on the investigation of individual behaviors.

But distributed cognition involves more than information exchange between individuals, rather, the nature of each subsequent action is contingent upon its predecessor, and new knowledge is thus created through what Weick and Roberts (1993) refer to as "heedful interrelating". Successive interactions build on one another and are not reducible to, or traceable back to, any one individual (Hargadon et al., 2006; Stahl, 2005; Vygotsky, 1978). Extending the idea of individual expertise as an 'emergent accomplishment', Weick and Roberts (1993) develop a similar, group-level concept they refer to as a "collective mind", a notion taken up and developed further by Tsoukas (1996):

“. . . the collective mind is an emergent joint accomplishment rather than an already defined representation of any one individual: the collective mind is constituted as individual contributions become more heedfully interrelated in time. Being an emergent phenomenon, the collective mind is known in its entirety to no one, 
although portions of it are known differentially to all" (Tsoukas, 1996: 15, emphasis in original).

More recently, based on interviews and observations of management consultants, engineering design consultants and internal consultants, Hargadon and Bechky (2006) offer several examples of how "the locus of creative problem solving shifts, at times, from the individual to the interactions of a collective" (p. 484) in moments of "supraindividual" or "collective creativity". They also identify four activities that precipitate moments of collective creativity: 'help seeking', 'help giving', 'reflective reframing' and 'reinforcing' (Hargadon et al., 2006). During these activities, implicit framings of problems or issues are made explicit, combined, and made sense of anew, potentially leading to creative or useful insights.

Distributed cognition and related theories (cf. situated cognition (Suchman, 1987), activity theory (Engeström, 1999; Vygotsky, 1978)) thus provide a rich vocabulary and also research methods for the study of collective knowing and collaborative knowing. As we will discuss later, this wider, more inclusive participation is also an important vehicle for the establishment of power relations that are more evenly and widely distributed.

\section{From Knowledge Transfer to Learning}

For many of the projects that make use of external consultants, knowledge transfer from consultant to client, is a common goal (Ko et al., 2005; Werr, 1997, 2002). Perhaps not surprisingly, given the research findings presented in this paper so far, the results of these transfer efforts are typically considered to be poor. But if, as we have proposed, knowledge is not so much transferred as it is created during knowing, then effective learning would seem to be dependent on participation in the activity of knowing or practice. This is the essence of the theory of situated learning (Lave et al., 1991).

\section{Situated learning theory}

Learning, according to the traditional view, is "a cognitive process involving a selective transmission of . . . codified bodies of knowledge within and from one context . . to the sites of their application" (Contu and Willmott, 2003: 284). In their study of four different types of apprenticeship, however, Lave and Wenger observed that while the process was effective at producing "skilled and respected" masters, very little direct instructing of the apprentices by the master took place (Lave et al., 1991: 30). Based on these observations, Lave and 
Wenger theorize that learning is not a matter of 'transferring' of knowledge from expert to apprentice, but rather the creating of knowledge, during the apprentices' participating in, and collaborating with, their peer group. From this perspective, learning is not an independent process that happens separate from social practice, but rather "an integral and inseparable aspect of social practice .... Social practice is the primary, generative phenomenon, and learning is one of its characteristics" (p. 31-34)—in other words, not just 'learning by doing' but rather 'learning is doing'. Thus, by re-directing current 'knowledge transfer' of 'skill transfer' efforts toward 'learning through participation', the potential for enhanced learning in consulting project environments-for both clients and consultants-seems promising. As we will return to later, power relations are important here as well, as they act as a gatekeeper on the scope of participation, and thus the degree of learning that can take place.

Situated learning theory provides useful vocabulary for the 'practice' of learning with the concept of "legitimate peripheral participation" in a community of practice. Participation, and thus learning, is 'legitimate' in the sense that one belongs to or has a right to participate, and thus learn, in the community of practice-including so-called 'novice' clients, junior consultants, etc. As a learner, one's participation in the community of practice is 'peripheral', moving toward 'full participation' as one gains experience and the ability to perform. However, there is no specific place designated as the periphery, and "most emphatically, it [the community] has no single core or center" (Lave et al., 1991: 37). It is more like the 'problem space' of ecological psychology. With situated learning theory, the focus of instruction broadens to include attention to the context, so that it affords greater opportunities for participating. In a consulting context, this would include, for example, the creation of a designated space for the project team, facilities for displaying in-progress work, for gathering input from those within and beyond the immediate project team. Finally, according to situated learning theory, the distinctions between learner/teacher, client/consultant or expert/novice are blurred as each contributes to and learns from what is collectively known and constructed by the community of practice-indeed the roles themselves become situational.

\section{An alternative approach to consulting practice}

In Table 1, we summarize the preceding discussion and put forward an outline of an alternative approach to consulting practice. In an approach based on knowledge, client and consultant roles are different, distinct, and fixed. In an approach based on knowing, the roles 
of client and consultant converge, and are situational, and the general focus shifts from possession to performing. The alternative perspective makes explicit provision for, and gives primacy to the creation of knowledge, i.e. individual and collective knowing, in context, according to locally determined, situational needs. The focus of problem solving shifts from accuracy to actionability, taking advantage of situational affordances, abilities and artifacts, including, for example, manuals, methods and information resources. All individuals, by virtue of being 'legitimate' participants, are empowered. Additional power consists of entitive power, such as that held by the project manager, because of their position, and power gained through performances that are considered to be successful, in context. Engagement with highly complex problems and other periods of intense collaboration can give rise to episodes of fully distributed or 'centerless' power relations.

Insert Table 1 about here

\section{On the viability of a consulting practice based on knowing}

In this final section of the paper, we discuss the viability of the practice approach outlined above. As this paper is exploratory, we do not see 'viability'-in the sense of, for example, 'likelihood of immediate adoption'-as the primary concern. Yet it is also our objective to produce something of relevance to clients, practitioners and researchers alike. We refer once again to Alvesson and Deetz (2000), who caution that, to be useful, research should not only avoid being hypercritical, it should also avoid the provision of alternatives that are simply utopian. From a research perspective, the grounds on which the charge of 'utopian' would be leveled against this paper are most certainly those of power and politics. Thus, leaving aside more 'operational' questions such as, for example, how the structure of consulting engagements and consulting firms might change, we will look instead at viability as: the possibility of achieving the distributed power relations upon which this more open-ended, participatory approach to consulting practice seems to depend. Our claim will be that, even amidst existing power relations, the dynamic nature of practice affords some space for alternative forms of practice to take hold. We draw examples to support this claim from both research and from practice. We begin with research. 
As highlighted by a number of studies, power and politics have not been well-integrated into the literature on organizational knowledge and knowing (e.g. Blackler et al., 2000; Contu et al., 2003; Coopey, 1995; Coopey and Burgoyne, 2000; Ferdinand, 2004; Fox, 2000; LaPalombara, 2001; Marshall et al., 2004; Willem and Scarbrough, 2006). Fortunately, three short but relevant papers (Clegg et al., 2004b; Clegg et al., 2004c; Sturdy et al., 2004), in a back-and-forth exchange, focus on the power and politics of management consulting, and in particular, the possibility of achieving alternative forms of consulting practice, given entrenched power relations - much the same question we face in this paper.

To briefly summarize the debate from these three papers, Clegg et al. (2004b) propose a new role for the consultant, as one who disturbs or interrupts organizational practice, for the purpose of opening up new 'departures for action', as opposed to their more traditional role, as one who seeks to improve or transform organizational practice, toward the goal of enhanced economic performance. In response, Sturdy et al. (2004) argue that the entrenched and managerialist power relations prevent the creating and sustaining of the 'emancipatory space' wherein an alternative form of consulting practice could take hold. Establishing a new form of practice, they argue, requires "'interrupting' and 'transforming' power relations rather than tinkering with managerial practice" (Sturdy et al., 2004: 339, emphasis in original). In other words, the challenge of changing consulting lies with changing power, not with changing practice.

Our response, in turn, would be that the two-power and practice-are inextricably related (Bourdieu, 1991; Clegg, 1989a; Foucault, 1977), and that practice itself is one way by which emancipatory spaces are constituted, the other way being by (managerial) decree. Power is not only what one has (or lacks), it also includes the power that (any) one constructs, through participation (Lave, 1993; Morriss, 1987). "Power is not a thing, but a process constituted within struggles" (Clegg, 1989b: 97), including the political acts taken to influence how the process unfolds. Leaving aside the 'by decree' option, the question then becomes whether or not, within consulting practice and the power relations thereof, sufficient opportunities exist for practicing alternatively, such that an emancipatory space for alternative practice is thereby created. Within the dynamic and unpredictable environments in which consulting work is situated, we argue, it seems infeasible that all opportunities for participation or alternative practice can be intentionally closed off. If this is correct, then some opportunities 
for participation and power creation remain. Hardy and Clegg's (1996) comparison of Marxist and Weberian views on power suggests this is indeed the case. They argue that power in organizational contexts is not simply a case of 'the haves' and 'the have nots'. For Marx, power is held by those with control and ownership of the means of production. For Weber, however, while acknowledging that power did indeed result from such ownership (entitive power) he argued that power nevertheless "was not reducible exclusively to the dichotomous categories of ownership and non-ownership of the means of production .... Weber's insights indicated that all organizational members had some creativity, discretion and agency to use power" and create power and a space for themselves, by applying, albeit not without struggle, their knowledge of the processes of production (Hardy et al., 1996: 623624). In consulting practice, as the project unfolds, different types of expertise fall in and out of favor, and "without a total theory of contexts, which is impossible, one can never achieve closure on what the bases of power are. They could be anything under the appropriate circumstances" (Hardy et al., 1996: 626). To summarize, it appears that power relations of ongoing practice are sufficiently distributed, to afford opportunities for the creation of emancipatory spaces. The examples from practice given below will help us understand more about the possible size, longevity and other properties of these spaces.

With the two examples from practice that follow, we hope to show that in project environments, power relations are indeed sufficiently distributed so as to allow for the creation of emancipatory spaces. In the first example, the creation of the space was quite unintended, and resulted from the complexity of the problem, where normal rules of practice or method could not exert hegemony. The second example, which we draw from our own experience as management consultants, shows a more deliberate creation of an emancipatory space. With both examples, we also hope to show that the activities that occur during consulting practice, are not dissimilar to those we have attributed to the alternative approach to practice outlined earlier.

The first example is taken from Blackler and McDonald (2000), and their involvement in a two-year action research project studying the innovation processes of a high-tech engineering organization in the defense industry. The authors are full-time academics, acting in a consultative role during the project. Near the midpoint of the project, the problems at hand became more "complex and diffuse", and the team entered a four-month period of what they 
refer to as "institutionalized knotworking" and "decentered collaboration". 'Knotworking', a useful term from Engeström (Engeström, Engeström, and Vahaaho, 1999), refers to "a rapid, distributed and partly improvised collaboration of actors and activity systems that, aside from the knot, are otherwise loosely connected" (Blackler et al., 2000: 840). For example, during complex collaborations, team boundaries and team membership change, as do priorities, technologies and procedures-but stable throughout this is a 'knot of interaction'. Below is their description of this period of the project:

"As top managers developed an interest in the project and the interests of both groups converged on issues that were of interest to everyone the process of collaboration displayed some of the characteristics of 'knotworking'. No one was in overall control of the collaboration. Those involved each contributed as best they could towards the understanding of an unfolding and complex series of problems. At this time it was the intrinsic interest of the situation, rather than external pressures, obligations or tradeoffs, that motivated the collaboration. Access to, and relations between, key participants possessed an urgency and flexibility that was driven by task priorities" (Blackler et al., 2000: 847).

In this passage the authors describe experiences not dissimilar to those we have outlined earlier in the paper: Power relations seem distributed; collaboration (and therefore learning) is 'decentered' and occurs across all levels, from board-level to project team members; and required skills were dictated by the unfolding situation, with each person contributing according to their own abilities. We would argue that the above description represents a kind of emancipatory space, albeit an unintentional one. This space was temporary, and yet powerful enough to bring about permanent changes in the team members, and in management. After this period of decentered collaboration they report:

"... things were now different than before. Management showed a continuing interest in, and respect for, the research project. The researchers' orientation to the company in particular and management problems in general had also changed significantly. Personal relations between all who had been involved remained cordial. Beyond this group the achievements of the project as a collaborative exercise was later to be acknowledged externally, in particular by a number of academics, 
industrialists and research administrators who had become interested in promoting closer industry/university links" (Blackler et al., 2000: 847).

The researchers also reported that the close collaboration "stretched [their] behavior, imaginations, attitudes and skills in such a way that it was simply not possible (for the authors at least) to shake free and walk away from the knot unchanged" (Blackler et al., 2000: 848). While of the opinion that such episodes cannot be 'engineered', the authors of this study nevertheless call for further detailed research on how such episodes can be nurtured and supported, including development of new metaphors, new language, boundary-crossing negotiation skills and even inculcating a general acceptance of, and tolerance for the problems that will inevitably arise. We maintain that cases such as this demonstrate the viability of emancipatory spaces that are capable of forcing the distribution of power relations, and permanently altering future practice and the practitioners.

As a final example, we draw from our own work as consultants, representing a total of 14 years experience with the business strategy units of two different mainstream management consultancies, and involving work across a number of industries in the Asia Pacific region and North America. In general, our project experiences were quite similar to those described above by Blackler and McDonald (2000): dynamic, complex, and (usually) rewarding. More important for our purposes here, however, were our experiences with creating, sustaining and then occupying what we now have the vocabulary to describe as an 'emancipatory space'.

During our experience as consultants, we began to develop, for whatever reason, a knack for framing complex client problems not only creatively, but also in such a way that they were highly actionable for our project teams. 'If you can't solve the problem, change the problem you're solving' was a phrase we used often. Our 'knack', however, was not well represented in the skill classifications of the firm's human resources department, and our projects, as a result, were not always carried out in strict accordance with the approved methodologies, even though, being a global, mainstream consultancy, there was at times considerable pressure to do so. Nevertheless, we were fortunate enough to have developed a positive reputation with our clients, and also with a network of internal sponsors who understood 'what it was that we were able to do'. In other words, we had successfully carved out an 'emancipatory space' for ourselves and our project teams. This space was never completely stable and often contested. For us, as well as for those to whom we reported, politics 
primarily took the form of steering covertly toward desired customers and projects, and avoiding having to publicly turn down requests from others that would have pulled us too far out of our own space. Many other such spaces existed as well, created by different people and groups, each with its own size, character and strength. There was a marked decrease in the level of politics inside the space, where decisions were more open and pragmatic, largely because of the often significant pressure to make progress toward addressing the clients' business issues.

Going back to the debate summarized above, Sturdy et al. (2004) question the ability for social actors-in this case consultants- to "step out and back from their roles and renegotiate them", and that Clegg et al. (2004b) "do not discuss how these spaces are created, maintained and sustained" (p. 338). In our case, at least, the spaces were created, maintained and sustained, albeit not without struggle and contestation, by practice. As for the ability to 'step out of one's official role' for the creation of such a space-or, in the case of consulting, to grow into one's official role as leader of a practice unit, focused on one's own niche-this has traditionally been a distinguishing, if diminishing (Poulfelt et al., 2005: 17) characteristic of consultancies. Thus in this example as well-and amidst existing relations of power and politics - the dynamics of practice, aided perhaps by the liminal spaces (Sturdy, Schwarz, and Spicer, 2006) within a partnership structure, afforded the creating and sustaining of what was for us a critically important space for alternative practice.

\section{Summary and Conclusion}

In this paper, we have argued, following a number authors (e.g. Collins, 2001, 2004; Heller, 2002; Salaman, 2002b), that there is a disconnect between the research and the practice of management consulting. While acknowledging the value of continued critical research, we have advocated a renewed focus on consulting practice, because it affords an opportunity for bringing clients, practitioners and researchers of consulting closer together. We have borrowed from the practice-based approaches to organization knowledge to better understand how key aspects of consulting might be handled differently if we shifted the focus of practice from knowledge to knowing. Finally, we have provided some albeit limited examples in an attempt to show that, largely because of the dynamic nature of practice environments, alternative forms of practice are possible, even amidst entrenched relations of power and politics. 
This paper, then, could be viewed as a call for a third phase of research on consulting, a call originally made several years ago, by Collins (2001), Salaman (2002b), and Heller (2002). Our view of this new phase of research is one that avoids hypercritique, as well as the less critical and "self-congratulatory" manner (Fincham et al., 2002: 7) of much of the earlier, OD-influenced research on consulting. In our view a useful research stream would embrace, pragmatically and critically, some level of 'performativity of practice', with the level and the objective of performance being set by those directly involved. Judging from other papers that also explore alternative forms of consulting (Clegg et al., 2004b; Czarniawska, 2001; Czarniawska and Mazza, 2003; Sturdy et al., 2006), a new and different phase of consulting research may already be underway.

One note of caution, however, as sounded by Collins $(2001 ; 2004)$ is that earlier attempts at 'a more constructive engagement with the advice industry' have been less than successful. They have, for example, focused on a debunking agenda, i.e. "the substitution of academic truth for consultancy distortion" (Collins, 2004: 558), or a 're-education' agenda (Abrahamson and Eisenman, 2001), both of which are essentially remedies for a condition the clients do not believe themselves to be suffering from. Other authors (e.g. Mohrman, 2001) argue in favor of active engagement with companies, and that "a connection must be made between researchers and the practitioners" who design and lead organizational change activities, from corporate restructuring all the way down to intradepartmental process improvement (Mohrman, p. 58). This is indeed recommendable, but what we find missing is the recognition that many of the 'practitioners' that are performing and sometimes leading these change activities are consultants, to whom on occasion entire functions of the business have already been, essentially if not officially, outsourced. Thus, to speak of 'practitioners' is to speak of both clients and consultants.

This in turn brings us to one last reason for a renewed focus on practice, and how this attempt at rapprochement between researchers and (both client and consultant) practitioners might be different from past attempts: we can put organizational problems 'in the center' and explore how the practice of consulting, i.e. the practice of addressing organizational problems, 'really' works, and quite regardless of who is performing that practice-researchers, consultants, clients or some combination thereof. This would certainly not be an 'expert-driven' practice, but neither would it be 'client-centric'. It would be 'problem centric'. We have the image of an equilateral triangle, with the problem space in the middle, and the three players at the 
points. If we more fully embrace the dynamics of practice the triangle might become a hexagon, an octagon, or even a circle (See Figure 4). Perhaps we could all get together for a little knotworking? 
Table 1: Alternative approaches to consulting practice

\begin{tabular}{|c|c|c|}
\hline Aspect of Practice & Knowledge & Knowing \\
\hline Role of client & Implementer & $\begin{array}{l}\text { Co-constructor of problems; joint participant in actions to } \\
\text { address them }\end{array}$ \\
\hline Role of consultant & Expert; diagnostician & $\begin{array}{l}\text { Co-constructor of problems; joint participant in actions to } \\
\text { address them }\end{array}$ \\
\hline $\begin{array}{l}\text { Problem identification } \\
\text { method }\end{array}$ & Diagnosis; values accuracy & Framing; values 'actionability' \\
\hline Problem solving approach & Application of pre-defined body of expert knowledge & $\begin{array}{l}\text { Applying of knowledge and experience, regardless of source } \\
\text { or ownership, as required by the situation; proactively seeks } \\
\text { affordances; makes use of mediating artifacts }\end{array}$ \\
\hline Participation & $\begin{array}{l}\text { Exclusionary; limited to those in possession of expert } \\
\text { knowledge }\end{array}$ & Inclusionary \\
\hline Learning & $\begin{array}{l}\text { Transfer of expert knowledge; unidirectional from } \\
\text { expert to novice }\end{array}$ & $\begin{array}{l}\text { Transfer of knowledge, and explicit provision for creation of } \\
\text { knowledge through participation; multidirectional }\end{array}$ \\
\hline Treatment of knowledge & Individually possessed resource; atemporal; portable & Product of knowing; temporal; situated \\
\hline $\begin{array}{l}\text { Relationship between } \\
\text { knowledge and practice }\end{array}$ & Separate, or no defined relation & Mutually constitutive \\
\hline Nature of expertise & Possessed, individual capability & $\begin{array}{l}\text { Emergent accomplishment, of both individuals and } \\
\text { collectives }\end{array}$ \\
\hline Power relations & $\begin{array}{l}\text { Based on possession; asymmetrical, comparatively } \\
\text { undistributed; centered on expert }\end{array}$ & $\begin{array}{l}\text { Based on possession and performance; comparatively } \\
\text { distributed; periodically centerless }\end{array}$ \\
\hline
\end{tabular}


Figure 4: Problem-centric consulting practice

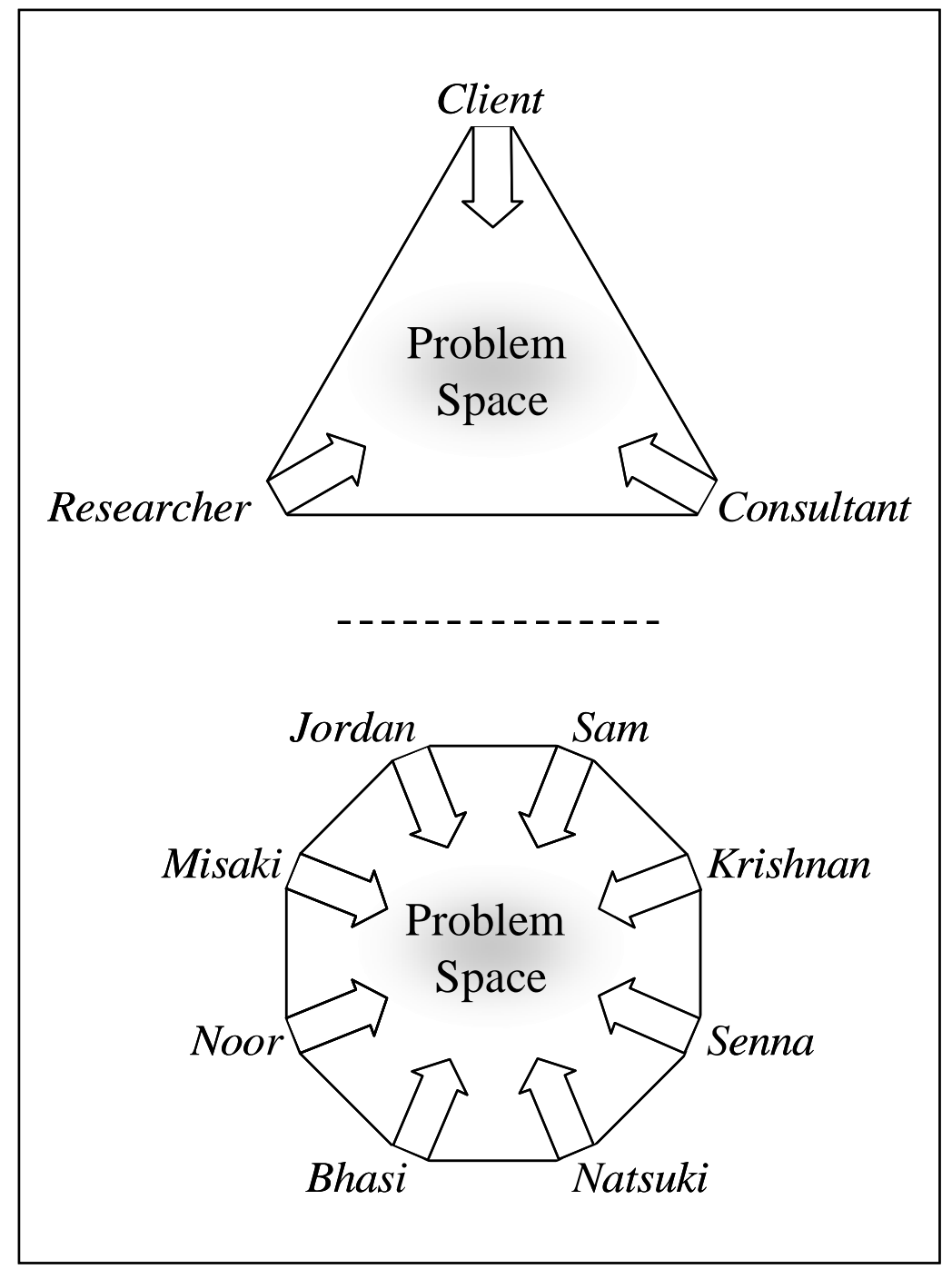




\section{Chapter 5: Brokering open, generative dialogue among clients and consultants}

\section{Introduction}

By the spring of 2008, I had completed the initial draft of an alternative, processual approach to consulting, as outlined in the preceding chapters. As mentioned in Chapter 2, I wanted to move away from what I viewed as the relative disengagement of traditional research, and toward action. Action research (Heron, 1996; Lewin, 1951; Reason and Bradbury, 2008; Reason and Torbert, 2001, and Aristotelian 'phronesis') attempts to move beyond disengagement, to embrace acting, engaging, doing. Action researchers seek not to understand organizations, so much as much as they do to change them. Reason and Torbert (2001) look at action research as the latest step in a progression away from positivism; on to the 'linguistic turn' (from the influence of Wittgenstein), which helped to expose the assumptions and deconstruct the constructedness of formerly unquestioned, scientifically derived 'reality;' and now to the 'action turn' of action research, which seeks to go beyond deconstruction, to construction. This is well in agreement with my views as I write this thesis, except I think there is another step we can take in this progression. It is a somewhat risky step, if your purpose is the writing of a dissertation and doing research (!), because it moves us away doing 'research' for the purpose of generating 'knowledge,' and more toward action, for the achieving of some specified purpose. A primary purpose of action research, according to Reason and Bradbury (2008) is "to produce practical knowledge that is useful to people in the conduct of their every day lives." But why must we do 'research,' which as I wrote above, implies that we are researching some thing, some reified object? Why can't we adopt the activist, humanistic, progressive spirit of Dewey's (1938) 'social inquiry,' but without considering it to be 'inquiry'? Why must we act in order to 'produce knowledge' instead of just 'acting,' in order to achieve a purpose, and with residual and re-usable knowledgeable as a fortuitous byproduct, just as 'innovations' are a fortuitous byproduct of 'innovating'? One response to the question often asked by academics-'How can academic research be more relevant to practice?'-is for academics to focus less on 'being relevant to practice,' and more on 'relevant practicing,' i.e. by working, right alongside clients and consultants, instead of producing research 'about' practice. With action research, Reason and Torbert propose to "forge a more direct link between intellectual knowledge and moment-to-moment personal 
and social action, so that inquiry contributes directly to the flourishing of human persons, their communities, and the ecosystems of which they are part" (Reason et al., 2001, p.7). Sounds good. But why must the focus be on the object of knowledge, and the forging of a link? For me, this detracts from purpose, and the idea of a 'link' comes too close to relying on the problematic and ineffective notion of 'transfer,' a transference that is made necessary whenever we focus on reified downstream knowledge, instead of upstream knowing. Acting does not preclude the use of theory, knowledge, experience or intuition. Action is, to quote Macmurray (1956) again, "a full concrete activity of the self in which all our capacities are employed," and to which I would add 'and by which the self is constituted and re-constituted.' At this point in the writing of the thesis, and the further development of an alternative approach, I wanted to go from 'action research' to just action, period, or better yet, acting, in order to be helping.

Summarizing, then, in letter form the purpose and results of my work to date, I made contact with a number of clients, consultants and academic researchers of consulting, and then followed up with a series of one-on-one and group conversations. In total, I spoke with just over 70 people: 22 during one-on-one discussions, 47 during group discussions and workshops, and 3 during the course of a business strategy project. These conversations were not for the purposes of 'validating' my research, but rather to share with clients and consultants ideas and tools that might be useful for their practice; they were not to form the basis of predictions or prescriptions for how consulting should be, but rather to discuss some ideas, and generate new ones, for how consulting could be. I 'seeded' these conversations with ideas from my own research, and then let them go in whatever direction they would. In this chapter, I want to share with you the results of these conversations.

\section{Results: The disconnectedness of clients and consultants}

Among the limitless number of conclusions, themes or 'key points' that could be constructed, the most important to emerge from these conversations has been simply this: While both clients and consultants understand and agree to the merits of a more pragmatic, relational and processual approach, taking advantage of the possibilities offered by this or any alternative approach to consulting practice seems to depend on dialogue between clients and consultants being much more open, and much more generative, than it is today. 
As for dialogue being 'open,' I'm referring primarily to moving away from conversations that maintain a strict adherence to the respective (and restrictive) official roles of the client and consultants, and also away from the official vocabularies and practices they are expected to make use of. In turn, I'm advocating a move toward open dialogue where clients and consultants - and also academic researchers of consulting — can "explore the individual and collective presuppositions, ideas, beliefs, and feelings that subtly control their interactions" (Bohm et al., 1991). On numerous occasions, consultants said that while the activities of a processual approach were attractive, such an approach could seldom if ever be discussed openly with clients, and could not be written explicitly into proposals and plans; despite their attractiveness. Even though similar activities were 'unofficially' underway anyway, when written into an RFP or proposal, the ideas would be seen as "too soft," "too indefinite," or otherwise "difficult to sell." Such comments came from both consultants and clients and consultants alike, and it was striking as I went from one conversation to the next, just how similar the comments of these two groups were overall. Any doubts I had as to whether clients and consultants were willing to continue on, despite a significant and ongoing gap between official accounts and the day to day activities of practicing-these doubts were removed. The story of The Emperor's New Clothes comes to mind.

As for being dialogue being 'generative,' I refer to the opportunity to move beyond the idea of communication as merely the transmittal of (already existing) information between (already existing, i.e. fully constructed) individuals (Shannon and Weaver, 1949) toward the notion of dialogue as the ongoing co-construction of meaning (Bouwen, 1998; Shotter, 1998), new vocabularies; new possibilities for action (Bohm et al., 1991; Gergen, McNamee, and Barrett, 2001), and also action itself, i.e. the use of language as a performative act (Austin, 1962; Taylor and Robichaud, 2004).

The purpose of this chapter, is to 'broker' more open and generative dialogue among clients and consultants, by telling each group something of what the various members of 'the other side' might have difficulty telling them directly. This is not to say they don't already know what the other side is saying (which I think they do), nor that their respective views are radically different (which, in my experience, and based on these conversations, they're not); it is simply to say that sometimes, it helps to have someone around who's willing (or naïve enough) to speak up, to suggest the emperor just might catch a chill, i.e. to 'broker' the 
conversations; to put things in writing, and also to provide some ideas, vocabulary and tools for how more open and generative dialogues might be accomplished.

\section{Format}

The conversations occurred during group workshops, and during one-on-one conversations (and also one-on-one follow-up conversations with some of those who had participated in a group workshop). I also had conversations with a few additional people during a business strategy project I was engaged in as a consultant. A difficult and rather tense political situation during this project (in other words, the project was perfectly normal!), however, limited the opportunities I had to speak openly of 'research,' although I was able gather notes on my own experiences, which are incorporated below. For the one-on-one conversations, I summarized in a 4-page letter my research to date (see appendix), and asked for participants to join a one-hour conversation. I sent letters to current and former colleagues, and obtained subsequent contact names from this first round. During the discussions, I began by presenting a brief overview (approximately 10-15 minutes) of my research and three ideas of a processual approach: organizing, knowing, and relating, in that order, and then spent the remainder of our time in conversation-listening to their views on these ideas, and jointly pursuing and developing others, as they arose. The group discussions, five in total, were structured similarly, beginning with a presentation by me, followed by conversation. Three of the group workshops were with client groups, and two with consultant groups, averaging 1015 participants per group. Client participants were from large, multinational corporations, and were all of management level, with titles ranging from 'Manager' to 'Senior Manager' to 'Vice President,' representing the information technology, telecommunications, industrial manufacturing and food manufacturing industries. Consultant participants ranged from Junior Consultants to Managing Partners, from seven different consultancies, raging from very small (7 people) to the largest of the 'Big 4' firms. For the academic researchers participating in one-one-one discussions, four in total, three were from management departments, one from psychology, and all were involved with research on the consulting industry and/or professional services management. 


\section{'Organization' to 'organizing'}

Of the three areas I 'seeded' the conversations with-the notions of organizing, knowing and relating - that of organizing 'resonated'67 most strongly for those with whom I met. Making use of Figure 5, people caught on quickly, and during the group workshops there were lots of nodding heads and exchanges of knowing glances between coworkers. The introductory story I told here was similar to that outlined in Chapter 2, namely that of the dynamic processes of 'organizing' becoming

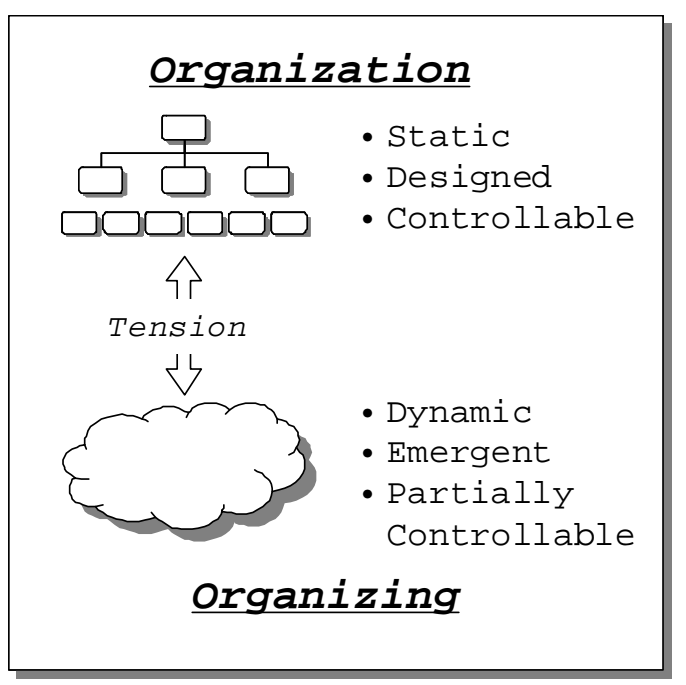
reified over time as the (assumedly) predictable and Figure 5: Organization and organizing controllable 'organization,' how the difficulty of organizational change was perhaps more understandable, given its attempt to control outcomes of processes once considered less than fully controllable, and how outcomes might be improved with an alternative assumption of change as the norm, stability the exception. I also asked how consulting might be different, under the alternative assumptions of organizing, of continuous change as the norm, and stability the exception.

An understanding of the notion of 'organizing'-although not necessarily by name-was evident from the very first conversation, which took place with Evelyn, an internal consultant with a telecommunications company:

Evelyn: "This is such a heavily matrixed organization, so, there's a great deal of comfort with this [pointing to 'organizing' on Figure 5], okay?"

Jeff: "That's good."

Evelyn: "Well it is and it isn't. It can be very messy. And if you're not well connected to that social network, it's going to be a little hard to get things done."

Jeff: "If we did a survey and put this thing [Figure 5] up on the wall and 100 [company name] people walked by, how many of them ... it sounds like they would say 'well, yeah ...'

\footnotetext{
${ }^{67}$ To borrow Keith Grint's phrasing (1994).
} 
Evelyn: "This [pointing to 'organizing'] is how business gets done."

Jeff: "They would already . . that's not news to them at all?"

Evelyn: "No."

When I asked if the understanding of, or familiarity with the notion of organizing was consistent across the various levels of management, however, Evelyn seemed less convinced. From her perspective, some, particularly executive-level management, believe that changes to organizing and the ways work is done, can be achieved by making changes to the formal organizational structure:

Evelyn: "Yeah, I think, sometimes the higher they [executives] go, um, I think there may be an expectation, that this [the 'organization' on Figure 5] is working better than it is, because, and I see that, and I do see that here, that there's an expectation that changing this [the 'organization'], will really affect the way we work [pointing to 'organizing']. And so we do this [make changes to organization charts], you know? 'Okay, now we're going to move these organizations over here, now we're going to put this over here.' And I mean I cannot tell you how many iterations I've seen in the nine years that I've been here. It can be a revolving door sometimes . . . and that's . . things may change over time, but it's not because you're changing that structure [of the organization]."

Ralph, a Vice President of new business development commented that projects, even successful projects, rarely go as planned, requiring managers and consultants to respond continuously to unexpected changes, issues and problems. I asked him how they responded in such situations of uncertainty:

Ralph: "When something pops up, do you take charge of it and change it so that it benefits the overall project, or do you, you know, struggle with it and do you, are you paralyzed with it, or you know, do you, do you know how to handle it? So that exception handling, constantly, managing that, I think that's what it is. . especially big projects, that's what they turn into. . . I mean every morning you come to work, and you already expect things to have totally fallen apart, and I have, if you get, some of my guys actually . . . some of 
them quit because of this factor. They could not handle the fact that, they knew the morning they came in, when they got, when everything was sorted out in the evening, and you have all these different time zones, so evening here is, you know, morning there, and you know, all that stuff, they know already when they just sorted out all the problems, now things look fine, that the next morning when they come in, then, if they're here in the US, then Europe has already been working for eight hours. So there's lots of things have gone wrong again. And you know, if you let that become, if that is really, if that feels really bad to you, then you can't manage in that kind of, they can't work in that type of situation, and some of them actually quit. And it was like 'No, this is crazy; this, this doesn't work; this is going to collapse, you know, next month.' I said 'No, it collapses every day, then you fix it, then you fix it, and you just have to embrace that kind of thing.' And, um, so every morning when you come in there's always a bunch of things that are not going the way you had thought, you know, the previous day, and then you kind of massage them and you work it, and then by the end of the day maybe things are moving again in, well things are constantly moving, but maybe you've solved something and steered it in the right way. So it's continuous contingency planning."

So much for 'official accounts' in RFPs and proposals of projects moving forward, in linear fashion, through discrete methodological steps! But despite the ready understanding and familiarity with the notion of 'organizing' and a processual view in general, it remains informal, and undocumented. Dianne, an HR Vice President commented:

Dianne: “A lot of what you've said here [in the introduction letter] it's, like I said earlier, it's all in place already, for the most part, but nobody's really written it down."

James, a project manager for a food products manufacturer commented on his project experiences, also mentioning specifically the gap between official and unofficial accounts:

James: "You have to have that basic training, so that you can, uh, basically talk the language of, that people expect you to say and do, and the plans need to look 
in a certain way .... On paper, I had all kinds of nice web sites set up, that showed exactly what we do, how we do it, all the processes, so it was, it was well documented. But in that type of mode [organizing], behind the scenes there are all kinds of things going on, that I think must be there. And, you know, I think that's just how you must operate to get things moving. It's just the normal way."

Some other ideas that emerged from the conversation on organizing included viewing projects as entrepreneurial start-ups, where there is an expectation from the beginning that events will not unfold as planned, and that those involved will need to be flexible and pragmatic. For one manager, this in turn led to the idea that rather than asking people to more closely embrace uncertainty, we might be better off by simply selecting different people - a less risk averse group initially, during start-up, transitioning to a different group as processes stabilized. "Some people like to just manage the farm, with those skills, and others like to build it" he commented. As for consultants, another client commented: "Consultants are just normal people . . . and it may be difficult for them to suddenly bounce around" from an expert to a more collaborative approach; they would have to be a "super consultant." There were also a few new and interesting turns of phrase: one researcher captured well the notion of continuous change by defining organizations as "temporary stabilizations of an ongoing process of organizing." One client urged his teams to think not of linear project plans, but of a "three-dimensional project space" to emphasize the need to draw information and insight from whatever direction may be useful for moving forward. Here there is similarity with our idea of 'emancipatory space.' One researcher commented that as we focus on upstream activities, we would also need to have a greater awareness, and a more explicit treatment, of our own values. As our focus shifts away from realizing some organizational ideal, it is our own ideas and values and choice that become a more important guide for practice. We would also need, she added, an expansion of our "behavioral repertoire."

\section{'Knowledge' to 'knowing'}

The second area of conversation focused on 'knowing' as the upstream activities resulting in 'knowledge.' The introductory story here, again as outlined in Chapter 2, was that, given the indeterminacy of consulting practice, 'stored' knowledge was never or seldom 'just right' for the situation at hand. I also asked how much room or latitude there is or could be to work 
more open-endedly and collaboratively, moving away from a focus on transference of expert knowledge, and toward a focus on practicing itself.

Because the earlier conversation had focused on the processual notion of organizing, the idea of 'upstream' activities resulting in downstream results—in this case knowledge-was readily understood. Compared to the conversation on organizing, however, several people commented that consultants would continue to be seen primarily as sources of expert knowledge, with knowledge being treated as an asset. The construction of the 'consultant' identity, and the 'expert consultant' identity, in particular, seem steadfast. Moving away from the paradigm of "clients paying for consultants' knowledge" could only happen slowly. In this way, and more than I expected it might, the conversation on 'knowing' often turned to conversation of the client-consultant relationship. Tim, a senior project manager for a hi-tech company, and also a former consultant said:

Tim: "You're being marketed as an expert. The knowledge you have as an expert consultant, the exchange of that $i$ s the relationship with your client . . . I know currently at [company name] when we've hired consultants in, um, they've all been more of the, of the knowledge transfer expert guys. Um, they've also been individuals; they haven't been consulting companies. They’ve been, you know, “Joe Expert' understands innovation; we're setting up an innovation thing; it's quicker for us to pay this guy fifty grand than for us to get, you know, than, than for us to try and figure it out for ourselves.' So it's more of the knowledge transfer, that's what we're seeing internally right now."

Some, like Mark, a senior manager with a large consultancy, were skeptical about the possibility of more open-ended, collaborative practice, without a primary focus and reliance on expert knowledge:

Mark: "I think it's just hard to come in and say [to the client] 'You have smart guys, we have smart guys; we have some experience, you guys have some industry experience; let's get a bunch of people in there and, and try to work this out.' I think that's just harder to sell to some executives, because they don't wanna hear that. They want to be able to say to their boss 'Oh yeah, we got these 
guys in, and they're killers, man. They've done this fifteen times. This, this problem's going away,' right? 'We have the knowledge and we're going to solve your problems."”

But less than 5 minutes later, in the same conversation, Mark also said:

Mark: "I was on a project at [consulting firm] where, you know, we were trying to come up with something, and I said 'I don't know how to do this,' and the client executive [the consulting firm partner] said, you know, she's like 'I don't know how to do this either, just make it up.' And I'm like, 'Well, okay.' So that's one level, right, of 'just making it up,' and I think a lot of that happens. The question is, um, do you tell clients that, right? And that's were I think the gap is."

The point we want to make by comparing these two passages, is that while it may indeed be 'harder to sell' projects pitched as exploratory, and as not relying on the possession or transfer of expert knowledge, a reasonable case can be made that this is precisely how projects often unfold in practice. And indeed, as Mark says, that's precisely where the gap is.

\section{'Relationships' to 'relating'}

In this third area of conversation, we focused on client-consultant relations. A processual perspective was once again readily understood, even though this was for most their first exposure - at least explicit exposure — to ideas such as self-contained individualism, relational or dialogical selves, self-other boundaries, etc. Although it was not explained as such during the initial letter, I had some success during the face-to-face conversations by focusing on the relationship as being the result of earlier or upstream activities of relating. I proposed that despite the strong theme of individualism in Western culture, meaning itself- of our words, actions and things-were socially and relationally constructed, and also that a new conception of 'professionalism,' one characterized not by 'critical distance' or even objectivity, but close collaboration, might be beneficial.

Esther, a vice president of sales for the industrial manufacturer where I was involved as a consultant said: 
Esther: 'I don't think professionalism is any less important than it's ever been, but it's just different. Like you say, strong client-consultant relationships are collaborative and kind of brutally honest. There's a, I think about 'stick-toitiveness,' a sort of 'not giving up.' The consultants I have worked best with, I don't think I hold them to unreasonable expectations about what we can or can't get done. But what they bring is energy and taking on ownership. Their professionalism is just that: they don't give up. And they feel really, personally responsible about not letting anything fall through the cracks.

Evelyn, the internal consultant referenced above said:

Evelyn: "It seems we need to do some letting go. If we don't over-rely on [organizational] structure and also let go of 'trust in knowledge,' then there's just 'trust.' It's simple, really, we create trust and relationships. But it also takes away excuses - that's what I mean, we don't invest, we don't blame 'the organization' or 'knowledge,' but we have to make it work, or make the relationship, together. If we don't undertake the tasks to make the relationship, then of course, it's not there. Sounds simple.

Janice, a training department manager for a manufacturing company commented:

Janice: "The idea of relating resulting in relationships-I think it's there whether we recognize it as such or not. I can think of one interesting story. There was a consultant who came in; we were working on a compensation project, a compensation policy for sales. He gave his initial presentation and we thought it was just okay, but then he said, near the end, some things we thought were very insightful, even though we had only talked with him briefly, just a preliminary, an introductory conversation. So we decided to give him a try, and we brought him in. But the results were wonderful. Over a couple of months, we created a strong working relationship. But I was skeptical at first, but it took that time to create that trust and relationship. He was also very laid back, and wouldn't make too many promises. Everybody else [on the selection committee] was looking for more concrete, more commitments up front. They had wanted to go with the bigger name 
consultancies, just because that would, you know, give them something to, it would legitimize it."

But there are limits, or situations, where close, open-ended collaboration is not desired, as one client reminded me:

Jerry: I had a consultant actually, working with us, uh, last year, a company. We were trying to launch a new product line and I had built a business plan for it ... One of the things that is good when you start something new, you realize pretty quickly that you get totally engrossed in that idea and it becomes huge groupthink. Everybody you're around they think the same way, you know, they say 'this must be.' So then we said let's have an external come in and do a study of similar things. Do they come up with same findings? And in that case, you really want this approach [pointing to 'expert approach']. Because, and what they tried to do, which annoyed me, was they tried to move toward a more collaborative approach. Basically, they wanted to ask me more stuff. But as soon as I give them more information, they start to think along the lines of what I'm doing, and then they think that 'Hey, if I say this, he's going to, you know, he expects this, so let's put that there.' You know, so when you want a kind of independent review of something, then it's very valuable to keep this [pointing to 'expert approach'], or I guess there could be some ideas that they have. But the important part is that they're independent. Because otherwise they just take what I say and then they regurgitate that and come back and kind of say something that's in line with what I already expected. And then I'm very happy. But, or, my kind of first thoughts are that 'Oh, yeah, I was right. Okay, this was great. Thank you guys.' But then the second thought is that 'Okay, what did I gain?' You know, I knew all this stuff. They came back and told me the same thing. I mean, I didn't need them to rewrite these slides in this manner that I already gave them. So there's, there's, in some cases that is very, very important. And when they start trying to move here [toward a 'collaborative approach'] then it's, it's really annoying, because then that whole thing that you're paying them a lot of money for disappears." 
Here, Jerry expresses thoughts similar to those I had, and that resulted in this thesis moving away from a replacement for the expert approach, and toward one alternative to it. Obviously, because of personal style, beliefs, the client's specific request-as was the case above-or just force of habit, identities of 'consultant' and 'client' will continue to be constructed, and the people filling these roles will continue to interact accordingly. Unfortunately, however, these official roles and the behavioral expectations that follow keep consultants confined to acting in limited ways, as experts, and clients to demanding from their consultants behavior appropriate to an expert.

\section{Reflecting on the results}

Many of these conversations turned out mostly as I expected they might. By this I mean that after several years of experience in consulting practice, I know (i.e. I believe) that it's messy, and that the messiness, for very understandable reasons, is often swept under the carpet, and that the official accounts of how the project is planned to be run, has very little resemblance to how it unfolds. And yet few, understandably, explicitly mention this gap; few suggest the Emperor just might be nude. So when I went into these conversations, attempting to foreground what is usually backgrounded, making things explicit, I expected that people would identify with that, that it would 'resonate' with them, and that we could, together, successfully co-construct some new ideas, not only for the alternative, processual approach I was proposing, but for new ideas possibilities for consulting practice in general. And it did resonate. Yes, this is 'my' thesis, and to some degree 'my' constructions of 'what happened' and 'what was said.' But in this case, and especially in regard to the notion of 'organizing,' I don't need to twist things around, to 'cherry pick' the statements and quotes that support my story, conveniently leaving non-supporting points behind, because what emerged strongly supported this conclusion: Consulting practice is an indeterminate, open-ended process that could, if we would let it, be much more so-not for the sake of simply being open-ended, but because practice could be much more innovative and creative than it currently is. The 'robust, proven consulting methodologies,' asked for by clients and promised by consultants, cannot peacefully co-exist with the unpredictable directions in which innovating (by definition, really) often takes us. The innovation that results from current consulting practice seems to do so in spite of the deterministic methods and restrictive roles we bury it under. I don't believe we can take advantage of this—a processual, pragmatic, relational approach —or any alternative ways of practicing consulting unless client-consultant relations are more open and more generative than they are today. 
But in other important ways, the results of these conversations were unexpected. For example, I thought that speaking the unspeakable would generate some momentum in the conversations, and that I would then be able to get to the generation and co-construction of new ideas, new vocabulary and new ways of practicing when changing is considered the norm. I expected that people would have their little tricks that they had used successfully, and that I would be able to capture them, write them down here in the thesis, so that others could read about them, and then try them out for themselves in their own practice. About the momentum I was right. What was unexpected, however, was that I (we) simply weren't nearly as successful as we hoped we'd be, in generating or describing a lot of new ways, specific and concrete, of practicing consulting. When it came up in conversation, as it often did, that projects—successful and unsuccessful—were invariably indeterminate, I would always ask, 'And what do you do in such cases? How do you get along?' The most frequent responses were: "I don't know," or "I've never thought about it," or "It's just something you learn with practice. It can't be taught." The notions-and the words themselves-of 'organizing,' 'knowing,' 'relating,' 'processual,' etc.—seemed to be more or less readily understood and even (unofficially) underway, but other new and additional vocabulary, and/or new and different ways of practicing were not forthcoming. Perhaps an alternative vocabulary is simply not there. Or, perhaps it's this: since the explicit, out-front embracing of uncertainty is backgrounded, it also languishes and fails to develop, at least in mainstream discourse or practice, and so when people are queried, they do not have a rich vocabulary ready to hand. It's important to note that the processual vocabulary I have made use of comes mostly from disciplines other than management, and certainly from outside consulting discourse, academic or otherwise. Or perhaps I simply tried to do too much during one set of conversations-first to propose that consulting practice was emergent and uncertain, and then, in addition, to move on to the storying and co-construction of specific ways for dealing with this uncertainty. At a minimum, I wanted to introduce new ideas during these conversations, and I suspected that the time for more open-ended conversation and co-construction might suffer. Whether it was limited time, and not 'slowing the conversation down' enough, as Bohm et al. (1991) recommend, or whether it was primarily an issue of limited vocabulary, I'm not sure. But whatever the cause, the result is the same: we were unable to co-construct a rich new set of ways for practicing. What did emerge from these conversations, was the disconnectedness of those filling the roles of clients and consultants, people who sit in different rooms, saying very similar things. The purpose of this chapter, therefore, is to 
broker more open and generative dialogue that can result in the co-construction of new vocabulary and new way of practicing. In this next section, then, I want to propose some ideas for how such dialogue might be accomplished.

\section{From 'sending messages' to 'co-constructing relational realities during dialogue'}

Throughout this thesis, our 'method' has been to construct an account of a prevailing viewbe it a view on 'organizations,' 'professionalism,' etc-and then re-story or re-construct the prevailing view into an alternative account, a proposal, for how we might go on differently. Sticking with that method here as well, then, the prevailing view on 'communicating,' the view we want to re-story must surely be this: communicating is the sending of messages back and forth between discrete and separate individuals (de Saussure, 1983; Shannon et al., 1949). These messages are structured according to grammatical rules, and are composed of words which represent or reflect concrete meanings. But are these meanings concrete? As we discussed earlier, the phrase 'the sky is blue' is meaningful for us not because of some inherent 'blue-ness' of the sky, but because we have previously agreed on what we would call 'blue.' So the meaning of 'blue' is concrete only to the extent that we have made it so. The understandability of the phrase depends on some earlier relational construction of meaning. Contrary to the transmission metaphor of communication, then, there seems to be some prior connection between what are considered separate individuals, a prior, relational constructing of meaning that makes 'the sky is blue' a meaningful phrase. And of course we could bring up other difficulties, difficulties that emerge as soon as we attempt to invoke meanings, beyond those which we have relationally co-constructed, such as, for example, the difference between 'dark blue' or 'navy blue,' or what the Japanese may mean when they say 'ao'-a word that can generally, but certainly not in all cases, be translated as 'blue.' It is the back and forth talking that we do during conversation, in order to work out the differences, and construct shared meaning, that we want to refer to as 'dialogue.'

To bring this back to our discussion on consulting, we've written that we hope to broker dialogue that is 'open,' and 'generative.' Focusing in for the moment on the first of these'open'-we want to make use of David Bohm's (Bohm et al., 1991) notion of dialogue, which is that of conversations, whereby people can "explore the individual and collective presuppositions, ideas, beliefs, and feelings that subtly control their interactions." "For example," writes Bohm, "we do not notice that our attitude toward another person may be profoundly affected by the way we think and feel about someone else [a different person] who 
might share certain aspects of his behavior or even his appearance. Instead we assume that our attitude towards her arises directly from her actual conduct." Dialogue allows for us to "slow down" and "examine the preconceptions, prejudices ... that lie behind his or her thoughts ... along with the roles he or she tends to habitually play."

Bohm's notion of dialogue, then, seems appropriate and useful for clients and consultants, as a method for setting aside, at least for the moment, the constructing and actioning of specific purposes, and simply talking openly, with one another, about the roles they play, the roles played by 'the other,' the 'identities' they construct-knowingly or unknowingly, and their expectations, experiences and heretofore unquestioned assumptions that shape their current views. Rather than relying on assumptions about the role of the client, or the consultant, we can co-construct some idea of what we want these roles to be, and also how prominent (or not) we want 'roles' to be in the first place. During my conversation with Jerry above, for example, he was clearly looking for the consultant to play the role of 'independent, expert evaluator,' rather than 'close collaborator.' I too, during my consulting experience, have learned some important (and some rather painful) lessons about the importance of dialogue, early and often, for clients and consultants alike to gain clarity on mutual expectations and understandings. As I discuss in the following chapter, this kind of open dialogue takes time, but it is, in my experience, well worth the investment, and much preferred to having the same conversation, weeks into the project, when problems arise, and differences in baseline understanding come into sharp relief. In Chapter 7, we introduce a simple framework of different ways that clients and consultants may choose to work together. This is not intended at all to be prescriptive, but more as a facilitator of dialogue about how they might prefer to work with one another.

Ken Gergen, Sheila McNamee and Frank Barrett (2001) propose a similar dialogical approach they refer to as 'transformative dialogue' which "may be viewed as any form of interchange that succeeds in transforming a relationship between those committed to otherwise separate and antagonistic realities (and their related practices) to one in which common and solidifying realities are under construction" (p. 682). Transformative dialogues have been used successfully by the Public Conversations Project ${ }^{68}$ to help address stalemated public controversies, e.g. abortion. Drawing from constructionist ideas, Gergen at al. propose six

\footnotetext{
${ }^{68}$ See www.publicvonversations.org
} 
'components' that are useful for transformative dialogues: 1) from blame to relational responsibility; that is, recognizing the shared responsibility that comes with a shift away from a view of people as self-contained individuals, and toward that of relationally-connected, dialogical selves; 2) self-expression-ensuring each voice is heard; 3) affirming the otherfinding something in the other person's expression to which you can lend agreement and support, or 'honoring the validity if their subjectivity;' 4) coordinating action and invitation to improvisation, including verbal and physical actions that are in response to the others; 5) selfreflexivity and polyvocality, refers to moving away from a view of self as singular, coherent and not fragmented, away from 'our position,' and toward allowing for the questioning of the self, and for other, perhaps 'self-contradictory' ideas to be voiced; and finally 6) the cocreation of new worlds, or the co-constructing of alternative futures, narratives of what could be.

In addition to dialogue that is 'open' and less instrumental or purpose-driven, we also see a need for dialogue that is more purposeful and 'generative': dialogue to construct the issues and opportunities we address during consulting practice; dialogue to construct new vocabularies for consulting practice-vocabulary that seemed, in the conversations above, to be not well-developed, and still insufficient for describing how it was that experienced clients and consultants 'get along' amidst the uncertainty of practice; dialogue that is not only enabling of action, but dialogue as action or acting. This is to treat dialogue (and the use of language more generally) as a performative act (Austin, 1962; referenced in Bouwen, 1998). Dialogue is embodied in our action (Gergen et al., 2004). Through dialog and conversations (activities which we could also call 'organizing'), we construct 'the organization' (Taylor et al., 2004) and also the closer-in constructed problems that guide action. This is using dialogue not just to reflect, but to 'do things to each other' (Bouwen, 1998).

Dialogue is also generative in the sense that in that can result in constructions that go beyond the sum of 'individual' contributions, and may result in unexpected or unforeseeable constructions as well. Similar to the idea of 'affirming the other' above, and drawing from the work of Bakhtin: I make a contribution to the dialogue, a contribution which in itself, however, may be an incomplete or non-actionable idea, and different from your ideas and experiences. A response is made, similarly incomplete and outside of my experiences, and so on, leading eventually to results that are greater than, and no longer traceable back to, the individual contributors. In this way, dialogue can also introduce a healthy tension. Dialogue 
can move us away from consensus, and, with effort, through dicensus, to a new and perhaps innovative consensus (Jabri, Adrian, and Boje, 2008).

\section{Summing up}

The processual constructions of organizing, knowing and relating had helped me out of the impasse I had reached earlier in my research. These constructions and the processual approach they enabled seemed to hold significant positive potential for improving consulting practice. I was excited to be bringing these ideas, and my research, out of the university and academic journals, and into the field to share and further develop them with others. Their reactions and the results were mixed. I was encouraged that these processual constructions and the notion of a processual approach were understood, seen as valuable, and, unofficially at least, already underway as well, to some degree. I was less than encouraged, however, with just how difficult it seemed to be to develop these ideas further, more concretely, and with more examples. The restrictive roles of both clients and consultants, the strength of longestablished and prevailing views about what constitutes acceptable language for RFPs and proposals, and the lack of a rich, alternative vocabulary-these challenges would not be overcome easily, or overnight. In the next chapter, however, we demonstrate, with a case study from practice, one successful example of how iterative rounds of engaged dialogue between clients and consultants led to the re-construction of the problem at hand, that in turn helped the team get 'unstuck' and bring the project to a successful completion. 


\section{Appendix to Chapter 5}

Tuesday, M arch 17, 2008

First, thank you very much for your time and assistance. This research is focused on the development of an alternative approach to business consulting. Thus we consider your ideas and our upcoming conversation to be more than just 'participation,' but rather as 'coconstruction' of this alternative approach. Copies of the materials produced, with appropriate changes to ensure the anonymity of individual participants and their organizations, will be made available to all the clients, consultants and researchers involved in this 'construction' project.

The purpose of this letter is to explain the background and purpose of our research, as preparation for our upcoming conversation. We begin with an introduction to what we mean by an alternative approach. Then we put forward three questions for discussion, corresponding to three aspects of consulting: the context for consulting, the client-consultant relationship, and the focus of consulting practice itself.

\section{Towards an alternative approach to business consulting}

By 'alternative,' we refer to an alternative to the traditional 'expert approach' to consulting, ${ }^{69}$ whereby a professional (i.e. an 'expert consultant'), detached and objective, applies a body of expert knowledge, according to a standardized method, for the resolution of clients' organizational problems. This approach is quite similar to that historically adopted by other professions, including medicine, law and public planning, and its origins can be traced back to the industrial revolution of the latter half of the nineteenth century, and even earlier, to the Enlightenment of the seventeenth century. The influence of these 'modernist' ideals extend beyond the image of the detached professional: the organization is considered a static, controllable entity, and knowledge is thought to be universal and transferable, unaffected by the passage of time and the changing of context.

\footnotetext{
${ }^{69}$ See, for example, Talcott Parsons' 'professional man' (1939), the 'doctor-patient' model of Ed Schein (1969) or the 'brain surgeon' in the model of David Maister (1997).
} 
Today, such an approach seems antiquated, at best. A client or consultant who acts 'detached,' for example, is unlikely to be our first choice for a partner in innovation or close collaboration. For experienced project managers and consultants, organizations-and especially the outcomes of organizational change initiatives-are anything but fully controllable. And knowledge, far from being readily transferable, is more often seen to be 'sticky' ${ }^{70}$ and firmly embedded within the contexts where it was first created. ${ }^{71}$

But while this image of the 'expert approach' may seem antiquated, it is nevertheless still a part of consulting today. Client RFPs and the consulting proposals given in response, for example, routinely call for a 'professional' approach, without specifying what sort of professionalism is being requested or provided. Despite the dynamic and unpredictable nature of project environments, we continue to frame change initiatives as a move from a "current state" to a "future state," as if organizations existed in static 'states' and as if the pathway to successful outcomes were both straightforward and controllable. And despite the well-known difficulties of 'knowledge transfer,' it is nevertheless considered to be a benefit we can unproblematically capture during the course of the project. $^{72}$

The reaction to what we have presented here thus far sometimes runs along the lines of the following: "Of course there are formal and informal activities, and of course there are 'official' vs. 'unofficial,' or even 'unwritten' versions of the project plan. It's also understood that the ideals of professionalism have changed. There's really nothing new here." We fully agree. Something that is new for many, however, is information on just how pervasive the disconnect between the official and unofficial accounts of practice is, and how long it has been going on. We offer three examples below.

Today, sophisticated methodologies and project plans are a given for most organizational change initiatives. However, in a research conducted here at our university, involving surveys and interviews with approximately 300 consultants, $86 \%$ reported that they did not work according to a formal methodology. ${ }^{73}$ Another example involves problem solving methods.

\footnotetext{
${ }^{70}$ We refer here to Eric von Hippel's (1994) notion that knowledge is difficult to move from where it is, to where it is needed, for purposes of problem solving. Knowledge that is difficult to transfer is considered to be 'sticky,' as measured by the cost of transfer. See also Szulanski (1997).

${ }^{71}$ See, for example Hansen et al. (1999), McDermott (1999), and Werr and Stjernberg (2003).

72 See Davenport and Prusak (2005), and Wood (2002) for a general discussion of knowledge transfer and knowledge management by consultancies, and Ko et. al (2005) for a focus on knowledge transfer during enterprise system implementations.

${ }^{73}$ See Visscher (2001).
} 
Project proposals and plans, along with university, corporate and consultancy training curricula, continue to focus on traditional problem solving techniques-clearly defining the problem, followed by the development and selection of alternatives. Yet, more than twenty five years ago, Donald Schön, a well known researcher of professional practice, observed that what managers encounter most often are not clear-cut problems to be solved, but "problematic situations characterized by uncertainty, disorder, and indeterminacy." ${ }^{74}$ And finally, a clear recognition of the tensions between the formal organization chart and the actual activities of the organization can easily be traced back to the very beginnings of modern organizational studies in the late 1930s. ${ }^{75}$ In other words, and in many cases, the 'official' version of consulting practice, as documented in RFPs, proposals and project plans, bears more resemblance to long-outdated images of professionalism, organizations, and knowledge than it does to the ongoing day-to-day project activities. This doesn't mean project plans aren't useful or required. And neither are we trying to eliminate the "art" of exceptional project managers and project teams. On the contrary, we are trying to incorporate the insightful and creative methods already in use by clients and consultants into the basis of an alternative approach to consulting. During our conversation, we want to explore the possibilities for how consulting practice might be different if we embrace continuously changing organizations as the norm, and stability the exception. We want to look at three aspects in particular: the context for consulting, the client-consultant relationship, and the focus of consulting practice itself.

\section{Context for consulting: From 'organizations' to 'organizing'}

As alluded to above, the earliest days of organizational studies were focused not on 'organizations,' but on the dynamic and unpredictable activities of 'organizing'-i.e. the activities of work itself. But as the size, scope and complexity of a successful enterprise grows, the ad hoc activities of 'organizing' become formalized into standardized processes and outputs of the designed 'organization,' which begins to take on a life of its own. At some point, work must begin to conform to the organization, instead of the other way around. As market/customer demands change, what were once useful, standardized rules become instead 'rules for rules' sake.' With increasing constraint, the activities of organizing continue, leading finally to an 'organizational change' initiative and a repeat of the cycle. Thus, contrary to what is implied by the phrase 'change management,' our 'organizations' are changing all the

\footnotetext{
${ }^{74}$ The Reflective Practitioner by Donald Schon (1983): pp. 15-16.

${ }^{75}$ See Chester Barnard's (1938) The Functions of the Executive
} 
time, with or without our involvement to manage the outcome of that change. From this perspective, the low success rate of organizational change initiatives is not so surprising. Mandating changes to processes and their outputs is one thing; achieving those changes in practice is quite another. In addition, there are limits to how much the emerging activities of 'organizing'-which are also a primary source of creativity and innovation-can or should be managed. We think there are useful ideas to be gathered by looking 'back to the future' of organizational change.

\section{$\ddot{y}$ We would like to discuss with you the implications and possibilities that follow when we consider the context for consulting engagements to be not 'the organization' but rather 'the multiple, dynamic and often conflicting processes of organizing.'}

\section{Client-consultant relationship: From 'self-contained individuals' to 'relational selves'}

The second of three areas we would like to discuss is the client-consultant relationship. A characteristic of modern Western thought is to view the world as a collection of 'things' with discrete and non-overlapping boundaries. This is evident in the conception of 'the organization' as a concrete, designed entity, as discussed above, and also in our conception of the individual as being 'self-contained' and separate from others. For Talcott Parsons, ${ }^{76}$ an important figure in the modern history of the professions, this separation and detachment from the client, and even an attitude of 'disinteredness' were considered to be required characteristics of the professional. From a Parsonian perspective, then, a relationship is something that exists between two discrete individuals-i.e. between a client and a consultant-and serves primarily as a conduit for the one-way transfer of information and knowledge, from the professional to the client. Our point here is not to criticize Parsons, but simply to say that times have changed, and that given our more recent focus on innovation and close collaboration, a different conception individual and the client-consultant relationship may be useful.

\footnotetext{
${ }^{76}$ For Parsons, professionals are characterized by the following five attributes: 1) neutrality, i.e. the physician is not emotionally engaged in his patients; 2) universal, i.e. the judge treats all alike, regardless of their social position; 3) collective, i.e. professionals are service-oriented and work for the common good; 4) functionally specific, i.e. the professional focuses upon the disease, or the crime, etc., and ignores all other aspects; and 5) achieved competence, i.e. the professional has his position because of demonstrated abilities, not because of ascribed status or entitlement. Taken from Brante (1988).
} 
In many non-Western cultures, e.g. Japanese, Chinese, Hindu, and even Western culture before the Enlightenment, the self-other boundary is not so clear, and self-identity and group identity to some extent overlap. ${ }^{77}$ From this perspective, people can be said to exist not on either side of, but rather within a relationship whose boundaries are defined by a culture, a family, or, in our case, a project environment. Even within our own (Western) culture, although it is not always recognized as such, our sense of self is defined by terms whose meanings are defined not individually, but relationally. To think of oneself as being kind, for example, is to believe that our thoughts and actions are more considerate of other people, as compared to the thoughts and actions of those around us. The meanings we attach to events and evaluations are also relationally defined. For example, little meaning will be attached to the opinion of a single person who considers a given project to have been wildly successful, while every one else in the organization feels it was a failure. ROI may be an 'objective' measure of project outcome, but the decision as to how project outcomes are measuredquantitatively, with measures like ROI, or more qualitatively-this is more likely to be determined by what the evaluating group or organization subjectively and relationally considers to be appropriate. As these simple examples hopefully demonstrate, we are already more in relation than may at first be apparent. We can make this relatedness more explicit by thinking of clients and consultants less as 'self-contained individuals' and more as 'relational selves.'

$\ddot{y}$ We would like to discuss with you your views on the nature of the clientconsultant relationship, where you feel your own self-other boundary lies, and the implications and possibilities for consulting practice that result from shifting that boundary closer in (more excluding of others), or further out (more including of others).

\section{Consulting practice: Shifting the focus from possession to practice}

Knowledge is considered to be an important competitive resource. And management consultancies are often considered to demonstrate 'best practice' in the management of those knowledge resources. ${ }^{78}$ Perhaps because of the importance placed on consulting knowledge, consulting practice-i.e. the doing of consultancy itself—seems to have been overshadowed. But while knowledge and experience are of course important, successful outcomes ultimately depend on how well they are applied in practice. The importance of practice increases even

\footnotetext{
${ }^{77}$ One important study is that of E.E. Sampson (1988).

${ }^{78}$ See Davenport and Prusak (2005) for a discussion of knowledge management in consulting.
} 
further, to the extent that we embrace the emergent activities of organizing, which call for knowledge and experience well beyond those of any one expert or individual. In fact, the indeterminate situations of practice are indeterminate precisely because they call for knowledge and experience beyond that which is currently and readily available. In our view, we think it would be useful to shift the primary focus of consulting away from the possession of, and the amassing of ever-more knowledge that may or may not be used, and toward practice itself; away from being expert-driven or even client-centered, and toward clients and consultants working together in the co-construction of meaningful outcomes.

$\ddot{y}$ We would like to discuss with you the viability of, and the possibilities for, a consulting approach that truly gives primacy to practice. How might the structure of consulting engagements change? Today, how much 'room' is there for alternative forms of practice, for more open-ended, emergent goals and collaboration?

We hope this letter has helped you understand the focus of our research, and we look forward to discussing with you the possibilities for this and other alternative approaches to business consulting.

Sincerely,

Jeff Hicks

Lecturer and Research Associate, University of Twente, The Netherlands

Executive in Residence, University of Texas, Dallas

j.n.hicks@utwente.nl 


\section{Chapter 6: If you can't solve the problem, change the problem you're solving}

\section{Introduction}

Similar to the purpose Chapter 5, the purpose of this chapter was to engage in more direct and ongoing co-construction with clients and consultants, and to further develop the processual approach. Yet, I was also conscious of the very different vocabulary of this community, compared to the vocabulary I had been using for the thesis. The challenge then, was to construct a story, based on a project, that could demonstrate for clients and consultants the potential usefulness of the approach I was developing. Based on constructionism, we tried to demonstrate that teams have an opportunity to not only 'find' problems, but to proactively 'design' them to be useful and actionable — and also more interesting and personally fulfilling —in the first place, and to develop these designed (i.e. constructed) problems through ongoing, iterative and engaged dialogue. Based on pragmatism, we introduced an alternative way of evaluating problems, based on their usefulness to practice, as opposed to the more traditional criteria of 'accuracy' or 'rightness,' according to some external standard 'out there.' We introduced the potential problems arising from premature closure, which we referred to in the paper as 'premature structuring.' To encourage dialogue and the construction of local, shared meaning during the project, we cautioned against 'cleaning up' too much — for the sake of creation of 'official accounts- the informal language and contextually rich, project-specific jargon that often emerges during projects.

Although the introductory letter for the interviews of Chapter 5 took far longer to write than did the paper that now constitutes Chapter 6, it has been the latter-the paper that appears next - that has been by far the most enthusiastically received by clients, consultants and academics as well. Friends I had worked with as a consultant before beginning my research told me, upon reading the letter from Chapter 5, 'That letter was only four pages, but it was very dense reading! You've really become an academic.' Colleagues at the university as well remarked that my way of writing and speaking had changed significantly since just two years before. With the paper here 
in the chapter, I was determined to not let technical/theoretical vocabulary stand in the way of making a close connection with clients and consultants, around ideas I remain convinced are useful for consulting practice. This paper was published in the Journal of Practical Consulting, in the spring of 2009, Volume 3, issue 2, pp. 14-21. 


\section{If you can't solve the problem, change the problem you're solving: Problem solving in environments of continuous change $^{79}$}

Jeff Hicks
University of Twente
Padmakumar Nair

University of Texas, Dallas

\section{Introduction}

What's your approach when you, or the project team you're working with get 'stuck' on a particularly complex or difficult problem? Often, project teams respond by crunching the numbers (yet) again, adding even more data, or even more sophisticated analyses. This approach can indeed be successful, especially if you find a 'smoking gun' hidden in the data, or a calculation error buried deep in a spreadsheet formula. But in our project experience, this 'brute force' analysis and ever-more-rigorous number crunching is certain to lead to fatigue, but seldom to an answer.

Instead, we see consistently that breakthroughs come not from a dogged determination to solve a seemingly unsolvable problem, but when we have the courage to change the problem we are solving. By viewing the problem from a different perspective; by iteratively changing and re-changing the issues we include or exclude, we are often able to re-frame or re-design the given problem into an alternative that is more actionable for the team. In fact, we consider project teams' underestimation of the amount of control they have over deciding and designing what the problem will be, to be one of the most important and most frequently occurring factors negatively affecting project team performance.

The purpose of this paper is to share our experience with some specific techniques focused not on 'finding the problem,' but on 'designing the problem' to make it more actionable and solvable in the first place. These techniques include problem framing,

\footnotetext{
79 This paper was published under the title: "If You Cannot Solve the Problem, Change It! Problem Solving in Environments of Continuous Change," in the Journal of Practical Consulting, (2009) Vol. 3, Iss. 2, pp. 14-21.
} 
the idea of 'affordances,' and sensemaking, all enabled by a certain 'thought style' that is more concerned with being useful than with being right. We demonstrate their application in practice during our recent project with the Japan operations of a global mobile telecommunications company that we will refer to as ClearCom.

\section{The ClearCom Case}

With an annual turnover of more than US\$150 billion, Japan's telecom market is one of the world's largest and most competitive. For some time, ClearCom's senior management team had been dissatisfied with the financial performance of the socalled 'indirect' sales channel, which referred to sales of ClearCom products made by independent retail stores. With each sale, ClearCom paid a 'sales commission' to the retailer in order to lower (or eliminate) the price the customer paid for the telephone handset. Thus, by shifting away from indirect sales and toward 'direct sales'—sales made by ClearCom's own retail stores or over the internet-ClearCom would be able to avoid or reduce the total sales commission paid, and thereby improve financial performance.

But while a shift from indirect to direct sales promised to improve profitability, it also brought about the serious issue of channel conflict. And in fact some of the small, neighborhood 'mom and pop' retail stores had already threatened to discontinue ClearCom products if direct sales efforts were increased. For several months, the ClearCom management team experimented with and modeled numerous ratios of direct to indirect sales, trying to find a balance between commission savings on one hand vs. potential lost revenue from disgruntled retailers on the other. Exasperated over the inconclusive deliberations, ClearCom asked our firm to assist them in answering the question: 'What is the optimal ratio of direct to indirect sales?'

After a few days reviewing the extensive analyses ClearCom had already completed, we reported that, while the rationale behind their question was understandable, we could not answer it with a sufficient degree of confidence. Was the optimal ratio 3070? Or perhaps 40-60? Whatever ratio we might derive, an equally strong case could be built in support of another. In addition, even if consensus around a certain ratio could be achieved, ClearCom management would still be left with the question of how to go about implementing it. 
As is often the case when teams find themselves stuck, a kind of myopia has already set in that prevents them from seeing the problem in any other way. When possible alternatives do emerge, the voicing of them may be discouraged because so much has already been invested along a previous line of reasoning. Attention becomes focused on one or more seemingly immovable constraints - in this case channel conflictback to which all analyses seem to naturally and inevitably lead.

Taking the issue of channel conflict as a starting point, we began a series of openended discussions and brainstorming sessions, trying to identify any underlying assumptions. What exactly was meant by the phrase 'channel conflict'? The team viewed this as 'retaliation by the retailers, taking the form of discontinuance of the sale of ClearCom products, in response to ClearCom's expansion of retail sales.' And how certain were they that such retaliation would occur? Consensus was that, in the case of the mom and pop stores, retaliation was likely, since these stores could switch from the exclusive sales of ClearCom products to those of a competitor, and because some store owners had already threatened to do so. In the case of the 'big box' retailers, however, retaliation seemed less likely, primarily because an important part of their sales strategy was to offer their customers a comprehensive selection of phones and service plans from all competing carriers. Thus the discontinuance of a major carrier, such as ClearCom, was considered unlikely.

Beginning with this discussion, it became increasingly clear that addressing the sales commission issue would require a very different approach for each of the retail formats. Of course this was known before, but it had been obscured by the previous framing of the problem as 'direct vs. indirect sales,' which resulted in combining both retail formats into a single category. These categories of 'direct' and 'indirect' made sense for doing financial analyses, but did not correspond to departmental boundaries, making it difficult for people to coordinate their efforts. 'Indirect sales,' for example, included both the small independent mom and pop retailers, and the much larger big box retailers. But within ClearCom, these were handled by different departments, pursuing different market strategies, and with employees who seldom interacted during the normal course of business. Similarly, the category of 'direct sales,' mixed 
together ClearCom retail stores and internet sales, again prohibiting effective coordination.

By treating these two retail formats separately, the discussion was brought back into alignment with departmental lines, and, more importantly, the expertise of those involved. This turned out to be an important first step in reframing the problem, which shifted away from a focus on the financial performance of the 'indirect' sales channel, and toward the financial performance of the 'retail' sales channel, and the two very different segments which comprised it.

A final turn in the eventual reframing of the problem occurred with the realization that for the mom and pop retailers, the most important threat was not necessarily lost sales revenues, which were small compared to the larger retailers, but rather the loss of a valuable customer information. While the larger retailers accounted for the vast majority of sales, it was the mom and pop stores, with their slower pace and more knowledgeable sales staff, who accounted for the richest source of information about customers' requirements, preferences, and their likes and dislikes. The key contribution of the mom and pop retailers, in other words, was not a financial one. This insight crystallized the idea that improving the retail channel meant improving both the financial and the non-financial components of channel performance. The team now considered the problem to be: 'How can we maximize the total performance of the retail channel?'

With this re-framing, the forward momentum and general atmosphere surrounding the project improved significantly, as plans and strategies appropriately tailored for each format began to emerge. The mom and pop stores, for example, were positioned as key retail 'listening posts,' and ClearCom began discussions with the retailers about new initiatives and technology to support them in this role. For the big box retailers, ClearCom introduced a new multi-tiered commission structure that rewarded the highest volume retailers, but lowered the total sales commission paid by ClearCom. Finally, at the completion of our involvement with the project, ClearCom had also begun developing, in consultation with all the retailers, a list of possible locations for new, ClearCom-owned stores that, by agreement, would be built outside the areas 
served by the existing retailers. Channel conflict remained an important consideration, but no longer the immovable constraint it was earlier thought to be.

\section{From 'being right' to 'being useful'}

As demonstrated in the ClearCom case, there are important differences between more traditional problem solving methods and what we are proposing (Table 2). This alternative approach involves a certain thought style that is more concerned with being 'useful'-according to the project team and key stakeholders- than with being 'right'-according to an external reference or standard. In the ClearCom case, the framing of the problem as 'direct vs. indirect' wasn't wrong, but neither was it useful or actionable.

Another difference with the traditional approach concerns the locus and nature of the problem itself. In this alternative approach, the problem-or, better yet, that which gets treated as problematic-is, to some degree, a matter of choice. As most of us have probably experienced, the nature of the problem is sometimes very dependent on the perspective from which it is viewed. Marketing, for example, may believe product prices are too high, while Finance believes they are too low. Which view is 'right'? Which is the 'real' problem? Perhaps, as is often the case, they are both real, and they are both right. But which of these gets treated as the problem is a matter of choice. That choice need not necessarily be guided solely by analyses, but also according to which view is likely to be most 'useful' in moving the team forward. Our choice as to what the problem is, directly influences our ability to solve it. 
Table 2 Being Right vs. Being Useful: Two Approaches to Problem Solving

\begin{tabular}{|c|c|c|c|}
\hline & & \multicolumn{2}{|c|}{ Problem Solving Approach } \\
\hline & & Traditional & $\begin{array}{c}\text { Proposed } \\
\text { Alternative }\end{array}$ \\
\hline \multirow{6}{*}{$\begin{array}{c}\text { Characteristics } \\
\text { of Approach }\end{array}$} & $\begin{array}{l}\text { Assumed nature of, } \\
\text { or treatment of 'a } \\
\text { problem' }\end{array}$ & $\begin{array}{l}\text { Exists 'out there,' } \\
\text { and is independent of } \\
\text { the perspective from } \\
\text { which the team views } \\
\text { it }\end{array}$ & $\begin{array}{l}\text { Product of project } \\
\text { team's design, } \\
\text { according to team's } \\
\text { chosen } \\
\text { interpretation }\end{array}$ \\
\hline & $\begin{array}{l}\text { Quality indicator } \\
\text { for problem } \\
\text { definition/design }\end{array}$ & Accuracy & $\begin{array}{l}\text { Usefulness, } \\
\text { actionability }\end{array}$ \\
\hline & $\begin{array}{l}\text { Primary team } \\
\text { activity }\end{array}$ & Finding, analyzing & Designing \\
\hline & $\begin{array}{l}\text { Number of possible } \\
\text { problem } \\
\text { definitions/designs }\end{array}$ & Single & Multiple \\
\hline & $\begin{array}{l}\text { Relation between } \\
\text { problem } \\
\text { definition/design } \\
\text { and solution }\end{array}$ & Separate & $\begin{array}{l}\text { Connected; } \\
\text { reciprocally } \\
\text { influencing }\end{array}$ \\
\hline & $\begin{array}{l}\text { Relation between } \\
\text { problem } \\
\text { definition/design } \\
\text { and team capability }\end{array}$ & $\begin{array}{l}\text { Problem defined } \\
\text { intentionally } \\
\text { separate from team } \\
\text { capability; gaps } \\
\text { filled at outset }\end{array}$ & $\begin{array}{l}\text { Problem designed to } \\
\text { maximize team } \\
\text { contribution; } \\
\text { remaining gaps } \\
\text { filled as necessary }\end{array}$ \\
\hline
\end{tabular}


From a more traditional problem solving perspective, problems are not chosen, and certainly not intentionally designed, but are thought to exist 'out there' and beyond the direct control of the project team. Since the problem is 'out there' a primary task of the team is to find it, and define it. As was the case at ClearCom, lack of progress in solving the problem is often attributed to not yet having found the problem. A 'root cause analysis,' for example, is a technique for finding the 'real' problem. Because the problem is considered to be 'out there,' analyses strive for problem definitions that are accurate, independently of the preferences and capabilities of the team members themselves. The result is a highly accurate description of $a$ particular problem that is not fully actionable by that particular team. This in turn often leads to a 'gap analysis' to identify the requirements for additional resources and different expertise. Gap analyses, however, are based on a number of assumptions: that the organization and the problem will 'hold still' while we implement; that resources and expertise will perform as expected, when expected; and more importantly, a gap analysis assumes that project outcomes are predictable and controllable, such that we can know beforehand specifically which resources and expertise we are going to need. But, as experienced project managers know all too well, projects rarely move in a linear, predictable manner, but unfold and emerge, often in unexpected ways. If we allow them to, project heroes can come from unlikely places.

In the next section, we introduce some specific ideas and techniques for designing problems that are actionable, and that take advantage of the creativity and innovative abilities of project team members.

\section{Affordance}

Because of the dynamic and emergent nature of practice, divergence between the project plan and the current situation is a common occurrence, and it is here that the idea of affordance can be quite useful. Emerging from the fields of psychology and industrial design, an affordance is simply an opportunity for action (Gibson, 1977). A pencil, for example, affords us the opportunity to write a note on a piece of paper. But in case what we need to do is punch some small holes in the paper, so that it can be placed in a notebook, the pencil affords us the opportunity to do that as well. By viewing familiar objects or situations in new or different ways, new and different opportunities are afforded to us. In a project environment, when the tasks prescribed by the project plan no longer help us move forward, the project team has the opportunity to ask 'Where can we go from here? What opportunities does our current 
situation afford?' The power of these kinds of questions lies in their open-endedness. While the next steps in a project plan are pre-determined, the affordances of any situation are limitless. Instead of looking down at the project plan, we can look around, and ask not 'What's next?' but 'What's possible?' Also, the answer to the question of 'Where are we now?' is open to interpretation every bit as much as is the question of 'Where can we go from here?' Often, however, project teams miss out on an opportunity for creativity when they treat a 'current state analysis' as being simply a matter of accurate description, saving all their creative energies for the envisioned 'future state.' The treatment of the current situation as the dead end of our current pathway, or the beginning of a new and more actionable one is a choice we make.

\section{Sensemaking}

So far, we have discussed two methods for designing actionable problems-framing and affordances. But amidst hectic and pressure-filled project environments, it can be difficult to know when to employ these techniques. Sensemaking can help us pick up on the 'weak signals' that a review of the current problem framing might be in order.

Based largely on the work of Karl Weick $(1969 ; 1995 ; 2001)$ sensemaking is, just as it sounds, making sense of any activity or situation. Sensemaking occurs, for example, when routine activities are interrupted by unexpected events. When, for example, during our morning commute the car in front of our own suddenly and unexpectedly brakes, we must quickly make sense of what is happening in the situation to avoid a collision. Most of our time during the day is spent not in a sensemaking mode, but in simply carrying out routines that we take mostly for granted. In his studies of accident investigations, Weick demonstrates how failure to make sense of an unfolding situation can have disastrous consequences: an entire firefighting crew is killed in a mountainous region of the US state of Montana after failing to pick up on several signals that the 'routine' blaze they are battling is anything but routine (Weick, 1993); two jetliners collide on a runway in the Canary Islands after crew and ground control personnel fail to make sense of the dangerous situation developing, again despite information and a number of signals that were openly available to them (Weick, 1990).

Fortunately, the situations faced by most project teams are rarely life-threatening, but the lessons these examples provide are quite applicable. Sensemaking reminds us of the 
importance of being attentive to and making sense of the signals we receive-and in particular the signals we do not understand. In the ClearCom case, for example, the difficulty the team experienced with their original framing of the problem was a clear signal that the way they were making sense of the situation was problematic. Questioning the usefulness of the framing earlier in the project might have avoided some of the delay in getting started in a more productive direction. Other examples of signals that the way we are making sense of a particular situation is problematic include, for example: a small piece of information that, while seemingly non-consequential, runs directly counter to our overall analysis; the market segment that simply will not fit easily into our current scheme for market segmentation; even the nagging feeling of an experienced executive that the temporary downturn in contract signings may not be so temporary. In our experience these are just the kind of signals we often decide to ignore, usually because, if we accept them and the implications they bring, they threaten to turn our existing plans, categorizations and problem framings upside down. But they are also the kind of signals that we ignore, often to our peril, like small cracks in windshield that will only grow larger if left unattended. Finally, and more positively, they are often signals of opportunity for creativity and innovation, if we can fend off time and budget pressures long enough to follow-up. Every unexpected event-positive or negative-is an opportunity for us to ask 'Why?' Key insights can be gained when, instead of treating something as 'odd,' we ask ourselves 'In what situation would this seemingly 'odd' event be perfectly normal?'

Finally, sensemaking need not only be in a reactive mode, nor do we need to wait for a crisis to occur before applying it. Proactively, managers can also engage in 'sensegiving' by proposing interpretations and explanations that help others make sense of otherwise indeterminate situations, thus providing a focal point for the team's efforts.

\section{Creativity Killers}

In this final section of the paper, we explain four of the most commonly observed practices that lessen the effectiveness of these techniques for designing actionable problems, and that we refer to collectively as 'creativity killers.'

\section{Premature Structuring}

Effective structuring can lend actionability to the problems we design. However, time and other pressures on the project team often result in premature structuring of the problem, 
which negatively affects not only actionability, but also the opportunities for innovation and creativity. In our experience, when teams settle on a particular problem definition, there is a general underestimation of the number of assumptions and decisions-explicit or otherwisethat have already been made, and an underestimation of how many possibilities that have already been excluded from the possible solution set. We have all the heard the expression that when the only tool you have is a hammer, all the problems look like nails. Likewise, if you've already decided that the problem is a nail, chances are the solution is going to look like a hammer! One way to evaluate whether a given problem may have been prematurely settled upon is to simply poll the members of the project team as to what the next steps are to address the problem. In our experience, the greater the variation in the responses, the greater the likelihood that the problem may have been hastily settled upon, and that a review of the current framing might be in order.

\section{Bullet Points}

Because of e-mail overload, multi-tasking and time pressure in general, we are often encouraged to deliver 'clear' and concise communications and presentations, using bullet points and discrete, non-overlapping 'chunks' of information. These techniques may be useful for ongoing communications, but during problem design, they often result in a loss of the details and nuance that help make problems locally-meaningful and actionable. The point may sound trivial, but we often see non-trivial improvements in problem design when we ask project teams to simply expand their bullet-point problem descriptions into full sentences or even paragraphs. Unnecessary detail can always be trimmed away later. Better yet, full problem definitions can later be distilled into definitions that are shorter, but rich with meaning for the project team. Often this distilled language, as discussed in the next section, can take the form of team-specific jargon.

\section{Unnecessary Avoidance of Slang and Jargon}

Most of us have probably been advised to avoid the use of slang or jargon in our own writing. But while their over-use can indeed be problematic (not to mention annoying), they can also be incredibly powerful. For example, we once worked with a chemical manufacturer who served a particular market segment that, for a number of reasons, was quite difficult to define. In conversation, the market segment was often described as being 'funky.' Often such words are excised from the 'official' project documentation, to make it appear more rigorous, scientific or smart. But used appropriately, jargon can effectively capture and communicate 
the locally 'meaning-full' essence of even complex issues. At the client's insistence, the word 'funky' remained in our final report.

\section{Conclusion}

In this article we have presented techniques for an alternative approach to problem solving in organizational contexts, for use in particular by project teams that find themselves stuck on a particularly difficult problem and without a clear path forward. This approach has been successful for us, in various types of projects, and at various locations in Asia, North America and Western Europe. Nevertheless, reactions to these techniques are divided, and represented by two fairly distinct groups: those who are skeptical, and a second group who are appreciative of the techniques, but unsure of how to apply them.

For the first group, changing the problem will always be simply another name for avoiding the problem - and our responsibility for solving it. For this group, a problem exists out there, and the challenge and responsibility of the project team is to find it, design a solution for it, and successfully implement. We have had the pleasure of working with project managers and directors who have masterfully carried off very difficult projects with this more traditional approach. For these managers and directors, although we believe them to be increasingly in the minority, the techniques presented here may hold limited value.

For the second group, questions are usually focused on how to apply these techniques, despite two key constraints: time/budget pressure and reporting requirements. Regarding the reporting constraint, the wider group of project stakeholders obviously expects to see quantitative analyses and clear rationale in support of team decisions. This does not, however, preclude the use of the proposed techniques to arrive at (often more innovative and creative) decisions in the first place, which can then be validated, and reported on, using more traditional analyses. For those who object to what they see as post hoc reasoning, we would respond that our proposed alternative is not dissimilar to the way many project decisions are currently made. Regarding the time/budget constraint, in our experience, discussions on problem design give a very high return on time invested, by ensuring that the project team is fully engaged with rich, actionable problem designs. Even one or two days of in-depth, honest and open-ended discussion—particularly at the beginning of the project—can have a significant positive impact. 
Finally, it is our belief that the use of these techniques can result in greater innovation and creativity, and also help to make the task of problem solving more personally fulfilling, through closer alignment between the work itself, and the hopes, desires and capabilities of the project team members. 


\section{Chapter 7: Summary and future actions}

\section{Introduction}

A dissertation written in a 'reflective practitioner' style, as this one is, has its advantages and its disadvantages. One advantage is that you can concentrate a little more on what you are trying to say and do, and a little less (explicitly, at least) on method, although for this dissertation, 'doing' the method means co-constructing relational realities with you, the readers, to achieve our purpose of helping. Thus, the process/content binary, like so many others-e.g. client/consultant, internal/external, planning/implementation, talking/doing-is collapsed. One disadvantage of this style of dissertation, however, is that it continues to emerge. And if the period of time covered by the thesis happens to also be one of significant change in the worldview of the subject 'practitioner' (i.e. yours truly), then the story is likely to take a number of twists and turns, and be more difficult for the reader to follow. This is especially problematic, because if the story is less interesting or difficult for the readers to follow, then the opportunities for co-constructing - and therefore the purpose as well-will suffer. In this final chapter, then, there is some clean-up work to do, to pull together the various ideas developed herein, so that the alternative approach we are putting forward becomes, hopefully, more concrete, practical, and helpful. I will begin by summarizing some of the important ideas, conclusions and also some of the hopes that have emerged during the construction of this thesis, and then propose some actions for the future. But first, a word about naming: thus far, we have simply referred to 'an alternative approach,' or a 'processual approach.' For purposes of clarity, I will refer to this approach as 'co-constructive consulting.' I believe the constructing of social and relational realities to be a slightly more important for this alternative approach than its 'processuality.' Secondly, the words 'coconstructive,' at least for purposes of a label (or thesis title), seem more accessible and more meaningful to more readers than 'processual.'

\section{'Found' vs. 'socially or relationally constructed' reality: Implications for practice}

Among the various differences between the co-constructive consulting approach we have developed here, and a more traditional approach, one of the most important is the differing view on reality. When we assume reality to be 'out there,' we are immediately separated from the world and from the people around us. And since the 'in here' counterpart to the 'out there' is a mental one (i.e. a non-physical one), we are also then separated even from our own 
bodies. This is a spectator's view. We are spectators on all that happens outside this safe and certain mental space, including our own socially lived lives. Perhaps one's view on reality seems much too philosophical to have a tangible influence on one's preferred way or style of practicing consulting? I suspect this is not because our view on reality doesn't have a tangible influence on practice, but simply because we take that view so much for granted that the effect it has not only on consulting practice, but our lives in general, becomes given, common sensical, invisible, and therefore unquestioned.

If, for example, we adopt the notion of reality being 'out there,' then it makes perfect sense that the first step for most projects would be to 'find' the problem. It makes sense that we would use logic trees and other tools in reductionistic fashion to try and find the single 'root cause' of the difficulty we are facing. It makes sense that the quality of that definition would be measured by the accuracy with which it corresponds to the reality 'out there.' It makes sense that we would first seek to 'establish the facts,'-as if our motivations and beliefs (which are built into our research tools as well) had no effect on what we searched for and found in the first place-and then decide in which direction to go. If the real problem is out there, it also makes sense that we would build teams to fit the problem (instead of the other way around) thereby asking people to contribute only a small and narrow portion of their whole selves, and virtually assuring a 'skill gap.' Because reality is out there, finding it becomes something akin to searching for a needle in a hay stack, and it makes sense that we would rely on experts, whose knowledge and tools, unlike our own, are very specialized, thus enabling them to find or diagnose the real problems and deal with them.

But of course there's a different view, one that considers reality to be that which we coconstruct as real, just as we once constructed the reality of witchcraft in Salem, or, more positively, just as $19^{\text {th }}$ century Londoners constructed a reality that 'bad air' that was the cause of what we today call tuberculosis - and in eliminating the 'bad air,' dramatically reduced the death rate from the condition. But when it comes to the social and relational construction of reality, we're not limited to retrospective reconstructions of past events, nor are we limited to our constructions being passive-on the contrary, our reality constructions can be both proactive, and in the present, and can, therefore, have significant and quite tangible implications for consulting practice. Efforts to 'find' the problem during consulting practice, for example, can shift to 'designing' the problem to be more actionable in the present moment; i.e. 'usefulness' trumps 'accuracy' as a determinant of the quality of problems, 
proposals and plans. We can design problems and opportunities that are inspiring for us, that take advantage of all our of life experiences, and with which we can fully engage. Action in the present considers pasts and possible futures, and is forward looking; it is undertaken 'in order to' achieve some purpose, more so than 'because of' cause and effects relations that we constructed, or based on a 'fact base' that we also constructed. We can rely not only on 'experts,' but also on our relational selves. Logic trees and other tools can remain useful for consulting practice, but less for purposes of finding the real problem, and more for the purposes of structuring the problems we have co-constructed, and for reaching agreement on the tasks we will undertake.

\section{Making the leap: the challenges of embracing a new and non-foundational view}

All this sounds simple enough: allowing for the co-construction of shared realities, above and beyond just multiple interpretations - otherwise known in consulting practice as scenariosof a single underlying reality. It sounds simple enough, and can be, but the difference is not at all a trivial one; it is the difference between one worldview, and another. If we embrace the constructedness of the problems we face in consulting practice, then a number of supporting assumptions that shored up our former approach (and former worldview) begin to be a lot less convincing. The whole idea of finding the 'root cause' of anything gets more than a bit shaky. And the result can be paralysis, just as it was for me after the first 18 months of my research. I constructed stories of the development of other professions, and used them to build a critique against the prevailing expert approach to consulting, only to be left with no alternative, because I knew no other way to go forward; I had no other vocabulary. Having arrived at an impasse, I had to give up, or make a leap. And so I made the leap, and managed, I believe, to get at least my fingertips onto the ledge of the other side.

The breakthrough was simply this: I saw there was another way, one that simply did not need the same assumptions about organizations, knowledge, or relationships. Critical academic scholars had written for years about the failings of consultancy, and meanwhile, in the marketplace, consulting continued to be a success. Medicine, public planning and other professions had also been subjected to scrutiny and criticism about their knowledge and their relationships with their patients/clientele. Yet these other professions hadn't ground to halt, but had emerged differently, and more variegated than before. So the breakthrough for me, as simple as this sounds, was that there was another way; there was more than one social reality, more than one story that could be constructed around consulting, just as there were multiple 
stories that had been constructed about physicians. Some stories in the 1960's constructed images of physicians as amoral perpetrators of horrific medical experimentation; other stories constructed physicians as dedicated to improving human life through medical science, and as having been caught up in the unfortunate zeitgeist of the day.

Similarly, in the RFPs, proposals, plans and management books, clients and consultants constructed stories of predictable and controllable organizations, even as the critical scholars constructed very different stories. But rather than seeing these stories as right or wrong, accurate or inaccurate, I came to see them as different performances, and as serving different purposes. I was finally able to let go of the felt need to 'prove' that the co-constructive consulting approach I was developing was 'better' than an expert approach. For the writing of the thesis, from this point forward, I wanted to demonstrate for the reader, and in the process to become capable of demonstrating, that 'proving' things to be one way or another, as the 'validated' and required basis of taking action, is not the only way of doing academic research, or of getting along in the world. We can, instead, make our purposes as clear as we can, and then offer proposals for how we could go on differently, in order to achieve those purposes, and allowing those purposes and proposals to be adopted by those who find them useful, and by others, not. For me, at least, great potential seems to open up before us, when we simply shift our focus and our energy away from this: trying to establish that the world (or 'the organization' or 'the real problem') is one way or another, and then taking action, based on assumed cause and effect relations; and toward this: acting to achieve our purposes, with the world being the ever-emerging result of how we are making it to be, through our acting.

\section{Processual re-constructions}

If, then, one is willing to make a leap, to embrace a new worldview, to embrace the notion of socially and relationally constructed reality, and to accept the invitation that constructionism offers, by taking action, then there are processual alternatives and other ways of practicing that can be useful. Three of these processual re-constructions-organizing, knowing and relating — share the idea of moving upstream, to focus on the activities of practicing itself, and less on the downstream results of practice. This means practicing while focused on the hereand-now, in consideration of pasts and possible futures, and constructing 'the organization' as the semi-permanent, semi-stable result of upstream activities of organizing. Conversations and open, generative dialogue are important forms of organizing. Through and during them, we do more than describe a reality out there and beyond our control, but rather we co- 
construct 'the organization' (or not, as necessary), and also the 'closer-in' constructions, i.e. 'issues,' 'problems,' 'opportunities' that can help guide day to day practice.

Knowing is another shift upstream, another way to focus on practicing itself, with useful knowledge as a fortuitous byproduct. A focus on knowing also helps avoid a reliance on the problematic notion of the 'transfer' of knowledge. The first priority is on practicing, and the useful ideas constructed in the process become the resulting knowledge, which may, or may not, be useful again in some other context. Knowing does not preclude the use of knowledge, information or experience, but makes use of them, and also physical artifacts, in addressing the issue at hand. The mediocre results of so many knowledge management programs suggests that at least some of these investments could be fruitfully redirected away from knowledge transfer and toward knowledge creation, through collaboration and coconstruction.

The third processual construction is relating, with once again a focus on the here-and-now relating with others, and with relationship viewed as a result. If we adopt the notion of people not as discrete and separate self-contained individuals, each with their own subjective realities, but rather as relational selves, for whom meaning itself is jointly constructed, then we have the basis for a powerful new form of collaborating. Roles and identities emerge through generative dialogue and action, and can also be intentionally constructed. The construction of the specific identities of 'client,' 'consultant,' 'expert,' however, are seen as optional. We participate in the co-constructing of local, meaning-ful language, and thus relating can be energizing, as we can engage more as whole and relational selves; people are free to bring whatever ideas, talents, passions or interests they believe to be useful for addressing the issue at hand. With a processual, rather than only an entitive view on power, relating both depends on, and is constitutive of power relations being more evenly distributed among project participants.

In addition to these processual re-constructions, there are other ways and tools for practicing that do not depend on traditional assumptions of prediction or control, or the same, static and individualistic identify constructions of 'client' and 'consultant.' The notion of 'closure,' for example, and the making explicit of it, can be useful: if we assume that reality is out there, consulting teams move forward once they believe they have found the 'root cause' or problem. With a constructionist approach, however, we can't assume we've 'found' the 
answer. There is a risk of paralysis, but teams nevertheless need to take action. Here, the notion of closure is useful. Invoking closure, when done explicitly and not prematurely, is a way to strike a balance between the ongoing constructing and consideration of various possible paths forward, vs. the need to take action. There are many other tools available as well: Gibson's (1977) idea of affordances; Weick's (1993; 1995) notions of sensemaking and sensegiving, mindfulness (Weick and Putnam, 2006), and "heedful interrelating" (Weick et al., 1993); problem framing, problem structuring (Star, 1990), situated learning (Lave et al., 1991), situated action (Suchman, 1987), distributed cognition (Clancey, 1995; Hutchins, 1993), collaborative knowing (Stahl, 2004) - all of these are useful ways of embracing uncertainty and 'getting along' in practice generally, and consulting practice in particular, by co-constructing our actions and our paths forward.

\section{The need for open, generative dialogue}

To share and further develop the co-constructive consulting approach, I undertook several conversations with clients, consultants, and researchers, as recorded in Chapter 5. The conclusion that emerged from those conversations was that taking advantage of the possibilities offered by this or any alternative approach to consulting practice seemed contingent upon dialogue between clients and consultants being much more open, and much more generative, than it is today. While both clients and consultants were amenable to a more exploratory and collaborative approach, their respective official roles made it difficult to explicitly recognize many of the informal, exploratory activities that were already underway, although in the background. Moreover, the vocabulary for describing these activities, and for co-constructing more of them, seemed limited. We proposed moving away from the notion of communication as merely the transmittal of pre-existing information between separate individuals. We introduced the notion of dialogue as a performative activity, useful for creating shared understandings (Bohm et al., 1991) and new possibilities for action (Gergen et al., 2001), and indeed, new action itself (Austin, 1962; Bouwen, 1998). In the paper that now constitutes Chapter 6, we continued our efforts to share and further develop our alternative approach, by demonstrating with a case study — and without relying on vocabulary with which clients or consultants might not be familiar-how pragmatism and social constructionism can be useful for practice. 


\section{A simple framework for facilitating dialogue}

Earlier in the process of writing this dissertation, I had assumed that the output would be a consulting approach to replace the prevailing and outdated expert approach. But I abandoned that plan, because it amounted simply to the replacement of one foundational position-an expert approach, with another-the approach I was developing. Thus, the goal of the dissertation shifted along the way, from developing a replacement, to developing an alternative. It was around this time that I created the chart below (see Figure 6, below), which describes four different consulting approaches. I hesitated at first to include this chart, because we could construct hundreds of possible consulting approaches, and because I want to avoid being prescriptive. The decision to include it here after all, however, is two-fold: one, to hopefully further clarify the approach we are proposing, and two, that this or a similar framework can facilitate more open and generative dialogue between clients and consultants. First some brief background, and then an explanation of the chart.

In the early stages of what may or may not result in a project, call it the early sales phase, clients and consultants often have a series of meetings to discuss what the issues an/or opportunities are, and what some possible plans for addressing it might be. Particularly when the client and consultant are working together for the first time, the tone of these meetings can be a bit cagey. The image I have is that of two sharks circling one another in a pool. The consultant often thinks: 'Is this a real project? Do they have a budget for it, or are they just pumping us for information and ideas? Would I like to work with these people?' And the clients often think: 'Do these people have the expertise I need? Have they really done this kind of work before? Is it likely that I'd enjoy working with them?' Assuming the project goes forward, all these and other questions are answered in due time, but when there's a problem during the project, it often means the answers-particularly in regard to the question 'would I like working with them'-will have come too late. Of course we can never fully predict what it will be 'like' to work with someone, but the purpose of the chart below is to provide clients and consultants with a tool that can hopefully at least facilitate conversation, to make explicit some of the questions that each may be considering, particularly before the project begins. Another purpose is to provide an opportunity to make use of some of the vocabulary that may be new and hopefully relevant for them.

In the chart there are two axes, having to do with one's conception of 'organization,' and of 'self.' With the vertical axis, we seek to recognize that people, whether client or consultant- 
have different views on the nature of 'organization.' Those with a more traditional understanding of organizations, for example, may view or construct an organization as a designed entity, over which we can exercise some control. Alternatively, others, like me, for example, find it useful to think not of an entity, but of the dynamic and emerging processes of

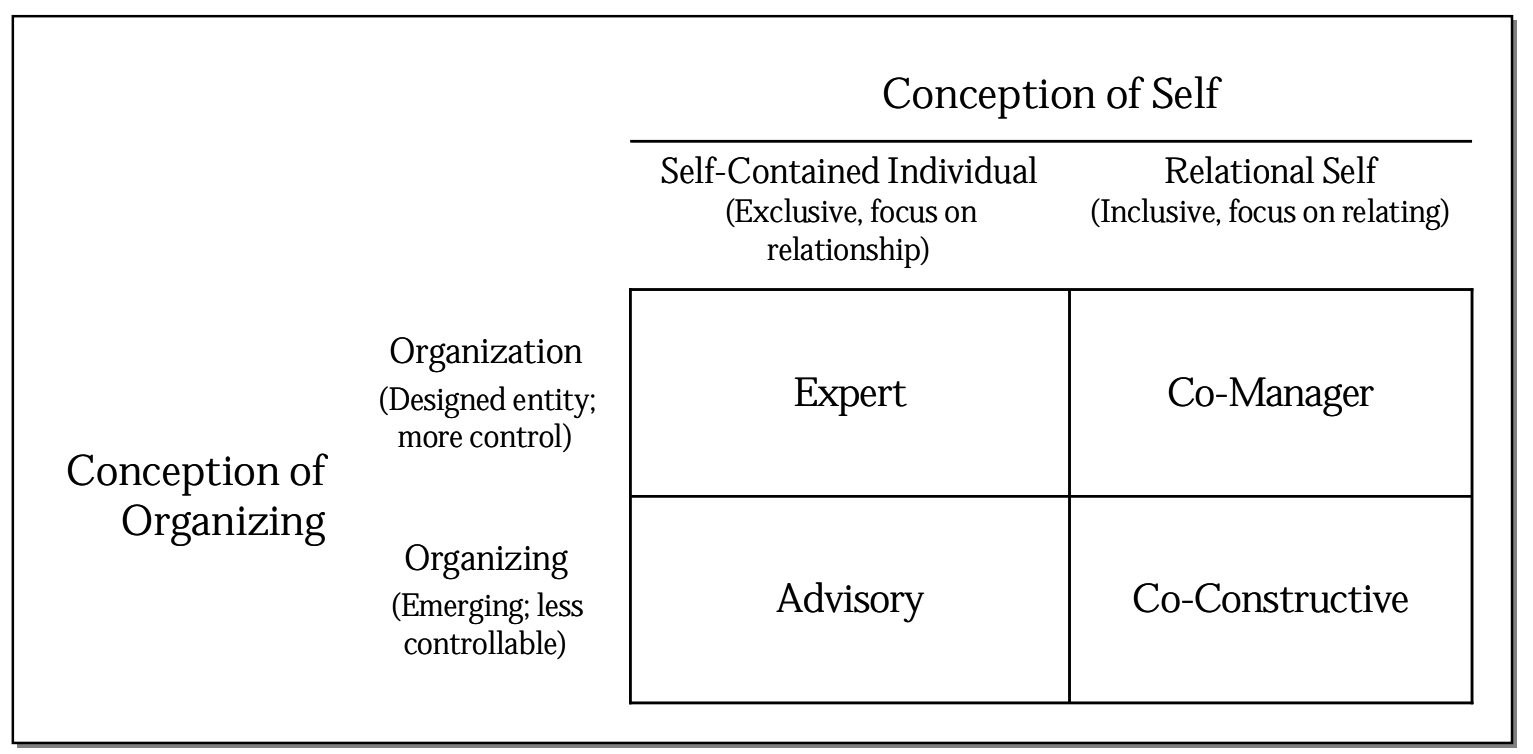

Figure 6: Four consulting approaches

organizing, over which we have partial control, at best. On the horizontal axis is the construction of self. A more traditional or modernistic construction of self is that of the 'selfcontained individual,' a construction that is exclusive of, and discrete and separate from others, and with self-other boundaries that do not overlap (see also Figure 3 in Chapter 3 ). Alternatively, the notion of the relational self is inclusive of others, the self-other boundaries overlap, and meaning is considered to be shared and jointly constructed.

The idea here is that one's preferred approach to consulting, an approach one feels most comfortable engaging in-whether consultant or client-depends on one's views on organizations, and the self. If, for example, one believes that organizations are the product of intentional design, that change outcomes can be controlled, and that people are separate and discrete individuals, such an outlook my indicate a preference for an expert approach to consulting. For this approach, and following from the assumption of controllability over change outcomes, the focus of practice would be on, for example, establishing clear problem definitions and the development of robust and comprehensive plans. The client consultant relationship would be exchange oriented. Knowledge transfer-from consultants to clientmay be a priority. The methods, tools and language used for planning documents would 
likely be more standardized, or at least, be closely aligned to the ideas of the author, rather than the more customized product of collaborative effort.

If however, one constructed self as self-contained, but with the assumption that the control over change outcomes was relatively lower, this might favor what we have labeled an advisory approach. The client's request of the consultant would be transactional: i.e. information, knowledge or perhaps advice, in exchange for a fee, but the consultant would have less responsibility for managing or predicting outcomes. Client-consultant relationships remain less collaborative, and more exchange oriented.

For a co-manager approach, one may favor close collaboration and the joint-construction of robust and comprehensive plans for executing organizational change initiatives. The object of the plans, as with the expert approach, is 'the organization' as an entity. Changes to the organizational are considered controllable, 'manageable;' good plans are thought to lead to good results. The methods, tools and the language of the planning, however, can be jointly developed, according to the conception of self as relational. Compared to the expert or advisory approach, the focus would be more on knowledge co-creation, rather than on knowledge transfer. Our co-manager approach is similar to the approaches of Edgar Schein, Chris Argyris, and other organizational development (OD) practitioners.

With a co-constructive approach, one favors close collaboration, and does not assume control over outcomes-organizational or otherwise. Goals are viewed as co-constructed, and plans are drawn up for achieving them, perhaps with non-standard methods or with language influenced by the preferences, styles and experiences of those involved. The key difference between this approach and the co-manager approach, is that the organization is not reified or treated as the tangible object of improvement efforts. Instead, the focus remains upstream, and day-to-day practice is guided by closer-in constructions of issues and opportunities. The expectation is that the plans as well as the goals, will change as the project unfolds.

Of course this is a very generalized account of different approaches, and is not at all intended to be prescriptive. We envision clients and consultants using this or a similar framework to gain clarity on their own preferred approach, and the preferred approach of their colleagues, either in general, or for a specific project or situation. And of course any number of 'variables' could be chosen for the axes. In our view, any framework that puts forward 
multiple possible approaches, and that can facilitate open and generative dialogue, is a useful framework. As Gergen et al. (2001) write: "transformative dialogue may be viewed as any form of interchange that succeeds in transforming a relationship" from an antagonistic one, toward one in which realities are ongoingly and equally (among all participants) coconstructed.

Finally, to further clarify the constructive approach, and to hopefully make good on the promise we made in the Introduction of extending the continuum of business consulting approaches beyond an expert and process consultation approaches, we offer a summary comparison table (see Table 3, below). 
Table 3 Summary comparison of three consulting approaches

\begin{tabular}{|c|c|c|c|}
\hline $\begin{array}{l}\text { Practice Approach } \\
\text { Aspects \& } \\
\text { Activities of Practice }\end{array}$ & Expert & Process Consultation & Co-Constructive Consulting \\
\hline $\begin{array}{l}\text { Overall consulting } \\
\text { process }\end{array}$ & $\begin{array}{l}\text { Independent experts objectively apply } \\
\text { standardized bodies of knowledge to } \\
\text { diagnose client problems, and plan } \\
\text { 'solutions.' }\end{array}$ & $\begin{array}{l}\text { Client and consultants work jointly to } \\
\text { diagnose client problems, and develop plans } \\
\text { for improvement, with less expectation or } \\
\text { claim to finality, as with the 'solutions' of } \\
\text { an expert approach. Compared to an expert } \\
\text { approach, more likely to include } \\
\text { 'implementation.' }\end{array}$ & $\begin{array}{l}\text { Teams co-construct problems and/or } \\
\text { purpose(s) and act to address problems and } \\
\text { achieve purpose(s). Less emphasis on } \\
\text { 'diagnosing,' and more on cycles of action } \\
\text { and evaluation, until the purpose is } \\
\text { considered achieved, or problematic } \\
\text { situation is replaced by a more pressing one. }\end{array}$ \\
\hline View on reality & $\begin{array}{l}\text { Reality exists 'out there' and independent of } \\
\text { our interpretation of it. }\end{array}$ & $\begin{array}{l}\text { Reality exists 'out there' and independent of } \\
\text { our interpretation of it. Reality is the } \\
\text { anchor, or non-relativistic standard, the } \\
\text { accurate correspondence to which forms the } \\
\text { ultimate basis of authority and power. }\end{array}$ & $\begin{array}{l}\text { Reality is socially and relationally } \\
\text { constructed, but the nature of reality is of } \\
\text { secondary importance, as compared to } \\
\text { action and the achieving of purposes. }\end{array}$ \\
\hline Measure(s) of success & $\begin{array}{l}\text { Achievement of pre-determined goals; } \\
\text { degree of knowledge transfer (consultant to } \\
\text { client) }\end{array}$ & $\begin{array}{l}\text { Achievement of pre-determined goals; } \\
\text { degree of knowledge transfer (consultant to } \\
\text { client), particularly in regard to knowledge } \\
\text { of the process }\end{array}$ & $\begin{array}{l}\text { Achievement of goals, pre-determined or } \\
\text { emergent; satisfaction of those involved; } \\
\text { knowledge creation, by those involved; } \\
\text { degree to which new and useful } \\
\text { performances are enabled }\end{array}$ \\
\hline $\begin{array}{l}\text { Assumed determinants of } \\
\text { success }\end{array}$ & $\begin{array}{l}\text { Possession of expert knowledge resources; } \\
\text { possession of analytical skills }\end{array}$ & $\begin{array}{l}\text { Adherence to process; Possession of expert } \\
\text { knowledge resources; possession of } \\
\text { analytical skills }\end{array}$ & $\begin{array}{l}\text { Performing successfully, i.e. 'success' or } \\
\text { 'solutions' are considered retrospective, not } \\
\text { prospective assessments; engaged } \\
\text { participants }\end{array}$ \\
\hline Role of client & Implementer & $\begin{array}{l}\text { Expert on 'content' and company- or } \\
\text { organization-specific knowledge }\end{array}$ & $\begin{array}{l}\text { Co-constructor of problems and purposes; } \\
\text { co-participant in action taken to address } \\
\text { them. Roles and identities emerge, or are } \\
\text { intentionally constructed, as necessary. }\end{array}$ \\
\hline Role of consultant & Diagnostician & Expert on consultation process & Same as above. \\
\hline $\begin{array}{l}\text { Problem/issue setting } \\
\text { process \& quality } \\
\text { indicators }\end{array}$ & $\begin{array}{l}\text { Finding and diagnosing problems/issues; } \\
\text { quality measured by degree to which } \\
\text { problem, as defined, corresponds to reality. }\end{array}$ & $\begin{array}{l}\text { Joint (client and consultant) finding and } \\
\text { diagnosing of problems/issues; quality } \\
\text { measured by degree to which problem, as } \\
\text { defined, corresponds to reality. }\end{array}$ & $\begin{array}{l}\text { Problems/issues are constructed; quality } \\
\text { measured by usefulness and actionability. }\end{array}$ \\
\hline Project plans & Deterministic; causality driven & Deterministic; causality driven; iterative & Exploratory; purpose driven; iterative \\
\hline
\end{tabular}




\begin{tabular}{|c|c|c|c|}
\hline $\begin{array}{l}\text { Practice Approach } \\
\text { Aspects } \\
\text { Activities of Practice }\end{array}$ & Expert & Process Consultation & Co-Constructive Consulting \\
\hline View on 'organization' & $\begin{array}{l}\text { The tangible, reified product of intentional } \\
\text { design. Assumed predictability \& } \\
\text { controllability of change outcomes; exist in } \\
\text { 'states.' }\end{array}$ & $\begin{array}{l}\text { The tangible, reified product of intentional } \\
\text { design. Assumed predictability \& } \\
\text { controllability of change outcomes. }\end{array}$ & $\begin{array}{l}\text { The 'downstream' result of upstream } \\
\text { activities of 'organizing,' constructed (or } \\
\text { not) as necessary. Of secondary } \\
\text { importance, compared to the processual, } \\
\text { emergent activities of 'organizing,' with } \\
\text { lower assumed controllability. }\end{array}$ \\
\hline View on 'knowledge' & $\begin{array}{l}\text { Functionalist, i.e. treatment of knowledge as } \\
\text { a transferable asset, possessed by expert. } \\
\text { Possessed knowledge is the source of expert } \\
\text { power. }\end{array}$ & $\begin{array}{l}\text { Functionalist, i.e. treatment of knowledge as } \\
\text { a transferable asset; possessed by client, } \\
\text { consultant, or co-produced by client and } \\
\text { consultant. Possessed knowledge is the } \\
\text { source of power. }\end{array}$ & $\begin{array}{l}\text { The 'downstream' result of upstream } \\
\text { activities of 'knowing.' The fortuitous } \\
\text { 'byproduct' or 'residue' of acting to achieve } \\
\text { purpose(s). Situated, i.e. limited } \\
\text { transferability. Knowledge 'transfer' is } \\
\text { considered instead to be 'local creation' of } \\
\text { knowledge }\end{array}$ \\
\hline View on 'relationship' & $\begin{array}{l}\text { Exchange oriented. Underlying metaphor is } \\
\text { that of a conduit for exchange of } \\
\text { information or knowledge between self- } \\
\text { contained individuals (clients and } \\
\text { consultants). Expert consultants maintain } \\
\text { 'critical distance' from clients, in the name } \\
\text { of objectivity/neutrality }\end{array}$ & $\begin{array}{l}\text { Collaboration, between self-contained } \\
\text { individuals, as compared to the expert } \\
\text { approach, but distance, and adherence to } \\
\text { formal roles remain, as compared to } \\
\text { constructive approach. Co-construction by } \\
\text { self-contained individuals. }\end{array}$ & $\begin{array}{l}\text { Downstream result of upstream activities of } \\
\text { 'relating.' Meaning is co-constructed by } \\
\text { relational selves. Identities, including those } \\
\text { of 'client' or 'consultant' are constructed } \\
\text { only as required' (i.e. they are optional). } \\
\text { Relating constructs relational realities, and } \\
\text { an 'emancipatory' or 'relational' space. }\end{array}$ \\
\hline View on 'power' & $\begin{array}{l}\text { Power is 'possessed' by the expert, i.e. } \\
\text { power is 'entitive.' Power 'over' others. }\end{array}$ & $\begin{array}{l}\text { Power is 'possessed' by client and } \\
\text { consultant. Power 'over' others. Initial } \\
\text { focus is to equilibrate an 'imbalanced } \\
\text { relationship,' with the helper being 'one- } \\
\text { up,' and the one who asked for help being } \\
\text { 'one-down.' }\end{array}$ & $\begin{array}{l}\text { Power is both possessed (i.e. entitive) and } \\
\text { constructed (i.e. processual). Focus is on } \\
\text { 'power to' and 'power with.' Co- } \\
\text { construction can lead to power relations that } \\
\text { are distributed, centerless. }\end{array}$ \\
\hline $\begin{array}{l}\text { Gap between 'official' } \\
\text { accounts of practice vs. } \\
\text { 'unofficial' activities of } \\
\text { practicing }\end{array}$ & $\begin{array}{l}\text { Significant gap. Unofficial and informal } \\
\text { activities of practicing are intentionally } \\
\text { backgrounded. }\end{array}$ & $\begin{array}{l}\text { Not directly addressed, except for, at an } \\
\text { individual level, the difference between } \\
\text { 'espoused theory' and 'theory-in-use,' i.e. } \\
\text { the theories that govern actions }\end{array}$ & $\begin{array}{l}\text { Intent is to minimize this gap, by } \\
\text { explicating and foreground ongoing } \\
\text { activities of practicing. }\end{array}$ \\
\hline $\begin{array}{l}\text { Representative works and } \\
\text { sources of more } \\
\text { information }\end{array}$ & $\begin{array}{l}\text { Block (2000), Fombrun and Neevins } \\
\text { (2004), Kubr (2002), Maister (1997; 2000) }\end{array}$ & $\begin{array}{l}\text { Argyris and Schön (1974), Schein (1969; } \\
\text { 1999) }\end{array}$ & $\begin{array}{l}\text { Anderson (1997), Hicks, Nair, and } \\
\text { Wilderom (2009), Lambrechts et al. (2009) }\end{array}$ \\
\hline
\end{tabular}


Chapter 7: Summary and future actions

\section{Future actions}

Although the writing of this dissertation did not start out this way, we have, along the way, tried to move beyond 'research,' and also beyond 'action research' to simply action. So rather than close with an agenda for future 'research,' I would like to list up and propose a few future actions which may be useful for those involved with business consulting.

The first of these, mentioned several times already because of its importance, is the facilitating of open and generative dialogue among the people involved in consulting, i.e. the people behind the identity constructions of 'client,' 'consultant' and 'academic researcher.' I do sense some recent changes, such as the focus of Capgemini on collaboration, as discussed in Chapter 2, but I believe these efforts are still built atop assumptions of people as discrete and separate individuals, or people constructed as roles, as reflected in their promise to "transfer knowledge and capabilities to clients during the course of our relationship." The notion of the self as relational, the relational co-construction of meaning and action through open and generative dialogue, and most importantly, the opportunities for rich collaboration that can thereby be realized, are mostly absent. Concrete actions include participating in projects, while applying ideas from pragmatism and relational constructionism, and publishing accounts of the results.

The second action, which can be seen as a particular topic of the first: encouraging and facilitating dialogue on the meaning of professionalism. In our view, both clients and consultants remain bound by the ideals of an unexamined and traditional professionalism. 'Objectivity' and 'neutrality' make sense only if we assume there is a reality out there, of which it is possible to get an objective or neutral view. If we adopt the notion of a relationally constructed reality, however, the objective view becomes 'the view from nowhere.' As a client, I might be looking for a different or external viewpoint, but never an objective one. I'm looking for a biased view-one biased in my favor. What then can be the 'new' professionalism? Do we even need the notion of 'professionalism'? If not 'critical distance,' then 'close collaboration'? If not 'objectivity,' then 'co-constructed, local and project-specific subjectivity'? For me, professionalism means dedication. If we relax our assumptions of predictability, then as a client I can't expect that the consultant has or can predict what the resolution will be; I can and will expect, however, that professionals are those people that remain dedicated and engaged, and that willingly assume "relational responsibility" with me 
for getting to some satisfactory solution, whatever it may turn out to be, and however long it may take. Esther, the vice president of sales I had a conversation with, also mentioned responsibility:

Esther: There's a, I think about 'stick-to-itiveness,' a sort of 'not giving up.' The consultants I have worked best with, I don't think I hold them to unreasonable expectations about what we can or can't get done. But what they bring is energy and taking on ownership. Their professionalism is just that: they don't give up. And they feel really, personally responsible about not letting anything fall through the cracks.

What does 'professionalism' mean for you?

Finally, another action is the development of alternative ways of practicing. This is picking up the task begun in Chapter 5. We are interested in hearing stories, and further developing and legitimizing the concrete and specific ways that people get along in practice, amidst uncertainty; ways that have been effective, but that may also have been intentionally backgrounded, simply because they do not align with the prevailing ideals of professionalism, of knowledge, of organizational behavior, etc. Our account of the history of these ideals suggests they are far from sacrosanct. The good news is that, despite all the criticism, people (i.e. clients and consultants) are nevertheless getting along somehow. A productive starting point, therefore, may be to simply bring to the foreground the creative, innovative ways of practicing that are already underway. From our own experiences, and also from social psychology, anthropology and other disciplines, we have a rich vocabulary from which to draw. One of the challenges is to 'translate' this already available work for possible application to consulting practice, not with assumption of transferability, but simply as additional ideas that people can try in their own practice. In my experience, even today, only a relatively small number of people in the larger consultancies refer to methods like 'sensemaking,' or 'problem framing,' by name, and far fewer are familiar with relational constructionist ideas. Adoption of these ideas and methods may be commonplace for certain boutique and/or academically oriented consultancies, but remain the exception for larger mainstream firms. 


\title{
Summing up
}

In the late 1960's, the profession of medicine was beginning to suffer from a 'crisis of confidence.' By 1970, Freidson wrote:

\begin{abstract}
"In our day we seem to be turning away from an uncritical optimism about the role of specialized knowledge in ordering human affairs. We have not yet arrived at a satisfactory new position, however, and in the meantime we are treated to despairing violence and self-defeating anti-intellectualism on the part of laymen and their champions, self-interested elitism on the part of the intellectual classes, and downright authoritarianism on the part of even those political leaders with humanitarian intentions" (Freidson, 1970a, p. xi).
\end{abstract}

What Freidson describes is not dissimilar, I believe, to the current situation for mainstream business consulting, namely: dissatisfaction with the prevailing approach-for the client, consultant and academic research communities alike-but without a satisfactory alternative. Meanwhile, these communities are for the most part engaged in essentially separate discourses. Scholars write critical accounts of the quality of consultants' knowledge, in journals that consultants do not read, even as clients cite 'gaining access to consulting knowledge' to be the single most important reason for hiring external consultants. Clients, meanwhile, are critical of consulting and the poor results of organizational change outcomes, even as the amount they spend on consulting services continues to rise. When it comes to business consulting, there seems to be a lot of talking at, about, or past one another, but seldom with one another.

Pragmatism and relational constructionism, I believe, can help bring these communities closer together, by engaging them in the achieving of co-constructed purposes. Having spent time in each of these communities, I wasn't the only client looking for new ways of organizing, nor the only business consultant looking for alternative ways of practicing and helping; and most recently, I'm certainly not the only academic wanting to put their theoretical knowledge to practical use. But purpose, it seems to me, is the starting point. Clear purposes, coconstructed through dialogue, are unifying. When pursuing a purpose, we make use of whatever works - theory, knowledge, tools, information, experience, hunch, wild guessesand it need not matter at all from where these tools come, nor what labels (e.g. theory, 
information, etc.) we-usually retrospectively —affix to them. Purpose provides a direction in support of which all the various talents and aspirations of different communities and people can align. The social and relational realities we construct are not random; rather they are guided by purpose. When our purpose was to reduce the suffering from what we now call tuberculosis, we constructed the reality that the condition was caused by 'bad air,' and we largely achieved our purpose. What purposes, then, shall we co-construct and realize? What shall we-yes, as clients, consultants and researchers, but also as people-what purposes shall we pursue? I believe these questions of purpose are the most important questions of all. I think they are more important than questions of 'how things (i.e. 'organizations') really are' or 'what the real problem is.' Questions of purpose are also more important than questions of 'how' we will achieve these co-constructed purposes- 'how' questions, as long as we don't relinquish our purpose, eventually answer themselves. We should also not underestimate, I believe, what we can achieve together. In 1962, when John Kennedy said "we choose to go to the moon," he set a clear purpose, and also created, long before we ever arrived there, the reality that travelling to the moon was possible. What purpose(s) then shall we choose to be pursuing today? I look forward to working with you. 


\section{Acknowledgements}

According to Arjen Wassenaar, a wise and inspiring man, as evidenced by his continuing appearance in people's work and in their conversations even some years after his 'retirement' from our faculty, the most-often read part of any $\mathrm{PhD}$ thesis are the acknowledgements. If he's right, and I suspect he is, then the acknowledgements are also one of the most important parts of the thesis, because when readers engage with the text, meaning results; meaning is coconstructed by writer and reader; re-lationships are re-created and re-inforced.

When writing up his own dissertation, my friend and colleague Michel Ehrenhard also took note of Arjen's advice about the acknowledgements. Michel's trick was to "hide the acknowledgements somewhere in the back" (Ehrenhard, 2009, p. 366) so that, presumably, readers (who might not otherwise understand just how thrilling his topic of structuration theory applied to middle managers in the Dutch central government really is) would have to read at least some of the thesis en route to what they were really interested in reading: the acknowledgements. Like Michel, I too assume that people will look for the acknowledgements, and also that using them is one way to get at least some of the thesis read (by those who, for some strange reason, can't see the patently obvious relevance of Heidegger's notion of dasein for the day-to-day practicing of consulting). My scheme for using the acknowledgements, however, is different: rather than hide them away, I've helped the reader out by identifying them right there in the table of contents-simply flip open the book, check the table of contents, 'Acknowledgements-page 211,' and boom, you're there. You can easily and efficiently skip the whole book. The trick, however, is that I want to sneak in one final point that's relevant for the thesis-right here in the acknowledgements section itself-before the section where I start name dropping.

Richard Rorty, referencing John Dewey, writes about the age-old debate between rigor and relevance, using the shape of an upper case letter " $T$ " where rigor is the depth of the vertical bar, and relevance the width of the horizontal bar. If we 'go deep' to ensure our research is rigorous, then we risk becoming less relevant, and leaving people behind. Indeed, the way to go deepest is to also go as narrow as you can get away with, i.e. to go straight down, limiting the number of people to whom you have to make your work understood (or believable or 
useful), and involving instead only a small group of specialists or experts who 'know what you're talking about.'

In my experience, writing a dissertation is more or less an exercise in drilling straight down. One's supervisors, promoters and committee members (and also office mates, friends, family and others who may find themselves confined in small spaces together with (or cornered by) the author, and unable to easily escape) come to know the work well. But outside of this small group, the opportunities for engaging and meaningfully co-constructing seem to me limited. Thus, as time went on during the writing of this dissertation, I lost interest in doing 'research,' and became more interested in 'action research,' and finally, just 'action,' or better still, 'acting' or 'performing,' with the performances being limited, unfortunately, to written accounts. I tried to go as 'wide' as I could get away with, not in the fashion of a "T" but of a triangle, like this: $\nabla$, by trying to make the text relevant and 'engageable' for clients, and consultants and academic researchers of consulting.

When it comes to business consulting, the current landscape looks to me very much like a "T" where clients and consultants have relevance at the expense of rigor, and vice versa for the researchers of consulting, and especially for the critical scholars, as discussed in Chapter 4. I'm proposing that the 'skipping over' we've made light of here, happens not only with dissertations, but with written accounts and publications on consulting in general. Academics, e.g. my colleagues and I here at the University of Twente, or at the University of Texas in Dallas, skip over the dissertation and go to the acknowledgements because there's an opportunity there for us to create a sense of connectedness with the work; to create meaning. When read, the acknowledgements, as compared to the research, are meaning-ful for us. Clients and consultants skip altogether much of the research that's published, regardless of its potential usefulness, because, among other reasons, they were not involved in its original construction, and also because it's written in language that inhibits them from co-creating meaning as a reader. The words are not meaning-ful for them. 'Practitioner journals' are written by academics but seldom read by practitioners, and the premise of such publications, it seems to me, simply prolongs the very gap—i.e. researcher/practitioner-it would be useful to close-or better yet avoid-in the first place. I'm proposing that along with the coconstructive approach to practicing we've sketched here, a new genre of written accounts of consulting (indeed of managing more generally?) might be useful as well. It might involve some of what we now call research, action research, ethnography, but also stylistic (e.g. 
dramaturgical and literary) elements that might even make it an interesting read-imagine that: 'research' or accounts of practicing that you don't want to skip over! But all of this is a future opportunity for co-constructing meaning-let's move on to the current opportunity.

$* * * * *$

Many authors write that they can never thank all the people who helped bring about a book. This is especially the case from a pragmatic, relational constructionist perspective, according to which "I" has meaning only relationally, that is, with others. For me, there is no core self, essential and unchanging. Rather, "I" am the result of all the interactions I have had, every single one of them, and their resulting combined meanings. I can't easily separate me from you, my contributions from yours, and in that sense I really do consider this 'our' book-so let me get on with thanking you, my many co-authors.

I think the best way to do this is chronologically. And that means that we start in 2003, when I said to my friend Padmakumar Nair (on the patio of the great Italian restaurant across from Hiroo hospital in Tokyo) that I was considering writing a $\mathrm{PhD}$ dissertation on consulting. But there were serious constraints, I explained: I had to keep my full-time job, so the program had to be part-time; preferably it would be in Europe, where neither I, nor my family, had spent much time, but wanted to; I would not have time to learn another language, so it needed to be a place where I and my children (in their school, at least) could speak English; and finally, it had to be a place where the topic of consulting would be an acceptable topic for a thesis. These are serious constraints indeed, but not for someone like Kumar, who called me not more than two weeks later to say "Jeff, I think I've found something for you. It's in the Netherlands, at the University of Twente. I think you'll like it there. There's a Professor there. Her name is Wilderom, Celeste Wilderom. She's interested in your topic. Please give her a call and discuss." Kumar, then, deserves a special word of thanks for getting me started, and, along with his wife and family_Jalaja, Krishnan and Bhasi-for keeping me going, with great south Indian cooking, conversation, and generous hospitality during my many visits to Dallas. Without Kumar's help, it's doubtful that I could have begun, or finished this work. I know of many other people with similar stories about Kumar-the world needs more like him. 
The next word of thanks goes to Celeste, with whom, after several e-mails, phone conversations and a couple of trips to Enschede, I was indeed able to begin my PhD research. Celeste, husband Sam, and daughters Noor and Senna welcomed me into their home, and helped me (and later my family) get acclimated to life in Europe and the Netherlands.

In 2004 I transferred to the US from Japan, and worked on the $\mathrm{PhD}$ 'remotely' from there, with trips to the Netherlands every few months. In 2006, again with the help of Kumar and Celeste, I contacted Jos van Hillegersberg about a teaching/research position in the Information Systems and Change Management department. Apparently my experience with both change management and IS (just enough of the latter to have survived at IBM) was a fit for the department, and in 2006, I left my consulting job of 10+ years, and along with my wife, three children, one cocker spaniel, one chinchilla and one hamster, relocated to the Netherlands. For importing the animals, we had meticulously followed every single EU/Dutch rule and regulation about vaccinations, RFID chips, etc., and had a stack of paperwork several centimeters thick to show for our efforts. The customs agent in Amsterdam at first raised an eyebrow at us and our travelling zoo, but after seeing the imposing stack of official papers, he simply waived us through. A word of thanks to that agent as well.

Some three and half years later, I can honestly say that Jos is best boss I've ever worked for. From the beginning, he has been open and fair, and set the tone for a great working environment in the department. Thanks, Jos. Others in the department, however, cut a more ominous figure, such as Fons Wijnhoven. Or at least that's what I thought initially, until I learned that behind the serious look and prodigious output, Fons is a sincere and caring person, a very good listener, and someone with whom I share a love for philosophy, and a firm conviction in the practical relevance thereof! Another colleague, who has recently shown an interest in philosophy_-something that bodes well for our future conversations, but not his productivity, is Michel Ehrenhard. Along with Kumar, Michel is certainly one of the people without whose help and friendship I could not have completed my work here. From providing me with books for learning words like 'epistemology,' 'ontology' and the difference between the two, to showing me where to find the best döner; from interesting conversations on structuration theory, Dutch politics, bricolage, pea soup, amusing/annoying co-workers and innumerable other topics, to-along with Ellen-helping my wife and 
children as well feel welcome and cared for-for all this and much more I owe a debt of gratitude that will be impossible to fully repay.

As those who have read more than the acknowledgements (!) will understand, the period of time covered by this thesis was one of significant change for me. Setting aside one's heretofore unquestioned beliefs of reality to embrace a new worldview—sounds exaggerated perhaps, but this was my experience-was difficult, as evidenced by the transitioning period of 'muddling through' related in Chapter 2. Helping to make sense of that new worldview, was Dian Marie Hosking. For some time, this name 'Hosking, D.M.' kept appearing as a reference in papers by Robert Chia, Haridimos Tsoukas and others, papers that I considered important for the thesis - the key difference being that whomever this 'Hosking' fellow was, he had written extensively on similar themes many years before these other authors. A google search revealed, now somewhat embarrassingly, that "D.M." stands for Dian Marie, but more promisingly, that she lived but a couple of hours away, in Utrecht! Long story short, Dian Marie agreed to be Promoter, and I can add her name to the list of people, without whose experience and wisdom, this work would not have reached completion. Her scholarship is visionary, and her hospice work selfless and exemplary.

Midway through the thesis I came to know Roland Mueller, my new office mate. Replacing my former office mate, Alea Fairchild-a female American IS scholar and competitive weightlifter married to a Belgian baron (who said academic life isn't interesting?) — the contrast with Roland, a smart and reserved Berliner, couldn't have been greater. Roland turned out to be a very good friend and invaluable confidant during difficult times. Together, we overcame slightly differing views on the philosophy of science, and with his partner Katje and Hiroko, my Japanese wife — a conspicuous foursome indeed—we survived a tour of the honky tonk bars in Bakersfield, California, thereby proving beyond doubt the true power of genuine friendship.

To Chintan and Simi Amrit, and Liudvika Leišytė thanks for taking me in so generously and providing a home away from home when my family was away; the same for Hanneke Klopper and husband Paul. For keeping office life lively, thanks to Diederik Rothengatter and again to Chintan, for some of the most ingenious and diabolical capers ever concocted (and successfully pulled off); to Daniel Moody for in-the-end-friendly revivals of the paradigm wars, skirmishes soon forgotten over Belgian beers at the Vestingbar; to Romana Aziz, 
together with whom we proved that Pakistanis and Americans can get along just fine; to Maria Iacob, for good advice on IT architecture, teaching, parenting and amusing stories of deer hunting — using the front bumper of an automobile—in Romania Thanks to Björn Kijl for your friendly nature and modesty, and for 'schooling us' all (in modest fashion, of course) on how to design and implement a successful business. To Ton Spil and Christiaan Katsma, thanks for your friendship and for providing a truly world-class soundtrack to my life here in the Netherlands. To Ismael, thanks for keeping me well fed, and good luck with your studies. To Daniel Klein and family, thanks for keeping us well housed, and best of luck in Bonaire.

Thanks to Peter Nes, Harry Kolkman, Stephan Maathuis, Harold Wilson, Eef Ehrenhard, Bart van Manen, Aard Groene, Efthymios Constantinides, Arjen Wassenaar and Dr. Peters for your help and inspiration: 'Ye been the salt of the erthe and the savour' (Chaucer, 1386). About recently made friends Reymond Loohuis, Liudvika Leišytė and Sjors van der Heide, the only unfortunate thing is that I didn't meet you sooner, so I look forward to making up for all that lost time, and the same for Lucas Meertens, Esther Jaiwai and Hans Moonen-I wish you all the best. For your positive energy and enthusiasm, thanks to Sander Nijenhuis, Elfi Furtmueller-Ettinger, Celeste Wilderom, Desiree van Dunn; for your inspiring potential: Yori Kamphuis; for your inspiring determination: Svetlana Khapova and Esther Klaster. Big ol' honkin' Texas-style thanks to Elke van de Veen and Marianne Sonneveldt for helpin' to 'get 'er done!' Thanks to Simon Dorris and Christian Boettcher for your help in 'field research' on the banks of the Mississippi, and to the crew at House of Performance in Utrecht for setting a good example for other consultancies in terms of innovation, and for a genuine concern for your clients' success.

For reviewing the thesis, thanks to committee members Paul van Loon, John Rijsman, René Bouwen, Dennis Muntslag, Marc Wouters, and Jos van Hillegersberg. For their help with interviews and workshops thanks to Lisa van de Bunt, Klaasjan Visscher, Jan Buter, Dinah Chesson, Tom Tevendale and Martin Arends.

In addition to all these friends and co-authors, are others who, while separated by distance or otherwise, remained inspirational: Joe and Ida White, Wood and Wilma Hicks, Joe and Lenore Wilson, the Oberlies family, Derek Lehmberg (are), Doug Kiel, Jerry Hoag, Greg Dess, Julie Judd, Debbi Stephens, Tom Wiggins, Loren Wiebe, Nathan Walker and Paul Lambert. 
Acknowledgements

And finally, I must of course thank my family: my wife Hiroko, daughters Misaki and Natsuki, and son Sam, each of whom took on various tasks and responsibilities that should have been mine, during the many months and years I worked on this thesis. And wherever we were in the world, we were in turn supported by Dola and Mike, George and Peggy, Steve and Lori and Jordan, Darlene and Gary, the Iseki family, the Yasuda family, and the Togami family. Looking back on the whole experience, I now truly understand and believe what so many authors mean when they write, as I will write now: Without all of you, none of this would have been possible. 


\section{References}

Abbott, A. D. (1988) The System of Professions: An Essay on the Division of Expert Labor. Chicago: University of Chicago Press.

Abrahamson, E. and Eisenman, M. (2001) 'Why Management Scholars Must Intervene Strategically in the Management Knowledge Market', Human Relations 54(1): 67-75.

Allmendinger, P. (2000) Planning in Postmodern Times. New York: Taylor \& Francis.

Alvesson, M. (1995) Management of Knowledge-Intensive Companies. Berlin: Walter de Gruyter.

Alvesson, M. (2001) 'Knowledge Work: Ambiguity, Image and Identity', Human Relations 54(7): 863-886.

Alvesson, M. and Deetz, S. (2000) Doing Critical Management Research. London: Sage.

Alvesson, M. and Johansson, A. (2002) 'Professionalism and Politics in Management Consultancy Work', in T. Clark, and R. Fincham (eds.) Critical Consulting: New Perspectives on the Management Advice Industry: 228-246. Oxford: Blackwell.

Alvesson, M., Karreman, D., Sturdy, A. and Handley, K. (2009) 'Unpacking the Client(S): Constructions, Positions and Client-Consultant Dynamics', Scandinavian Journal of Management 25(3): 253-263.

Alvesson, M. and Robertson, M. (2006) 'The Best and the Brightest: The Construction, Significance and Effects of Elite Identities in Consulting Firms', Organization 13(2): 195-224.

Anderson, H. (1997) Conversation, Language, and Possibilities: A Postmodern Approach to Therapy. New York, N.Y.: BasicBooks.

Anderson, H. (2007) 'The Therapist and the Postmodern Therapy System: A Way of Being with Others', Paper presented at the 6th Congress of the European Family Therapy Association and 32nd Association for Family Therapy and Systemic Practice UK Conference, Glasgow, Scotland.

Anderson, H. and Goolishian, H. (1992) 'The Client Is the Expert: A Non-Knowing Approach to Therapy', in S. McNamee, and K. J. Gergen (eds.) Therapy as Social Construction. London: Sage Publications.

Argyris, C. (1970) Intervention Theory and Method; a Behavioral Science View. Reading, Mass.: Addison-Wesley.

Argyris, C. and Schön, D. (1974) Theory in Practice. San Francisco: Jossey-Bass.

Ashford, M. (1998) Con Tricks: The Shadowy World of Management Consultancy and How to Make It Work for You. London: Simon \& Schuster.

Ashford, M. (2000) Con Tricks: The Shadowy World of Management Consultancy and How to Make It Work for You. London: Simon \& Schuster.

Augier, M. (2005) 'Notes on the Evolution of a Research Community: Organization Studies in Anglophone North America, 1945-2000', Organization science 16(1): 85.

Austin, J. (1962) How to Do Things with Words. London: Oxford University Press.

Balint, M. (1957) The Doctor, His Patient and the Illness. London: Pitman.

Baritz, L. (1960) The Servants of Power; a History of the Use of Social Science in American Industry. Middletown, Conn.: Wesleyan University Press.

Barley, S. R. and Kunda, G. (1992) 'Design and Devotion - Surges of Rational and Normative Ideologies of Control in Managerial Discourse', Administrative Science Quarterly 37(3): 363-399.

Barnard, C. I. (1938) The Functions of the Executive. Cambridge, Mass.: Harvard University Press. 
Barrett, F. J. (1998) 'Coda: Creativity and Improvisation in Jazz and Organizations: Implications for Organizational Learning', Organization Science 9(5): 605-622.

Bechky, B. A. (2003) 'Sharing Meaning across Occupational Communities: The Transformation of Understanding on a Production Floor', Organization Science 14(3): 312-330.

Beecher, H. K. (1966) 'Ethics and Clinical Research', The New England journal of medicine 274(24): 1354-1360.

Beer, M. and Nohria, N. (2000) 'Cracking the Code of Change', Harvard Business Review 78(3): 133-141.

Bergson, H. (1946) The Creative Mind. New York: Carol Publishing Group.

Bernstein, R. J. (1991) Beyond Objectivism and Relativism : Science, Hermeneutics, and Praxis. Philadelphia: University of Pennsylvania Press.

Blackler, F. (1995) 'Knowledge, Knowledge Work and Organizations: An Overview and Interpretation', Organization Studies 16(6): 1021-1046.

Blackler, F. and McDonald, S. (2000) 'Power, Mastery and Organizational Learning', Journal of Management Studies 37(6): 833-852.

Blake, R. R. and Mouton, J. S. (1976) Consultation. Reading, Mass.: Addison-Wesley Pub. Co.

Block, P. (2000) Flawless Consulting: A Guide to Getting Your Expertise Used. New York: Jossey-Bass/Pfeiffer.

Bohm, D., Factor, D. and Garrett, P. (1991) Dialogue - a Proposal.

Boje, D. M. (1995) 'Stories of the Storytelling Organization - a Postmodern Analysis of Disney as Tamara-Land', Academy of Management Journal 38(4): 997-1035.

Boreham, P. (1983) 'Indetermination: Professional Knowledge, Organization and Control', The Sociological review 31(4): 693-718.

Bourdieu, P. (1991) Language and Symbolic Power. Cambridge, MA: Harvard University Press.

Bouwen, R. (1998) 'Relational Construction of Meaning in Emerging Organization Contexts', European Journal of Work and Organizational Psychology 7(3): 299-319.

Brandon, J. (1988) 'Where Consultants Fall Down', Management Today May: 109-119.

Brante, T. (1988) 'Sociological Approaches to the Professions', Acta Sociologica 31(2): 119142.

Braverman, H. (1974) Labor and Monopoly Capital: The Degradation of Work in the Twentieth Century. New York, N.Y., [etc.]: Monthly Review Press.

Brown, J. S. and Duguid, P. (1991) 'Organizational Learning and Communities-of-Practice: Toward a Unified View of Working, Learning, and Innovating', Organization Science 2(1): 40-57.

Brown, J. S. and Duguid, P. (2001) 'Knowledge and Organization: A Social-Practice Perspective', Organization Science 12(2): 198-213.

Brunsson, N. (1985) The Irrational Organization: Irrationality as a Basis for Organizational Action and Change. Chichester [West Sussex]; New York: Wiley.

Brunsson, N. (1989) The Organization of Hypocrisy: Talk, Decisions, and Actions in Organizations. Chichester; New York: Wiley.

Brunsson, N. and Olsen, J. P. (1993) The Reforming Organization: Routledge.

Callon, M. (1986) 'Some Elements of a Sociology of Translation - Domestication of the Scallops and the Fishermen of St-Brieuc Bay', Sociological Review Monograph: 196233.

Capgemini, (2008) 'How We Work Together', Accessed: July 1st, 2008. Link: http://www.capgemini.com/collaboration/ 
Carlile, P. R. (2004) Transferring, Translating, and Transforming: An Integrative Framework for Managing Knowledge across Boundaries, Vol. 15: 555-568.

Chaucer, G. (1386) 'The Summoner's Tale' The Canterbury Tales.

Chia, R. (1996) Organizational Analysis as Deconstructive Practice. Berlin: Walter de Gruyter.

Chia, R. and Holt, R. (2006) 'Strategy as Practical Coping: A Heideggerian Perspective', Organization Studies 27(5): 635-655.

Clancey, W. (1995) 'A Tutorial on Situated Learning', Paper presented at the Proceedings of the International Conference on Computers and Education, Taiwan.

Clark, T. (1995) Managing Consultants: Consultancy as the Management of Impressions: Open University Press.

Clark, T. (2004) 'The Fashion of Management Fashion: A Surge Too Far?' Organization 11(2): 297-306.

Clark, T. and Fincham, R. (eds.). (2002) Critical Consulting: New Perspectives on the Management Advice Industry: Blackwell Publishing.

Clark, T. and Salaman, G. (1998a) 'Creating the 'Right' Impression: Towards a Dramaturgy of Management Consultancy', Service Industries Journal 18(1): 18-38.

Clark, T. and Salaman, G. (1998b) 'Telling Tales: Management Gurus' Narratives and the Construction of Managerial Identity', Journal of Management Studies 35(2): 137-161.

Clegg, C. and Walsh, S. (2004a) 'Change Management: Time for a Change!' European Journal of Work and Organizational Psychology 13(2): 217.

Clegg, S. (1989a) Frameworks of Power. London: Sage.

Clegg, S. R. (1989b) 'Radical Revisions: Power, Discipline and Organizations', Organization studies 10(1): 97-115.

Clegg, S. R., Kornberger, M. and Rhodes, C. (2004b) 'Noise, Parasites and Translation Theory and Practice in Management Consulting', Management Learning 35(1): 31-44.

Clegg, S. R., Kornberger, M. and Rhodes, C. (2004c) 'When the Saints Go Marching In: A Reply to Sturdy, Clark, Fincham and Handley', Management Learning 35(3): 341-344.

Clifford, J. (1988) The Predicament of Culture : Twentieth-Century Ethnography, Literature, and Art. Cambridge, Mass.: Harvard University Press.

Cohen, T., Blatter, B., Almeida, C., Shortliffe, E. and Patel, V. (2006) 'A Cognitive Blueprint of Collaboration in Context: Distributed Cognition in the Psychiatric Emergency Department', Artificial Intelligence in Medicine 37(2): 73-83.

Collins, D. (2001) 'The Fad Motif in Management Scholarship', Employee Relations 23(1): 26-37.

Collins, D. (2004) 'Who Put the Con in Consultancy? Fads, Recipes and 'Vodka Margarine", Human Relations 57(5): 553-572.

Contu, A. and Willmott, H. (2003) 'Re-Embedding Situatedness: The Importance of Power Relations in Learning Theory', Organization Science 14(3): 283-296.

Cook, S. D. N. and Brown, J. S. (1999) 'Bridging Epistemologies: The Generative Dance between Organizational Knowledge and Organizational Knowing', Organization Science 10(4): 381-400.

Cooper, R. and Burrell, G. (1988) 'Modernism, Postmodernism and Organizational Analysis: An Introduction', Organization Studies 9(1): 91-112.

Cooperrider, D. (1987) 'Appreciative Inquiry in Organizational Life', in R. Woodman, and W. Pasmore (eds.) Research in Organizational Change and Development, Vol. 1: 129169. Greenwich, CT: JAI Press.

Cooperrider, D. L., Sorensen, P. F., Whitney, D. and Yaeger, T. F. (2000) Appreciative Inquiry : Rethinking Human Organization toward a Positive Theory of Change. Champaign, Ill.: Stipes Pub. 
Coopey, J. (1995) 'The Learning Organization, Power, Politics and Ideology', Management Learning 26(2): 193-213.

Coopey, J. and Burgoyne, J. (2000) 'Politics and Organizational Learning', Journal of Management Studies 37(6): 869-885.

Crozier, M. (1964) The Bureaucratic Phenomenon. Chicago: University of Chicago Press.

Crucini, C. (2002) 'Knowledge Management at the Country Level: A Large Consulting Firm in Italy', in M. Kipping, and L. Engwall (eds.) Management Consulting: Emergence and Dynamics of a Knowledge Industry: 109-128. Oxford: Oxford University Press.

Cummings, T. (2004) 'Intervention Strategies in Management Consulting', in L. Greiner, and F. Poulfelt (eds.) The Contemporary Consultant: 211-228. Mason, OH: SouthWestern.

Cummings, T. (2005) 'Intervention Strategies in Management Consulting', in L. Greiner, and F. Ploufelt (eds.) The Contemporary Consultant: 211-228. Mason, OH: Thomson.

Czarniawska, B. (2001) 'Is It Possible to Be a Constructionist Consultant?' Management Learning 32(2): 253-266.

Czarniawska, B. and Mazza, C. (2003) 'Consulting as a Liminal Space', Human Relations 56(3): 267-290.

Davenport, T. and Prusak, L. (2005) 'Knowledge Management in Consulting', in L. Greiner, and F. Poulfelt (eds.) The Contemporary Consultant: 305-326. Mason, OH: Thomson.

de Saussure, F. (1983) Course in General Linguistics (R. Harris, Trans.). London: Duckworth. (2006) Accessed: Link: http://www.deloitte.com

Derber, C., Magrass, Y. R. and Schwartz, W. A. (1990a) Power in the Highest Degree: Professionals and the Rise of a New Mandarin Order. New York: Oxford University Press.

Derber, C., Schwartz, W. A. and Magrass, Y. R. (1990b) Power in the Highest Degree : Professionals and the Rise of a New Mandarin Order. New York: Oxford University Press.

Dewey, J. (1938) Logic, the Theory of Inquiry. New York: H. Holt and Company.

DiMaggio, P. J. (1983) 'The Iron Cage Revisited: Institutional Isomorphism and Collective Rationality', American Sociological Review 48(2): 147.

Edwards, D. and Potter, J. (1992) Discursive Psychology. London: Sage.

Ehrenhard, M. L. (2009) The Structuration of Managing for Results: A Practice Perspective on Middle Managers in the Dutch Central Government: Dissertation, University of Twente.

Eisenhardt, K. M. and Bourgeois, L. J. (1988) 'Politics of Strategic Decision-Making in HighVelocity Environments - toward a Midrange Theory', Academy of Management Journal 31(4): 737-770.

Empson, L. (2001) 'Introduction: Knowledge Management in Professional Service Firms', Human Relations 54(7): 811-817.

Engel, G. L. (1977) 'Need for a New Medical Model - Challenge for Biomedicine', Science 196(4286): 129-136.

Engeström, Y. (1999) 'Activity Theory and Individual and Social Transformation', in Y. Engeström, R. Miettinen, and P. Raija-Leena (eds.) Perspective in Activity Theory: 19-38. Cambridge: Cambridge University Press.

Engeström, Y., Engeström, R. and Vahaaho, T. (1999) 'When the Centre Does Not Hold: The Importance of Knotworking', in S. Chaiklin, M. Hedegaard, and U. Jensen (eds.) Activity Theory and Social Practice: Cultural-Historical Approaches: 345-374. Aarhus: Aarhus University Press. 
Ernst, B. and Kieser, A. (2002) 'In Search of Explanations for the Consulting Explosion', in K. Sahlin-Andersson, and L. Engwall (eds.) The Expansion of Management Knowledge: Carriers, Flows and Sources. Palo Alto, CA: Stanford University Press.

Fayol, H. (1949) General and Industrial Management. London: Pitman.

Feldman, M. S. (2000) 'Organizational Routines as a Source of Continuous Change', Organization Science 11(6): 611-629.

Feldman, M. S. and Pentland, B. T. (2003) 'Reconceptualizing Organizational Routines as a Source of Flexibility and Change', Administrative Science Quarterly 48(1): 94-118.

Ferdinand, J. (2004) 'Power, Politics and State Intervention in Organizational Learning', Management Learning 35(4): 435-450.

Fincham, R. (1999) 'The Consultant-Client Relationship: Critical Perspectives on the Management of Organizational Change', Journal of Management Studies 36(3): 335351.

Fincham, R. (2000) 'Management as Magic: Reengineering and the Search for Business Salvation', in D. Knights, and H. Willmott (eds.) The Reengineering Revolution: Critical Studies of Corporate Change: 174-191. London: Sage.

Fincham, R. and Clark, T. (2002) 'Introduction: The Emergence of Critical Perspectives on Consulting', in T. Clark, and R. Fincham (eds.) Critical Consulting: 1-18. Oxford: Blackwell.

Fish, S. E. (1980) Is There a Text in This Class? : The Authority of Interpretive Communities. Cambridge, Mass.: Harvard University Press.

Fombrun, C. J. and Neevins, M. D. (eds.). (2004) The Advice Business: Essential Tools and Models for Management Consulting. Upper Saddle River, NJ: Pearson Prentice Hall.

Foucault, M. (1977) Discipline and Punish : The Birth of the Prison. New York: Pantheon Books.

Fox, S. (2000) 'Communities of Practice, Foucault and Actor-Network Theory', Journal of Management Studies 37(6): 853-867.

Freidson, E. (1970a) Profession of Medicine; a Study of the Sociology of Applied Knowledge. New York: Dodd, Mead.

Freidson, E. (1970b) Professional Dominance: The Social Structure of Medical Care. New York: Atherton Press.

Freidson, E. (1988) Professional Powers: A Study of the Institutionalization of Formal Knowledge. Chicago: University of Chicago Press.

Gaver, W. W. (1996) 'Situating Action Ii: Affordances for Interaction: The Social Is Material for Design', Ecological Psychology 8(2): 111-129.

Geertz, C. (1973) The Interpretation of Cultures. New York: Basic Books.

Gergen, K. J. (1994) Realities and Relationships: Soundings in Social Construction. Cambridge, MA: Harvard Univ Press.

Gergen, K. J. (1999) An Invitation to Social Construction. London; Thousand Oaks, Calif.: Sage.

Gergen, K. J., Gergen, M. M. and Barrett, F. J. (2004) 'Dialogue: Life and Death of the Organization', in D. Grant, C. Hardy, C. Oswick, and L. Putnam (eds.) The Sage Handbook of Organizational Discourse: 39-59. London: Sage.

Gergen, K. J., McNamee, S. and Barrett, F. J. (2001) 'Toward Transformative Dialogue', International Journal of Public Administration 24(7): 679-707.

Gibson, J. J. (1977) 'The Theory of Affordances', in R. Shaw, and J. Bransford (eds.) Perceiving, Acting, and Knowing: 67-82. Hillsdale, NJ: Erlbaum.

Giddens, A. (1986) The Constitution of Society : Outline of the Theory of Structuration. Cambridge: Polity. 
Gill, J. and Whittle, S. (1993) 'Management by Panacea - Accounting for Transience', Journal of Management Studies 30(2): 281-295.

Glückler, J. and Armbruster, T. (2003) 'Bridging Uncertainty in Management Consulting: The Mechanisms of Trust and Networked Reputation', Organization Studies 24(2): 269297.

Goffman, E. (1959) The Presentation of Self in Everyday Life. Garden City, N.Y.: Doubleday.

Granovetter, M. (1985) 'Economic-Action and Social-Structure - the Problem of Embeddedness', American Journal of Sociology 91(3): 481-510.

Grant, R. M. (1996) 'Toward a Knowledge-Based Theory of the Firm', Strategic Management Journal 17: 109-122.

Greeno, J. (1994) 'Gibson's Affordances', Psychological Review 101(2): 336-342.

Greeno, J. (1998) 'The Situativity of Knowing, Learning, and Research', American Psychologist 53(1): 5-26.

Greiner, L. and Poulfelt, F. (eds.). (2004) The Contemporary Consultant. Mason, OH: SouthWestern.

Greiner, L. and Poulfelt, F. (eds.). (2005) The Contemporary Consultant. Mason, OH: Thomson.

Greiner, L. E. and Metzger, R. O. (1983) Consulting to Management: Prentice-Hall Englewood Cliffs, NJ.

Grint, K. (1994) Reengineering History: Social Resonances and Business Process Reengineering, Vol. 1: 179-201.

Gross, E. (1969) 'Change in Technological and Scientific Developments and Its Impact on the Occupational Structure', in R. Perrucci, and J. E. Gerstl (eds.) The Engineers and the Social System: 17-50. New York: John Wiley.

Hall, P. G. (1989) 'The Turbulent Eighth Decade : Challenges to American City Planning', Journal of the American Planning Association. 55(3): 275-282.

Halverson, C. (2002) 'Activity Theory and Distributed Cognition', Computer Supported Cooperative Work (CSCW) 11: 243-267.

Hansen, M. T., Nohria, N. and Tierney, T. (1999) 'What's Your Strategy for Managing Knowledge?' Harvard Business Review 77(2): 106-116.

Hardy, C. and Clegg, S. (1996) 'Some Dare to Call It Power', in S. Clegg, C. Hardy, and W. Nord (eds.) Handbook of Organizational Studies. London: Sage.

Hargadon, A. B. and Bechky, B. A. (2006) 'When Collections of Creatives Become Creative Collectives: A Field Study of Problem Solving at Work', Organization Science 17(4): 484-500.

Hayek, F. A. (1945) 'The Use of Knowledge in Society', Economic Review 35(4): 519-530.

Heelas, P. and Lock, A. (1981) Indigenous Psychologies : The Anthropology of the Self.

Heidegger, M. (1962) Being and Time, Trans. J. Macquarrie and E. Robinson. Oxford: Blackwell.

Heller, F. (2002) 'What Next? More Critique of Consultants, Gurus and Management', in T. Clark, and R. Fincham (eds.) Critical Consulting: New Perspectives on the Management Advice Industry: 260-271. Oxford: Blackwell Publishers.

Hendry, C. (1996) Understanding and Creating Whole Organizational Change through Learning Theory, Vol. 49: 621-641.

Hermans, H. J., Kempen, H. J. and Van Loon, R. J. (1992) 'The Dialogical Self: Beyond Individualism and Rationalism', American Psychologist 47(1): 23-33.

Heron, J. (1996) 'Quality as Primacy of the Practical', Qualitative Inquiry 2(1): 41-56.

Hicks, J. and Nair, P. (2009) 'If You Can't Solve the Problem, Change the Problem You're Solving', Journal of Practical Consulting 3(2): 14-21. 
Hicks, J., Nair, P. and Wilderom, C. P. M. (2008) 'The Case of Murata Chemicals', in D. Lester, and J. Parnell (eds.) Organization Theory: A Strategic Perspectice. Cincinnati, $\mathrm{OH}$ : Thomson.

Hicks, J., Nair, P. and Wilderom, C. P. M. (2009) 'What If We Shifted the Basis of Consulting from Knowledge to Knowing?' Management Learning 40(3): 289-310.

Hirschkorn, K. A. (2006) 'Exclusive Versus Everyday Forms of Professional Knowledge: Legitimacy Claims in Conventional and Alternative Medicine', Sociology of Health \& Illness 28(5): 533-557.

Hobday, R. and Cason, J. (2009) 'The Open-Air Treatment of Pandemic Influenza', American Journal of Public Health 99(S2): S236-S242.

Hosking, D. M. (2005) 'Bounded Entities, Constructivist Revisions, and Radical ReConstructions', Cognition, Brain, Behavior 9(4): 609-622.

Hosking, D. M. (2006) 'Organizations, Organizing, and Related Concepts of Change', in D. M. Hosking, and S. McNamee (eds.) The Social Construction of Organization. Ljubljana: Liber.

Hosking, D. M. (2007) 'Discourses of Relations and Relational Processes', in O. Kyriakidou, and M. Ozgilgin (eds.) Relational Perspectives in Organizational Studies: A Research Companion. Cheltenham, UK: Edward Elgar.

Hosking, D. M. (in press) 'Telling Tales of Relations: Appreciating Relational Constructionism', Organization Studies.

Hosking, D. M. and Bass, A. (2002) Constructing Changes in Relational Processes. Introducing a Social Constructionist Approach to Change Work.

Hosking, D. M. and Morley, I. E. (1985) Processes of Influence, Negotiation and Exchange: University of Warwick.

Hosking, D. M. and Morley, I. E. (1991) A Social Psychology of Organizing: People, Processes and Contexts. New York: Harvester Wheatsheaf.

Hutchins, E. (1993) 'Learning to Navigate', in J. Lave, and S. Chaiklin (eds.) Understanding Practice: Perspectives on Activity and Context: 35-63. New York: Cambridge University Press.

Jabri, M., Adrian, A. and Boje, D. M. (2008) 'Reconsidering the Role of Conversations in Change Communication: A Contribution Based on Bakhtin', Journal of Organizational Change Management 21(667-685).

Jackson, B. (2002) 'A Fantasy Theme Analysis of Three Guru-Led Management Fashions', in T. Clark, and R. Fincham (eds.) Critical Consulting: New Perspectives on the Management Advice Industry: 172-188. Oxford: Blackwell.

James, W. (1909/1996) A Pluralistic Universe. Lincoln, NE: University of Nebraska Press.

Jamous, H. and Peloille, B. (1970) 'Changes in the French University-Hospital System', in J. A. Jackson (ed.) Professions and Professionalization. Cambridge: Cambridge University Press.

Jeffcutt, P. (1994) 'From Interpretation to Representation in Organizational Analysis Postmodernism, Ethnography and Organizational Symbolism', Organization Studies 15(2): 241-274.

Johnson, T. J. (1972) Professions and Power. London: MacMillan.

Katz, J. (1984) The Silent World of Doctor and Patient. New York; London: Free Press ; Collier Macmillan.

Katz, J. and Kahn, R. L. (1966) The Social Psychology of Organizations. New York: Wiley.

Kennedy Information. (2004) Global Consulting Marketplace, 2004 - 2006: Key Data, Trends and Forecasts

Kennedy Information. (2007) Global Consulting Marketplace 2007 - 2010: Key Trends, Profiles and Forecasts 
Kilduff, M. (1993) 'Deconstructing Organizations', Academy of Management Review 18(1): 13-31.

Ko, D. G., Kirsch, L. J. and King, W. R. (2005) 'Antecedents of Knowledge Transfer from Consultants to Clients in Enterprise System Implementations', MIS Quarterly 29(1): 59-85.

Kogut, B. and Zander, U. (1992) 'Knowledge of the Firm, Combinative Capabilities, and the Replication of Technology', Organization Science 3(3): 383-397.

Kubr, M. (2002) Management Consulting: A Guide to the Profession. Geneva: International Labour Office.

Kuhn, T. S. (1970) The Structure of Scientific Revolutions.

Lambrechts, F., Grieten, S., Bouwen, R. and Corthouts, F. (2009) 'Process Consultation Revisited: Taking a Relational Practice Perspective', Journal of Applied Behavioral Science 45(1): 39-58.

LaPalombara, J. (2001) 'Power and Politics in Organizations: Public and Private Sector Comparisons', in M. Dierkes, A. Antal, J. Child, and I. Nonaka (eds.) The Handbook of Organizational Learning and Knowledge: 557-581. Oxford: Oxford University Press.

Larson, M. L. (1979) The Rise of Professionalism, Vol. 63: 490: American Academy of Pediatrics.

Larson, M. S. (1990) 'In the Matter of Experts and Professionals', in M. Burrage, and R. Torstendahl (eds.) The Formation of the Professions. London: Sage.

Lave, J. (1993) 'The Practice of Learning', in S. Chaiklin, and J. Lave (eds.) Understanding Practice: 3-32. New York: Cambridge University Press.

Lave, J. and Wenger, E. (1991) Situated Learning: Legitimate Peripheral Participation. New York: Cambridge University Press.

Law, J. (1994) Organizing Modernity. Oxford, UK; Cambridge, Mass., USA: Blackwell.

Law, J. (1998) 'After Meta-Narrative: On Knowing in Tension', in R. Chia (ed.) In the Realm of Organization: 88-107. London: Routledge.

Lawrence, P. R. and Lorsch, J. W. (1967) Organization and Environment: Managing Differentiation and Integration. Boston: Grad. Sch. Bus. Admin., Harvard University.

Lewin, K. (1951) Field Theory in Social Science: Harper \& Brothers New York.

Lindblom, C. E. (1959) 'The Science of Muddling Through', Public Administration Review 19(2): 79-88.

Lyons, J. O. (1978) The Invention of the Self : The Hinge of Consciousness in the Eighteenth Century. Carbondale: Southern Illinois University Press.

Macmurray, J. (1956) The Self as Agent, The Gifford Lectures. West Conshohocken, PA: Templeton Press.

Maister, D. (1997) True Professionalism. New York: Free Press.

Maister, D. H. (2000) The Trusted Advisor. New York: Touchstone.

Markham, J. (2003) 'Accountants Make Miserable Policemen: Rethinking the Federal Securities Laws', North Carolina Journal of International Law \& Commercial Regulation.

Marshall, N. and Rollinson, J. (2004) 'Maybe Bacon Had a Point: The Politics of Interpretation in Collective Sensemaking', British Journal of Management 15: S71S86.

Matson, W. (1966) 'Why Isn't the Mind-Body Problem Ancient?' in P. Feyerabend, and G. Maxwell (eds.) Mind, Matter and Method: Essays in Philosophy and Science in Honor of Herbert Feigl: 92-102. Minneapolis: University of Minnesota Press.

Maturana, H. R. and Varela, F. J. (1998) The Tree of Knowledge: The Biological Roots of Human Understanding. Boston: Shambhala. 
McDermott, R. (1999) 'Why Information Technology Inspired but Cannot Deliver Knowledge Management', California Management Review 41(4): 103-117.

McKenna, C. D. (2006) The World's Newest Profession : Management Consulting in the Twentieth Century. New York: Cambridge University Press.

McKinsey \& Company, (2006) 'What We Believe', Accessed: August 6. Link: http://www.mckinsey.com/aboutus/whatwebelieve/index.asp

McNamee, S. and Gergen, K. J. (1998) Relational Responsibility: Resources for Sustainable Dialogue. London: Sage.

Millerson, G. (1964) The Qualifying Association. London: Routledge \& Kegan Paul.

Mohrman, S. A. (2001) 'Seize the Day: Organizational Studies Can and Should Make a Difference', Human Relations 54(1): 57-65.

Morris, C. (1972) The Discovery of the Individual, 1050-1200: University of Toronto Press.

Morriss, P. (1987) Power: A Philosophical Analysis. New York: St. Martin's Press.

Nardi, B. (1995) 'Studying Context: A Comparison of Activity Theory, Situated Action Models, and Distributed Cognition', in B. Nardi (ed.) Context and Consciousness: Activity Theory and Human-Computer Interaction: 69-102. Cambridge, MA: Massachusetts Institute of Technology.

National Audit Office, X. (2006) Central Government's Use of Consultants: Report by the Comptroller and Auditor General (Hc 128)

National Baseball Hall of Fame, (2006) Accessed: August 9th, 2006. Link: www.babeballhalloffame.org

Newell, S., Bresnen, M., Edelman, L., Scarbrough, H. and Swan, J. (2006) 'Sharing Knowledge across Projects - Limits to Ict-Led Project Review Practices', Management Learning 37(2): 167-185.

Management Constulting News (2006) 'Meet the Masterminds: Christopher Mckenna on the Past and Future of Consulting', Accessed: October 7, 2006. Link: http://www.managementconsultingnews.com/interviews/mckenna interview.php

Nicolini, D., Gherardi, S. and Yanow, D. (2003) Knowing in Organizations: A Practice-Based Approach. Armonk, N.Y.: M.E. Sharpe.

Nikolova, N. (2006) The Client-Consultant Relationship in Professional Business Service Firms, Unpublished doctoral dissertation, Faculty of Management, Economics and Social Sciences, University of Cologne: Faculty of Management, Economics and Social Sciences at the Univerisity of Cologne.

Nonaka, I. and Konno, N. (1998) 'The Concept Of "Ba": Building a Foundation for Knowledge Creation', California Management Review 40(3): 40-54.

Nonaka, I. and Takeuchi, H. (1995) The Knowledge-Creating Company: How Japanese Companies Create the Dynamics of Innovation. New York: Oxford University Press.

Orlikowski, W. J. (2002) 'Knowing in Practice: Enacting a Collective Capability in Distributed Organizing', Organization Science 13(3): 249-273.

Orr, J. E. (1996) Talking About Machines : An Ethnography of a Modern Job. Ithaca, N.Y.: ILR Press.

Oswick, C., Keenoy, T. and Grant, D. (2000) 'Discourse, Organizations and Organizing: Concepts, Objects and Subjects', Human Relations 53(9): 1115-1123.

Parkin, F. (1979) Marxism and Class Theory: A Bourgeois Critique. New York: Columbia University Press.

Parsons, T. (1937) The Structure of Social Action; a Study in Social Theory with Special Reference to a Group of Recent European Writers. New York; London: McGraw-Hill Book Co., Inc.

Parsons, T. (1939) The Professions and Social Structure, Vol. 17: 457-467: University of North Carolina Press. 
Parsons, T. (1956) 'Suggestions for a Sociological Approach to the Theory of OrganizationsI', Administrative Science Quarterly 1(1): 63-85.

Patriotta, G. and Spedale, S. (2009) 'Making Sense through Face: Identity and Social Interaction in a Consultancy Task Force', Organization Studies 30(11): 1227-1248.

McGraw-Hill, (2000) 'The Consultant's Scorecard: Tracking Results and Bottom-Line Impact of Consulting Projects', Accessed: Link:

Polanyi, M. M. (1967) The Tacit Dimension. New York: Doubleday.

Popper, K. R. (2002) The Logic of Scientific Discovery: Routledge.

Popper, K. R., Petersen, A. F. and Mejer, J. (1998) The World of Parmenides : Essays on the Presocratic Enlightenment. London; New York: Routledge.

Poulfelt, F., Greiner, L. and Bhambri, A. (2005) 'The Changing Global Consulting Industry', in L. Greiner, and F. Ploufelt (eds.) The Contemporary Consultant: 3-22. Mason, OH: Thomson.

Powell, W. W. and DiMaggio, P. J. (1998) The New Institutionalism in Organizational Analysis. Chicago: Chicago Univ. Press.

Pugh, D. S., Hickson, D. J., Hinnings, C. R., McDonald, M. N., Turner, C. and Lupton, T. (1963) 'A Conceptual Scheme for Organizational Analysis', Administrative Science Quarterly 8(3): 289-315.

Rainwater, L. (1970) Behind Ghetto Walls; Black Families in a Federal Slum. Chicago: Aldine Publishing Company.

Rainwater, L. (1973) 'The Lessons of Pruitt-Igoe'.

Rasiel, E. M. (1999) The Mckinsey Way: Using the Techniques of the World's Top Strategic Consultants to Help You and Your Business. New York: McGraw-Hill.

Reason, P. and Bradbury, H. (eds.). (2008) Handbook of Action Research: Participative Inquiry and Practice. Los Angeles: Sage.

Reason, P. and Torbert, W. (2001) 'Toward a Transformational Science: A Further Look at the Scientific Merits of Action Research', Concepts and Transformations 6(1): 1-37.

Reddy, M. (1979) 'The Conduit Metaphor: A Case of Frame Conflict in Our Language About Language', in A. Ortony (ed.) Metaphor and Thought: 284-324. New York: Cambridge University Press.

Reed, M. I. (1996) 'Expert Power and Control in Late Modernity: An Empirical Review and Theoretical Synthesis', Organization Studies 17(4): 573-597.

Reitman, W. R. (1965) Cognition and Thought; an Information-Processing Approach. New York: Wiley.

Robbins, S. P. (1990) Organization Theory : Structure, Design, and Applications. Englewood Cliffs, N.J.: Prentice Hall.

Rogers, C. R. (1951) Client-Centered Therapy, Its Current Practice, Implications, and Theory. Boston: Houghton Mifflin.

Rorty, R. (1979) Philosophy and the Mirror of Nature: Princeton University Press.

Rorty, R. (1989) Contingency, Irony, and Solidarity. Cambridge: Cambridge University Press.

Rothman, D. J. (1991) Strangers at the Bedside a History of How Law and Bioethics Transformed Medical Decision Making. New York, NY: Basic Books.

Ryle, G. (1949) The Concept of Mind. London: Hutchinson.

Salaman, G. (2002a) 'Understanding Advice: Toward a Sociology of Management Consultancy', in T. Clark, and R. Fincham (eds.) Critical Consulting: New Perspectives on the Management Advice Industry. Oxford: Blackwell.

Salaman, G. (2002b) 'Understanding Advice: Toward a Sociology of Management Consultancy', in T. Clark, and R. Fincham (eds.) Critical Consulting. Oxford: Blackwell. 
Sampson, E. E. (1977) 'Psychology and American Ideal', Journal of Personality and Social Psychology 35(11): 767-782.

Sampson, E. E. (1988) 'The Debate on Individualism: Indigenous Psychologies of the Individual and Their Role in Personal and Societal Functioning', The American psychologist 43(1): 15.

Sandercock, L. (1998) Towards Cosmopolis : Planning for Multicultural Cities. Chichester, England; New York: J. Wiley.

Sarvary, M. (1999) 'Knowledge Management and Competition in the Consulting Industry', California Management Review 41(2): 95-107.

Schaffer, R. (2002) High-Impact Consulting : How Clients and Consultants Can Leverage Rapid Results into Long-Term Gains. San Francisco, CA: Jossey-Bass Publishers.

Schatzki, T. R., Knorr-Cetina, K. and Savigny, E. v. (eds.). (2001) The Practice Turn in Contemporary Theory. New York: Routledge.

Schein, E. (1969) Process Consultation: Its Role in Organization Development. Reading: Addison-Wesley.

Schein, E. (1988) Process Consultation: Its Role in Organization Development. Reading: Addison-Wesley.

Schein, E. (1997) 'The Concept Of "Client" From a Process Consultation Perspective: A Guide for Change Agents', Journal of Organizational Behavior 10(3): 202-216.

Schein, E. (1999) Process Consultation Revisited: Building the Helping Relationship: Addison-Wesley.

Schein, E. (2002) 'Consulting: What Should It Mean?' in T. Clark, and R. Fincham (eds.) Critical Consulting: 21-27. Oxford: Blackwell.

Schön, D. A. (1983) The Reflective Practitioner: How Professionals Think in Action. New York: Basic Books.

Schutz, A. and Wagner, H. R. (1970) Alfred Schutz on Phenomenology and Social Relations : Selected Writings. Chicago; London: University of Chicago Press.

Schwandt, T. A. (1996) 'Farewell to Criteriology', Qualitative Inquiry 2(1): 58-72.

Scott, W. R. (2004) 'Reflections on a Half-Century of Organizational Sociology', Annual Review of Sociology 30: 1-21.

Sells, S. B. (1964) 'Toward a Taxonomy of Organizations', in W. W. Cooper, H. J. Leavitt, and M. W. Shelly II (eds.) New Perspectives in Organization Research: 515-532. New York: Wiley.

Selznick, P. (1948) 'Foundations of the Theory of Organization', 13(1): 25-35.

Senge, P. M., Kleiner, A., Roberts, C., Ross, R. B. and Smith, B. J. (1994) The Fifth Discipline Fieldbook: Strategies and Tools for Building a Learning Organization. New York: Currency Doubleday.

Shannon, C. E. and Weaver, W. (1949) The Mathematical Theory of Communication. Urbana: University of Illinois Press.

Shenhav, Y. (1994) 'Manufacturing Uncertainty and Uncertainty in Manufacturing: Managerial Discourse and the Rhetoric of Organizational Theory', Science in context 7(02): 275-305.

Shenhav, Y. (2000) 'The Roots of Uncertainty in Organization Theory: A Historical Constructivist Analysis', Organization 7(3): 373.

Sheth, J. N. and Sobel, A. C. (2000) Clients for Life : How Great Professionals Develop Breakthrough Relationships. New York: Simon \& Schuster.

Shotter, J. (1993) Conversational Realities: Constructing Life through Language. London: Sage.

Shotter, J. (1995) 'The Manager as Practical Author: A Rhetorical-Responsive, Social Constructionist Approach to Social-Organizational Problems', in D. M. Hosking, H. P. 
Dachler, and K. J. Gergen (eds.) Management and Organization: Relational Alternatives to Individualism: 125-147. Aldershot: Avebury.

Shotter, J. (1998) 'The Dialogical Nature of Our Inner Lives', Philosophical explorations 3: 185-200.

Spender, J. C. (1996) 'Organizational Knowledge, Learning and Memory: Three Concepts in Search of a Theory', Journal of Organizational Change Management 9(1): 63-78.

Stahl, G. (2004) Building Collaborative Knowing: Elements of a Social Theory of Cscl, What We Know About Cscl and Implementing It in Higher Education: Kluwer Academic Publishers, Norwell, MA.

Stahl, G. (2005) 'Group Cognition in Computer-Assisted Collaborative Learning', Journal of Computer Assisted Learning 21(2): 79-90.

Star, S. (1990) 'The Structure of Ill-Structured Solutions: Boundary Objects and Heterogeneous Distributed Problem Solving' Distributed Artificial Intelligence: Vol. 2: 37-54: Morgan Kaufmann Publishers Inc.

Steele, D. J., Blackwell, B., Gutmann, M. C. and Jackson, T. C. (1987) 'Beyond Advocacy: A Review of the Active Patient Concept', Patient Education and Counseling 10(1): 3-23.

Sturdy, A. (2004) 'The Adoption of Management Ideas and Practices - Theoretical Perspectives and Possibilities', Management Learning 35(2): 155-179.

Sturdy, A., Clark, T., Fincham, R. and Handley, K. A. (2004) 'Silence, Procrustes and Colonization - a Response to Clegg Et Al.'S 'Noise, Parasites and Translation: Theory and Practice in Management Consulting", Management Learning 35(3): 337-340.

Sturdy, A. and Grey, C. (2003) 'Beneath and Beyond Organizational Change Management: Exploring Alternatives', Organization 10(4): 651-662.

Sturdy, A., Schwarz, M. and Spicer, A. (2006) 'Guess Who's Coming to Dinner? Structures and Uses of Liminality in Strategic Management Consultancy', Human Relations 59(7): 929-960.

Suchman, L. A. (1987) Plans and Situated Actions: The Problem of Human-Machine Communication. Cambridge: Cambridge University Press.

Szulanski, G. (1996) 'Exploring Internal Stickiness: Impediments to the Transfer of Best Practice within the Firm', Strategic Management Journal 17(1): 27-43.

Taylor, F. W. (1911) The Principles of Scientific Management. New York; London: Harper \& Bros.

Taylor, J. R. and Robichaud, D. (2004) 'Finding the Organization in the Communication: Discourse as Action and Sensemaking', Organization 11(3): 395-413.

Tsoukas, H. (1996) 'The Firm as a Distributed Knowledge System: A Constructionist Approach', Strategic Management Journal 17(1): 11-25.

Tsoukas, H. and Chia, R. (2002) 'On Organizational Becoming: Rethinking Organizational Change', Organization Science 13(5): 567-582.

Tuan, Y. F. (1982) Segmented Worlds and Self: Group Life and Individual Consciousness: University of Minnesota Press.

Van de Ven, A. H. and Poole, M. S. (1995) 'Explaining Development and Change in Organizations', Academy of Management Review 20(3): 510-540.

Visscher, K. (2001) Design Methodology in Management Consulting. Enschede, Netherlands: Doctoral Dissertation, University of Twente.

von Bertalanffy, L. (1956) 'General Systems Theory', in L. von Bertalanffy, and A. Rapoport (eds.) General Systems: Yearbook of the Society for the Advancement of General Systems Theory, Vol. 1: 1-10. Ann Arbor, MI: The Society.

von Hippel, E. (1994) 'Sticky Information and the Locus of Problem-Solving - Implications for Innovation', Management Science 40(4): 429-439. 
Vygotsky, L. S. (1978) Mind in Society: The Development of Higher Psychological Processes. Cambridge: Harvard University Press.

Walsh, J. P., Meyer, A. D. and Schoonhoven, C. B. (2006) 'A Future for Organization Theory: Living in and Living with Changing Organizations', Organization science 17(5): 657.

Walsh, K. (2001) 'The Role of Relational Expertise in Professional Service Delivery', in A. Buono (ed.) Current Trends in Management Consulting: 23-42. Greenwich, CT: Information Age Publishing.

Weber, M. (1968) Economy and Society; an Outline of Interpretive Sociology. New York: Bedminster Press.

Weick, K. E. (1969) The Social Psychology of Organizing. Reading, MA: Addison-Wesley.

Weick, K. E. (1990) The Vulnerable System: An Analysis of the Tenerife Air Disaster, Journal of Management, Vol. 16: 571-593.

Weick, K. E. (1993) The Collapse of Sensemaking in Organizations: The Mann Gulch Disaster, Administrative Science Quarterly, Vol. 38: 628-652.

Weick, K. E. (1995) Sensemaking in Organizations. Thousand Oaks: Sage Publications.

Weick, K. E. (2001) Making Sense of the Organization. Oxford: Blackwell.

Weick, K. E. and Putnam, T. (2006) 'Organizing for Mindfulness: Eastern Wisdom and Western Knowledge', Journal of Management Inquiry 15(3): 275-287.

Weick, K. E. and Quinn, R. E. (1999) 'Organizational Change and Development', Annual Review of Psychology 50(1): 361.

Weick, K. E. and Roberts, K. H. (1993) 'Collective Mind in Organizations: Heedful Interrelating on Flight Decks', Administrative Science Quarterly 38(3): 357-381.

Weick, K. E., Sutcliffe, K. M. and Obstfeld, D. (2005) 'Organizing and the Process of Sensemaking', Organization Science 16(4): 409-421.

Werr, A. (1997) 'The Functions of Methods of Change in Management Consulting', Journal of Organizational Change Management 10(4): 288-307.

Werr, A. (2002) 'The Internal Creation of Consulting Knowledge: A Question of Structuring Experience', in M. Kipping, and L. Engwall (eds.) Management Consulting: Emergence and Dynamics of a Knowledge Industry: 91-108. Oxford: Oxford University Press.

Werr, A. and Stjernberg, T. (2003) 'Exploring Management Consulting Firms as Knowledge Systems', Organization Studies 24(6): 881-908.

Willem, A. and Scarbrough, H. (2006) 'Social Capital and Political Bias in Knowledge Sharing: An Exploratory Study', Human Relations 59(10): 1343-1370.

Wolf, W. B. (1958) 'Organizational Constructs: An Approach to Understanding Organizations', The Journal of the Academy of Management 1(1): 7-15.

Wood, P. (2002) 'The Rise of Consultancy and the Prospects for Regions', in T. Clark, and R. Fincham (eds.) Critical Consulting: New Perspectives on the Management Advice Industry: 50-73. Oxford: Blackwell Publications Ltd.

Zizek, S., Wright, E. and Wright, E. L. (1999) The Zizek Reader. Oxford, UK; Malden, MA: Blackwell Publishers. 